Prepared for:

Division of Reactor Development

U.S. Atomic Energy Commission

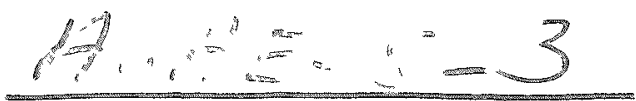

\title{
AN EVALUATION \\ OF HEAVY WATER REACTORS \\ FOR POWER
}

By:

D. P. HERRON

W. H. NEWKIRK

A. PUISHES

\section{AMERICAN-STANDARD - ATOMIC ENERGY DIVISION REDWOOD CITY, CALIFORNIA}

ISSUED: | OCTOBER 1957 CONTRACT: AT-(04-3)-109 


\section{DISCLAIMER}

This report was prepared as an account of work sponsored by an agency of the United States Government. Neither the United States Government nor any agency Thereof, nor any of their employees, makes any warranty, express or implied, or assumes any legal liability or responsibility for the accuracy, completeness, or usefulness of any information, apparatus, product, or process disclosed, or represents that its use would not infringe privately owned rights. Reference herein to any specific commercial product, process, or service by trade name, trademark, manufacturer, or otherwise does not necessarily constitute or imply its endorsement, recommendation, or favoring by the United States Government or any agency thereof. The views and opinions of authors expressed herein do not necessarily state or reflect those of the United States Government or any agency thereof. 


\section{DISCLAIMER}

Portions of this document may be illegible in electronic image products. Images are produced from the best available original document. 
TABLE OF CONTENTS

Summaxy

T

Introduction.

II General Discussion of Heavy Water Reactors . . * . 5

Natural Versus Enriched Uranium in Heavy Water Reactors 。 。 , 6

Selection of Reactor Designs . 。 , o . 8

II Results and Discussion o 。 . 。

Core Design $\quad . \quad \ldots \quad 13$

Reference Reactor Designs . . . . 19

Design of Equipment for Heavy Water Reactors . . . 23

Comparison of Heavy Water Reactor Economics with Other Types , 25

Effect of Modifying the Ground Rules , . . . 26

IV Appendices

A Heat Transfer

B. Mechanical Features and Detailed Cost Estumates

C Costs of Fuel Cycle Steps

D. Methods of Reactor Physics Calculations

f Review of Heavy Water Designs

F Study of Pressure and Containment Vessels

by Consolidated Western Steel 


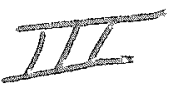

TABLES

Table 1 Sumary of Results for Boiling Cores

Table II Sumary of Results for Pressurized (Non-Boiling) Cores

Table III Selection of Optimum 100 EMW Boiling Reactor Design, One Batch Loading

Table IV Sumary of Reference Designs (One Batch Loading)

Table $V$ Heavy Water Inventory

Table VI Heavy Water Losses

Table VII U. S. Power Costs from Various Reactor Types (100 to 250 EMW Size)

Table VIII Effect of Modifying the Economic Ground Rules

Table A - Boiling Reactor Heat Fiur Values

Table B $\times$ I Effect of Turbine Throttle Pressure on Construction Costs

Table B-II Boiling Heavy Water Reactor Power Plants, Detailed Construction Costs

Table B-III Pressurized Heavy Water Reactor Power Plants, Detailed Construction costs

Table BuIV Approximation of a 500 EMW Boiling $D_{2}{ }^{O}$ Plant

Table C.T Enriched Uranium Prices

Table CuII Fuel Element Cost Estimates

Table C.III Sumary of Fuel Conversion and Fabrication Costs

Table D-I Fuel Element A, Reactor Parameter Survey

Table D II Fuel Element B, Reactor Parameter Survey

Thble D.IIT Geometrical Bucklings for Vaxious Core Sizes: Right Cylinders 


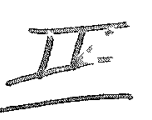

FIGURES

Figure 1 Effect of Capital Charges on Power Cost

Figure 2 Effect of Fuel Cycle Costs on Power cost

Figure 3 Fuel Element

Figure 4, $5 \quad ?^{f}$ vs. MWD/Metric Ton

Figure 6, 7 Buckling vs. MWD/Metric Ton

Figure 8,9 U-235 Burn-out

Figure 10, 11 Pu Formation

Figure 12, 13 Burn-up Costs and Pu Credit

Figure $14 \quad$ Xenon Transient

Figure 15 Effect of Enrichment Fuel Cycle Cost

Figure 16, 17 Flow Sheets for Six Designs

Figure B-1 Turbine Sealing system

Figure B-2, 3 Effect of Feedwater Heaters on Fuel and Capital Cost 4, 5, (Boiling and Pressurized)

Figure $B-2,7$ Pressure Vessel Costs

Figure B-8 Effect of Pressure Vessel Cost on Unit Power Costs

Figure C-1 Effect of Zirconium Content on Fuel Element Cost 


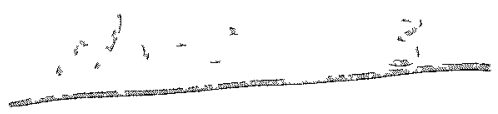

Purpose - This study conducted for the $U$. S. Atomic Energy Commission in the Project Size Up series. Its purpose was to evaluate heavy water powerproducing reactors. Particular attention was paid to the merits of using natural uranium compared with enriched uranium in this reactor type and to the problems of pressurewvessel and equipment design.

Scope - Reference designs for pressurized and direct-boiling heavy water reactors were prepared for electxical outputs of 20, 100, and 250 electrical megawatts. A number of possible core designs were considered and those utilized which seemed most appropriate to give low cost power. The technology and costs available today were employed in the preparation of the overmall plant designs. The Consolidated Western Steel Division of $U$. $S$. Steel Corporation assisted in this study by preparing a comprehensive report on the design of large pressure vessels and containment vessels. Zirconium clad metal uranium fuel elements were used as the basis for this study, but the effect of using uranium oxide and stainless steel cladding was also considered.

Principal Results

The principal results found were:

1) Over a wide range of operating conditions and economic situations, enriched uranium (up to perhaps $1.4 \% \mathrm{~J} \times 235$ ) is presently more economic to employ in heavy water reactors than is natural uranium. The chief reason for this is that enriched uranium permits a sufficiently favorable combination of longer exposure time, smaller lattice spacing, and lower critical mass so that the savings in fuel-cycle cost and capital charges more than compensate for the higher cost of the enriched uranium.

2) In the longer range, the use of natural uranium may become more economic as zirconium fabrication costs decrease, continuous charge-discharge devices are developed to permit longer exposure levels, and pressure-vessel technology advances so that the large critical masses and core diameters required are not such an economic penalty on the natural uranium. The results of this study agree quite well with the data and discussions of the Canadians on this matter. 
3) Both the relatively high capltal cost and the additional charges for heavy water inventory and Losses make the economics of the heavy water reactor more sensitive to size than for other types. A comprehensive analysis of the equipment requirements indicated that neither the pressure vessel nor the leakage restrictions present Insurmountable problems. The following costs were estimated on the basls of a moderate amount of optimism that present nuclear fabrlcating costs wild be hmproved somewhat:

20 EMW $100 \mathrm{EMW}$ 250 EMN

Bol11ng Pressur1zed Boillng Pressurlzed Bol11ng Pressurized

$\$ / \mathrm{kw}$ 540 695 306 374 247 302

M11s/kwh:

\begin{tabular}{|c|c|c|c|c|c|}
\hline $\begin{array}{c}\text { Capital charge } \\
(15 \%)\end{array}$ & 11.6 & 14.9 & 6.6 & 8.0 & 5.3 \\
\hline Fuel cycle cost & 2.5 & 2.4 & 2.3 & 2.3 & 2.6 \\
\hline$D_{2} \mathrm{O}$ losses & 2.1 & 1.7 & 0.8 & 0.7 & 0.6 \\
\hline $\begin{array}{c}\mathrm{D}_{2} \mathrm{O} \text { irventory } \\
(12 \%)\end{array}$ & 3.0 & 3.0 & 1.4 & 1.2 & 0.9 \\
\hline $\begin{array}{l}\text { Operating and } \\
\text { maintenance }\end{array}$ & 1.8 & 1.8 & 1.2 & 1.2 & 1.0 \\
\hline Total & 21.0 & 23.8 & 12.3 & 13.4 & 10.4 \\
\hline
\end{tabular}

In the size of 100 EM and above, these costs are in the same range as slightly enrlched light water reactors. The sma11 heavy water reactor (20 EMN) has relatively high power costs, however, compared with possible light water designs. 


\section{INTRODUCTION}

\section{Scope}

Under Project "Sizemp" American Standard has been performing a series of reactor evaluations for the Division of Reactor Development of the U.S.Atomic Energy Commission. This study is an analysis of pressurized and boiling heavy water reactors with particular emphasis on the following areas requested by the $\mathrm{AEC}$ :

1) Power Level = Effect of plant size on cost of power in the range of 50 - 200 EMW. (The largest size was later raised to 250 EMW, and an extrapolation to $500 \mathrm{EMW}$ was made.)

2) Pressure Vesse1 - The effect of power variation on pressure vessel specifications, cost, and fabrication problems.

3) D20 Losses and Contamination As reliable an estimate as possible of the $\mathrm{D}_{2} \mathrm{O}$ loss in a high pressure, high temperature system, in particular the possible losses from the turbine in a boiling design. An estimate of possible rates of contamination of the $\mathrm{D}_{2} \mathrm{O}$ by in leakage, $e \mathrm{~g}_{\text {. }}$ of condensed cooling water.

4) Natural Uranium vs. Enriched Uranium Operation A Aiscussion of the effect on pressure vessel specifications and on reactivity lifetime of the core, including the effect of xenon transients on allowable specific power.

5) Cost Reduction Potential - An estimate of the potential for cost reductions arising from technological advances for both the boiling and pressurized design.

\section{Approach}

This study was performed in two phases:

Phase 1 - A generalized reactor physics study was carried out to determine the effect of core design and enrichment on the reactivity limits which the fuel in heavy water reactors can attain before loss of criticality The choice of fuel element designs and other parameters ias dictated primarily by the objective of determining under what conditions natural uranium could compete economically with slightly enriched uranium. 
Phase 2 - The design of a bol11ng and pressurized reference reactor was carried out for each of the three electrical outputs:

$$
\begin{array}{r}
20 \text { EM } \\
100 \text { EMI } \\
250 \text { EMW }
\end{array}
$$

In addition, a preliminary estimate was made of a 500 EMN reactor.

In selecting design critexia for the referemce reactors, the optimum deslgn parameters developed in Phase I were ut1lzed. Upon these criterla were imposed heat transfer 1 imitations. In addition, heavy water inventory and losses were establlshed: operating pressures and flow rates through the core were optimimed unt power generating costs were calculated. The reactors were then evaluated in comparison wh 1 tht water sighty entched reactors and other types to determine the condtions under which heavy water reactors would be most attractive.

\section{Linitatlons to Study}

Important objectlves of this atudy were (a) to analyze the relathe attractiveness of natural versus exiched uranium in heavy water reactors and (b) to compare heavy water pressurized and bolling reactors in terms of equipmens costs, heawy water inventory and losses, and fuel-cycie costs. Hence the following limitations were adopted to eliminate extraneous variables which would not appreclably affect the cormaxdson:

1.) Metalle urantum fuel elements were employed in all of the destgrs considered, since they permit higher reactivty levels than uranlum oxlde elements and hence present the best cont case for natural uranium. Cost data were gathered and qualltative observatlons made on the effect of substituting usenlum oxide for uranium metal.

2) Direct cycle reactors only were consldered in the bolling reactor category. Thts deciston was based on an estlmate of the lower capltal equdpment cost for the direct cycle versus the lower $\mathrm{D}_{2} \mathrm{O}$ inventory requirement of the indirect type.

3) Pressurized-she11 reactors were considered rather than pressurizedtube reactors, since the pressure vessel study indicated that quite large, high pressure vessels could be fabricated. The pressurized eliminates the problem of pressure sealing the tube coolant from the she11 
fluid and hence is more straightforward. In the very large sizes, however, there is some possibility that a practical pressurized-tube design might be developed which would give lower power costs than the pressurized-shell type. Such a pressurized-tube reactor is now under development in Canada.

4) Zirconium cladding only was considered, since the use of such materials as stainless steel would preclude the use of natural uranium metal fue1. Until there are further reductions in the cost of fabricated zirconium, it is possible that enriched fuel clad in stainless steel would give lower power costs in heavy water reactors than would zirconium-clad fuel.

\section{Sub-contractual Assistance}

The Consolidated Western Steel Division of the U. S. Steel Corporation was requested to carry out design and cost studies on the large reactor and containment vessels required for heavy water reactors. The results of their study were used in the large reactor designs The complete text of the study is included in Appendix $F$ of this report.

\section{GENERAL DISCUSSION OF HEAVY WATER POWER REACTORS}

The characteristics of heavy water reactors may be summarized as follows:

\section{Advantages}

1) Excellent neutron economy giving low burn up costs.

2) Ability to use natural uranium.

3) Long neutron 1ifetime, giving some safety advantages.

\section{Disadvantages}

1) $\mathrm{D}_{2} \mathrm{O}$ has poorer slowing - down properties than $\mathrm{H}_{2} \mathrm{O}$. Hence large lattice spacings and large cores are required to achieve practical values of resonance escape probability and reactivity

2) Stringent design measures are required $\circ$ minimize leakage and to recover heavy water which does escape The expected leakage cost for heavy water is a significant item

Because of these characteristics, heavy water power reactors are large and have relatively high capital costs and low fuel.cycle costs. In this respect they are similar to the British gas-cooled Calder Hall type of reactor, and, like the Calder Hall reactor, they will be economically attractive in a situation in which capital funds are available at low annual charges. 
The various factors which make up the capital charge that must be assessed on the construction cost of a nuclear power plant were discussed in a previous Size-up report 1 . In the United States, private utilities must levy a capital charge of about $15 \%$ per year on the construction cost of a nuclear plant, while in Europe this charge may be as $10 \mathrm{w}$ as $8 \%$ because of the lower interest rates and taxes which prevail there. Hence heavy water reactors will compete more favorably with other reactor types in Europe than in the United States.

Figure 1 shows the effect of the capital charge rate on the unit power cost in mills per kilowatt hour at two plant factors and at various capital plant costs expressed in dollars per kilowatt. Figure 2 shows the contribution of the fuel-cycle cost to the unit power cost as a function of the obtainable exposure level of the fuel, with plant efficiency and fuel-cycle cost per kilogram of fuel as parameters. Both of these figures may be derived directly from the equations given previously 1 .

It may be observed from Figure 1 that at a plant factor of $80 \%$ and a capital cost of $\$ 350$ per kilowatt, reduction of the capital charge rate from $15 \%$ to $8 \%$ would result in a difference of $3.5 \mathrm{mills}$ per kilowatt hour in the calculated power cost. The importance of achieving exposure levels above $5,000 \mathrm{MWD} /$ ton so as to reduce the fuel-cycle cost can be seen from Figure 2.

Another important factor is the inventory charge on the heavy water. Although this material may be purchased at $\$ 28$ per pound, the less expensive procedure would be to rent it from the U. S. AEC at $4 \%$ per dollar-year.

\section{Natura1 vs. Enriched Uranium in Heavy Water Reactors}

Recent data on the integrity of zirconium-clad fuel elements indicates that exposures of 5,000 MWD/ton and above with uranium metal and exposures of 10,000 MWD/ton and above with uranium oxide may be achieved before the element falls metallurgically. By using slightly enriched fuel in heavy water reactors, it is feasible, of course, to obtain sufficlent reactivity to achieve these exposure levels, and hence fairly low fuel-cycle costs are quite possible. However, a majority of the heavy water designs available postulate the use of natural uranium as fuel, since it has been felt that a primary reason for

1 American-Standard, "Comparison of Calder Hall and PWR Reactor Types," Report AECU-3398, p。49, March, 1957. 
Figure 1

7 Fired Charges for Power Gereration

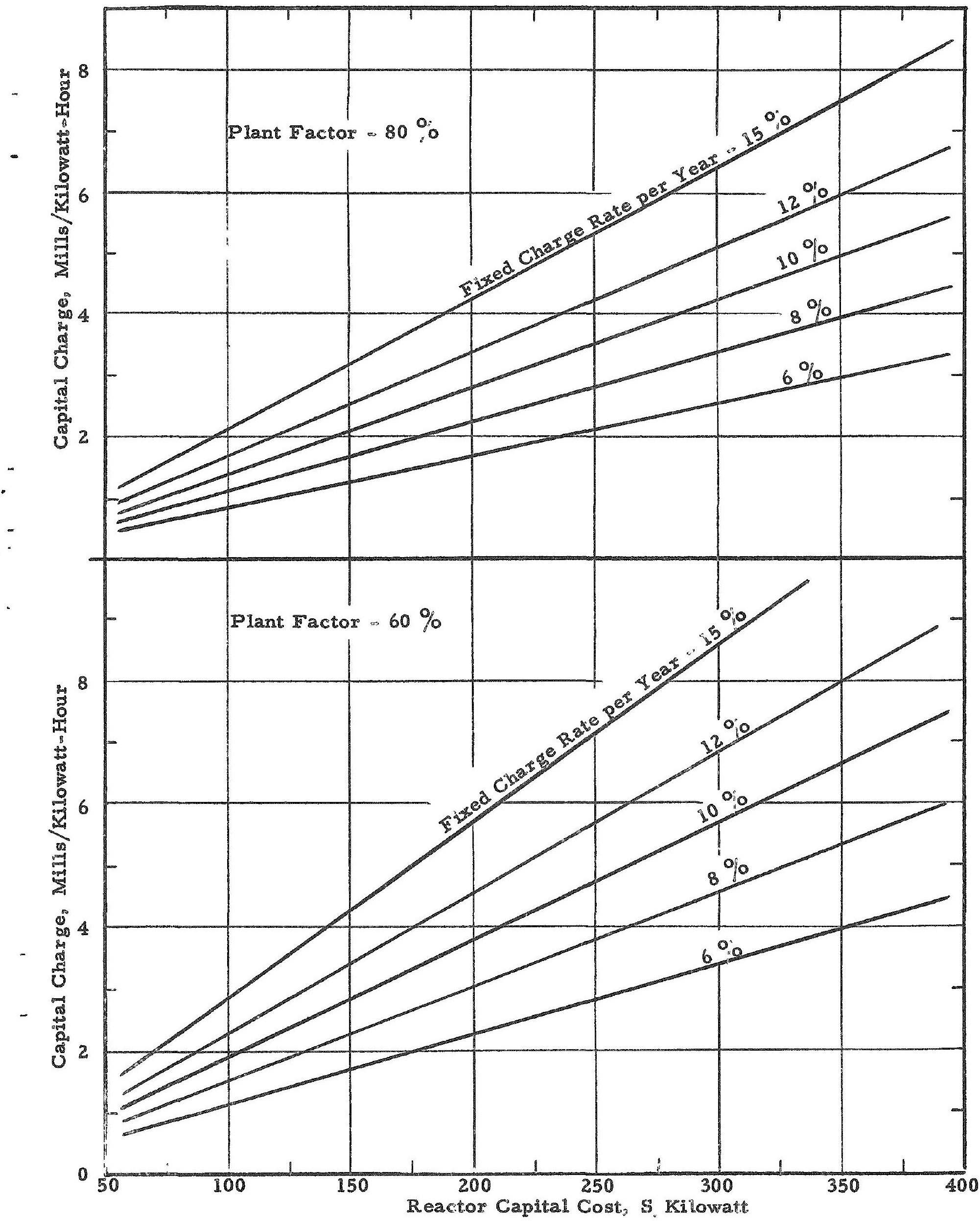


Figure 2

Fuel Cycle and Burnup Costs to

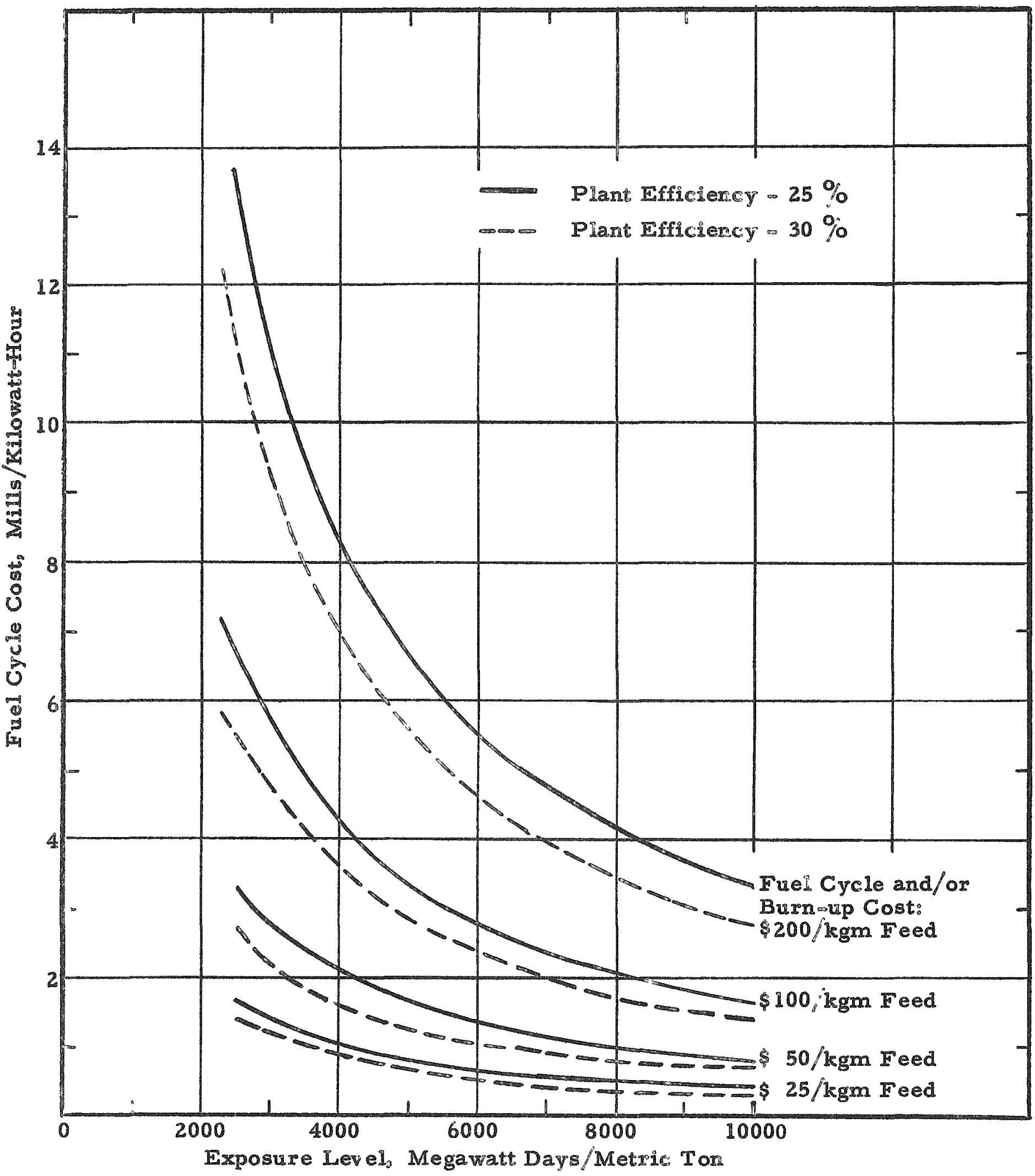


employing heavy water would be to permit countries feeling unsure of a continuing supply of enriched uranium to base their nuclear power economy on natural uranium. The achievement of long reactivity lifetime with natural uranium is somewhat more difficult than with enriched uranium and necessitates the employment of special means, such as the continuous charge-discharge schedule envisaged in the Canadian heavy water pressurized reactor. 2

The advantages of enriched uranium compared with natural uranium are as follows:

Advantage

1) Lower critical mass.

2) Greater reactivity.
Cost Saving

1) Smaller reactors.

2) Lower inventory of heavy water.

1) Lower fuel cycle cost.

2) Less frequent shut down.

3) Use of oxide fuel to avoid fuel element failure.

4) More flexibility in operation.

The disadvantages of enriched uranium are:

1) Expense - The cost per unit of fuel is higher than for natural uranium.

2) Availability - Enriched uranium requires an isotope separation plant for its production. Natural uranium will probably always be more readily available than enriched uranium, although this may not be serious because of the willingness of the $U$. $S$. and other countries to make large quantities of enriched uranium available to nations not having isotope separation facilities

In view of the above considerations, the situation under whic h natural uranium can compete is a favorable combination of the following conditions:

1) Large core required At high power outputs, where heat transfer is the factor limiting core design, there is no advantage to enriched uranium so far as tending to reduce the core size is concerned.

2) Radiation damage limiting When the exposure level becomes limited by radiation damage rather than reactivity, enrichment offers no economy through extending the exposure level.

2 W B. Lewis, "Low Cost Fuelling Without Recycling, "AECL 382, December 1956.

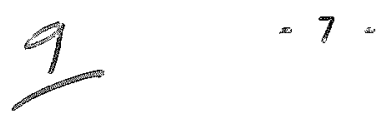


3) Long exposure level possible with natural uranium - By various rearrangements of fuel, continuous charge-discharge, or other devices, it may be possible to extend the exposure level with natural uranium. If a sufficiently high exposure level can thus be reached, the lower burn-up cost of natural uranium will eventually more than outweigh the even longer exposure 1 evels possible with enrichment. As described in Appendix $\mathbb{E}$, the Canadian concept of heavy water reactors envisages exposure levels of up to $10,000 \mathrm{MLD} / \mathrm{metric}$ ton, achievable with natural uranium oxide by a semi-continuous charge-discharge. Benedict and Pigford $\underline{3}$ have also pointed out the considerable extension of reactivity possible by improvements on the one-batch method of core loading.

\section{Selection of Reactor Designs}

Since the basic objective of this study was a rather broad comparison of different heavy water reactor designs, it was felt that both boiling and pressurized reactors should be included in several different electrical outputs and that other important variables such as core design and operating pressure should be carefully considered. Electrical outputs considered are 20, 100, and 250 EMW, and rough estimates were prepared for 500 EMW. The 20 EMW design studied is of interest, primarily because it is probably below the minimal plant size at which any heavy water reactor can be expected to compete favorably with 1 ight water reactors. The 100 and $250 \mathrm{EMW}$ reactors are most representative of the sizes of current interest. The $500 \mathrm{EMW}$ reactor was investigated to determine whether pressure-vessel limitations might impose an upper 1 imit on the power output from heavy water reactors.

A number of heavy water reactor designs have been published. Certain of these are discussed in Appendix E. The general problem of designing a heavy water reactor for minimum-cost power consists of selecting the best balance among the following factors which affect the economics:

The amount of fuel element surface per unit welght of fuel - In general, for a low critical mass and long reactivity lifetime, the fuel should be consolidated to the maximum extent allowable by heat transfer considerations.

3 M. Benedict and T. H. Pigford, "Fuel Cycles in Single-Reglon Thermal Reactors," Paper 57-NESC-41, 2nd Nuclear Conference, Philadelphia, March, 1957. 
The lattice spacing - A large lattice spacing in heavy water reactors improves reactivity but involves higher costs for heavy water and the pressure vessel.

Heat transfer design - The recirculation rate of the liquid phase through the core in the boiling type improves heat transfer but increases pumping cost. In the pressurized type, there is an optimum design involving flow rate of the primary coolant, heat txansfer surface, steam generating pressure, etc.

Steam conditions - The steam pressure affects the efficiency of the power plant, the plant construction costs, and the fuel-cycle cost. It has been pointed out 3 that in nuclear power plants the marginal cost of heat will quite probably be lower than in conventionally-freled plants. This is particularly true in heavy water reactors and will favor a fairly low-pressure plant.

Other variables in the plant design such as turbine throttle pressure, condenser back pressure, the amount of feed water, heating, etc, were considered in the study. However, major explasis was centered on the variables listed above, as is pointed out in the following paragraphs.

\section{Euel Elements (See igure 3)}

Calculations were perfomed on cores employing uranium metal plate elements. The first element considered (Element "A") is similar to that in the heavy water reactor deslgn presented by Argone National Laboratory at the Geneva Conference 4 , except that a somewhat greeter plate thickness was used to reduce fuel fabrication costs and improve reactivity, The fuel plate is an alloy of $1.5 \% \mathrm{Nb}, 5.0 \% \mathrm{Zr}$, and $93.5 \% \mathrm{v}$ by welght. The plate thickness is $0.17 \mathrm{in}$., the cladding is $20 \mathrm{mills}$ of $\mathrm{Zx}$. Six plates are assembled in a 5-in. ID, 1/16-in. thick $\mathrm{Zr}$ shroud. The total fuel plate width is $21 \mathrm{in}$, and the water channel is $0.35 \mathrm{in.}$ thick. The width of the widest plate is $451 \mathrm{n}$.

The second element (Element "B") is essentially identical to that described in the above-mentioned Argonne design. A thinner plate is employed

4H. P. Iskenderian, et al., Geneva Conference Raper, P/495, Vo1. 3 (1955). 


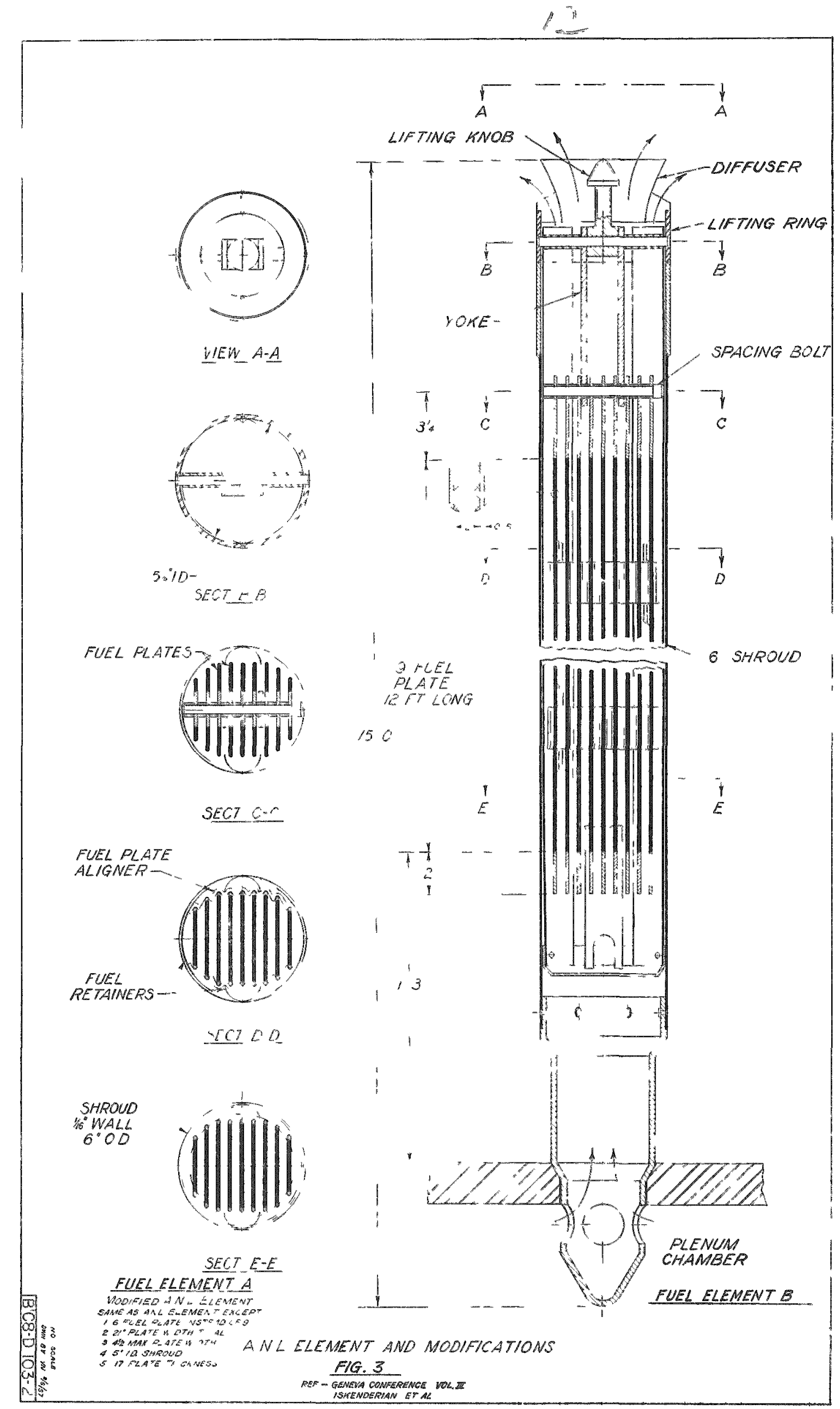




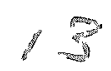

than with Iement $A$, and consequently there is more heat-transfer surface per unit weight of uranium. Element $B$ is more expensive co manufacture but may be necessary at high power outputs when heat transfer is the critical consideration. The same alloy is employed as in Element A. The plates are 012 in. thick, clad with 20 mills of Zr. Nine fuel plates with a cotal width of 29.78 in. are assembled in a 6-in. ID, 1/16-in. thick $\mathrm{Zr}$ shroud, with a 0.35 -in. water channel between plates. The width of the widest place is caken as 4.5 in. Element $B$ contains the same anount of uraniun per lineal foor as Element $A$ General Physics Considerations

A detailed description of the methods employed to determine core reactivity as a function of exposure and the isotopic composition of the fuel during exposure is given in Appendix D.

In summary, if a reactor core is considered composed of fuel elements Type A or B, of a certain latrice spacing and cotal core size, then for a given enrichment the following can be calculated:

1) The reactivity lifectme or the MD/ton obtainable srom physics considerations.

2) Those costs and values which are functions of isotopic content:

a) value of the metal at time of charging into the reactor

b) value of the metal at time of discharge

c) value of the produced $\mathrm{Pu}$ at ime of discharge

3) Fuel fabrication cost per unit of elsctric power produced which is inversely proportional to exposure attainable.

Costs from (2) and (3) are necessary to determine the core design and enrichment which would result in minimum fuel-cycle cost.

The 1ifetime of the reactor loading is calculated by means of the variation in material buckling $B_{\text {mat }}^{2}$, defined as:

$$
B_{\text {mat }}^{2}=\frac{\frac{k_{\infty}}{k_{\text {eff }}}-1}{M^{2}}
$$

where $\mathrm{M}^{2}$ is the migration area associated with the lattice under consideration. Since the variation of $k_{\infty} / k_{\text {eff }}$ with exposure level can be calculated (see Appendix $D$ ), curves can be constructed of $B_{\text {mat }}^{2}$ as a function of exposure 1 evel. 
In order for a the

In order for a reactor to remain critical, the material buckling $\mathrm{B}_{\mathrm{mat}}^{2}$ must always be equal to or greater than the geometrical buckling $\mathbf{B}_{\text {geom }}^{2}$ Assuming a reflector saving in radius and half height of $1.1 \mathrm{ft}$ for the core diameters calculated ( $9 \mathrm{ft}$ to $13 \mathrm{ft}$ ), the geometrical buckling can be found as a function of core diameter and height. The reactivity limit of a given core design is that at which the value of the material buckling has fallen to the value of the geometrical buckling.

Values of $k_{\infty}$ and $B_{m a t}^{2}$ were first calculated for newly charged metal for different entichments, lattice spacings, and coolant densities. The formulas, cross sections used, etc., are given in Appendix D. All cases calculated employ the "hot" cross sections and include equilibrium ge and Sm. The boiling cases were considered to have an average density of coolant of $0.66 \mathrm{gm} / \mathrm{cc}$. The pressurized cases are considered to have an average coolant densicy of $0.95 \mathrm{gm} / \mathrm{cc}$. To illustrate the effect of the variation of coolant density additional boiling cases with an average denaity of coolant of $0.4 \mathrm{gm} / \mathrm{cc}$ were considered. These cases are reported in Appendix $D$ and extend the range over which the control effect of variable recirculation rate is demonstrated.

From such physics calculations, the behavior of the reactor parameters. and the isotopic content of the fuel as a function of exposure were calculated. These results yleld the maximm obtainable exposure and the fuel-cycle costs.

The cores selected on the basis of physics parameters were then examined carefully from the standpoint of heat transfer to make certain that the choice was suitable from both the physics and heat removal standpoints.

Two buckling curves were calculated for each enrichment. One curve describes the buckling behavior of a core, each element of which begins its irradiation at the same time. The exposure is assumed to be uniform over the core, and the "exposure obtainable" refers to the maximum uniform exposure permitted. When this average exposure is reached, the entire fuel charge is unloaded and new metal charged.

A second curve was calculated for the average buckling of a reactor operated on the basis of continuous charge-discharge when the exposure distribution of the loading has reached equilibrium. In this mode of operation it is assumed that the loading is composed of a mixture of fuel elements whose exposures are uniformly distributed between zero and the maximum allowable exposure. The average buckling for any region is taken as the volume-weighted average of the 
elements composing the region. Under the above assumption this "average buckling" is simply the running average of the batch loading buckling curve.

The assumption was made that practical operation was possible in the continuous charge-discharge case with $k_{\text {eff }}: 1$ and in the one-batch loading for all keff's down to and including $k_{\text {eff }}=1$.

For the extreme case of a base load plant whose power is never varied and which, upon being shut down. remains down for 40 hours or more, the assumption of operation with $k_{e f f}=1$ is close to feasible. The effect of the xenon transient after shut-down is illustrated in the section on senon transients below.

\section{Heat Transfer}

The selection of permissible heat fluxes in both pressurized and boiling water reactors is at present rather complicated because of a variety of steadyand unsteady-state conditions which must be considered. In pressurized reactors, a great deal of work has been carried out on the burn-out effect; that is, the localized fomation of a vapor film adjacent to the fuel element surface and eventual melting of the metal. However, the design heat flux is usually only a fraction of the burn-out value because of non-uniformities possible in actual operation and because of unsteady-state effects. For example, in the Shippingport PWR design, heat flux was apparently limited by imposing a restriction of no film boiling if the primary coolant pumps failed. In the boiling case, instability caused by chugging will limit heat flux and permissible void fraction.

Design heat fluxes published for reactors presently proposed are as follows:

Boiling

EBWR

Dresden

E1k River
Average Heat $F 1 u x, 1$

$\mathrm{Btu} / \mathrm{hr}-\mathrm{sq} \mathrm{ft}$

$44,000-100,0002$

120,0003

74,000

1 Raytheon Corporation, "Nuclear Reactor Data" 2nd Ed., 1956.

2 The design average beat flux for EBWR was 44,000. However, in a heavy water design for the EBWR ( $H$. P. Iskenderian, "20-EMW D20-Moderated Expeximental Boiling Water Reactor Design Studies," ANL-5685, Feb, 1, 1957), it is assumed that an average flux of 100,000 is achievable. The large gap existing in general between the design average and the burn-out heat flux is illustrated by the fact that the burn-out heat flux for EBWR is 750,000 .

3 Based on an assumed maximum to average flux ratio of 2.5 . 
Pressurized

PWR (BIanket)

Yankee

Consolidated Edison

Belgian Thermal Reactor

Canadian $\mathrm{D}_{2} \mathrm{O}$ NPD Initial Design
Average Heat Flux, 1

$\mathrm{Btu} / \mathrm{hr} \operatorname{sg} \mathrm{ft}$

$$
\begin{gathered}
65,000-100,000 \\
100,000 \\
169,000 \\
96,000 \\
-100,000
\end{gathered}
$$

Based on these values, it was concluded that use of an average heat Ilus of $120,000 \mathrm{Btu} / \mathrm{hr}-\mathrm{sq}$ ft would be appropriate for both bolling and pressuriged reactor types, in view of the uncertainties inherent in the present knowledge of reactor heat transfer and also because 1 t was desired to compare reactor economics with existing designs on a comparable degree of conservatism.

For the reactor output desired, several possible core designs were selected which gave low fuel-cycle costs and were within the heat transfer 1 imitation described above. A comparison was then made of the cost of capital plant, heavy water inventory and losses, and fuel-cycle cost at various turbine pressures to determine the optimum core design and turbine pressure. Preliminary study of several other variables such as condenser back-pressure and feedwater heating cemperature indicated that use of constant reasonable valueg for these items would not cause serious deviation from the optimum design.

III. RESULTS AND DISCUSSION

\section{Core Design}

As described previously, the initial phase of this study consisted of general coremdesign calculations to determine the effect of (a) core diameter, (b) enrichment, (c) fuel element design, and (d) lattice spacing on fuel-cycle cost. The degree of enrichment affects the fuel-cycle cost only, while the three other variables listed also affect the plant cost, heat transfer capability, and $\mathrm{D}_{2} \mathrm{O}$ inventory costs. Thus, as a starting point in the analysis, it is of interest to determine the enrichment which results in minimum fuel-cycle cost with core diameter, fuel element design, and lattice spacing as parameters.

1Raytheon Corporation, "Nuclear Reactor Data," 2nd Ed., 1956. 4C. Kennedy, "Atomic Energy in Canada," AEGI Publication, 1956. 


\section{1}

Tables I and II are arranged in this manner to show the results of the physics calculations on boiling and pressurized cores, respectively.

Maximum Exposure Leve1s Attainable

Because of the large fixed cost involved in fabricating fuel elements, the attainable energy release per ton of fuel (that is, the exposure level) is of major importance in determining the fuel-cycle cost in mills/kwh. The maximum exposure levels permitted by available reactivity are shown for two fuel loading methods - one-batch loading and continuous charge-discharge.

The infinite multiplication factor, $k_{\text {cos }}$ which measures reactivity, may rise initially due to plutonium build up and then in all cases falls because of neutron absorption by fission products and the eventual depletion of fissionable material. of the four factors ( $i_{0} e_{,}, p \in p f$ ) composing $k_{c o}, \varepsilon$ and $p$ are assumed independent of exposure level, and thus the variation of the product pf can be used to show changes in reactivity.

Values of $\mathrm{ff}^{\mathrm{as}}$ a function of exposure level are shown in Figures 4 and 5 for three typical boiling and pressurized cores. Complete tabulations of the reactor physics results for fresh metal in the cores studied are included in Appendix D, as well as the geometrical bucklings for various core designs. (See Tables D I, D II, and D III.)

Figures 5 and 6 show reactivity changes expressed in terms of the material buckling rather than $k_{\infty}$. Geometrical buckling values for various core diameters are marked on these curves The exposure level corresponding to the geometrical buckling value at a particular core diameter represents the maximum attainable exposure at this diameter.

Figures 7 through 13 show U-235 burnmup, plutonium isotope formation, and the burn up cost and plutonium credit as a function of exposure level for the illustrative cores.

It may be noted in Tables I and II that the enrichment has a marked effect on the attainable exposure 1eve1, as would be expected. With batch loading of boiling cores, the maximum exposure level attainable with natural uranium for the desigms investigated was 4,040 MW/metric ton. Enrichment to $1.1 \% \mathrm{U}=235$ wil1 permit exposure levels of over 10,000 MWD/ton based on reactivity considerations.

* The results of Tables I and II were calculated using a thermal output of 370 MW and a thermal efficiency of $28.6 \%$, both corresponding roughly to the 100 EMW design. The inventory charge and fuel-cycle cost for other conditions of output and efficiency will vary slightly and have been corrected in the subsequent section in which reference design costs are tabulated. 
Lavid

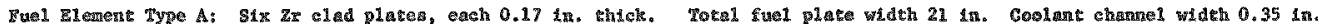
Tol Elene

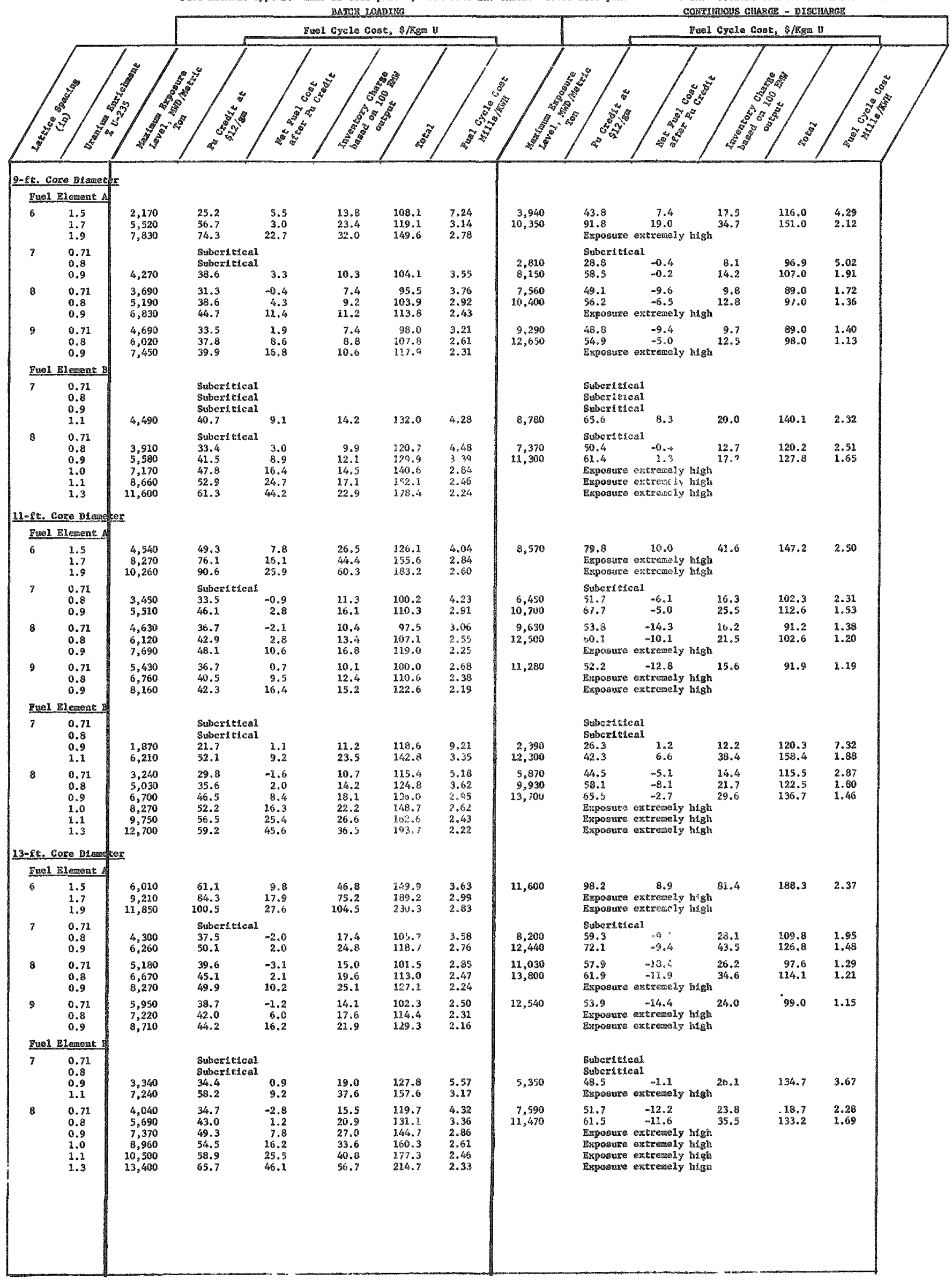


TABLE II

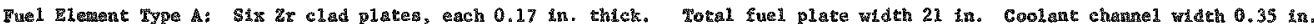
Fuel Element Type B: Ntne Zr clad plates, each 0.12 in. ehick. Total fuel plate width 30 in. Coolant channel width 0.35 in.

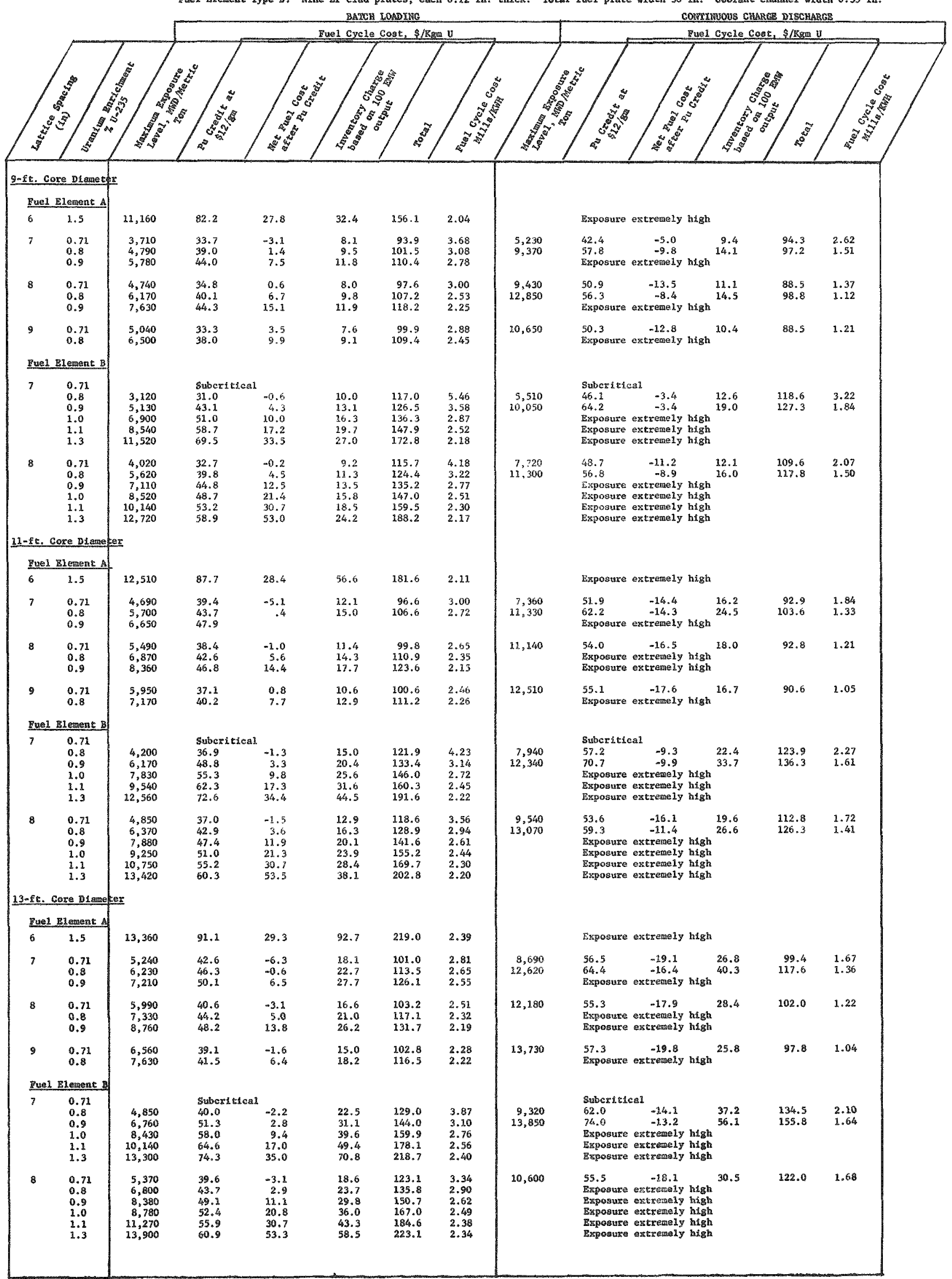




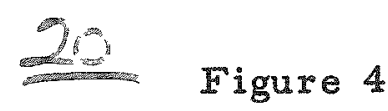

off vs. MWD/Metric Ton

Fuel Element B, 8" Lattice Spacing, Boiling

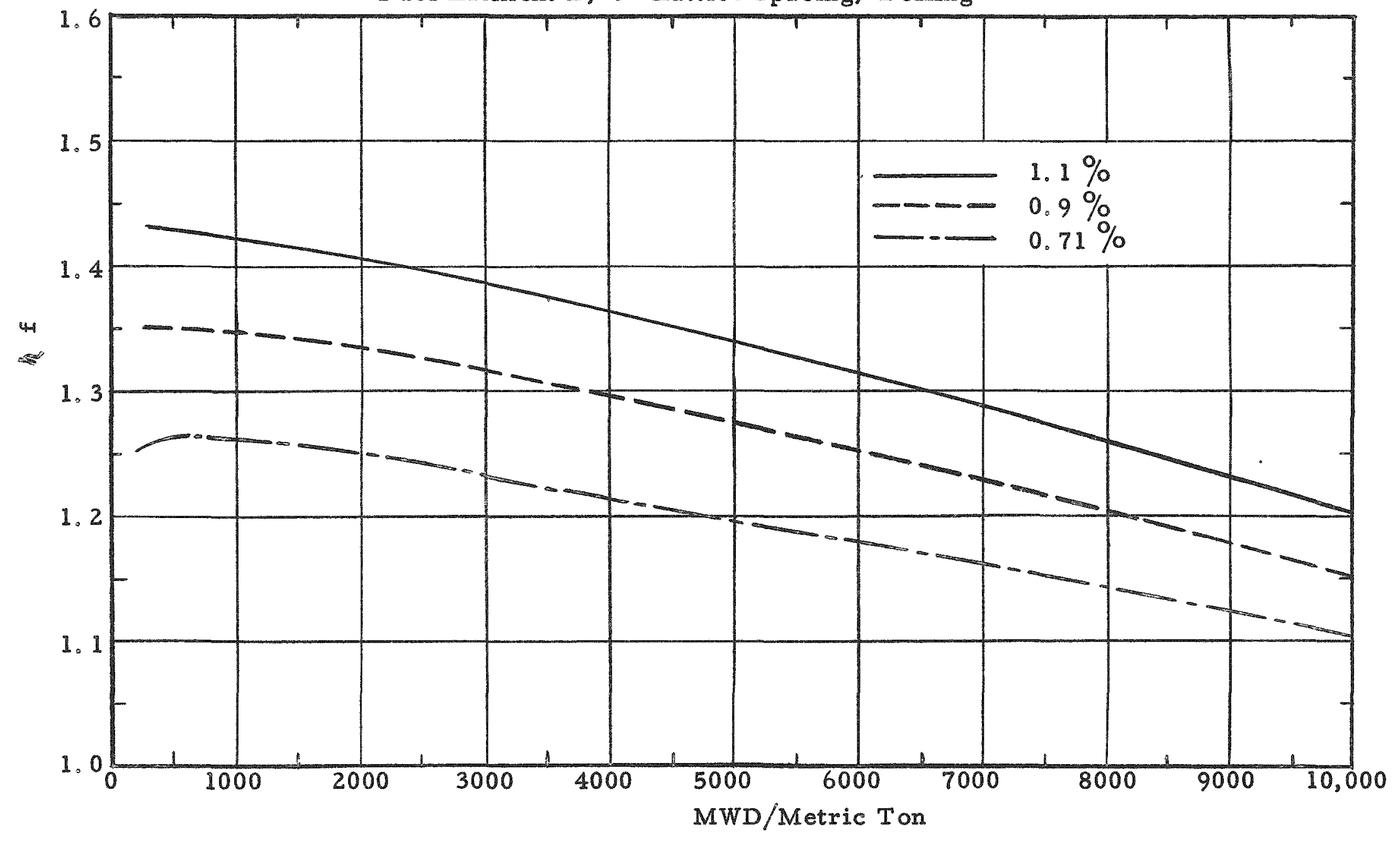




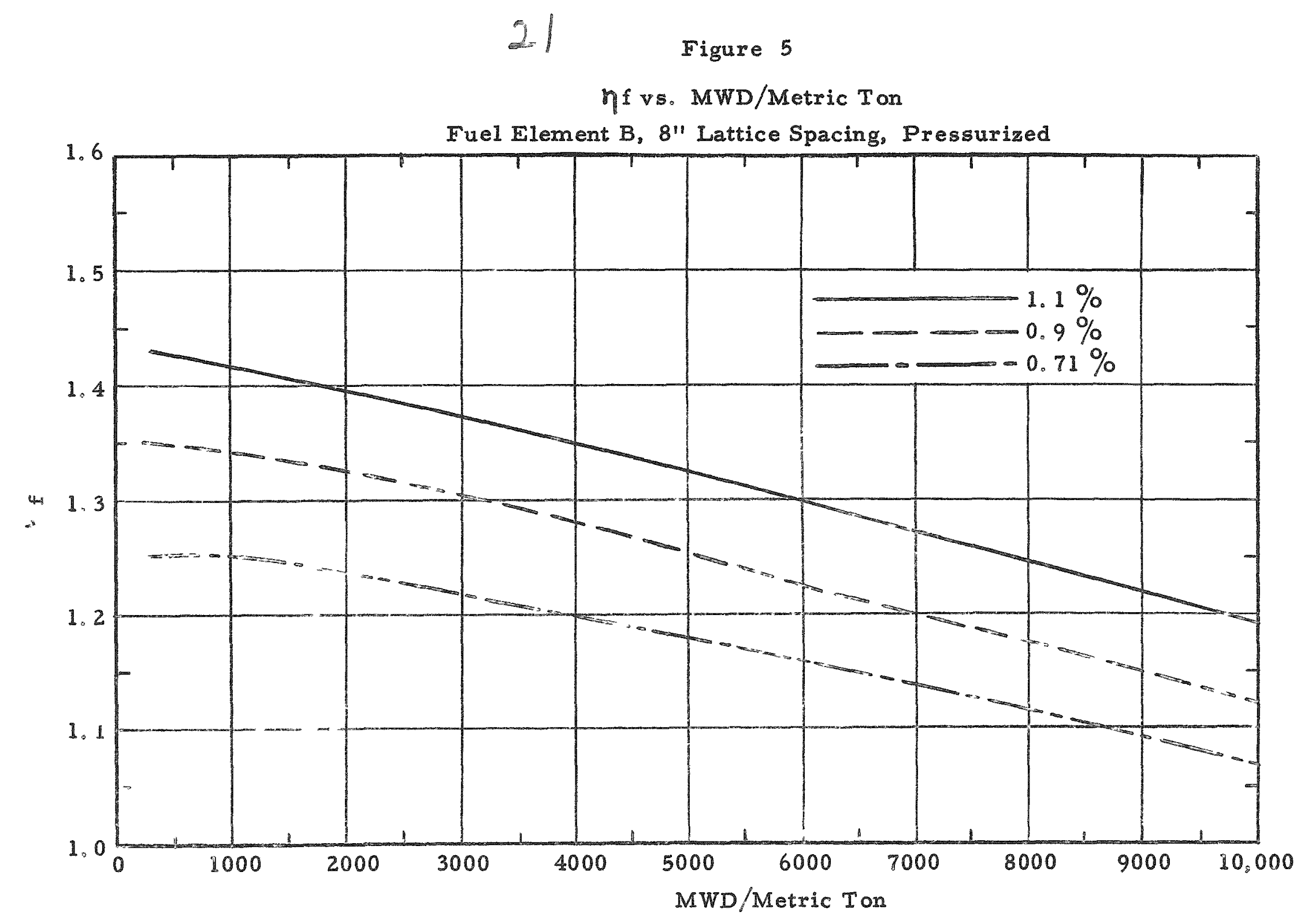


Figuxe 6

Material Buckling vs, MWD Metric Ton

Fuel Element B, 8" Lattice Spacing, Boining

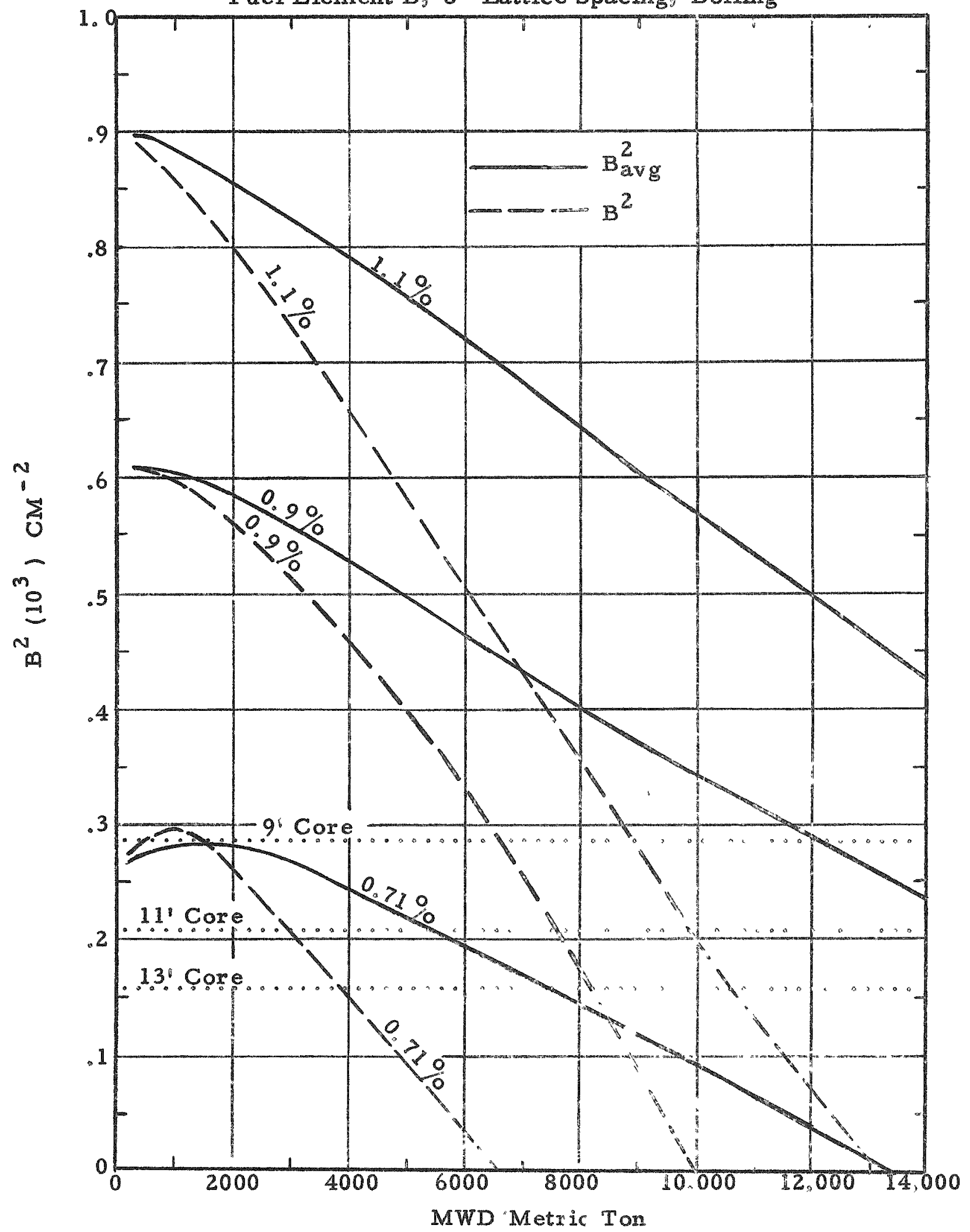


$2 \Rightarrow$ Figure 7

Material Buckling vs. MWD/Metric Ton

Fuel Element B, 8" Lattice Spacing, Pressurized

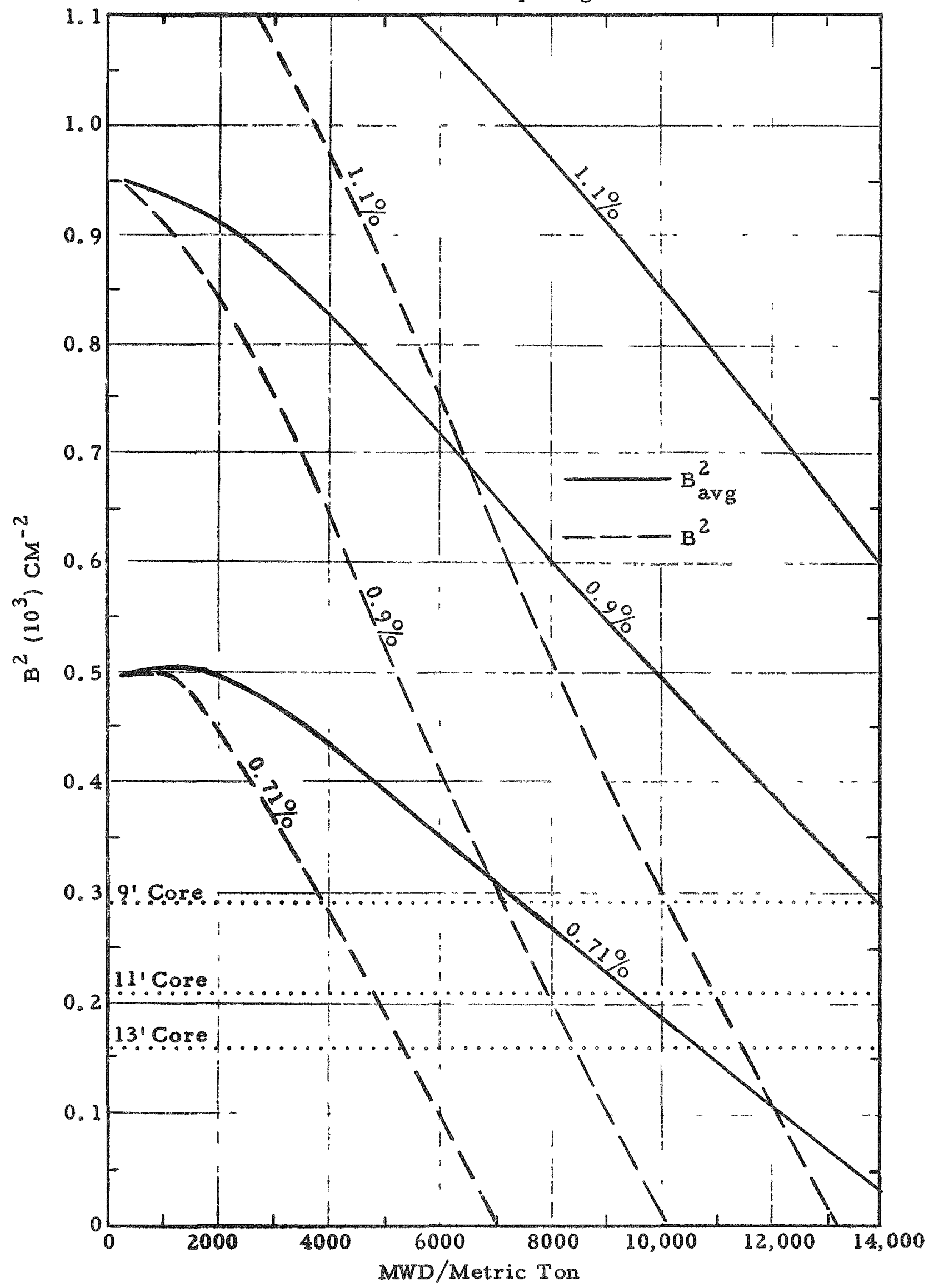


Figure 8

Ratio of $\mathrm{U}^{235}$ Remaining to Initial $\mathrm{U}^{235} \mathrm{vs}$. MWD/Metric Ton

Fuel Element B, 8" Lattice Spacing, Pressurized

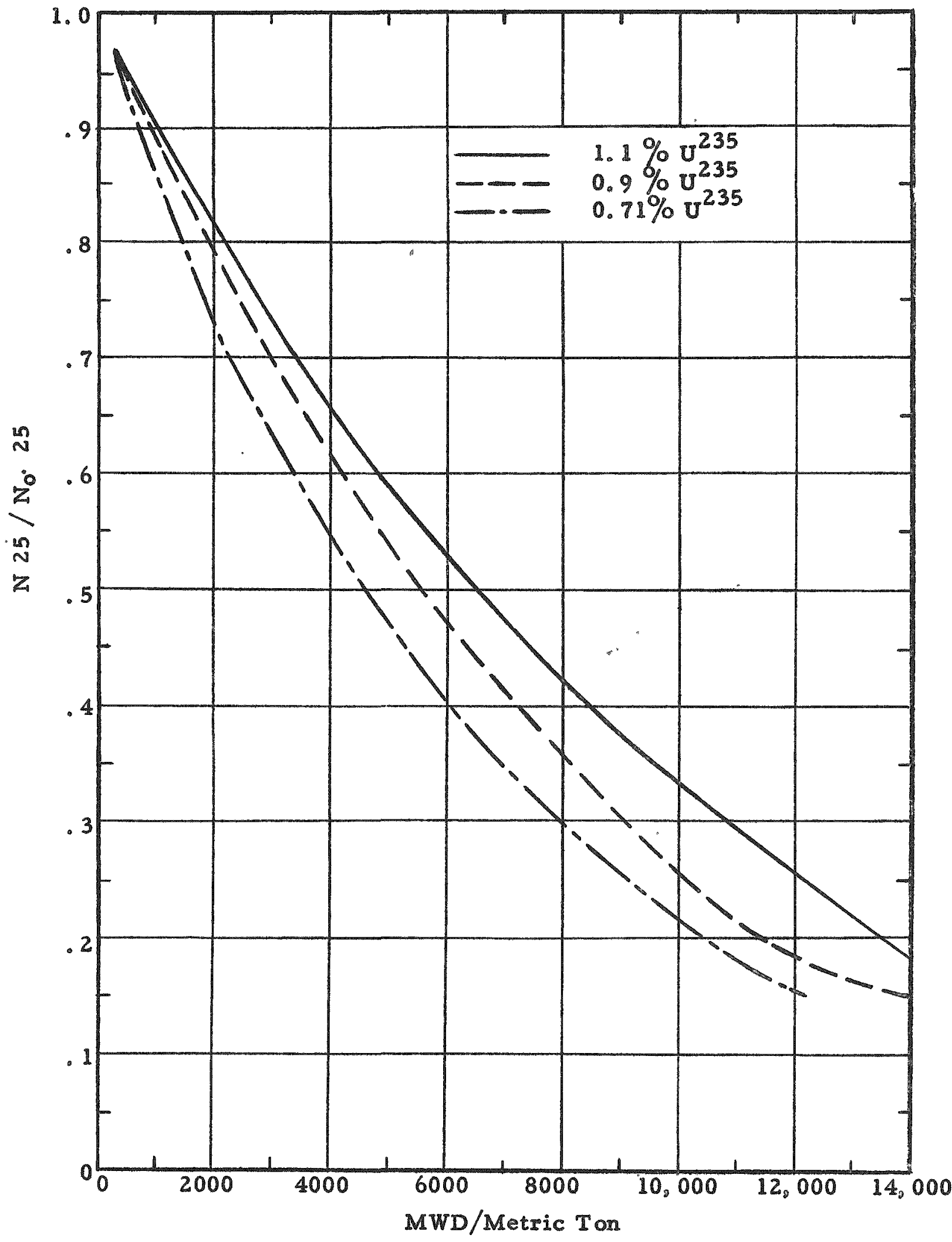




\section{5}

Figure 9

Ratio of $U^{235}$ Remaining to Initial $U^{235}$ พ. MWD/Metric Ton Fuel Element B, 8" Lattice Spacing, Boiling

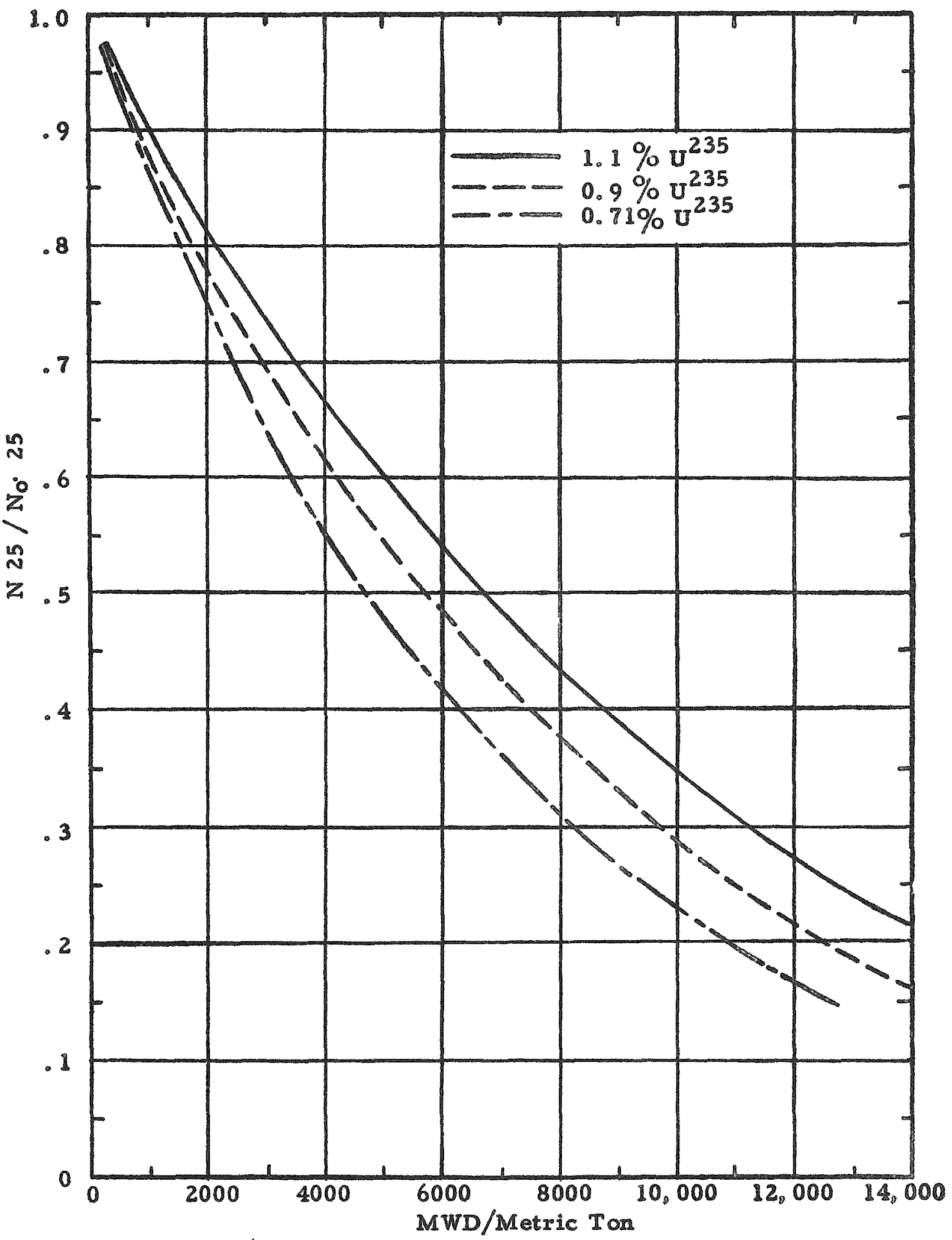


ERuge iu

- G Grans Metric Ton of Pu Isotopes vs. MWD/Metric Ton

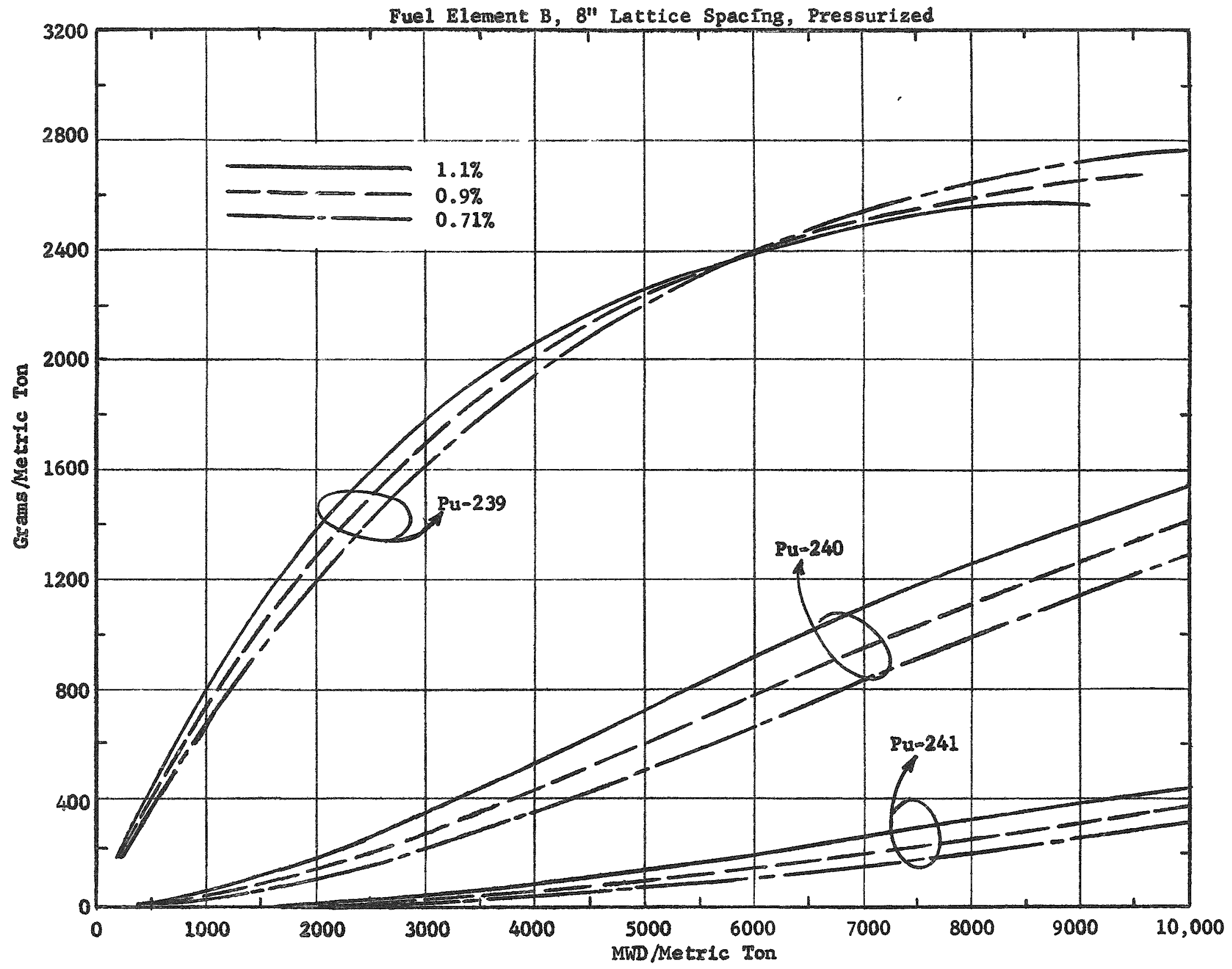


Grams/Metric Ton of Pu Isotopes Vs. MWD/Metric Ton

Fuel Element B, 8" Lattice Spacing, Boiling

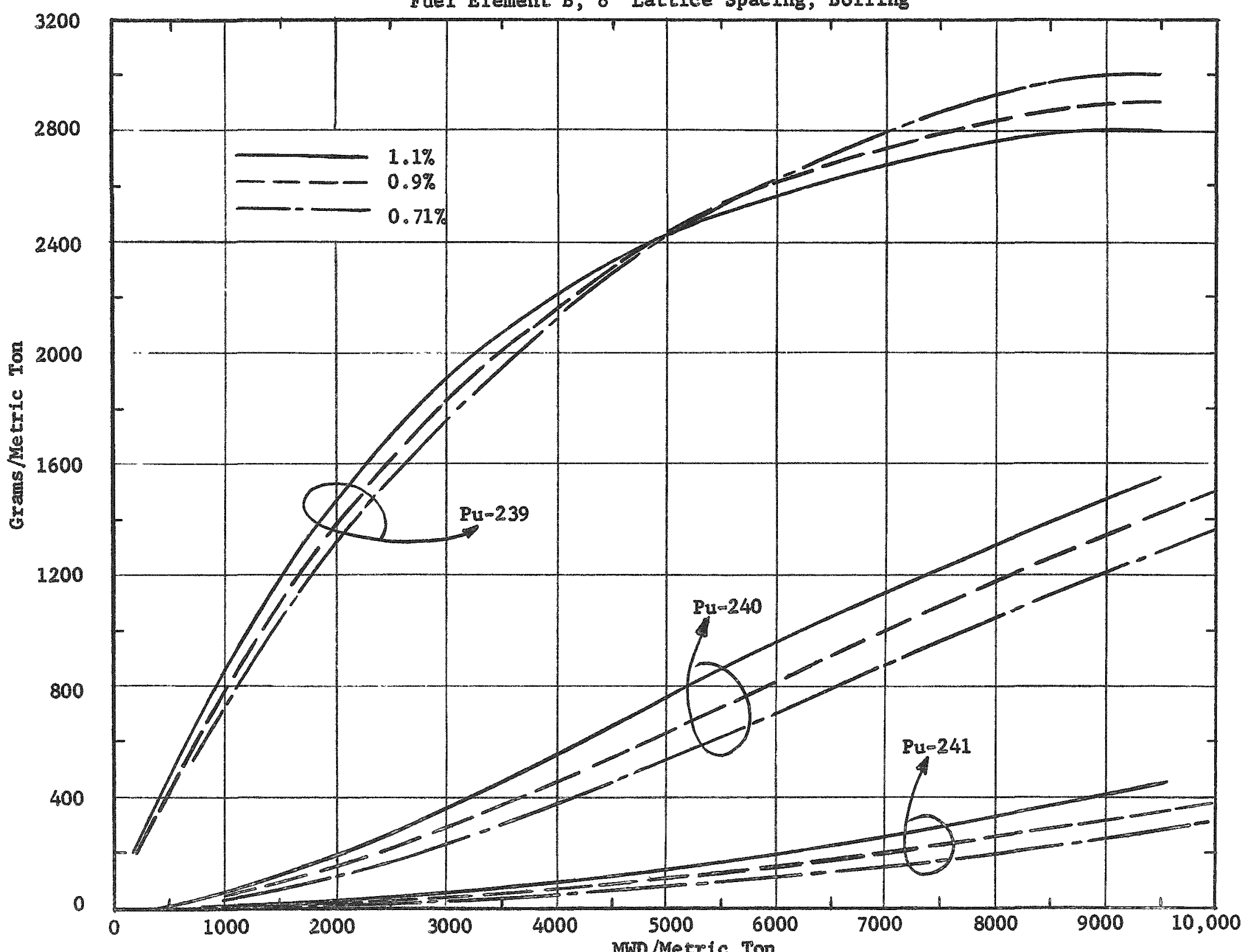


Figure 12

Uranium and Pu Value vs. MWD/Metric Ton

Fuel Element B, $8^{\prime \prime}$ Lattice Spacing, Boiling

Separative Work t $\$ 37.50 / \mathrm{kg}, \mathrm{Pu}$ as Metal at $\$ 12 / \mathrm{gram}$

Tails Concentration at 0.22 wt. $\% \mathrm{U}-235$

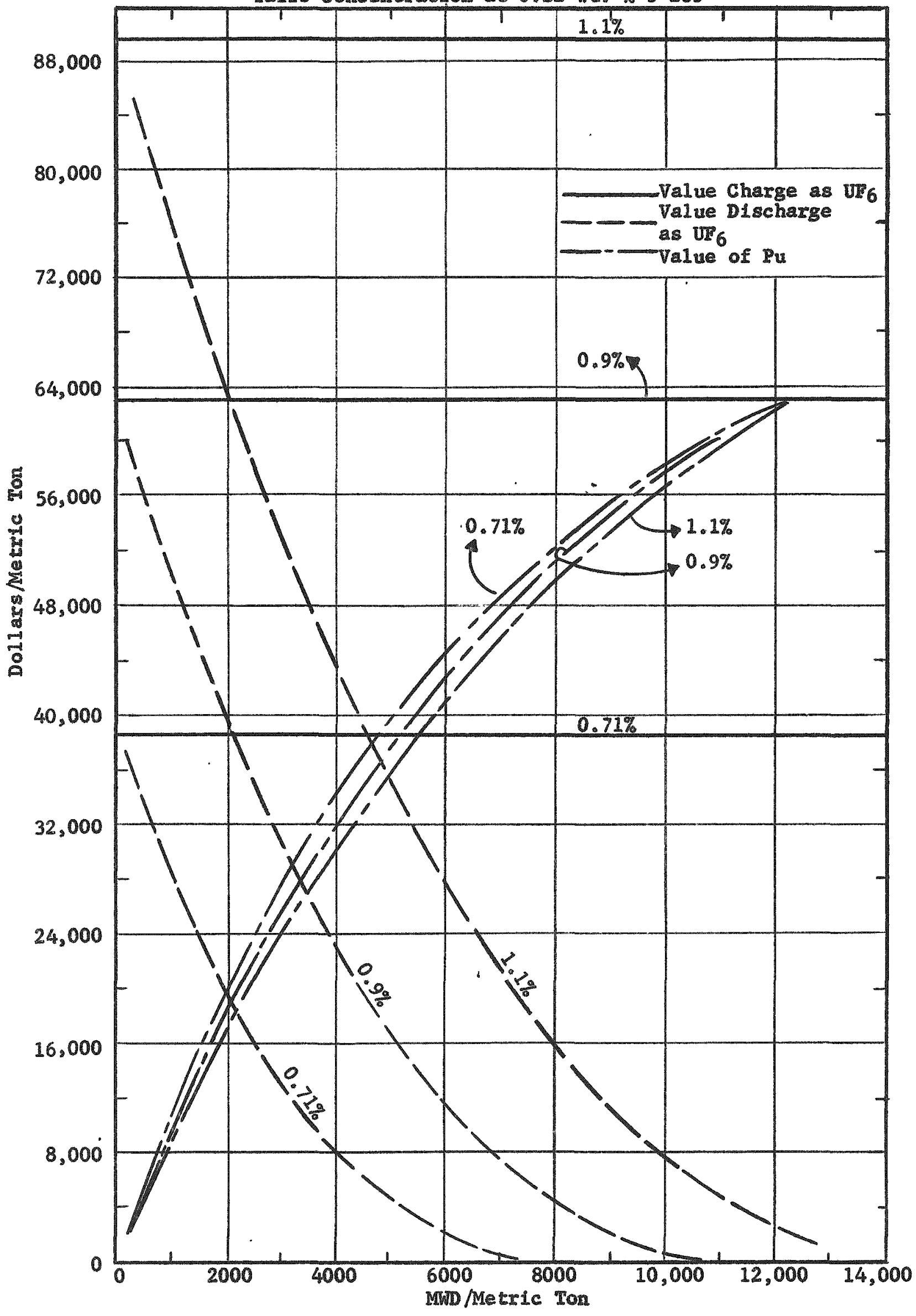


Tigure 13

27 Uranium and Pu Value va. MW/Mstric Ton

Tuel Elemen B, $8^{\text {n }}$ Lattice Spacing, Fregsurized Separative Work at $\$ 37.50 / \mathrm{kg}$. Pu as Meral at $\$ 12 / \mathrm{gm}$ Tails Concentration at 0.22 wt \% U 235

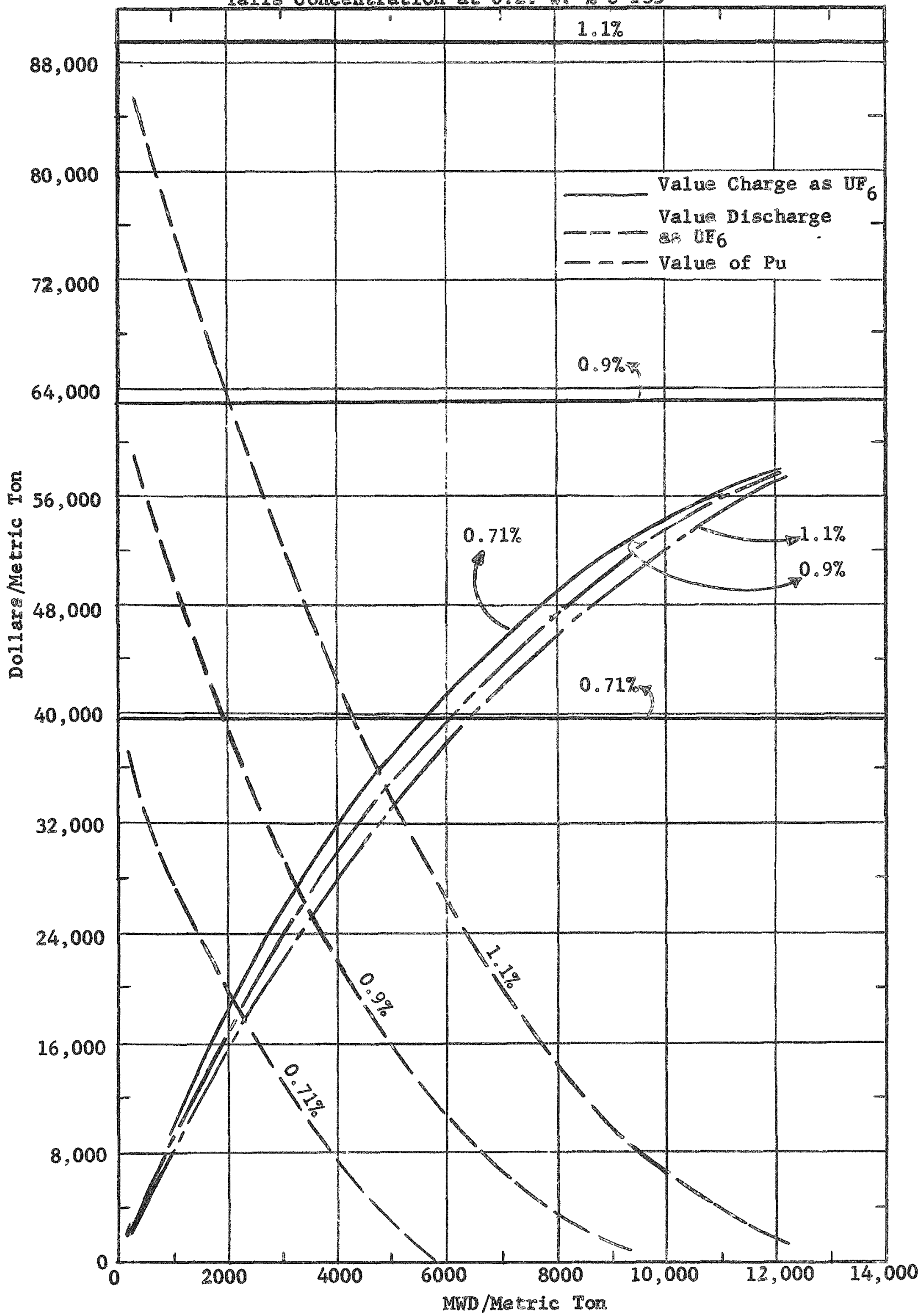




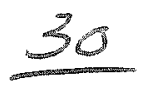

In the continuous charge adischarge case, it appears possible to achieve exposure levels of above 10,000 MWD/ton with natural uranium, as has also been predicted by groups at Argonne and Chalk River 1,2

Pressurized (non-boiling) cores of the same fuel element type and lattice spacing will have somewhat longer reactivity lifetimes than boiling cores because of the greater amount of moderator present and lower neutron 10ss. Also, the greater the clumping (reduction of fuel surface-tomass ratio) and the larger the lattice spacing, the longer is the reactivity lifecime at a given enrichment. This occurs because the resonance escape probability, $k_{\infty}$, and material buckling all increase with lattice spacing, although at the expense of less plutonium production. Lewis ${ }^{2}$ concludes that the use of a large latrice spacing results in increased buckling at the start of ixradiation, and chis is preferable to mitigating the loss of reactivity with exposure by increasing plutonium prow duction.

Relatively small variations in the values of certain of the constants employed in the reactor physics calculations may have a considerable effect on the calculated reactivity lifetimes, and much additional experimental data would be desirable to corroborate the results presented here. Two particular points of caution should be noted:

1) The physics calculations were based on the assumption of a uniform exposure (flat flux) over the core and hence are somewhe optimistic. In an actual reactor, various flattening measures such as graded enrichment zones could be employed, although this would cesult at best in incomplete flattening. Flattening by use of a graded lattice spacing would also be feasible.

2) A k eff of 1.0 was assumed adequate at the reactivity limit, where presumably the control rods would be entirely out.

Xenon Transients

Some attention was devoted to the effect of renon transients on the necessary excess reactivity. An example was calculated of the material buckling transient for a boiling lattice composed of Type B fuel elements on 8-in. centers, utilizing fuel of $1 \%$ enrichment. It was assumed that the reactor was operating

$\frac{1}{2}$ H. P. Iskenderian, et al., Geneva Conference Paper, P/495, Vol. 3 (1955)

2 W. B. Lewis, "Low Cost Fuelling Without Recycling," AECL 382, December, 1956. 


\section{1}

on newly charged metal with equilibrium genon and samarium at a power density of $25 \mathrm{MW} /$ metric ton. The reactor was then assumed to be shut down in a negligibly short time, and the xenon transient shown by Figure 14 would ensue. The curve gives the material buckling available at any time if the reactor could be returned to full power in a negligibly short period.

Assuming the general shape of the buckling transient due to xenon to be the same for any point in the exposure history of the loading, the following observations may be made:

1) The geometrical buckling required for criticality is roughly 150 microbucks, and the newly charged metal lattice has about 750 microbucks of reactivity. Hence 600 microbucks are available for exposure at the start, and from Figure 14 a maximum of only about half of this ( 300 microbucks) is lost to the senon transient. Therefore, with the unirradiated fuel the reactor could be immediately re-started at any time. Immediate start-up at any time would continue to be possible through approximately half the exposure life of the fuel, but then a shutdown in the vicinity of 10 hours in length would become impossible, and on further exposure the "barred" shutdown period would gradually expand until at the reactivity lifetime of the fuel it would cover roughly 36 hours.

2) In the boiling cores, the formation of steam bubbles and reduction in coolant density from $0.95 \mathrm{gm} / \mathrm{cc}$ to $0.66 \mathrm{gm} / \mathrm{cc}$ causes a loss in material buck 1 ing of about 400 microbucks. Since only 300 microbucks are required to override xenon at any time, a boiling reactor could be re-started at maximum xenon override and be brought up to at least one-quarter the usual bubble density (and hence usual power) with the 100 microbucks available in excess of that needed for xenon. (By increasing the recirculation rate in the core, even higher powers could be achieved at a constant bubble density.)

The requirement that maximum and instantaneous xenon override be available at all times is quite stringent. It could limit the attainable reactivity lifetimes markedly and hence increase fuel-cycle costs. This effect could be relaxed by permitting shutdowns and start-ups in which the power is changed gradual1y with time rather than requiring a fast start-up. When more reactivity is avai1able in a reactor at low power than at high power, due to boiling voids or temperature effects, the reactor can be re-started sooner and the power gradually raised. Xenon burn up is thus added to natural decay to hasten the reduction in transient xenon. 
Xenon Transient for Case of $1 \%$ Enrichment

Fuel Element B, 8" Lattice Spacing, Boiling, $23 \mathrm{MW} / \mathrm{T}$, at Start of Fuel Cycle

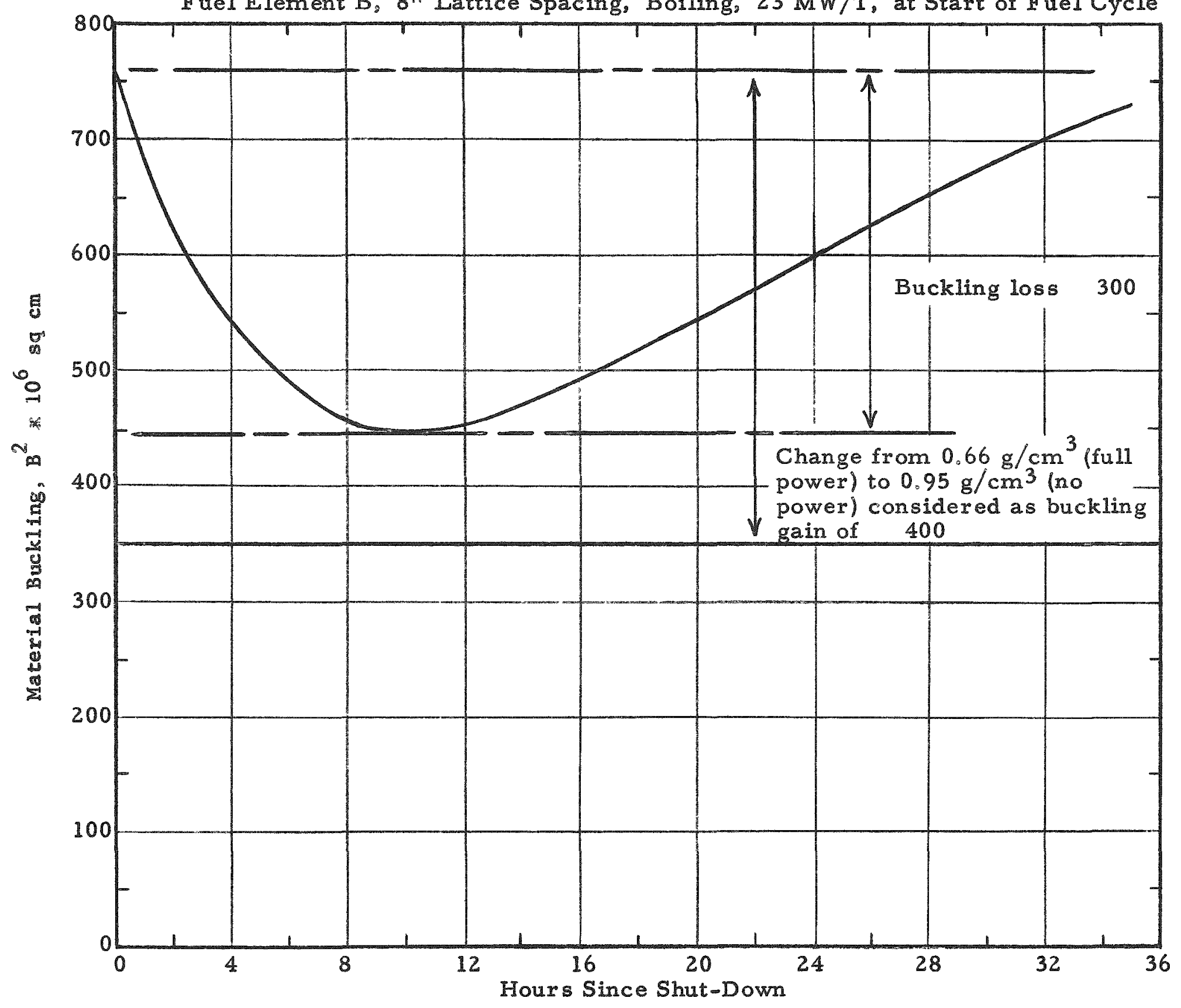




\section{Fuel Cycle Economies}

The core design resulting in minimum power generating cost represents a balance among several varying cost factors. The general effects of changing core parameters may be sumarized as follows:

Change

1) Increased enrichment.

2) Increased lattice spacing.
Beneficial Effects

1)

Longer exposure leve1.1) Closer lattice spacing. Smaller core and $D_{2}{ }^{O}$ inventory.

2) Longer exposure 1eve1.2)
Detrimental Effects

Higher burn-up cost. Higher inventory charge.

Higher net fuel burn-up cost due to decreased plutonium production.

Larger core and $\mathrm{D}_{2} \mathrm{O}$ inventory,

3) Less heat transfer area (hence larger core required.) fabrication cost. Lower critical mass. Longer exposure.

Figures 8 through 13 show, for typical cores, the variation of U-235 depletion, plutonium build-up, and net fuel burn up cost with exposure level. The effect of core design on the fuel-cycle costs is shown in Tables I and II. The following conclusions may be drawn from the tabulated values (as will be discussed later, it is important to note that these conclusions are quite sensitive to the assumed values of such factors as fuel fabrication costs, radiation damage 1 imits, and plutonium credit):

1) In all cases considered, the use of enriched uranium results in a lower total fuel-cycle cost than the employment of natural uranium, if there is no radiation damage 1 imit. In the onewbatch loading of pressurized cores, a maximum reactivity lifetime of $6,560 \mathrm{MWD} / \mathrm{metric}$ ton was calculated for natura1 uranium (Case 13-A-9).* This value is in agreement with estimates given us by Savannah River and Hanford.

* For convenience, core designs in Tables I and II are referred to by diameterfuel element-lattice spacing sequence, e.g., 13-A-9. 
2) The optimum degree of enrichment for the onembatch loading cases is above $1 \%$. In every case for which results were available, net fuel-cycle costs decreased steadily with enrichment but appeared to be leveling off in the vicinity of $1.3 \%$. For the continuous charge-discharge cases the optimum entichment is lower, perhaps 0.8 or $0.9 \% \mathrm{U} \times 235$. This is because with continuous chargemischarge the exposure levels at any given enrichnent are considerably longer than for the cases of one-batch 1oading, and hence the higher burn-up costs with enriched materials are of greater importance in the total fuel-cycle cost per kilowatt hour.

3) As expected, Fue1 Element A, because of the greater degree of uranium clumping and the lower fabrication cost of the thickex plate, shows lower fuelcycle costs for a given lattice spacing and enrichment than does Fuel Element $B$. (However, Fuel Element $B$ has greater heat transfer surface and may be required at large power outputs).

4) At a given lattice spacing and enrichment, increasing the core dia. meter will result initially in a decrease and then occasionally in a sight increase in fuel cycle cost because of the counteracting effects of exposure level and fuel inventory charge. (See Cases $9-\mathrm{B}-8,11-\mathrm{B}-8$, and $13-\mathrm{B}-8$ at $1.3 \%$ enrichment in the boiling cores,) Since larger cores raise the reactor capital cost and heavy water inventory charge markedly, it is usually more economic for any particular lattice spacing and enrichment to use as small a core as permitted by heat transfer considerations.

5) In many cases a desired exposure level can be achieved either by the use of a relatively large lattice spacing or by increasing the enrichment. The fuel-cycle cost alone is roughly 0.1 to $0.3 \mathrm{mills} / \mathrm{kwh}$ lower if a given exposure level is achieved by a wider lattice spacing. However, in most cores heat transfer is the limiting factor, and the total powermenerating cost is usually lower if a fairly closempaced lattice is used along with sufficient enrichnent to permit a long exposure level.

6) Because of the excellent neutron economy of heavy water reactors, the fuel element fabrication cost and the inventory charges are considerably more important than the net fuel cost after plutonium credit.

7) With the fabrication costs assumed, it appears that in reactors opera ted by one-batch loading, fuel-cycle costs of between 2.1 and 2.5 mills/kwh are readily attainable if radiation damage does not limit exposure level. In the continuous charge-discharge case, a fuel-cycle cost of slightly more than $1.1 \mathrm{mills}$ is achievable, providing the fuel element can withstand perhaps 12,000 MWD/ton before failing metallurgically. 


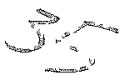

Figure 15 shows the effect of enrichment on the fuel-cycle cost for typical core design. The dotted lines fanning out from the oxigin are generalized "indifference curves" (constant cost curves). Each dotted line is the locus of various combinations of exposure levels and per-kilogram fuel-cycle costs which result in the indicated constant unit fuel-cycle costs per unit of electrical energy produced (mills/kwh). The exposure levels and per-kilogram fuel-cycle costs actually attainable with the illustrative core at various enrichments are represented by the points on the operating curve, with bar graphs showing the cost breakdown:

Although the per-kilogram fuel-cycle costs are higher for the enriched cores, the extension of the attainable exposure level results in an over-all reduction in mills/kwh. It will be noted, however, that at higher enrichments the net fuel cost and inventory charges become important, so that there is an optimum enrichment resulting in the lowest fuel-cycle cost in mills/kwh. Minimum fuel-cycle cost is achieved at the point where the operating curve becomes tangent to the adjacent indifference line. This would occur in the example shown at somewhere slightly beyond $1.3 \%$ enrichment, with a minimum fuel-cycle cost of about $2.2 \mathrm{mi} 11 \mathrm{~s} / \mathrm{kwh}$.

Since the fixed cost for fuel fabrication represents a major portion of the per-kilogram fuel-cycle cost, it will be found in general that the minimum-cost point will occur at high exposure levels, i.e., in the upperaright portion of the indifference diagrams such as Figure 15.

In the continuous charge-discharge cases, exposure levels with natural uranium are considerably longer than in the one-batch loadings. Here again, however, there is an apparent advantage in enrichment.

\section{Reference Reactor Designs}

With the results of the physics parameter survey as a guide to the core designs having low fuel-cycle costs, other design variables in the reactor turbogenerator system were then considered. Feasible core designs from the

* As shown by the bar graphs, the processing and fabrication cost is somewhat lower for normal uranium, since conversion to UF 6 for passage through the diffusion plant before reduction to metal is unnecessary. This cost rises slightly at higher enrichments, because included in it is the conversion of the increasing amounts of plutonium from nitrate to metal. 
36

Figure 15

Effect of Envichment on Fuel cycle cost

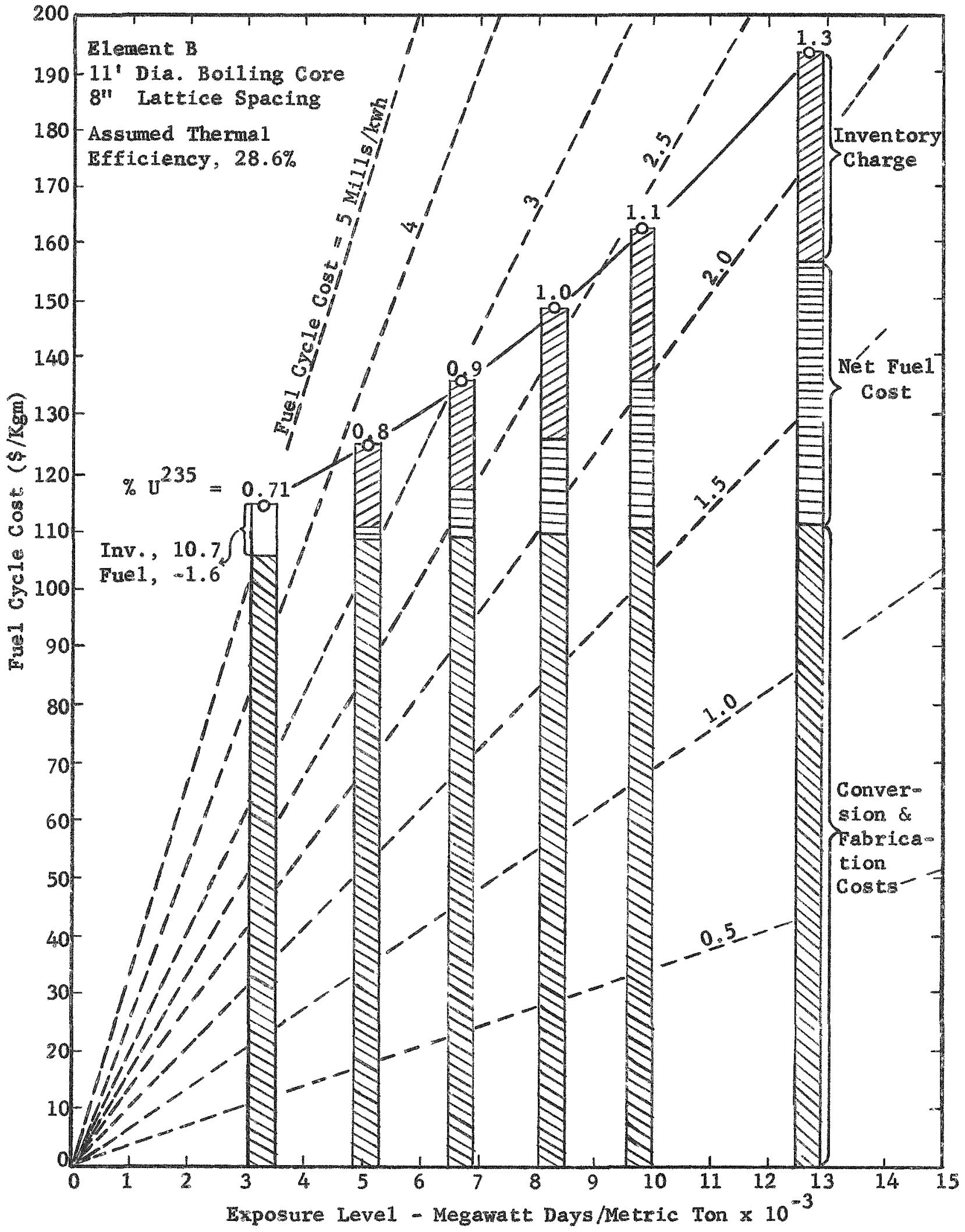




\section{3}

standpoint of heat transfer were determined and core selections for the reference designs were made on an economic basis.

Heat Transfer

As discussed previously. there is no satisfactory way of arriving at permissible heat fluxes in a reactor whthout lengthy and detalled analysis of many possible operating condtions. Hence permissible average beat fluxes of $120,000 \mathrm{Btu} / \mathrm{hr}-\mathrm{sq} \mathrm{ft}$ were assumed in order to place the reference reactor designs presented here on a comparable basis of conservatism with existing bolling and pressurlzed reactors.

Under this assumption of limiting heat flux, the mindmum core diametars required for heat transfer can be calculated:

\begin{tabular}{|c|c|c|c|}
\hline \multirow{2}{*}{$\begin{array}{l}\text { ELectrical } \\
\text { MW }\end{array}$} & \multirow{2}{*}{$\begin{array}{c}\text { Lattice Spacing } \\
(\operatorname{In} .)\end{array}$} & \multicolumn{2}{|c|}{ Required Core Diamete } \\
\hline & & Element A & Eleme \\
\hline 20 & $\begin{array}{l}6 \\
7 \\
8 \\
9\end{array}$ & $\begin{array}{l}5.5 \\
6.1 \\
6.7 \\
7.2\end{array}$ & $\begin{array}{l}4.9 \\
5.4 \\
5.9 \\
6.4\end{array}$ \\
\hline 100 & $\begin{array}{l}6 \\
7 \\
8 \\
9\end{array}$ & $\begin{array}{r}9.5 \\
10.4 \\
11.4 \\
12.3\end{array}$ & $\begin{array}{r}8.4 \\
9.3 \\
10.1 \\
11.0\end{array}$ \\
\hline 250 & $\begin{array}{l}6 \\
7 \\
8 \\
9\end{array}$ & $\begin{array}{l}12.5 \\
13.7 \\
15.0 \\
16.2\end{array}$ & $\begin{array}{l}11.1 \\
12.2 \\
13.4 \\
14.5\end{array}$ \\
\hline
\end{tabular}

\section{Core Selection}

For each power output, several combinations of fuel element type, lattice spacing, and required core diameter were selected which resulted in low fuelcycle costs. As explained in more detail in Appendix $A$, equipment sizes and plant themal efficlencies were then calculated and the designs compared to find that design yielding the lowest total power generating cost.

Table III shows the calculations for the 100 EMW boiling reactor, one batch loading. Consideration of the designs compared indicate that by use of higher enrichment cores than those calculated, the fuel-cycle cost for the cases involving Fuel Element $A$ might be reduced considerably. From the total costs shown in the last colum, Fuel Element $B$ with an 8 -in. lattice spacing and Fuel Element $\mathrm{A}$ with a 7-in. or an 8-in. Lattice spacing all give about the same power costs at a given exposure level. This cost would be roughly $11.0 \mathrm{mills} / \mathrm{kwh}$ 
TABIE III

SELECTION OF OPTIMUM 100 EMW BOILING REACTOR DESIGN, ONE-BATCH LOADING

\begin{tabular}{|c|c|c|c|c|c|c|c|c|c|c|c|c|}
\hline \multirow[b]{2}{*}{$\begin{array}{c}\text { Fuel } \\
\text { Element } \\
\end{array}$} & \multirow[b]{2}{*}{$\begin{array}{l}\text { Lattice } \\
\text { Spacing } \\
\text { (in.) } \\
\end{array}$} & \multirow[b]{2}{*}{$\begin{array}{c}\text { Enxich } \\
\text { ment } \\
(\% \quad 0235) \\
\end{array}$} & \multirow[b]{2}{*}{$\begin{array}{c}\text { Attainable } \\
\text { Exposure Leve1 } \\
\text { (MWD Metric Ton) } \\
\end{array}$} & \multirow[b]{2}{*}{$\begin{array}{l}\text { Vesse1 } \\
\text { Dia. } \\
\text { (ft) } \\
\end{array}$} & \multirow[b]{2}{*}{$\begin{array}{l}\text { Turbine } \\
\text { Pressure } \\
\text { (psig) } \\
\end{array}$} & \multirow{2}{*}{$\begin{array}{l}\text { Plant } \\
\text { Effi- } \\
\text { ciency } \\
(\%) \\
\end{array}$} & \multirow{2}{*}{$\begin{array}{c}\text { Total } \\
\text { Capital } \\
\text { Cost } \\
\text { (SMM) } \\
\end{array}$} & \multicolumn{5}{|c|}{ Mills per kilowatt-hour\% } \\
\hline & & & & & & & & $\begin{array}{l}\text { Capital } \\
\text { Charge }\end{array}$ & $\begin{array}{l}\text { Fuel } \\
\text { Cycle } \\
\text { Cost } \\
\end{array}$ & $\begin{array}{c}\mathrm{D}_{2} \mathrm{O} \\
\text { Inventory } \\
\text { Charge } \\
\end{array}$ & $\begin{array}{c}\mathrm{D}_{20} \\
\text { Losses } \\
\end{array}$ & Tota 1 \\
\hline A & 7 & 0.9 & 5,500 & 13 & $\begin{array}{l}400 \\
600 \\
800\end{array}$ & $\begin{array}{l}29 \\
30 \\
31\end{array}$ & $\begin{array}{l}30.6 \\
31.4 \\
32.5\end{array}$ & $\begin{array}{l}6.56 \\
6.73 \\
6.96\end{array}$ & $\begin{array}{l}2.87 \\
2.77 \\
2.68\end{array}$ & $\begin{array}{l}1.38 \\
1.38 \\
1.38\end{array}$ & $\begin{array}{l}0.80 \\
0.979 \\
1.13\end{array}$ & $\begin{array}{l}11.61 \\
11.87 \\
12.15\end{array}$ \\
\hline & 8 & 0.9 & 7,900 & 14 & $\begin{array}{l}400 \\
600 \\
800\end{array}$ & $\begin{array}{l}29 \\
30 \\
31\end{array}$ & $\begin{array}{l}30.9 \\
32.0 \\
33.1\end{array}$ & $\begin{array}{l}6.60 \\
6.82 \\
7.06\end{array}$ & $\begin{array}{l}2.22 \\
2.14 \\
2.07\end{array}$ & $\begin{array}{l}1.58 \\
1.58 \\
1.58\end{array}$ & $\begin{array}{l}0.863 \\
1.06 \\
1.22\end{array}$ & $\begin{array}{l}11.26 \\
11.60 \\
11.93\end{array}$ \\
\hline & 9 & 0.9 & 8,700 & 15 & $\begin{array}{l}400 \\
600 \\
800\end{array}$ & $\begin{array}{l}29 \\
30 \\
31\end{array}$ & $\begin{array}{l}31.3 \\
32.6 \\
33.7\end{array}$ & $\begin{array}{l}6.68 \\
6.96 \\
7.20\end{array}$ & $\begin{array}{l}2.13 \\
2.06 \\
1.99\end{array}$ & $\begin{array}{l}1.82 \\
1.82 \\
1.82\end{array}$ & $\begin{array}{l}0.93 \\
1.14 \\
1.31\end{array}$ & $\begin{array}{l}11.56 \\
11.98 \\
12.32\end{array}$ \\
\hline B & 7 & 1.1 & 5,300 & 12 & $\begin{array}{l}400 \\
600 \\
800\end{array}$ & $\begin{array}{l}29 \\
30 \\
31\end{array}$ & $\begin{array}{l}30.3 \\
31.1 \\
32.0\end{array}$ & $\begin{array}{l}6.50 \\
6.67 \\
6.86\end{array}$ & $\begin{array}{l}3.75 \\
3.62 \\
3.51\end{array}$ & $\begin{array}{l}1.26 \\
1.26 \\
1.26\end{array}$ & $\begin{array}{l}0.73 \\
0.90 \\
1.03\end{array}$ & $\begin{array}{l}12.24 \\
12.45 \\
12.66\end{array}$ \\
\hline & 8 & 1.3 & 12,700 & 13 & $\begin{array}{l}400 \\
600 \\
800\end{array}$ & $\begin{array}{l}29 \\
30 \\
31\end{array}$ & $\begin{array}{l}30.6 \\
31.4 \\
32.5\end{array}$ & $\begin{array}{l}6.56 \\
6.73 \\
6.96\end{array}$ & $\begin{array}{l}2.19 \\
2.12 \\
2.05\end{array}$ & $\begin{array}{l}1.38 \\
1.38 \\
1.38\end{array}$ & $\begin{array}{l}0.80 \\
0.979 \\
1.13\end{array}$ & $\begin{array}{l}10.93 \\
11.21 \\
11.52\end{array}$ \\
\hline
\end{tabular}

* These charges are besed on: (a) capital charge of $15 \%$ per dollar-year, (b) carrying charge of $12 \%$ for non nuclear core parts and $\mathrm{D}_{2} \mathrm{O}$, (c) rental of fuel from AEC at $4 \% \mathrm{per}$ dollar year, and (d) a plant factor of $80 \%$. 


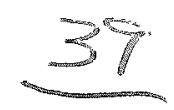

at exposure levels near 5,000 MWD/ton and $10.5 \mathrm{mills} / \mathrm{kwh}$ in the $10,000 \mathrm{MWD} / \mathrm{ton}$ range. In all cases the 400 psi turbine pressure resulted in the lowest power cost, since the additional investment for the bigher-pressure plant is larger than the fuel-cost saving at the better thermal efficiency.

In the continuous charge-discharge case for the 100 EMW boiling reactor, the same heat-transfer restrictions apply, and so the same combinations of fuel-element type, lattice spacing, and vessel diameter should be examined. The A-7 core benefits relatively more than the others from the longer exposure levels permitted by continuous charge-discharge.

The reference designs for the various reactors as obtained by the above procedure are summarized in Table IV for the one-batch loading method. Figures 16 and 17 show flow diagrams of the boiling and pressurized designs, respectively.

A similar table could be prepared for the continuous charge-discharge cases, although this was not done here. It might be noted that the continuous charge discharge loading method results in savings in power cost of 1.0 to $1.5 \mathrm{mil1s}$, providing the longer exposure levels with this type of loading are metallurgically achievable.

These costs are calculated on the U. S. "grivate uthity" basis noted on Table III: The $15 \%$ capital charge rates used imposes a particularly heavy penalty on $\mathrm{D}_{2} \mathrm{O}$ reactors because of their high capital costs. In a later section the effect of lowering this charge rate to that used by other countries wi11 be examined.

\section{EMN Designs}

It has been generally supposed that $D_{2}$ O reactors in small size are not particularly economic, and the results shown in Table IV substantiate this. The cost of the pressure vessel and the $D_{2} \mathrm{O}$ inventory charge and losses are a11 disproportionately bigh for small power outputs, and the calculated cost of power in both the boiling and pressurized designs is over $20 \mathrm{mills} / \mathrm{kwh}$.

* It should be noted that interest on construction funds is not included in these cost totals. This is a legitimate cost and will raise the capital charge item in mills/kwh about $11 \%$ 。 


$\frac{20 \mathrm{EM}}{\text { Boiling }}$

\begin{tabular}{rrr}
10.80 & 13.90 \\
0.52 & 0.52 \\
3.46 & & 3.47 \\
\hline 14.78 & & 17.89 \\
540 & & 695
\end{tabular}

\begin{tabular}{rr}
11.65 & 14.89 \\
2.47 & 2.40 \\
2.10 & 1.74 \\
2.97 & 2.98 \\
1.80 & 1.80 \\
\hline 21.00 & 23.80
\end{tabular}

\section{DESIGN GHARACTERISTICS}

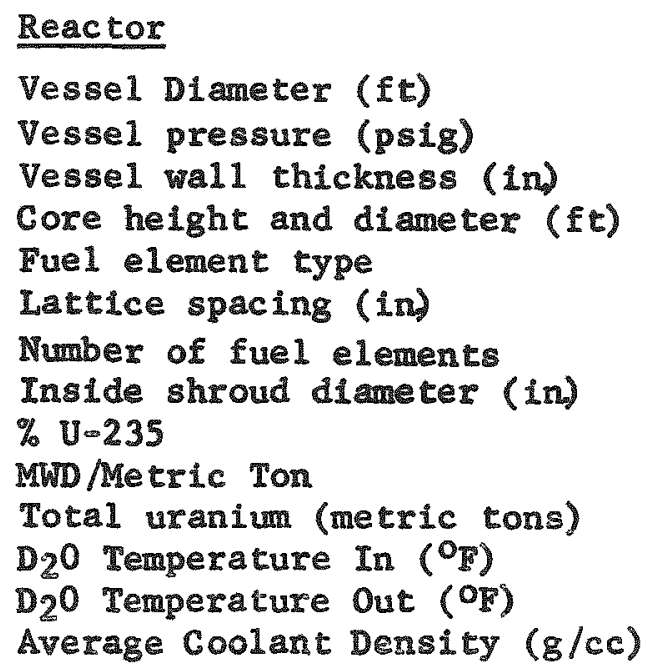

Reactor

Vessel Dianeter ( $f t$ )

Vessel pressure (psig)

Vessel wall thickmess (in)

Core height and diameter (ft)

Fuel element type

Lattice spacing (in)

Number of fuel elements

Inside shroud diameter (in)

$\% \mathrm{U}-235$

MWD/Metric Ton

Total uranium (metric tons)

$D_{2} 0$ Temperature In $\left({ }^{\circ}\right)$

$D_{2} 0$ Temperature Out (OF)

Average Coolant Density ( $\mathrm{g} / \mathrm{cc}$ )

100 EMW

Boiling Pressurized

$$
\begin{aligned}
& 61.70 \quad 75.50 \\
& 4.03 \quad 4.03 \\
& \underline{11.30 \quad 13.16} \\
& 77.03 \quad 92.69 \\
& 247 \quad 302
\end{aligned}
$$

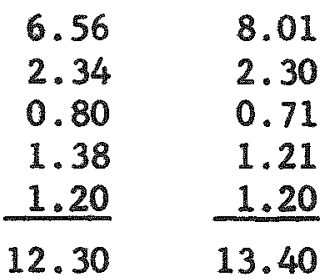

5.28

2.55

0.64

0.90

1.00

10.40

6.43

2.26

0.45

0.78

1.00

10.90

Feedwater seturn temperature 
TABLE IV (cont.)

$\frac{20 \mathrm{EMW}}{\text { Bolling Pressurlzed }} \quad \frac{100 \mathrm{EMW}}{\text { Bolling Pressurized }} \quad \frac{250 \mathrm{EMW}}{\text { Boiling Pressurized }}$

DESIGN CHARAC TERISTICS (cont.)

\section{Heavy Water}

Inventory (metric tons)

$$
\text { ( } \mathrm{Rgm} / \mathrm{EkW})
$$

Losses (metric tons/year)

$\begin{array}{ll}56.2 & 56.4 \\ 2.81 & 2.82 \\ 4.76 & 3.95\end{array}$

$\begin{array}{rr}131 & 115 \\ 1.31 & 1.15 \\ 11.1 & 8.05\end{array}$

214

183

4.76

3.95
$87,500 \quad 87,500$

$235 \quad 235$

- 3,200

Average core heat flux (Btu/hr-sq ft)

Reactor heat output (Btu/hr $\times 10^{-6}$ )

Heat Exchanger area ( $s q \mathrm{ft}$ )

\section{Hydrodynamics}

Coolant velocity in critical channel

$$
\text { (ft/sec) }
$$

Coolant circulation rate (GPM)

$\begin{array}{rr}16,400 & 8.0 \\ & 13,700 \\ 400 & 400 \\ .253 & .294 \\ 1.5 & 1.5 \\ 29 & 29\end{array}$

\section{Turbogenera tor}

Turbine throttle pressure (psig)

Steam Flow ( $1 \mathrm{~b} / \mathrm{hr} \times 10^{-6}$ )

Condenser pressure (in. Hg)

Overa11 thermal efficiency (\%)

$$
\begin{array}{rr}
120,000 & 120,000 \\
1,170 & 1,170 \\
-\quad & 16,000
\end{array}
$$

$$
\begin{array}{rr}
120,000 & 120,000 \\
2,940 & 2,940 \\
- & 40,000
\end{array}
$$

$.856 \quad .732$

$18.2 \quad 12.8$




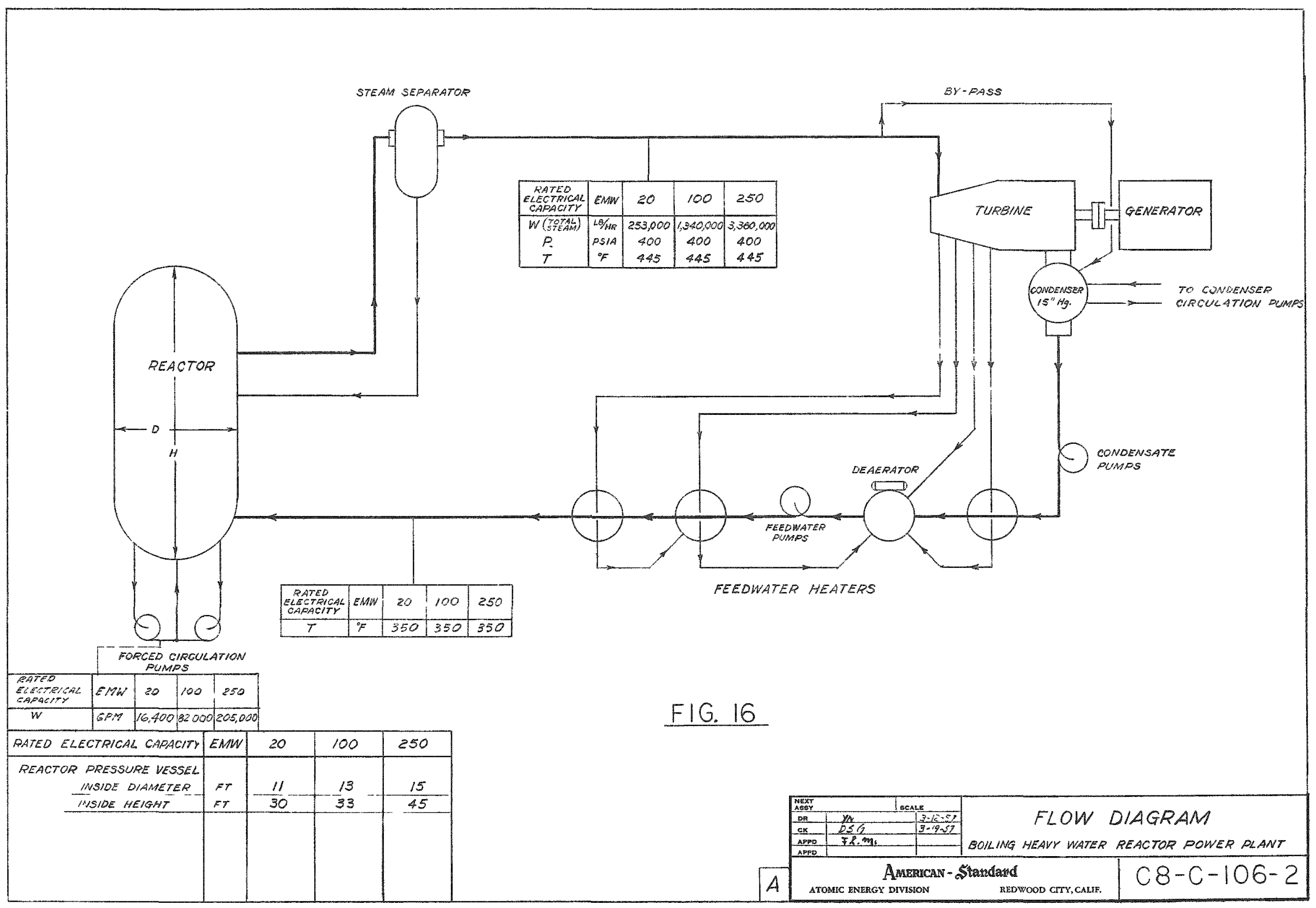




\section{3}

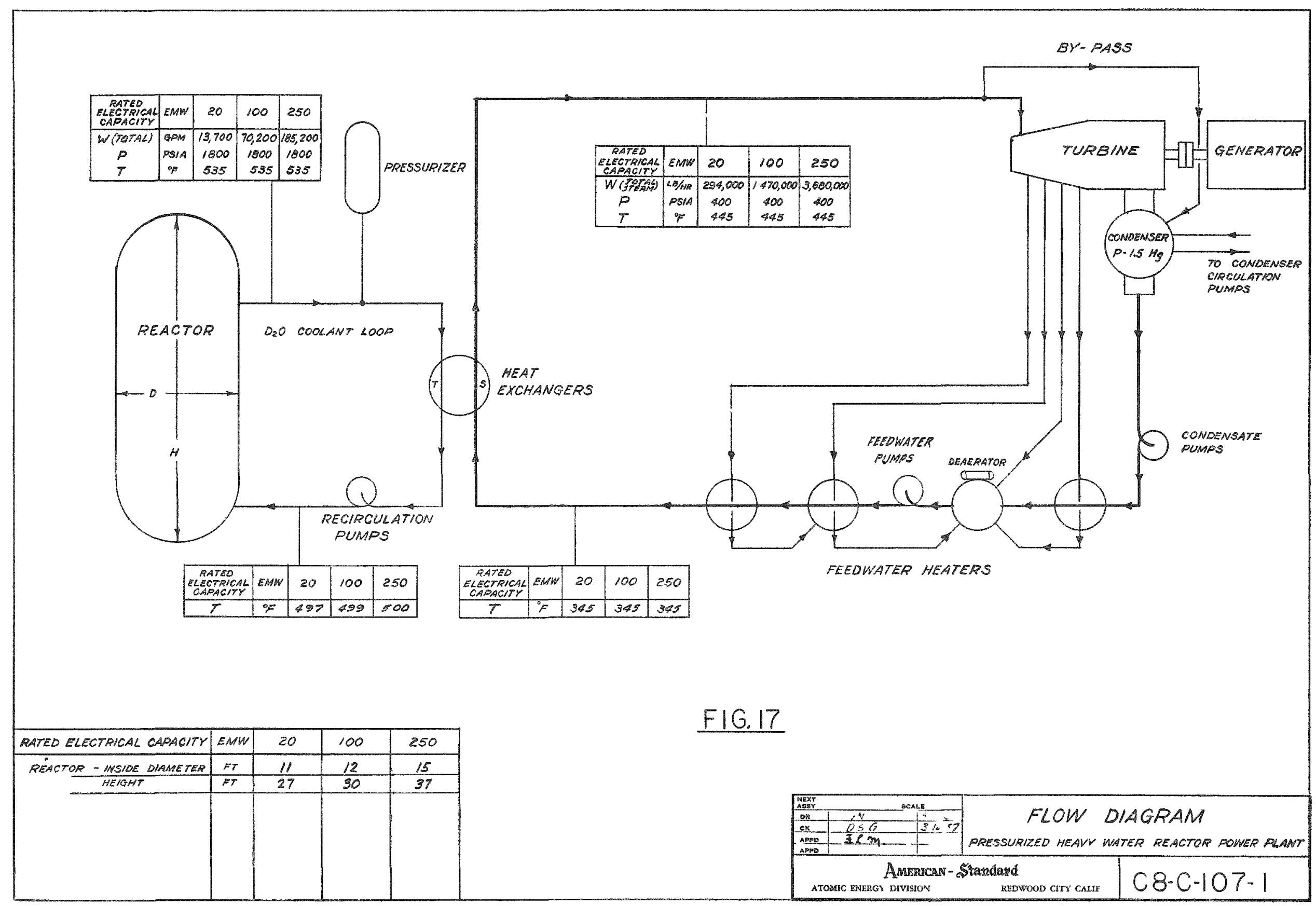


Of the six reference reactor designs, the two 20 EMW reactors were the only ones in which heat transfer was not the limiting factor on core design. As Table IV shows, the 8-ft diameter cores assumed for these reactors were larger than needed to remove the required amount of heat, even with the "clumped" Type A fuel element and a 9-in. lattice spacing.* A fuel element having an even smaller ratio of surface to mass would have been suitable for these core designs and would probably have given a slightly better design, or alternatively the reactor vessel diameter could have been reduced somewhat. However, even a painstaking optimization of this size would undoubtedly still result in power generating cost of at least $20 \mathrm{mills} / \mathrm{kwh}$.

\section{EMW Designs}

Because of the large effect of size on the unit capital charge, the $100 \mathrm{EMW}$ designs show greatly reduced generating costs compared to the 20 EMW designs. In the $100 \mathrm{EMW}$ size (as in the $250 \mathrm{EMW}$ designs), heat transfer is a limiting factor. It is economic in the boiling $100 \mathrm{EMW}$ design to utilize a 10.1-ft diameter and an 8-in. 1attice spacing, but because of the higher pressure in the reactor vessel of the pressurized design, a smaller vessel and tighter pitch are more appropriate. With the higher pressure in the reactor vessel and the additional cost of the heat exchanger, the pressurized 100 EMW design has about 1.5 mills higher capital charge than for the boiling design. However, it shows slightly better fuel economy, and the inventory and losses of heavy water are somewhat smaller than for the boiling design. The net effect is about a 1-mill differential in favor of the boiling design in this size.

\section{EMW Designs}

The very high heat-generation rates required for this power output necessitate the use of a fairly small lattice pitch in order to stay within the fabricating capability of pressure-vessel manufacturers. Since a $15-\mathrm{ft} I . D$. vessel appears to be near the upper limit at the present time, both designs were fixed at this vessel size. The small lattice pitch in the boiling case makes a long reactivity lifetime difficult to achieve in the one-batch loading method, and at the highest enrichment studied (1.3\% U-235), an exposure level of only 9,000 MWD/metric ton was calculated and is shown on Table IV. This imposes a slight penalty on the

* No reactor physics studies were made for cores smaller than $8 \mathrm{ft}$ in diameter in this study. A considerably more detailed analysis of the effect of the reflector becomes necessary in the smaller cores. 


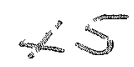

50 EMW boiling case, since in all the other cores the entichment was chosen to permit 10,000 MWD/metric ton for the diameter and lattice pitch used, but the penalty is not much more than $0.1 \mathrm{mi} 11 / \mathrm{kwh}$.

As the reactor output increases, the economic advantage of the boiling type as compared with the pressurized type diminishes, since the effect of the capital cost becomes less important and the pressurlzed type enjoys a small advantage in the cost of $D_{2} Q$ inventory charge and losses.

A very preliminary cost estimate was carried out for a 500 EMW design. It was assumed that this might be built after sufficient operating experience was obtained with smaller $D_{2}$ o reactors so that a marked relaxation of the average heat flux limitation of $120,000 \mathrm{Btu} / \mathrm{hr}-\mathrm{sq}$ ft could be effected. Such a design is discussed briefly in Appendix B. As expected, it shows extremely encouraging power economics because of the low captal cost per kilowatt combined with the low fuel-cycle cost inherent in the $\mathrm{D}_{2} \mathrm{O}$ reactor.

\section{Design of Equipment for Heavy Water Reactors}

The large pressure vessels and the high cost of heavy water create some special problems in $\mathrm{D}_{2} \mathrm{O}$ reactors not possessed by other types. A number of equipment suppliers were consulted, and the results of their recommendations are summarized here and discussed more thoroughly in Appendix $B$.

pressure Vessel Design

Particularly for the larger $\mathrm{D}_{2} \mathrm{O}$ reactors, the plate thicknesses required for the reactor pressure vessel tax the existing fabrication facilities in the United States to the upper limits of their capacity. The Consolidated Western Steel Division of U. S. Steel Corporation was engaged to study all phases of the pressure-vessel problem, and their report is included as Appendix F. It covers in detail the upper limits of vessel fabrication and the attendant problems and costs. In general, it may be concluded that no insurmountable problems should be encountered in the fabrication of the vessel, al though in the larger sizes the vessel must be constructed by welding together a series of forged rings.

One problem which deserves particular atcention, however, is that of the garma heating in the very thick walls required for these pressure vessels. Thermal shields were included in the area surxounding the core of the six 


\section{6}

reference reactors described, but the problem would have to be considered much more carefully in the detailed design of a large $D_{2} O$ reactor.

For the conceptual reactor designs included here, curves were constructed showing the variation in reactor vessel cost as a function of pressure and vessel diameter (see Appendix B).

Pumps, Turbines, and Heat Exchangers

In early $\mathrm{D}_{2} \mathrm{O}$ reactor designs, quite elaborate precautions were taken to minimize the inventory and leakage of heavy water. The drop in price of this material from $\$ 80$ to $\$ 28$ per pound and the considerable capacity available in the U.S. for supplying heavy water for power reactors makes these earlier stringent measures poor economy under present conditions. After detalled discussions with equipment suppliers, it was felt that the use of conventional equipment, modified with special seals and $\mathrm{D}_{2} \mathrm{O}$ collection systems, was the most appropriate design philosophy.

As discussed in more detail in Appendix B, centrifugal pumps were utilized, equipped with special mechanical seals and collection devices to contain $D_{2} O$ runoff. A special shaft seal was also employed on the turbogenerator and is said to result in a virtually leak-proof machine. The turbogenerator casing was enclosed in a welded metal she11. The additional costs for these features and also for use of saturated steam and for moisture removal were included in the cost estimates.

Heat exchangers for the pressurized designs were provided with special moisture-removal equipment and were also provided with sensitive instrumentation to detect $\mathrm{H}_{2} \mathrm{O}-\mathrm{D}_{2} \mathrm{O}$ contamination.

Handling and Losses of Heavy Water

In preparing this report, discussions were held with the operators of the Savannah River reactors and with the Argonne CP-5 reactor to determine actual operating experience with the handing and losses of heavy water. Although a few years ago there was considerable apprehension over the possible hazard from the tritium formed in the moderator and coolant, subsequent experience has shown that tritium build-up is relatively small. With the many precautions against leakage taken when $D_{2} O$ is present, the hazard from tritium is believed to be no greater than from any other form of radioactivity. The heavy water problem, therefore, remains principally one of the minimizing of inventory (and hence of fixed charges), and the reduction of losses. 


\section{$4 t^{2}$}

The required inventory of heavy water was calculated from the dimensions of the equipment used for the reference designs. The expected losses, however, are considerably more difficult to estimate, particularly the figure that should be included for random accidental spillage. It was concluded that the following figures represented a fair estimate of the expected losses for near-term reactor designs (expressed in per cent of total inventory per year):

\begin{tabular}{lccc} 
& $\begin{array}{c}\text { Norma1 } \\
\text { Leakage }\end{array}$ & $\begin{array}{r}\text { Accidental } \\
\text { Sp111age }\end{array}$ & Total \\
\cline { 2 - 3 } & $5 \%$ & $2 \%$ & $7 \%$ \\
Boiling & $6 \%$ & $2.5 \%$ & $8.5 \%$
\end{tabular}

It might be noted that these loss figures are somewhat higher than other estimates which have been published. Several reactor designs described by the Argonne National Laboratory have included a $5 \%$ annual $\mathrm{D}_{2} \mathrm{O}$ loss, while the recent figures given for a Canadian 200 EMW power reactor (see Appendix E) has a heavy water loss of only about $2 \%$ of the inventory per year.

Tables $V$ and VI summarize the values for heavy water inventory and losses, respectively, used in this report. The total heavy water costs for both inventory and losses range from 1 to $2 \mathrm{mills} / \mathrm{kwh}$ in the $1 \mathrm{argex}$ plants and from 4 to $5 \mathrm{mi} 11 \mathrm{~s} / \mathrm{kwh}$ in the smaller plants. Hence they represent an appreciable item in any case.

\section{Comparison of Heavy Water Reactor Economics with Other Types}

The cost of power from the heavy water reference designs given in Table IV can be compared with the estimated power costs from light water reactors and from the Calder Hall type now in the design or construction phase.

A useful sumary of the cost estimates for these other reactor types is contained in the excellent report recently published by the Euratom Advisory Committee $\frac{3}{0}$ Since the publication of the Euratom report, significant cost increases have been reported for many of the U. S. reactors now under way. (There are no data yet on whether the Calder Hall type, called "PIPPA", by Euxatom, will similarly experience significant cost increases, but this would not be surprising.)

The cost totals for heavy water reactors given in Table IV were calculated before the recent U. $S$. reactor cost increases were publicized and to a certain

3 Euratom Publication, "A Target For Euratom," June, 1957. 
TABLE $V$

HEAVY WATER INVENTORY

\section{EMW}

\section{BOILING CASES}

Heavy water in reactor proper - ib

Heavy water external to reactor $-1 b$

Total heavy water in system - $1 \mathrm{~b}$

Heavy water per $\mathrm{kw}-\mathrm{lb}$

Total cost heavy water in dollars a $\$ 28 / 1 \mathrm{~b}$

Unit power cost Q .80 L.F. and

$12 \%$-mills/kwh

Cost of heavy water - $\$ / \mathrm{kw}$

\section{RRESSURIZED CASES}

Heavy water in reactor proper - Ib

Heavy water external to reactor $-1 \mathrm{~b}$

Total heavy water in system - $1 b$

Heavy watex per $k w$ - $1 b$

Total cost heavy water in dollars @ $\$ 28 / 1 b$

Unit power cost @ .80 L.F. and $12 \%-$ mills/kwh

88,000
35,640
123,640
6.18
$3,462,000$

2.970

173

104,000

- 20,000

124,000

6.20

$3,472,000$

2.979
100 EMW

170,000

117,820

287,820

2.88

$8,059,000$

1.382

80

168,000

84,580

252,580

2.52

$7,072,000$

1.213

\section{$250 \mathrm{EMW}$}

200,000

270,025

470,025

1.88

$13,160,000$

0.903

53

198,000

205,620

403,620

1.61

$11,301,000$

0.775 


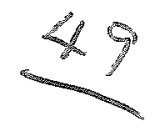

TABLE VI

HEAVY WATER LOSSES

\section{EMW}

100 EMW

250 EMW

BOILING CASES

Loss of heavy water per year in dollars a $\$ 28 / 1 b$

294,000

2.100

35

Loss of heavy water - $1 \mathrm{~b} /$ day

PRESSURIZED CASES

Loss of heavy water per year in dollars c $\$ 28 / 1 b$

Unit cost of losses $a .80$ L.F. mills/kwh

Loss of heavy water - 1b/day
243,000

1.736

29
495,000

0.707

59
685,000

0.979

81

0.639

130

91,000

0.452

94 


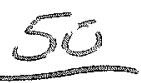

extent were derived by a comparative method using these earlier U. S. reactor costs. Hence it is felt that the earller estimates of Yankee, Dresden, and Calder Hall as given in the Euratom report are a fairer comparison with the heavy water reactor costs reported here. The Euratom report data, somewhat modifled to conform to the ground rules shown in Table III, were thus employed, and it must therefore be recognized that all of the data discussed here for nuclear power costs may be $10 \mathrm{w}$ by 10 to $20 \%$. (The Ruraton authors wisely foresaw such uncertalnties in estimated costs and added a f1at 25\% contingency to the values they calculated for mils/kwh.)

Table VII shows the economic comparison of the 100 EW and 250 EMW heavy water designs with the Yankee, Dresden, and Calder Mall reactors. Because of differences in output and of the preparation of the cost estimates by various groups, it is difficult to say that the totals shown will permit clear-cut conclusions. The heavy water reactors in general appear capable of producing power in the same cost range as the slightly enriched light water and natural urantum Calder Hall types.

\section{Effect of Modifying the Ground Rules}

A number of assumptions were necessarily made 1 in order to calculate the fuel-cycle costs and total power-generating costs presented above. Certain of these assumptions are quite dependent upon the future pattern of technological development and upon the economic setting in which a heavy water reactor might be constructed. It is the purpose of this section to discuss several possible changes in the ground rules used and to apprajse the effects of these changes on the results presented.

The items to be examined are:

A. Modifications primarily affecting the fuel-cycle cost:

1. A $\$ 30$ credit per gram of plutonium rather than $\$ 12$ per gram.

2. An upper limit of 4,000 MW/metric ton on exposure level because of radiation damage.

3. The use of continuous charge-discharge of fuel elements.

4. The effect of lower fabrication costs for wixconium elements.

5. The use of uranium oxide rather than uranium metal.

6. The use of stainless steel instead of zirconium cladding. 
TABLE VII

U. S. POWER COSTS FROM VARIOUS REACTOR TYPES

(100 to 250 EMW Size)

\begin{tabular}{|c|c|c|c|c|c|c|c|}
\hline & Yankee & Dresden & $\begin{array}{c}\text { Calder } \\
\text { Hal1 } \\
\text { Type } \\
\end{array}$ & $\begin{array}{r}D_{2} \\
\text { Boi }\end{array}$ & $\begin{array}{l}0 \\
\text { Iing }\end{array}$ & Pres & rized \\
\hline Net Power Output (MN) & 134 & 180 & 150 & 100 & 250 & 100 & 250 \\
\hline P1ant Cost (\$MM) & 39.2 & 45.0 & $-*$ & 30.6 & 61.7 & 37.4 & 75.5 \\
\hline$\$ / \mathrm{kw}$ & 342 & 250 & $450 *$ & 306 & 247 & 374 & 302 \\
\hline Power Cost (mi11s/kwh) & & & & & & & \\
\hline Capital charge $(15 \%)$ \% & 7.3 & 5.3 & 9.6 & 6.5 & 5.3 & 8.0 & 6.4 \\
\hline Net fuel-cycle cost *\% & 3.7 & 4.0 & 1.8 & 2.3 & 2.6 & 2.3 & 2.3 \\
\hline Operating and maintenance & 1.0 & 1.0 & 1.0 & 1.2 & 1.0 & 1.2 & 1.0 \\
\hline $\mathrm{D}_{2} \mathrm{O}$ Losses & $=$ & - & - & 0.8 & 0.6 & 0.7 & 0.4 \\
\hline $\mathrm{D}_{2} \mathrm{O}$ Inventory & - & - & - & 1.4 & 0.9 & 1.2 & 0.8 \\
\hline Total & 12.0 & 10.3 & 12.4 & 12.2 & 10.4 & 13.4 & 10.9 \\
\hline
\end{tabular}

* In the Euratom report, it appears that the construction cost for the Calder Ha11 reactor type was based upon British cost levels, while the costs for Yankee and Dresden were based upon the considerably higher construction cost levels in the U. S. This would be an inconsistent comparison. From previous Size-Up studies and from detailed design work for a U. S.-constructed Calder Hall type carried out by Atomics International (see NAA-SR-1833 and NAA-SR-1955), a Calder Ha11 type reactor station in the $150 \mathrm{MW}$ size range would cost $\$ 450$ to $\$ 500 / \mathrm{kw}$ on a consistent U. S. construction-cost basis instead of the $\$ 400 / \mathrm{kw}$ used by Euratom。

* This charge can be read from Fig. 1 at the assumed plant factor of $80 \%$ 。

*th The fuel inventory charge is included here but is calculated on the U. $S$. basis of $4 \%$ /year instead of the $8 \%$ assumed by Euratom. Carrying charges for non-nuclear inventory are also included. 
B. Modifications affecting the total power-generating cost:

1. Different charge rates for capital plant, inventory, etc.

2. Higher permissible heat fluxes.

Use of a $\$ 30 / \mathrm{gm}$ Plutonium Credit

The AEC has offered to pay $\$ 30$ per gram or higher for plutonium sold to it before July, 1963, but suggests that after that date the buying price might fall gradually to the fuel value, generally assumed to be nearer $\$ 12 / \mathrm{gm}$. The effect of a higher plutonium credit is to cut the fuel-cycle cost/kwh roughly in half and to lessen the advantages of enrichment, since the per-kilogram fuel-cycle cost is reduced and therefore longer exposure levels are not so important in achieving a low fuel-cycle cost. These changes are illustrated by tabulating costs for the 13-B-8 pressurized cores shown in Table II for one-batch loading:

With $\$ 12 / \mathrm{gm}$ Pu Credit

Fuel Cycle

Enrichment Ru Credit Total Cost Cost $(\%$ U-235) (\$/kgm U) (\$/kgm U) (Mi11s/kwh)

$\begin{array}{llll}0.71 & 39.6 & 123.1 & 3.34 \\ 0.8 & 43.7 & 135.8 & 2.90 \\ 0.9 & 49.1 & 150.7 & 2.62 \\ 1.0 & 52.4 & 167.0 & 2.49 \\ 1.1 & 55.9 & 184.6 & 2.38 \\ 1.3 & 60.9 & 223.1 & 2.34\end{array}$

With $\$ 30 / \mathrm{gm}$ Pu Credit

Fuel Cycle
Pu Credit Total Cost

It will be noted that the optimum enrichment falls from above $1.3 \%$ to 1. $1 \%$ when the plutonium credit is increased.

\section{A Radiation-Damage Limit to Exposure}

The discussion so far has assumed exposure levels of 9,000 MwD/metric ton and above are attainable with uranium metal fuel elements. This is the assumption employed in the $\mathrm{D}_{2} \mathrm{O}$ reactor designs described by Argonne National Laboratory. Particularly in the near future, however, the frequency of fuel-element failure may be too high at these long exposure levels because of radiation damage. Hence the effect of an upper limit on the feasible exposure level should be examined. 


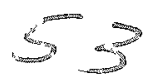

If the maximum exposure level is limited by radiation damage, then obviously for a given fuel element type, lattice spacing, and core diameter, only sufficient enrichment to reach the limiting exposure level can economically be utilized. For a radiation-damage 1imit of (say) 4,000 MWD/metric ton, an examination of Tables I and II indicates that natural uranium would be optimum over a wide range of core designs. At this lower exposure level, the fuel-cycle cost would rise from slightly more than 2 mills to somewhat over $3 \mathrm{mills} / \mathrm{kwh}$.

It will also be noted that the advantage of continuous charge-discharge loading would be lost if radiation damage prevented utilization of the reactivity gains thereby made possible.

The prospect of such a radiation-damage limit occurring is more 1ikely with uranium metal fuel elements than wh uranium oxide elements. There is thus more assurance of economic usefulness of enriched uranium with oxide cores than with metal cores for this reason and also because the reactivity of natural uranium oxide cores is somewhat worse than for metal cores.

\section{Continuous Charge-Discharge Loading}

The advantage of continuous charge-discharge loading is that it extends the reactivity lifetime of the fuel. Because of the hyperbolic shape of the curve of fuel-cycle cost as a function of exposure level (see Figure 2), this reactivity extension is of substantial benefit to the natural and slightly enxiched uranium cores. From Tables I and II it may be seen that even with natural uranium, exposure levels of over $10,000 \mathrm{MWD} / \mathrm{metric}$ ton may be obtained by continuous charge-discharge, and the resulting fuel-cycle costs are only 1.0 to $1.5 \mathrm{mi} 11 \mathrm{~s}$. Under the ground rules employed, however, even with con tinuous charge-discharge the use of enrichment will permit a still further reduction in fuel-cycle costs if radiation damage does not limit exposure.

Comparing similar core designs, it appears that continuous charge-discharge will allow a sufficiently longer reactivity lifetime to reduce the fuel cycle cost by 1.2 to $1.5 \mathrm{mills}$ per kilowatt hour for exposure levels above $5,000 \mathrm{MWD} /$ metric ton. Using a capital charge of $15 \%$ and an $80 \%$ plant factor, from Figure 1 this saving in fuel-cycle cost is the equivalent of about $\$ 60$ per kilowat in capital cost, or \$6 million in a 100 EMW plant. Hence, if the continuous charge-discharge planned by the Chalk River group cost no more than an additional $\$ 6$ million, it will be worthwhile?

* In Canada, the capita1 charge used is less than $15 \%$, and an even greater capital-cost premium than $\$ 6$ million would still look attractive. 
Lower Fuel Fabrication Costs

The fabrication costs used in Project Size-Up for metal plate elements clad with zirconium are:

$$
\begin{array}{ll}
\text { Element A } & \$ 57 / \mathrm{kgm} \mathrm{U} \\
\text { Element B } & \$ 75 / \mathrm{kgm} \mathrm{U}
\end{array}
$$

These costs are unattainable now but might be achieved after perhaps five years. Beyond that, lower costs are possible and are postulated in many studies even for oxide fuel elements, which today are more expensive than the metal type.

Lower fuel fabrication costs result in a relatively heavier weighting of the burn-up cost in fuel cycle economics and hence favor the lower enrichments. Thus for the core design 13-A-9 in Table II, it can be calculated that if the fuel fabrication cost were $\$ 38 / \mathrm{kgm}$, instead of $\$ 57 / \mathrm{kgm}$, the natural uranium would have as low a fuel-cycle cost as the enriched uranium (both costs being equal to about $1.79 \mathrm{mil} 1 \mathrm{~s} / \mathrm{kwh}$ ).

It is perhaps appropriate at this point to compare the results obtained in Project Size-Up with the Canadian work on pressurized $\mathrm{D}_{2} \mathrm{O}$ reactors. As discussed in Appendix $\mathrm{E}$, the Canadians assume the following:

1) Low conversion costs and zirconium fabrication costs. - A total of $\$ 30 / \mathrm{kgm}$ for all chemical conversion, shipping, and fuel-fabrication costs (exclusive of inventory charges) is assumed by the Canadians. In Project Size-Up, these costs (at least for the near term) are estimated to be upwards of $\$ 75 / \mathrm{kgm}$. The Canadian assumption weights the argument in favor of natural uranium, as has just been discussed.

2) Continuous charge-discharge. - Because of the long exposure levels believed attainable by this loading method, natural uranium is again favored.

3) Low $\$ / k w$ capital cost and low capital charge, pressurized tube design. - All three of these factors minimize the importance of the pressurevessel cost and hence make large cores and large lattice spacings less expensive. Again this permits increased exposure level and favors natural uranium.

Using the ground rules and assumptions employed by the Canadians, the results of this Size-Up report would corroborate their conclusion that natural uranium is a very economic fuel. However, it is felt that certain of these assumptions will not be realizable for a number of years, and that during a 


\section{5}

considerable interim period there are decided advantages to enriched uranium in $D_{2} O$ reactors, not. the least of which are the smaller cores, tighter lattice spacings, and extended heat transfer surface in fuel elements which can thus be employed.

Another result of the Canadian set of ground rules is that their calculated power costs will be considerably lower than those calculated in this and other $\mathrm{U}$. S. reports. The lower capital charge rate of $8.5 \%$, for example, cuts the fixed charge for a given design almost in half.

\section{Comparison with Oxide Elements}

A comparison based on zirconium cladding can be made directly with two lattice configurations taken from a Canadian design study for the NPD reactor. The fuel element considered by the Canadians consists of pellets of uranium oxide $\left(\mathrm{UO}_{2}\right)$ contained in a zircaloy sheath $0.030 \mathrm{in}$. thick. Nineteen of these elements plus the $D_{2} O$ coolant flowing in the spaces between elements are contained in a zircaloy coolant tube 0.040 in. thick. A 0.5 -in. helium insulating gap separates this from an aluminum tube $0.025 \mathrm{in}$. thick. In the unit ce11, the total cross section of the fuel is $25 \mathrm{sq} \mathrm{cm}$, with $22.5 \mathrm{sq} \mathrm{cm}$ of coolant, $6.21 \mathrm{sq} \mathrm{cm}$ of zirconium element sheath, $2.688 \mathrm{sq} \mathrm{cm}$ of zirconium coolant tube, and $1.911 \mathrm{sq} \mathrm{cm}$ of aluminum tube. The radius of the element is $0.647 \mathrm{~cm}$, the average heat flux is $125,000 \mathrm{Btu} / \mathrm{hr}-\mathrm{sq} \mathrm{ft}$, and the power per lineal foot of assemb $1 \mathrm{y}$ is $0.094 \mathrm{MW}$.

Case "10-1-1" has a lattice spacing (triangular array) of 7.32 in.; Case "10-1-2" has a lattice spacing of 7.92 in. The values used for $\mathbb{M}^{2}, f, p$, and are those reported by the Canadians for their design study. I was changed to agree with the constants used in the present report (see Appendix D), and the change of $\mathrm{M}^{2}$ with enrichment is smal1 and was approximated. Equilibrium xenon and samarium were included as in all other calculations. The core diameter necessary for 100 EMW of power was calculated based on the above heat flux.

The exposure attainable was estimated by assuming the losses in buckling with exposure for each enrichment to be the same as those of the Element $B$, 8-in. lattice spacing, pressurized. The depleted uranium concentration appropriate to the corresponding enrichment case at this same exposure level 


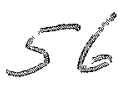

for Element B, 8-in. lattice spacing was used. The plutonium credit was adjusted slightly by the ratio of the infinite reactor initial conversion ratios.

$$
\text { I.C.R. }=\frac{N_{28}}{N_{25}} \frac{\sigma_{28}}{\sigma_{25}}+\eta 25 \epsilon(1-p)
$$

This ratio describes the plutonium production relative to $\mathrm{U}-235$ fission at the start of exposure.

The values calculated for $k_{\infty}$, buckling, and initial conversion ratio are as follows:

\begin{tabular}{|c|c|c|c|c|}
\hline & Wt \% U-235 & $\underline{k_{\infty}}$ & $e^{2}$ & I.C.R. \\
\hline Case 10-1-1 & $\begin{array}{l}0.71 \\
0.8 \\
1.0 \\
1.3\end{array}$ & $\begin{array}{l}1.0836 \\
1.1301 \\
1.2138 \\
1.3036\end{array}$ & $\begin{array}{l}309.310^{6} \mathrm{~cm}^{-2} \\
481.4 \\
791.3 \\
1167.7\end{array}$ & $\begin{array}{l}0.8748 \\
0.8121 \\
0.7118 \\
0.6192\end{array}$ \\
\hline Case 10-1-2 & $\begin{array}{l}0.71 \\
0.8 \\
1.0 \\
1.3\end{array}$ & $\begin{array}{l}1.1113 \\
1.1594 \\
1.2459 \\
1.3388\end{array}$ & $\begin{array}{r}389.3 \\
557.4 \\
860.1 \\
1303.1\end{array}$ & $\begin{array}{l}0.8213 \\
0.7587 \\
0.6584 \\
0.5657\end{array}$ \\
\hline $\begin{array}{l}\text { Element B, } \\
\text { 8-in. } \\
\text { Pressurized }\end{array}$ & $\begin{array}{l}0.71 \\
0.8 \\
1.0 \\
1.3\end{array}$ & $\begin{array}{l}1.1077 \\
1.1546 \\
1.2392 \\
1.3295\end{array}$ & $\begin{array}{r}502.8 \\
734.6 \\
1175.0 \\
1681.0\end{array}$ & $\begin{array}{l}0.8612 \\
0.7986 \\
0.6983 \\
0.6056\end{array}$ \\
\hline
\end{tabular}

For purposes of calculating the fuel element fabrication cost (here taken as including UT 6 to finished element) for the oxide elements, the prescription contained in the summary of Appendix $C$ was employed. For these elements, $20.8 \%$ zirconium by weight, a fuel element fabrication cost of $\$ 58.2 / 1 b$ of uranium was estimated. Converting to oxide the schedule in Table C-III, the corresponding fuel conversion plus fabrication costs become $\$ 156 / \mathrm{kgm}$ uranium for natural metal and $\$ 156.6 / \mathrm{kgm}$ uranium for enriched metal.

The costs appropriate to the 100 EMN pressurized case are as follows (total costs are not shown for the continuous charge-discharge case, since there are no estimates available of the additional capital cost needed to permit this type of fuel scheduling): 
One-Batch Loading

Wt $\%$

$\mathrm{U}-235$
Fuel-Cycle

Cost

Mi11s/kwh Mi11s/kwh
Continuous Charge-Discharge

Maximum

Exposure Level

MWD/Metric Ton
Fuel-Cycle

Cost

Mills/kwh

Case 10-1-1. Core diameter and height, $11.5 \mathrm{ft}$ Fixed costs (mills/kwh):

Capital charge, $8.44 ; \mathrm{D}_{2} \mathrm{O}$ inventory, $1.76 ; \mathrm{D}_{2} \mathrm{O}$ 1oss, 1.07 . Operating and maintenance, 1.2 .
0.71
2895
8.92
21.39
5460
3.80
0.8
4145
6.56
19.03
5.02
17.49
1.3
8070
3.90
16.37
8030
3.48
12350
2.62
Extremely high

Case 10-1-2. Core diameter and height, 12.0 ft. Fixed costs (mills/kwh): Capital charge, $8.55 ; \mathrm{D}_{2} \mathrm{O}$ inventory, $1.89 ; \mathrm{D}_{2} \mathrm{O}$ 10ss, 1.14 . Operating and maintenance, 1.2 .
0.71
3990
6.6
19.38
7640
3.47
0.8
5010
5.54
18.32
4.53
17.31
1.3
9472
3.56
16.34
9940
13820
2.91
2.40

Element B. 7-in. lattice spacing, 9-ft core diameter and height. Fixed costs (mi11s/kwh): Capital charge, $8.01 ; \mathrm{D}_{2}$ O inventory, $1.21 ; \mathrm{D}_{2}$ O loss, 0.71 . Operating and maintenance, 1.2.

$\begin{array}{lccc}0.71 & \text { Subcritical } & & \\ 0.8 & 3120 & 5.46 & 16.59 \\ 0.9 & 5130 & 3.58 & 14.71 \\ 1.0 & 6900 & 2.87 & 14.00 \\ 1.1 & 8540 & 2.52 & 13.65 \\ 1.3 & 11520 & 2.18 & 13.31\end{array}$

Subcritical
5510
16050
Extremely high
Extremely high
Extremely high

The preceding results indicate for the batch loading, comparing on the basis of equivalent exposure, that the fuel-cycle costs wi11 be about 1,0 to $1.5 \mathrm{mil1s} / \mathrm{kwh}$ higher for the oxide than the metal case chosen. This difference is reducible to less than $1 \mathrm{mill} / \mathrm{kwh}$ for the continuous charge-discharge case. Also, due to the reduction in specific power (MW/cu ft of core) the $\mathrm{D}_{2} \mathrm{O}$ costs and the pressure vessel costs are increased for the oxide cases.

Extrapolating the results slightly, this comparison, based on these specific fuel elements, indicates that oxide elements must be exposed for more than $15,000 \mathrm{MWD} /$ ton to reach the same range of power costs as for the metal plate elements exposed to 5,000 MWD/ton.

It should be bome in mind that the oxide cases considered may not be an "optimized" design. 
Use of Stainless Steel Elements

As described in Appendix $C$, estimates were made of the cost of fabricating uranium oxide fuel elements using stainless steel rather than zirconium as a cladding. An estimate of $\$ 53 / \mathrm{kgm}$ was made for the PWR-type element which wi11 be used in the Yankee reactor* and $\$ 31 / \mathrm{kgm}$ for the stainless steel counterpart of the Dresden zirconium element.

To determine whether stainless steel might be a more economic material than zirconium, reactor physics calculations were carried out assuming stainless steel instead of zirconium in the 11-ft diameter boiling core, 8-in. lattice spacing.

Costs were based upon rod-type oxide elements clad with either zirconium or stainless steel of the same thickness used in the Canadian study. It was assumed that relative reactivity effects for this type of element could be satisfactorily approximated by performing further physics calculations for flat plate metal elements, with the atom ratio of cladding metal to uranium taken as equivalent to the cladding thickness of the Canadian design for oxide elements.

The fabrication cost for the zirconium element was $\$ 128 / \mathrm{kgm}$, giving a total of $\$ 156.6 / \mathrm{kgm}$ of fuel for processing plus fabrication cost. For stainless steel, based on the oxide element comparison, a fabrication cost of one-fifth of this, or $\$ 25.6 / \mathrm{kgm}$, was assumed.

The enrichments, exposure levels, and fuel-cycle costs are shown in the table below. Stainless steel is significantly cheaper, even at high exposure levels, on the basis of the fabrication costs for zirconium and stainless steel elements used here.

\section{Zirconium Element}

\section{Enrichment Exposure}

0.71

0.8

0.9

1.0

1.1

1.3

0.71

0.8

0.9
3240

5030

6700

8270

9750

12700

5870

9930

13700
Mi11s/kwh

Enrichment One-Batch Loading
7.38

5.15

4.10

3.55

3.22

2.83
Stainless Steel Element

Continuous Charge-Discharge
4.19
2.0
13138
20285
2.02
2.58
2. 25
2.03

6748

10537

14163

2.85

2.42

2. 25

$$
\text { . }
$$


TABLE VIII

EFFECT OF MODIFYING THE ECONOMIC GROUND RULES

\begin{tabular}{|c|c|c|c|c|c|c|c|}
\hline \multirow[b]{2}{*}{ Net Power Output (MW) } & \multirow{2}{*}{$\frac{\text { Yankee }}{134}$} & \multirow{2}{*}{$\frac{\text { Dresden }}{180}$} & \multirow{2}{*}{$\begin{array}{c}\text { Calder } \\
\text { Ha11 } \\
\text { Type } \\
150\end{array}$} & \multicolumn{2}{|c|}{$\begin{array}{c}\mathrm{D}_{2} \mathrm{O} \\
\text { Boiling } \\
\end{array}$} & \multicolumn{2}{|c|}{$\begin{array}{c}\mathrm{D}_{2} \mathrm{O} \\
\text { Pressurized } \\
\end{array}$} \\
\hline & & & & 100 & 250 & 100 & 250 \\
\hline$\$ / k w$ & 342 & 250 & 450 & 306 & 247 & 374 & 302 \\
\hline \multicolumn{8}{|l|}{ Mi11s/kwh: * } \\
\hline Base Case Costs (Table VII) & 12.0 & 10.3 & 12.4 & 12.2 & 10.4 & 13.4 & 10.9 \\
\hline \multicolumn{8}{|l|}{ Base Case Modified by: } \\
\hline 1) Renting $\mathrm{D}_{2} \mathrm{O}$ (at $\left.4 \% / \$-\mathrm{yr}\right)$ & 12.0 & 10.3 & 12.4 & 11.3 & 9.8 & 12.6 & 10.4 \\
\hline $\begin{array}{l}\text { 2) Capital charge } 13 \% \text {, } \\
\text { charges for fuel, } \mathrm{D}_{2} \mathrm{O}, \\
\text { and non-nuclear core } \\
\text { parts at } 8 \% \\
\text { (Euratom basis) }\end{array}$ & 11.5 & 9.8 & 11.5 & 10.8 & 9.4 & 11.9 & 9.7 \\
\hline $\begin{array}{l}\text { 3) Capital charge } 9 \% \text {, } \\
\text { charges for fuel, } \mathrm{D}_{2} \mathrm{O} \text {, } \\
\text { and non-nuclear core } \\
\text { parts at } 5 \% \\
\text { (approximate U.K. basis) }\end{array}$ & 9.0 & 8.0 & 8.7 & 8.7 & 7.7 & 9.4 & 7.7 \\
\hline
\end{tabular}

* As noted previously, no charge for interest on construction is included here. Strictly speaking, this should be added in, but it has little effect on differences between reactor types. 


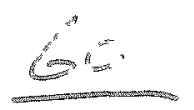

Different Charge Rates for Capital Plant, Inventory, Etco

The economic comparisons given so far in this report wexe based on ground rules applying to the U. S. private utility industry, assuming that heavy water would be purchased at $\$ 28 / 1 \mathrm{~b}$, with the appropriate carrying charge of $12 \%$ per dollar-year levied against the total cost of the heavy water needed.

There are other possible ground rules which might well apply in situations where the construction of heavy water power reactors would be of interest. For example, if plants were entirely government-financed, the annual charges for depreciating and non-depreciating investment would be considerably lower.*

The total power generating costs for the reactor types included in Table VII can easily be converted to other ground rules. Table VIII shows the effect on the total power cost as a result of modifications in the economic assumptions:

1) Rental of $\mathrm{D}_{2} \mathrm{O}$. The renta1 of $\mathrm{D}_{2} \mathrm{O}$ from the $\mathrm{AEC}$ at $4 \%$ /dollar-year rather than its purchase and payment of a 12\%/do11ar-year annual carrying charge would reduce the $D_{2} O$ inventory charge by two-thirds. Such a reduction represents 0.5 to $0.9 \mathrm{mills} / \mathrm{kwh}$ in the $\mathrm{D}_{2} 0$ reactor cases shown.

2) Use of Euratom Basis. The Euratom report on nuclear reactors used a somewhat lower capital charge and an $8 \%$ annul carrying charge for fuel. The Calder Hall reactor and the $D_{2}$ reactors show the greatest cost reduction with this set of ground rules compared with the base case, chiefly because of the lower capital charge and lower $D_{2} O$ charge, respectively.

3) Use of United Kingdom Basis. In computing the cost of power from reactors of the Calder Hall type, the United Kingdom group employed quite low annual charges. As can be seen from Table VIII, such a basis is particularly helpful to the Calder Hall economics because of the large capital cost of this reactor.

Higher Permissible Heat Fluxes

An important reason for the difference between the low nuclear power costs calculated in long-range forecasts (such as those published in the $\mathrm{AEC}$-sponsored

* For a discussion of the various charges involved in reactor economics, see Section $V$ of an earlier Project Size-Up study, "Comparison of Calder Ha11. and PWR Reactor Types," AECU-3398, March, 1957.

** The Calder Hall plant type constructed in Britain would probably cost only about two-thirds as much as shown in Table VII for U. S. construction. Hence in Britain on the U. K. basis, the power cost would be in the range of 7 to $8 \mathrm{mi} 11 \mathrm{~s} / \mathrm{kwh}$ as concluded in the previous Project Size-Up report on the Calder Hall reactor。 


\section{1}

study "Project Dynamo") and the considerably higher costs predicted today is the optimism assumed for heat fluxes. The average flux value of $120,000 \mathrm{Btu} / \mathrm{hr}-\mathrm{sq} \mathrm{ft}$ used in this present study appears low, yet today's reactor designers are unwilling to go higher until operating experience is obtained.

If a higher permissible heat flux were employed, the core size for a given output could be made smaller or a "clumped" fuel element could be used, giving lower fuel fabrication costs and longer reactivity lifetimes.

As an example, if the permissible heat flux of the 100 EMW boiling design were doubled to a value of $240,000 \mathrm{Btu} / \mathrm{hr}-\mathrm{sq} \mathrm{ft}$, the Type A element could be used with a 7-in. 1attice spacing and an 11-ft diameter vessel (rather than the 13-ft diameter vessel shown for this combination in Table III). It should thus be possible to obtain roughly $10,000 \mathrm{MWD} /$ metric ton with 1.3 or $1.4 \%$ enrichment and a fuel-cycle cost of about $2 \mathrm{mi} 11 \mathrm{~s} / \mathrm{kwh}$ instead of the $2.34 \mathrm{mil} / \mathrm{s} / \mathrm{kwh}$ shown in Table IV. The saving in pressure vessel cost, shielding, etc., would be $\$ 600,000$ or $0.12 \mathrm{mil1s}$ in addition. Thus the total saving would be in the order of $0.5 \mathrm{mills}$ out of $12 \mathrm{mills} / \mathrm{kwh}$.

Somewhat larger savings will occur if the higher heat flux assumption is employed to raise the total power output rather than to reduce the size of the pressure vessel. As discussed in Appendix B, doubling the heat output of the 250 EMW boiling design could, along with other economies, permit a cost reduction of perhaps 2 or $3 \mathrm{mills} / \mathrm{kwh}$. 
62

IV APPENDICES 


\section{APPENDIX A}

HEAT TRANSFER

\section{Introduction}

On the larger sizes of power reactors, the rate at which heat can be removed from the core is frequently the limiting design factor. The purpose of this section is to discuss the factors which limit the rate of heat removal in boiling and pressurized reactor systems and to describe the manner in which the six reactor designs were obtained.

Heat transfer at the high fluxes necessary in power reactors is presently not entirely understood, and rather anomalous results have been obtained in many of the heat transfer studies made on such factors as burn-out heat flux. Because of the uncertainties of neutron flux distribution, hot channel factors, safety factors required for possible loss of coolant flow, etc., design practice is to choose a conservatively low value for average heat flux. This practice is followed in the designs included in this report.

\section{Bolling Heavy Water Reactors}

For this study only steady-state heat transfer conditions were analyzed; consequently, the limits imposed by transient (time dependent) variations must be allowed for by appropriate factors of safety which may be determined by comparison with existing reactors and/or specific experiments.

The factors which limit the steady-state power output of the bolling heavy water reactors can be considered in four categories:

1) Transition from nucleate to firm boiling, causing burn-out

2) Excessive void fraction

3) Excessive material temperature

4) Twomphase flow Instab11ity 
1. Burn-Out Heat Flux

The accurate prediction of the value of the heat flux which corresponds to the transition from nucleate to firm boiling - the "so-called "burn-out" condition - is not yet possible. Since burn-out can impose the upper limit on the rate of heat removal from any given core, its quantitative prediction has been studied extensively.

The mechanisms involved in this phenomenon are apparently quite complicated and depend on elusive surface characteristics of the heat transfer area as well as the usual heat transfer rate parameters. As a result, no theoretical relationships have been found which adequately describe the performance of experimental systems, and the empirical relationships which describe the experimental data from one apparatus are rarely applicable to another.

This situation leads to extremely conservative designs for reactor systems, because the value of the heat fluxes which are deemed allowable are chosen at or below the lowest value predicted by any of these empirical relationships. This is the policy which was pursued for the current bolling reactor designs. The following empirical correlation was employed, which was based upon a thorough examination of the existing data: 1

$$
\frac{q^{\prime \prime} \text { perm }}{10^{6}}=11 \mathrm{P}^{-21}\left(\frac{\mathrm{G}}{10^{6}}\right) \cdot 5\left(\frac{\mathrm{L}}{\mathrm{D}}\right)-.38
$$

where

$$
\begin{array}{ll}
q^{\prime \prime} \text { perm } & =\text { permissible heat flux } B t u / h r-s q \text { ft } \\
G & =\text { mass flow velocity, } 1 \mathrm{~b} / \mathrm{hr}-\mathrm{sq} \mathrm{ft} \\
\mathbf{P} & =\text { absolute pressure, } 1 \mathrm{~b} / \mathrm{sq} \mathrm{in} . \\
\mathrm{L} & =\text { boiling length of channel, ft } \\
\mathrm{D} & =\text { equivalent diameter of channel, ft }
\end{array}
$$

This correlation is intended to apply only to cases where the exit steam quality* is less than $15 \%$ and for values of G greater than $0.6 \times 10^{6} 1 \mathrm{~b} / \mathrm{hr}-\mathrm{sq} \mathrm{ft}$.

1 Kaiser Engineers Nuclear Power Study, "Preliminary Design of a Boiling Heavy Water Reactor," TID 5301, November 29, 1953 (Confidentia1)

* "Quality" in boiling water reactor cores is used here to refer to the ratio of mass flow rates of vapor and liquid at any particular point. 


\section{$\tan ^{2}$}

Balow about $40 \%$ quality the data of Lowdermi $1 \mathrm{k}$ and Weiland 2 show no effect of quality on the burn-out heat flux However, data from the Argonne National Laboratory 3 suggest $15 \%$ as a conservative upper limit, For high values of steam quality insufficient liquid is in contact with the hot metal surfaces to remove the heat at the maximum possible rate.

Since the equation suggested by the Raiser study predicts zero permissible heat flux at zero mass flow velocity, it ceases to be applicable at low flow rates, and the value of burn-out heat flux associated with pool bolling becomes 1imiting. McAdams 4 shows data on the relationship between heat flux in pool boiling and temperature difference for various system pressures. The burn-out value of heat flux is shown to increase with increasing pressure, reach a maximum at about $1500 \mathrm{lb} / \mathrm{sq}$ in., and then decrease with further increase in pressure.

These maximum (burn-out) values of heat flux range between about $400,000 \mathrm{Btu} / \mathrm{hr}-\mathrm{sq}$ ft at atmospheric pressure and $1,500,000 \mathrm{Btu} / \mathrm{hr}-\mathrm{sq}$ ft at $1500 \mathrm{lb} / \mathrm{sq}$ in. and represent the upper limit to the heat flux in non-flow systems. With increased flow rate, the burn-out heat flus should increase from the static value, but the increase would not be great, since turbulence caused by the steam bubbles alone is very great compared to the additional contribution associated with convective flow.

It may be observed that the maximum permissible values of heat flux as predicted by the Raiser correlation are substantially below the pool boiling burn-out values given by McAdams. If the pool boiling data are realistic, the other values are conservative by a considerable factor. The conservative values, however, are quite consistent with the values used in the designs of the existing or currently envisaged boiling reactors as shown in Table A-I.

$\underline{2} W$. Lowdermilk and $W . F$. Weiland, "Some Measurements of Bol1ing Burn-Out," NACA RM-E54R10.

3 S. McLain, "Reactor Engineering Lectures," ANL-5424.

4 W. H. McAdams, "Heat Transmission," Third Edition, McGraw Hi11, 1954, Fig, 14-14, P. 382 . 
BOILING REACTOR HEAT FLUX VALUES\%

Reactor

Borax II

Borax III

Experimental Boiling Water Reactor

Dresden Nuclear Power Station
Heat F1ux $\frac{\text { Btu }}{\text { hx } x \text { sq ft- }{ }^{\circ} \mathrm{r}}$

Average

37.000

68,000

170,000

44.000

110,000

120,000

Note: Underlined values were tabulated: the other values are based on an assumed maximum to average flux ratio of 2.5 .

* "Nuclear Reactor Data 2," Raytheon Manufacturing Company. 


\section{Excessive Void Fraction}

Reduced heat transfer performance due to liquid "starvation" of the heat transfer surface accompanies excessive vold fraction cr steam quality. This condition is similar to the burn"out phenomeron in which the hot surface is suddenly covered by a blanket of steam which acts as a very large resistance to the flow of heat. The starvation condition itsel is much loss serious than burnout, because its effect apfears gradually as the 1ocal quinity increases. If not arrested by reducing power or increasing coolant flow rate, however, it can lead to the serious burn-out conditlon at values of heat flux less than anticipated on the basis of lower quality.

In addition, it has been observed that certain nuclear instabilities occur when the vold fraction of the moderator exceeds some 1 imit depending on operating conditions. These nuclear instabilities create problems in the control of light water reactors which can be mitigated satisfactorily by restricting the maximum allowable vold fraction to approximately $20 \%$ for oferating pressures in the vicinity of $600 \mathrm{lb} / \mathrm{sq}$ in.

\section{Material Temperature}

The various reactor core components are subject to many environmental strains, mechanical and thermal stresses, deterioration by corrosion, and deformations due to phase transitions. Either the condition itself or the capacity of the material components to resist the effect, or both, is sensitive to the temperature level and/or the temperature gradients mithin the core. An analysis was ferformed for this study to determine the maximum temperature of each material of which the fued elements are fabricated. These calculated temperatures may be compared with maximu ailowable temperatures for each material to determine th: conditions under which the heat cransfer performance will be limiced due to excessive materiai temperatures.

For uranium metal fuel elements, the temperature depentent transition from its alpha to its beta phase imposes a. limitation, because an associated volume change leads to warpage and possibly rupture of tho alemert. This transition occurs at approximately $1224^{\circ} \mathrm{F}$.

To eliminate this temperature Iimitgion and to prevent damage from the uranium-water raction in the event of chadding rupture, uranium oxide fuel is often substituted. No outstanding gain in heat transfer rate is 


\section{0}

assoclated, however, because the thermal conductivity of the oxide is very much lower than the metal, and a correspondingly greater temperature difference is required for the same heat flux at the wall.

zirconium cladding is subject to corrosive attack by water above about $620^{\circ}$ F. This 1 imitation will not affect boiling reactors operating below about $1500 \mathrm{lb} / \mathrm{sq} \mathrm{in}$, because the saturation temperature is $596^{\circ} \mathrm{F}$ at this pressure, and the temperature difference between the metal wall and the saturated 1 iquid corresponding to the burnout heat flus is only about $20^{\circ} \mathrm{F}$.

Other material 11mitations, particularly those associated with thermal and flow transients, possibly can impose additional restrictions on the reactor performance, but the reliability of their analytical prediction is not great, and none are included here.

\section{Two-Phase Flow Instab11ity}

A peculiar relationship between pressure drop and mass flow velocity in two-phase flow systems has been observed. 5 The pecullarity stems from the variation of pressure drop with mass flow rate. As total mass flow rate through a given bolling system is increased from zero, the pressure drop passes through a maximum, followed by a minimum, and then the normally expected increase as the square of the velocity. With this characteristic, through a finite range of flow rate, more than one value of mass flow rate is possible for a given pressure drop.

Interpreted in connection with the parallel reactor coolant passages, which are connected to the same headers top and bottom and consequently all operate with the same pressure drop, a situation is possible whereby substantially different flow rates can occur in the passages, and the possibility of oscillations from one flowing state to the other is particularly disturbing from the point of view of reactor control. Further, there is a possibility of burn-out failure if, in a channel designed to operate at one flow rate, a substantially diminished flow occurs, with a proportionally increased vold fraction.

5 D. H. Weiss, "Pressure Drop in Two-Phase F1ow", ANL 4916, October 20, 1952 


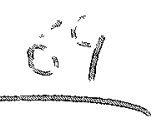

Boiling Core Design Conflgurations

Several assumptions regarding the systems and the mathematical relationships which describe the flow of heat and fluid within these systems were made to facilitate the heat transfer design:

1) The cores are assumed to be right circular cylinders, each consisting of a bundle of parallel fuel elements, in length equal to the core height, and arranged so that their longitudinal axis is vertical. Heavy water coolant flows upward through each element, and additional heavy watex, as moderator, fills the spaces between the elements

2) The geometrical relationships for the three bolling cores, as we1 1 as the pressurized ones, are presumed flxed and are presented in Table IV of Section III.

3) The rate of heat generation is assumed to be described by the $J_{0}$ Bessel function radially and by the cosine function longitudina11y. These functions are restricted to zero values at radil and balf geight values equal respectively to the actual core radii and half heights plus the reflector savings, It is believed that the control rods and other flattening devices would in practice make the distribution of heat more uniform. These assumptions are, hence, conservative.

4) Thermal and hydrodynamic entrance lengths axe neglected, and steady-state heat and fluid flow rates are assumed.

5) The ratio of the steam velocity to the liquid velocity in the boiling coolant channels is assumed to be constant and equal to 2,0 . Actually this. "slip" ratio is a function of mass flow rate through the channel, position in the channel, pressure, and possibly other parameters, but these relationships are not sufficiently well known to warrant their incorporation into the analysis. The data of Lottes and $11 \mathrm{mn}^{6}$ indicate that the value of the slip ratio varies between 1 and 3 for conditions similax to those imposed for this study.

6 B. A. Lottes and W, S. F1inn, "A Method of Analysis of Natural Circulation Boiling Systems," Argonne Nationa1 Laboratory, March, 1956. 
6) The individual coolant flow channels axe oxificed such that the flow through each channel is directly proportional to the heat produced by that element. This imglies that the ratio of the heat production by an element to the coolant mass flow rate through the element is constant: consequentiy, the stean quality distribution with height is the same for all channels.

7) The coolant inlet temperature is assumed to be $10^{\circ}$ below the saturation temperature in each core. Some such difference is required to prevent cavitation in the recirculation pumps, but the numerical value chosen is purely arbitrary.

8) The coolant recirculation rate is maintained at value giving an average coolant density of $0.66 \mathrm{gm} / \mathrm{cc}$ in the shroud. (This is a rather arbitrary assumption, being that used in a heavy water design presented by Argonne National Laboratory?

Based on these assumptions, the liquid recirculation rates required for the three boiling reference reactors are shown in Table IV of Section III. Because of the low pressure drop through the reactor, the required pumnging power for recirculation is falrly smal1, and, as noted previously, the effects of a xenon transient during shutdown might be partially ovexcome by lncreasing the recirculation rate to raise the average coolant density and thereby gain reactivity。

\section{Pressurized Cases}

\section{Heat Exchanger Design}

As has been described, the core design for each of the six reference reactors was selected on the basis of a limiting average heat flux of $120,000 \mathrm{Btu} / \mathrm{hr}-\mathrm{sq}$ ft. The possible combinations of lattice spacing, core diameter, and fuel element type that could comply with this restriction were then examined and a combination selected which seemed most appropriate from the standpoint of fuel-cycle cost and a reasonably small vessel diameter.

The coolant flow rate could then be chosen on the basis of an economic balance between pumping power and heat exchanger surface and the following additiona1 limitations:

I H. P. Iskenderian, et al, "Heavy Water Reactors," Geneva Conference Paper, P/495, 1955. 
1) Since a pressure of over roughly $1800 \mathrm{psi}$ in the reactor vessel resulted in increases in vessel cost without commensurate savings due to higher thermal efficiencies, this value was selected as the operating pressure. The water outlet temperature from the reactor was then set at $535^{\circ}$, giving a safety factor of $90^{\circ} \mathrm{F}$ between this water temperature and the saturation temperature corresponding to 1800 psi.

2) The maximum allowable zirconium surface cemperature was set at $620^{\circ} \mathrm{F}$ in order to avoid excessive corrosion. (As noted later, this did not turn out to be a critical restriction because of the high recirculation rates employed to reduce the heat exchanger cost and because of the conservative value employed for the average heat flux in the core.)

To simplify the calculations, it was assumed that the feedwater heaters raised the feedwater to $350^{\circ} \mathrm{F}$ before it entered the steam generator, since this appeared to be a reasonable choice over a wide range of operating conditions: As a considerably simplified and conservative procedure, it can be assumed that the preheater-boiler duty of the steam generator can be treated as a single unit with the surface temperature on the steam side uniformly at saturation temperature plus a constant temperature increment dependent on the steam pressure as follows:

\section{Steam Pressure (psia)}

400

600 1000
Temperature Increment $(\Delta T)$

( ${ }^{\circ}$ I)

29

25

20

With this simplification, the usual $10 \mathrm{~g}$-mean temperature difference equation simplifies to:

$$
\frac{T_{2}-T_{1}}{T_{2}-\left(T_{b}+\Delta T\right)}=1-e^{-\frac{U A}{W C}}
$$

8 J. V. Salisbury, "Steam Turbines and Their Cycles,", p. 302, J。 Wiley, 1950 


$$
\text { where } \quad \begin{aligned}
\left(T_{2}-T_{1}\right) & =\text { temperature drop of primary coolant }=\left(535-T_{1}\right) \\
T_{b} & =\text { steam temperature } \\
W & =\text { primary coolant flow rate } \\
C & =\text { specific heat of primary coolant } \\
U & =\text { over-all heat transfer coefficient (assumed } \\
\mathrm{A} & =\text { to be constant at } 300 \mathrm{Btu} / \mathrm{hr} \text { sq } \mathrm{ft}-\mathrm{F} * \text { ) }
\end{aligned}
$$

The flow rate, $w$, should be selected so as to minimize the total of investment charges and operating costs for the circulating pump and heat exchangers.

Studies indicated that at reasonable values of core pressure drop there was a definite "knee" in the curve of heat transfer area needed versus the flow rate, $w$ since increase of the flow rate up to the knee effected significant savings in heat exchanger costs, while furthex increase of the flow rate beyond the knee bad 1ittle effect on the heat exchanger, the flow rate at the knee was selected provisionally as optimum for the various reference reactor desigms. These flow rates are shown on Igure 17

\section{Core Hydrodynamics and Heat Transfer}

The primary coolant flow rate as selected above was then evaluated for its influence on the heat transfer and hydrodynamics in the core and to check whether the value of core pressure drop assumed above was in fact a sufficiently close estimate

The possible limiting factors for beat transfer in pressurized water reactors are:

1) Material Temperature - The material temperature 1imitations for pressurized water reactors are essentially the same as those imposed in boiling water systems.

2) Pressure Drop - The pressure difference across the reactor core Induces mechanical stresses in the structural parts which generally are proportional to the pressure drop Appropriate designs are required to insure an adequate structural configuration to withstand these stresses; inasmuch as the magnitude of these design problems increases with loading, ultimately a point

* Private communication from Ross Heat Exchanger Division 


$$
\rightarrow \sum^{\infty}
$$

is reached beyond which this non-uniform pressure loading will limit the coolant Flow rate; hence the power output.

3) Pumping Power - The power required to circulate the coolant through the core, heat exchanger, and external piping is proportional to both the pressure drop and the coolant flow rate. This power level is limited to a fraction of the total power delivered by the reactor; the exact 1 imiting fraction is imposed by economic considerations.

4) Erosion and Corrosion - Since high velocity coolant flowing past a solid surface can remove fragments of the metal by an erosion or abrasion mechanism as well as by chemical attack, it may be necessary to 1 imit the maximum velocity; hence the maximum rate of heat removal. The magnitude of such a limitation would be imposed by the results of experimental tests involving rather specific configurations and no attempt to estimate this limit has been made for this study.

The following values have been reported for heat fluxes in pressurized water reactors: 2

Average Heat Flux (Btu/hr-sq ft)

\section{Reactor}

PWR * Seed

Blanket

Yankee

Belgian Thermal Reactor

Consolidated Edison

Canadian $\mathrm{D}_{2} \mathrm{O}$ NPD Reactor
112,000

65,000

100,000

95,500

169,000

100,000

The idealizations on which the core calculations were based are quite similar to the boiling reactor analyses; there are a few exceptions:

1) As with the boiling cores, the pressurized cores are assumed to be right circular cylinders, each consisting of a bundle of parallel fuel elements, in length equal to the core height and arranged so that their longitudinal axis is vertical. Heavy water coolant flows upward through each

9 Raytheon Corporation, "Nuclear Reactor Data" Vo1 2.

* These PWR heat fluxes are based on the minimum design output of 60,000 electrical kilowatts. It is expected that in actual operation they can be exceeded by at least $50 \%$. 


\section{4}

element and additional heavy water, as moderator, fills the spaces between the elements.

2) The geometrical relationships are presumed fixed.

3) Heat generation distribution is the same as for the boiling reactors. The rate of heat generation is assumed to be described by the $J_{0}$ Bessel function radial1y and by the cosine function longitudinally These functions are restricted to zero values at radii and half height values equal respectively to the actual core radii and half heights plus the reflector savings.

4) Thermal and hydrodynamic entrance lengths are neglected, and steadystate heat and fluid flow rates are assumed.

5) The individual coolant flow channels are oxificed such that the flow through each channel is directly proportional to the heat produced by that element. This implies that the ratio of the heat production by an element to the coolant mass flow rate through the element is constant.

6) The avexage heat flux was limited to $120,000 \mathrm{Btu} / \mathrm{hr}-\mathrm{sq}$ ft.

7) The maximum wall temperature was not allowed to exceed $620^{\circ} \mathrm{F}$, which is about the masimum temperature at which zirconium can safely be used. Actual1y, at an average heat flux of $120,000 \mathrm{Btu} / \mathrm{hr}-\mathrm{sq}$ ft, the primary coolant rate used was relatively large to minimize the heat exchanger cost, and hence the wall temperature in the critical channel was always below $620^{\circ} \mathrm{F}$ in a11. designs. The uranium metal center temperature was also well below the metal transition temperature.

8) The outlet coolant temperature was also presumed constant at $535^{\circ} \mathrm{F}$, so as to give a $90^{\circ} \mathrm{F}$ safety factor below the bulk saturation temperature corresponding to the reactor vessel pressure of 1800 psi. 


\section{APPENDIX B $\quad b$}

MECHANICAL FEATURES AND DETAIIED COST ESTIMATES

In selecting the size and type of equipment for nuclear power plants, a certain amount of optimization is usually employed, especially in connection with the selection of the best steam cycle. This generally takes the form of balancing increased construction costs due to more efficient (e.g., higher pressure) equipment against savings in fuel resulting from the use thereof.

In the case of a nuclear plant the selection of the best plant cycle for a given size and type of power plant has always presented a difficult problem for the obvious reason that the two controlling factors, namely, anticipated fuel costs and construction costs, are not sufficiently well known to permit a precise analysis. Not until a sufficient number of these plants have been built and operated will we be able to predict an optimum design with a high degree of reliability. A reasonable approximation may be made, however, and this was done in this report, as outlined below.

The best conventional American plants are now showing a fuel cost of about $3 \mathrm{mills} / \mathrm{kwh}$. If nuclear power plants are to compete, they must do considerably better than this because of the inherently higher construction costs of the 1atter. A number of recent studies have indicated that for nuclear plants presently contemplated a fuel cost of $2 \mathrm{mills} / \mathrm{kwh}$ is reasonable to expect within the lifetime of the plant. With the over-a11 thermal efficiencies expected of about $30 \%$, this corresponds to a marginal steam cost of about \$0 20 per million Btu. It may be stated that nuclear construction costs show a rapid increase with increases in design pressure, and, since the possible fuel savings are relatively small as the pressure is raised, it appears that the tendency toward less efficient steam cycles for nuclear plants will continue for some time to come.

Before going into the actual optimization of the cycles, selection of equipment, and freezing of plant designs, it should be mentioned that both the dual cycle and the closed bolling cycle were considered and eliminated as constituting a separate problem for study. The use of superheated steam was eliminated as not offering any contribution toward the know-how of a heavy water nuclear power plant at this time. The selection of the best cycle then resolved itself to determination of steam turbine throttle pressure, condenser vacuum, and extent to which regenerative feedwater heating is to be employed. 
The major pieces of equipment which go to make up the principal cost of a nuclear plant, the cost of which varies not only with size but with the plant cycle to be selected, are*
1) Main condenser
2) Feedwater heaters
3) Main heat exchanger (steam generator) - pressurized case
4) Reactor pressure vesse1
5) Containment vesse1
6) Turbo-generator
7) Reactor feed pumps and recirculating pumps
8) Interconnecting piping

\section{Design Philosophy}

As indicated previously in this report, the use of a heavy water reactor for power purposes introduces two design problems arising from the high cost of the heavy water. These are (1) maintenance of low heavy water inventory and (2) reduction of leakage As pointed out above, the cost of heavy water has been reduced considerably from what it was just a few years ago, and consequent1y expensive designs to maintain low inventory and reduce leakage are no longer justified In fact, investigation has indicated that the extremes resorted to on some of the earlier studies were actually prompted as much by the scarcity as by the cost of heavy water. For this reason designs and specifications were confined to conventional types and materials as much as possible, this being consistent with the spixit of the study which is to confine ourselves as much as possible to known technology

Following the general practice in nuclear plants now being built or contemplated, stainless steel is used where there is contact with hot water and carbon steel where the contact is primarily with steam. Monel tubes are used on high-temperature feedwater heaters, while copper nickel is used on the lower temperature units other materials are discussed in connection with the individual pieces of equipment

No canned rotor pumps are used, it being the philosophy to rely on mechanical seals and to recover slight leakage through an enclosed drainage system Rather than pay a high premium for special designs to prevent leakage, such as double tube heat exchangers, suitable instrumentation and alarms are provided which is reflected in slightly higher instrument costs. 
Such other special features which are provided are discussed under the specific pieces of equipment which follow.

\section{Main Condenser}

Wide variations in plant operating conditions make a painstaking optimization of condenser design of doubtful value This is especially true in a nuclear plant where the tendency toward providing condensers of smaller area because of lower anticipated fuel costs, and hence less need for high vacuum, is counteracted by the need for additional surface to take care of "dumping" steam during periods of load interruption. For this reason it was decided to standardize condenser back-pressures at 1.5-in. Hg. This corresponds to the preferred standards of the Joint AIEE-ASME Comittee on Steam Turbine-Generators for large turbo-generators, as used in the design specifications of most modern conventional plants, and represents average operating conditions in most plants of the United States.

Using an average inlet circulating temperature of $65^{\circ} \mathrm{F}$ and average heat transfer coefficlent of $570 \mathrm{Btu} / \mathrm{hr}-\mathrm{sq} \mathrm{ft} /{ }^{\circ} \mathrm{F}$ representing a cleanliness factor of $85 \%$, the condenser surfaces were designed for full throttle flow at the rated capacities studied herein The elimination of one of the variables in the cycle is thus effected.

Conventional materials were used for tubes and tube sheets, but in the case of the boiling cycle, consistent with what is considered best practice at present, a double tube sheet with leak-off detection was provided to prevent contamination of $\mathrm{D}_{2} \mathrm{O}$ with $\mathrm{H}_{2} \mathrm{O}$

\section{Feedwater Heaters}

In a nuclear plant the advantages of feedwater heating are not analogous to those prevailing in a conventional plant, since it is desirable to get the most heat possible out of the reactor using a low reactor coolant inlet temperature Even in nuclear plants, however, the economy of regenerative feedwater heating is so great that its use seems imperative This is in addition to the fact that turbine extraction openings and piping must be provided for moisture removal in any case Calculations were made to verify these facts and to help determine to what extent feedwater heating should be carried out in the plants being studied 
18

The curves on Figures $B-2$ and $B-3$ show how fuel and fixed charges vary with the number of feedwater heaters for both the boiling and $\mathrm{pressurized}$ cases for various pressures in a 100 EMW plant. The curves on Figures $B-4$ and $B-5$ show the corresponding total power cost in mills/kwh based on a fuel-cycle cost of $\$ 0.20 / \mathrm{million} B t u$. Attention is invited to the points at which the curves level off rapidy, indicating relatively small savings through the use of additional heaters. This appears to be four heaters for the boiling case and six heaters for the pressurized case. The difference is due to the slightly better station heat rate obtained with the boiling plant because of the smaller amount of auxiliary power required.

The difference, however, is comparatively small and probably beyond the 1imits of accuracy of a study such as this. For this reason, we have adopted four heaters for both the boiling and pressurized cases.

Although the figures were worked out for the 100 EMW plant only, it is felt that the results apply with acceptable accuracy for the 20 EMW and 250 EMW cases also, since for low-pressure plants the turbine heat rates do not vary a great deal with size in this range. This has been verified by data supplied by manufacturers for several previous studies.

\section{Main Heat Exchangers (Steam Generators)}

The pressurized $D_{2} O$ cores entail the use of an expensive piece of additional equipment, namely, the main heat exchanger or steam generator. The design of this exchanger was presented to two of the leading manufacturers of this type of equipment. The cost data which they developed utilizing their experiences with the Shippingport and Dresden projects for the several cases checked rather closely and formed the basis of the figures for this item shown in the estimated construction costs. The heat transfer area required was calculated as explained in Appendix A.

\section{Reactor Pressure Vesse1}

The general dimensions of the vessels required for different capacities and types, based on our determination of core sizes, were transmitted to Consolidated Western steel, who produced the designs and costs given in their report incorporating the provisions for leak tightness (Appendix F). 
Jín

Based on these, data curves of pressure vessel costs versus diameter for various pressures were plotted (Figure $B-6$ ).

For the higher pressures and larger diameters the curves shown on Figure B-7 were plotted.

The effect of the pressure vessel cost on the final unit power cost is shown on Figure B-8. It is obvious that this wil1 be more marked in the case of smaller plants where it may go as high as $18 \mathrm{mills} / \mathrm{kwh}$. In the 1 arger plants, the effect is less noticeable, the maximum shown being less than $0.5 \mathrm{mills} / \mathrm{kwh}$. It would appear, therefore, that in most cases the effect of pressure vessel cost on final unit power cost is not as vital as is sometimes supposed.

\section{Containment Vesse1}

The required volumes of containment vessel were established by computing the volume of steam produced by converting the normal contents of the reactor and adjacent piping at the operating temperatures and pressures to steam at 30 psig and allowing $20 \%$ additional for machinery and equipment Using these volumes, Consolidated Western produced the designs and costs given in theix report and shown in the cost tabulations, Tables B-II and B-III

\section{Turbo-Generator}

In the case of the pressurized cycle, the turbo-generator presents the usual problem connected with use of saturated steam and moisture removal This is reflected in higher costs for these units, especially in the larger sizes With the boiling cycle the problem of prevention of leakage becomes of even greater importance when heavy watex is used The manufacturers agree that a virtually leak-proof machine may be built utilizing a special shaft seal similar to that shown on the accompanying sketch, Figure $B=1$, and further enclosing the casing in a welded metal shell or "can" similar to that emploved on mercury vapor turbines This increases the cost from $2 \%$ to $10 \%$, depending on the size, and this is provided for in the estimates

\section{Pumps}

These were mentioned in the general discussicn above The capacities and heads required being already established by the previous work, prices were obtained for basically standard pums, the only special provisions being in the mechanical seals, the extra costs of which showed up in our estimates 


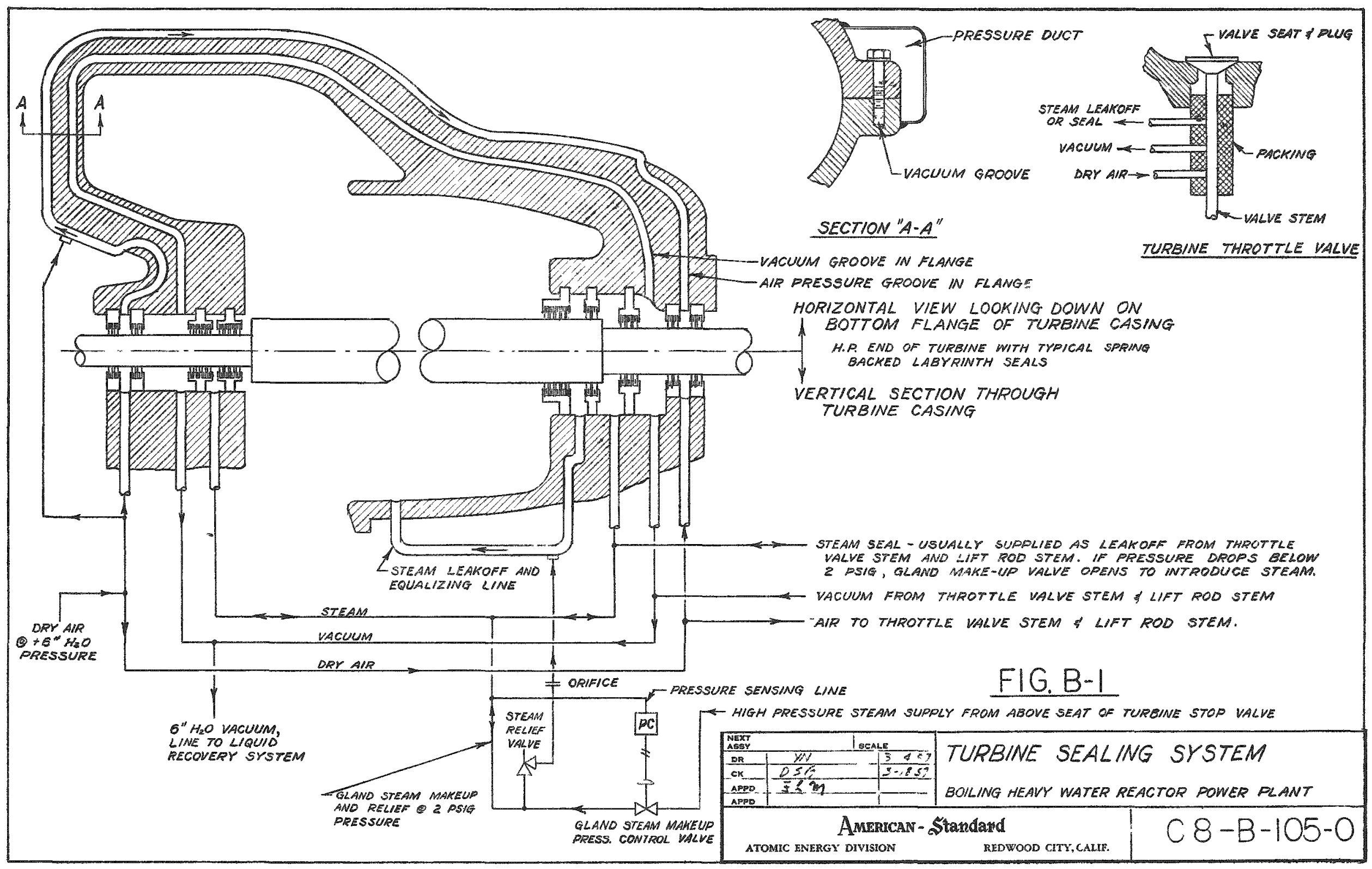


81

Figure $B-2$

$100 \mathrm{EMW}$

Boiling Heavy Water Reactor Power Plant

Fuel Cost (at $\$ 0.20$ per Million BTU)

Feedwater Heaters Installed Cost

As a Function of Number of Feedwater Heaters

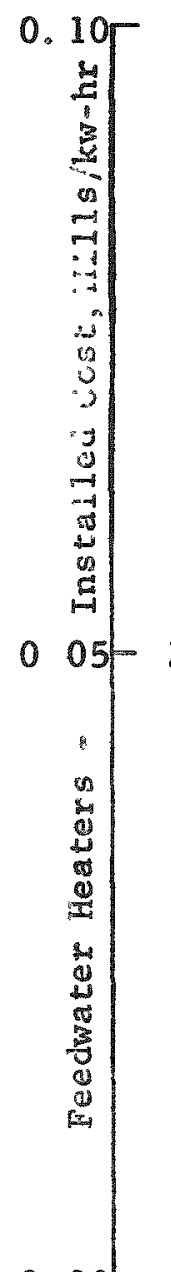

0.00

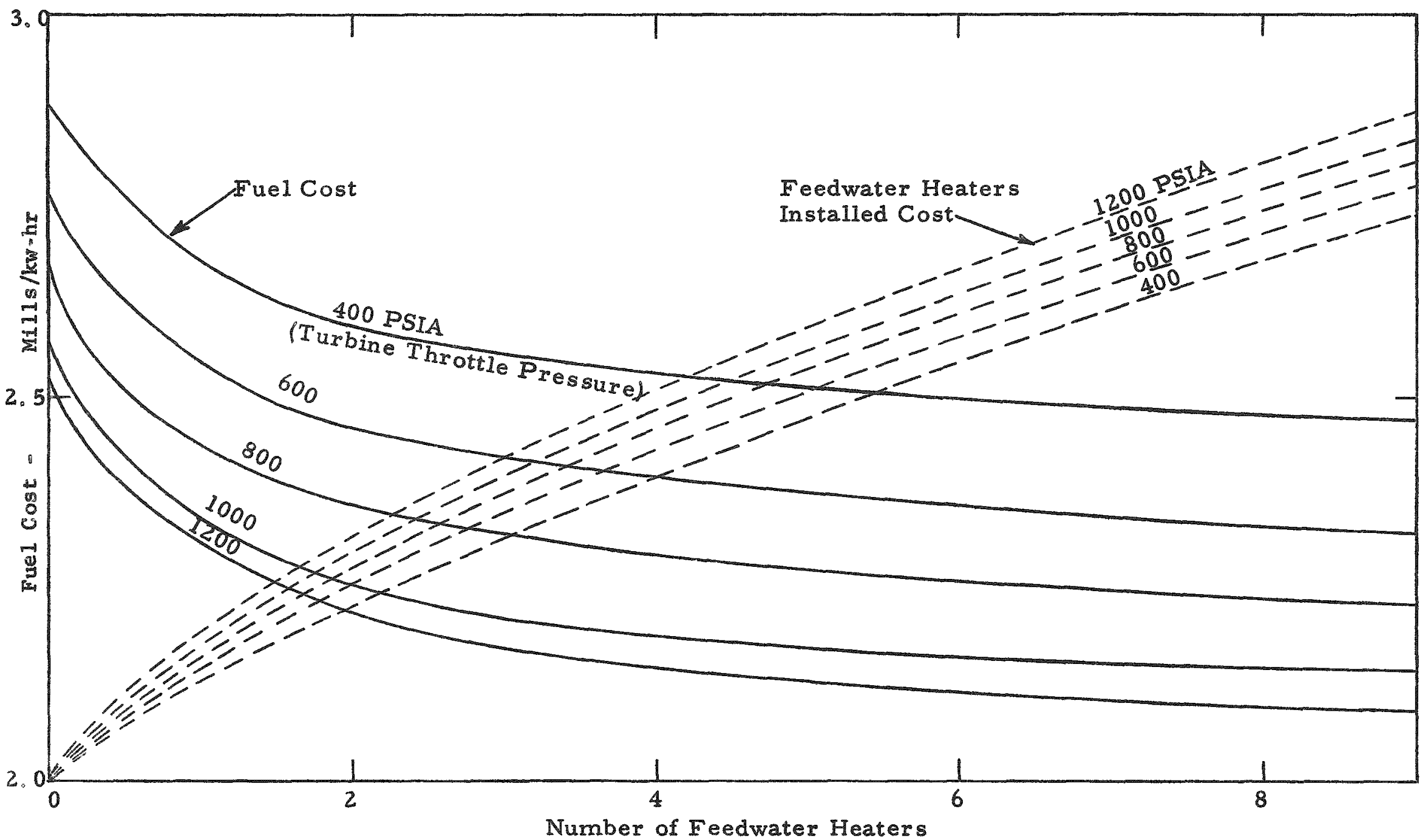




$$
\text { 82 Figure } B-3
$$

Pressurized Heavy Water Reactor Power Plant

Fuel Cost (at 0.20 per Million BTU)
Feedwater Heaters Installed Cost As a Function of Number of Feedwater Heaters

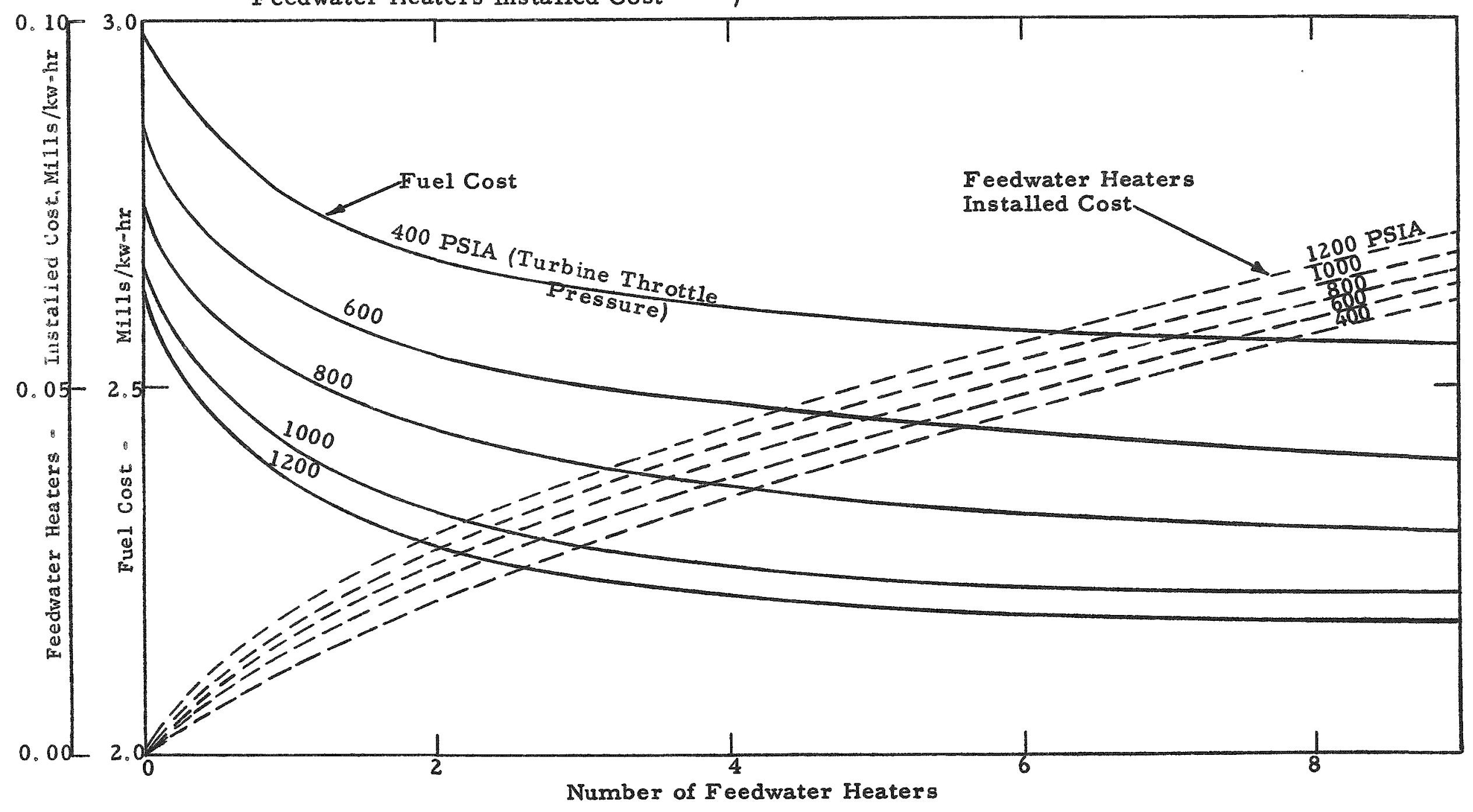




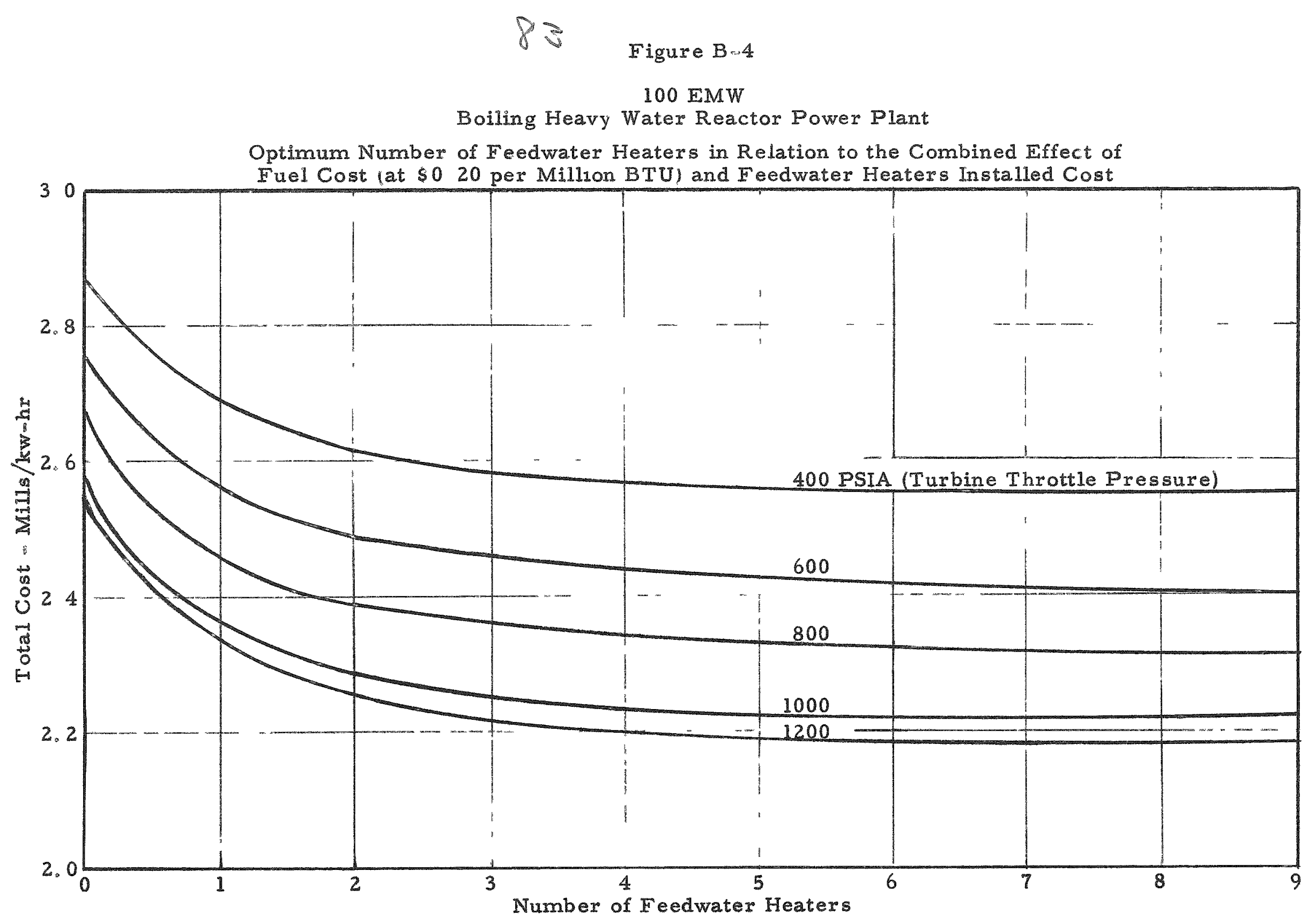




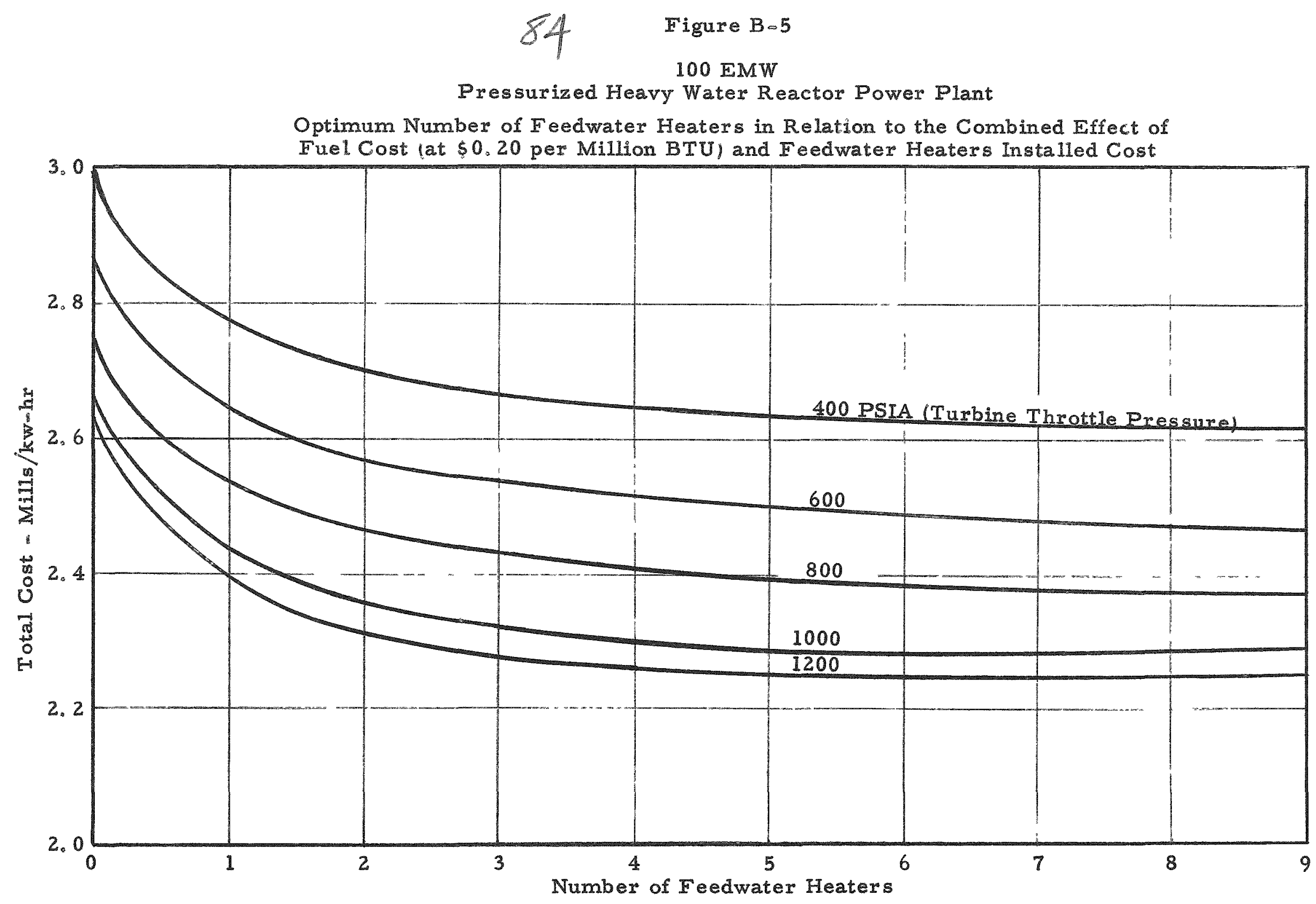




$$
\begin{aligned}
& \text { Figure } B-6 \\
& \text { Pressure Vessel Costs, } \text { D2 }_{2} \text { O Reactors }
\end{aligned}
$$

Stainless Clad Code Vessels Based on Study by Consolidated Western Cost of Bare Vessel

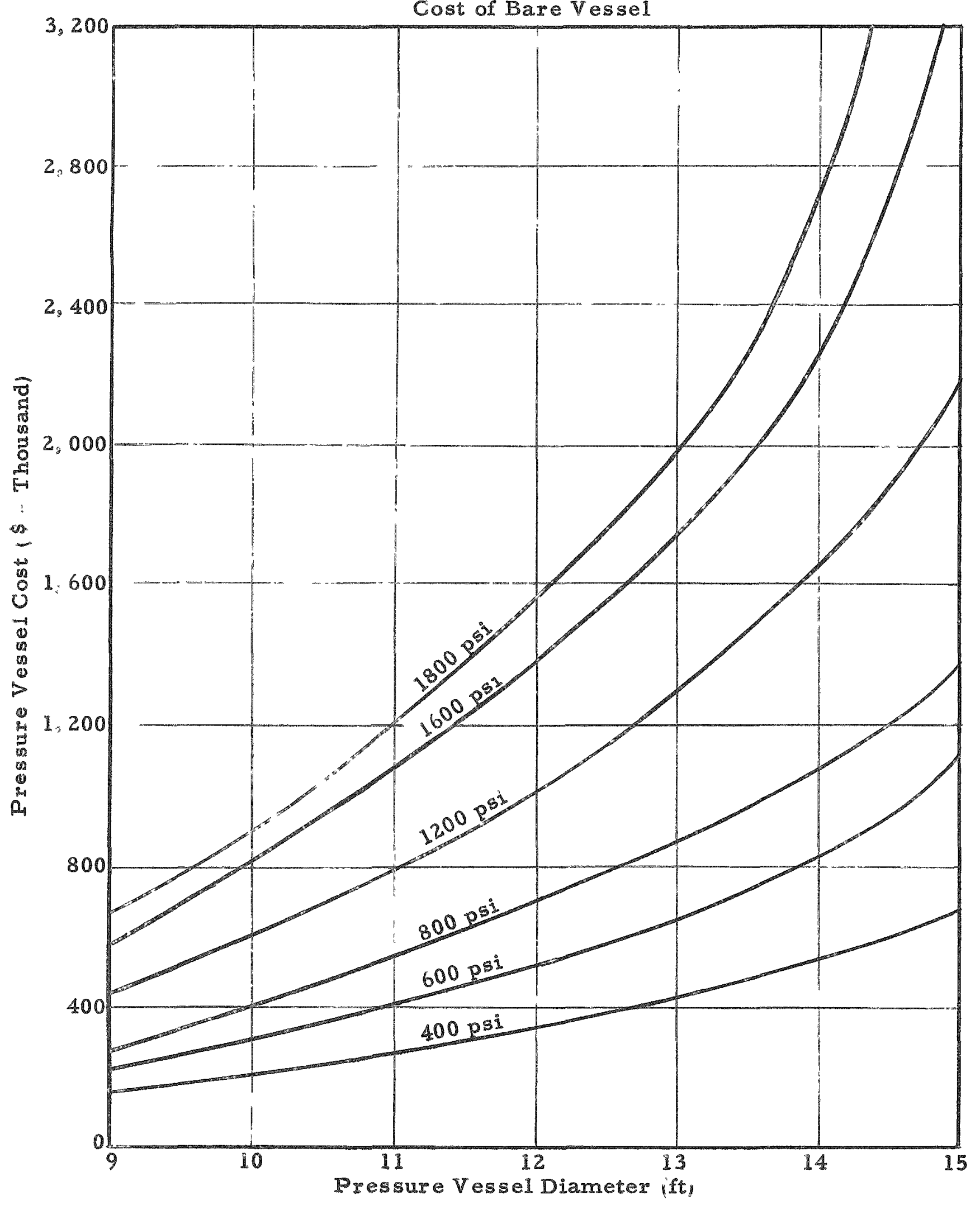


Figure $\mathrm{B} \times 7$

Larger Vessel Costs, Pressurized $D_{2}$ C Cases

Stainless Clad Code Vessels Based on Study by Consolidated Western Cost of Bare Vessel

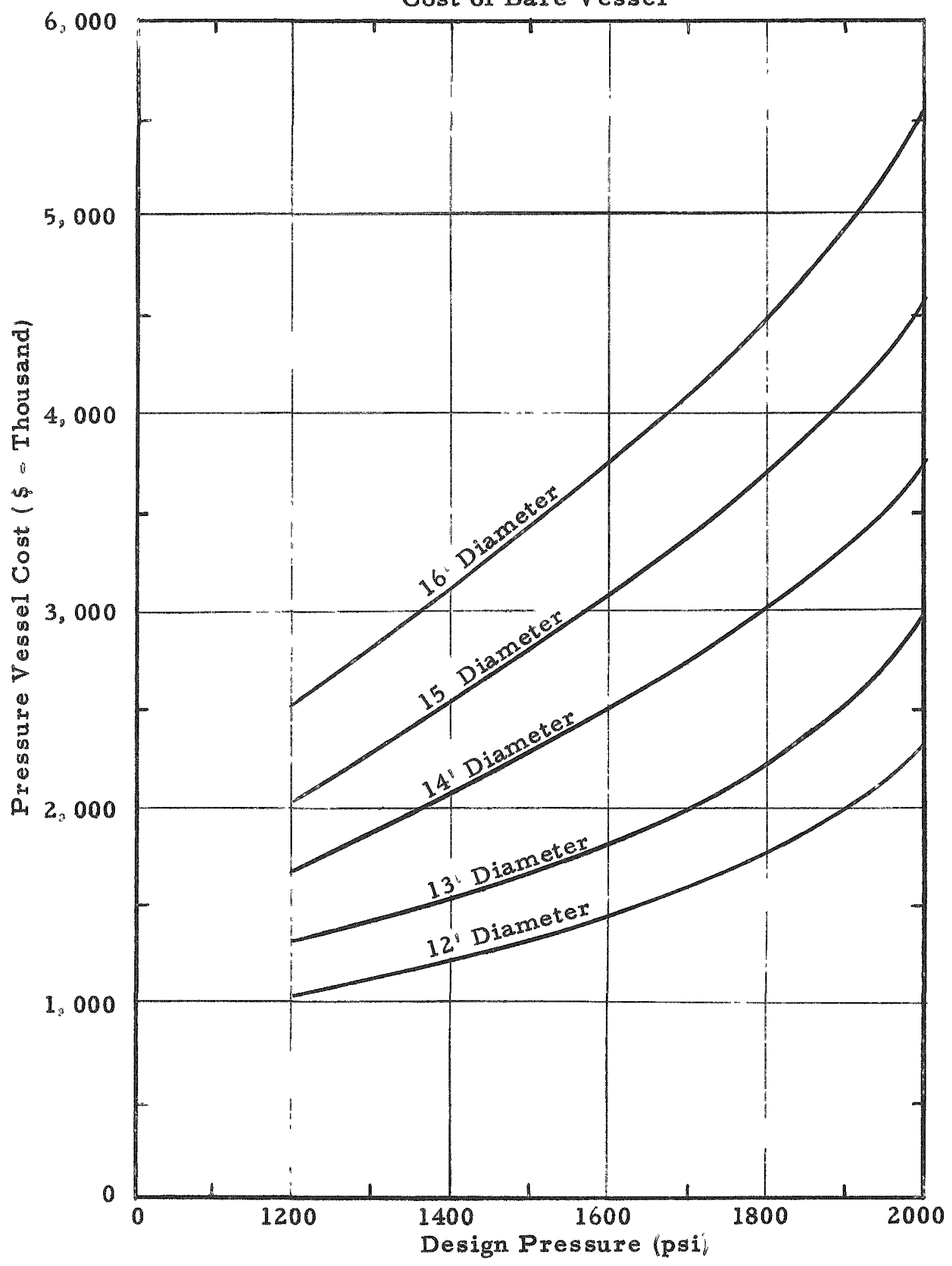




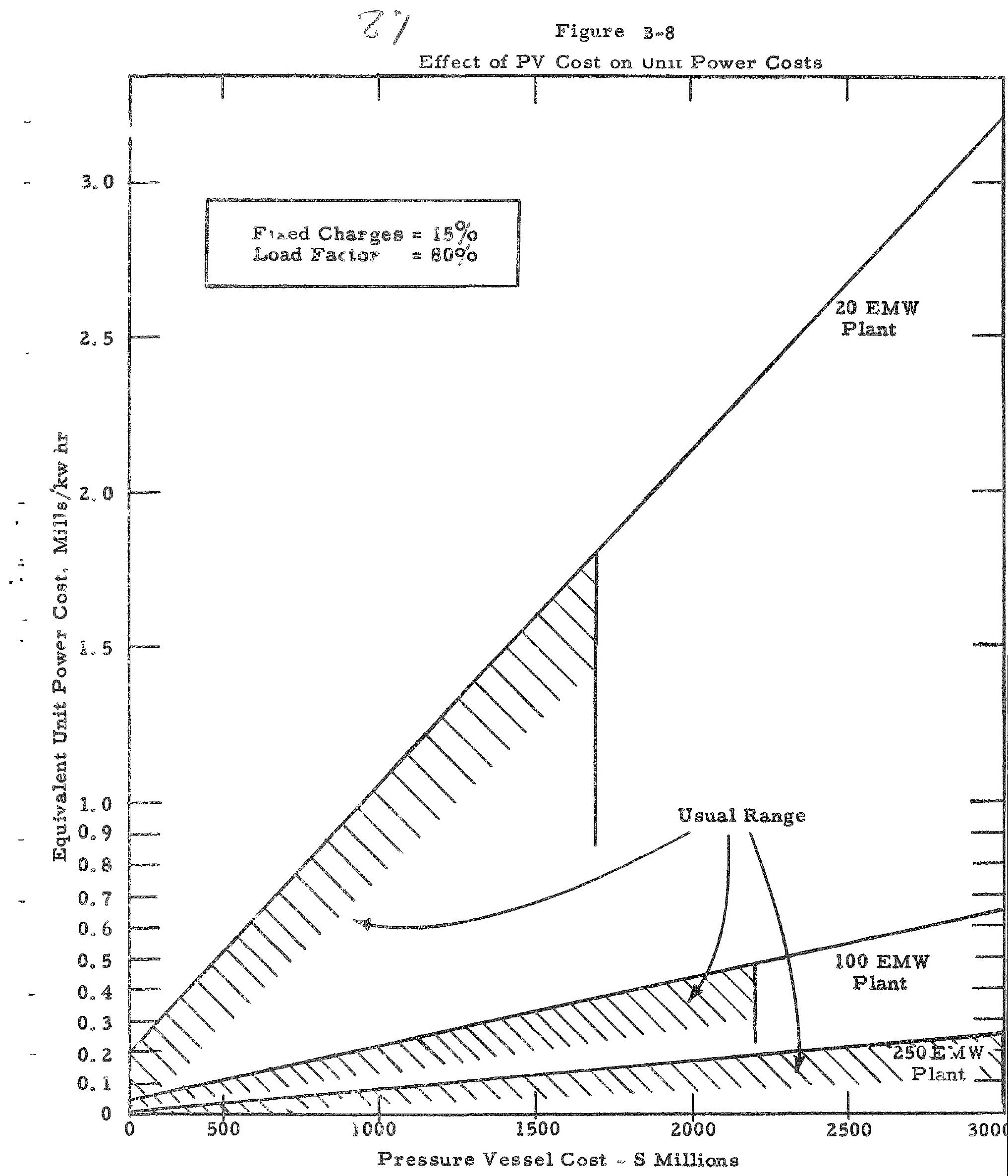




\section{$x^{2}$ \\ Heat Rates. Steam Cycle, and Cost Estimates}

The net station heat rates and efficiencies were calculated for each pressure, using four feedwater heaters and the condenser conditions previously established The efficiencies are shown at the head of the appropriate columns of Tab1e $B-I$

It is seen that the efficiencies average about $30 \%$ and improve about $1 \%$ for each of the incremental pressure increases shown Using the fuel cost of 2 mils/kwh established previously, it follows that savings in fuel cost for each pressure increase amcunt to $2 \times \frac{1}{30}=066 \mathrm{mil} 1 \mathrm{~s} / \mathrm{kwh}$.

At the base of the columns of Table $B=I$ are seen the unit fixed costs for construction in mills/kwh for each of the pressures given It is obvious that even in the most favorable cases, namely, the large size bolling plants, the increased cost of going to the next higher pressure amounts to $0.1 \mathrm{mi} 11$. In the less favorable pressurized cases this amounts to several mills. In no case is it less than the saving in fuel cost which is realized.

The obvious conclusion is, therefore, that it does not pay to go to the higher steam pressures for heavy water plants of the type currently contemplated. This may not necessarily be true a few years from now when unit construction costs may decrease more rapidly than fuel costs because of improved technology and experience

Detailed construction cost estimates for the boiling heavy water plants as fixed by the foregoing analysis are shown in Table B-III.

\section{Design for 500 EMW}

At the later request of AEC an approximation of unit power costs in a heavy water plant having a capacity of 500 EMW was made The latter size was selected, since several of the larger utilities bave indicated that they will be going to this size turbo generater by 1962 .

Obviously, construction cost data for plants utilizing units of this size is much less reliable than that given previously in this report. For this reason a detailed cost estimate was not made, but the following method was used (See Table B-IV)

A boiling heavy water plant utilizing a throttle pressure of $800 \mathrm{psi}$ saturated was adopted It was assumed that by the above date the conservative average heat flux of $120,000 \mathrm{Btu} / \mathrm{hr}=\mathrm{sq}$ ft could be doubled as operating 


\section{9}

TABLE B-I

EFTECT OF TURBINE THROTTLE PRESSURE ON CONSTRUCTION COSTS

\begin{tabular}{|c|c|c|c|c|c|c|c|c|c|c|c|}
\hline \multirow[b]{2}{*}{ Turbine Throttle Pressure } & \multicolumn{3}{|c|}{20 EMV } & \multicolumn{4}{|c|}{$100 \mathrm{BMW}$} & \multicolumn{4}{|c|}{250 EMW } \\
\hline & 400 & 600 & 800 & 400 & 600 & 800 & 1,000 & 400 & 600 & 800 & 1,000 \\
\hline Cycle Efficiency \% & 29 & 30 & 31 & 29 & 30 & 31 & 32 & 29 & 30 & 31 & 32 \\
\hline $\begin{array}{l}\text { Total Construction Costs } \\
\qquad \times 10^{6}\end{array}$ & 10.8 & 11.5 & 12.1 & 30.6 & o11in & $\begin{array}{l}\mathrm{g} \mathrm{Cas} \\
32.5\end{array}$ & 33.5 & 61.7 & 62.9 & 64.1 & 65.9 \\
\hline Construction Cost $/ / k$ & 540 & 575 & 605 & 306 & 314 & 325 & 335 & 247 & 251 & 256 & 264 \\
\hline Unit Costs Mills/kwh & 11.65 & 12.3 & 13 & 6.56 & 6.73 & 6.96 & 7.17 & 5.28 & 5.38 & 5.50 & 5.65 \\
\hline & \multicolumn{11}{|c|}{ Pressurized Cases } \\
\hline $\begin{array}{l}\text { Total Construction Costs } \\
\$ \times 10^{6}\end{array}$ & 13.9 & 14.8 & 17.1 & 37.4 & 40.4 & 49.6 & $=$ & 75.5 & 80.5 & 105.0 & $=$ \\
\hline Construction Costs $\$ / \mathrm{kw}$ & 695 & 740 & 855 & 374 & 404 & 496 & $=$ & 302 & 322 & 420 & $=$ \\
\hline Unit Costs Mills/kwh & 14.89 & 15.8 & 18.3 & 8.01 & 8.68 & 10.6 & - & 6.49 & 6.92 & 9.02 & $=$ \\
\hline
\end{tabular}




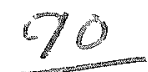

TABLE B-II

BOILING HEAVY WATER REACTOR POWER PLANTS

DETAILED CONSTRUCTION COSTS

$\$ 1000$

Rated Rlectrical Capacity EMW

Turbine Throttle Pressure PSIA

(310) Land

(311) Structures \& Improvements

(312) Reactor Plant

Reactor Vesse1.

Reactor Shielding

Reactor Core \& Fittings

Fuel Hand1ing Equipment

Contro1 Rod Drives

Recirculation Pumps

Interconnecting Piping

Instrumentation \& Controls

$\mathrm{D}_{2} \mathrm{O}$ Treatment \& Recovery System

Steam Separator

Containment Vesse1

$$
\text { Sub-Tota1 }
$$

20

400

40

800

528

250

320

770

264

126

322

378

60

50

386

3,454

(314) Turbo-generator Equipment

Turbo-generator, incl, auxiliaries Condenser, inc1, circulation pumps Condensate Pumps

Feedwater Heaters

Feedwater Pumps

Interconnecting Piping

Instrumentation \& Controls

$$
\text { Sub-Total }
$$

(315) Accessory Electrical Equipment

(316) Miscellaneous Plant Equipment

$$
\text { Sub-Tota1 (A) }
$$

Engineering (c) 20\%

overhead @ 10\%

$$
\text { Sub-Total }
$$

Contingency @ 20\%

Total Construction Cost

Tota1 Unit Construction Cost

$$
\$ / k w
$$

Mi $11 \mathrm{~s} / \mathrm{kwh}$
1,366

196

23

41

58

188

222

2,094

450

137

6,975

1,395

698

9,068

1,814

10,882

544

11. 655
100

250

400

500

7,500

3,500

690

777

500

1,200

820

393

378

535

839

255

87

590

1,000

2,000

900

550

1,062

1,190

1,080

624

163

724

6,287

10,070

5,134

945

42

185

104

600

961

7,971

1,300

395

19,653

3,920

1,965

25,538

11,410

2,140

73

435

182

1,760

2.134

18,134

2,500

808

39,512

7,900

3,950

51,362

5,110

10,300

61,662 
91

TABIE $B-I I I$

PRESSURIZED HEAVY WATER REACTOR POWER PLANTS

DETAILID CONSTRUCTION COSTS

$\$ 1000$

Rated Electrical Capacity EMW

20

Reactor Operating Pressure PSIA

1800

Turbine Throttle Pressure PSIA

(310) Land

400

(311) Structures \& Improvements

40

800

(312) Reactor Plant

Reactor Vessel
Reactor Shielding
Reactor Core \& Fittings
Fuel Handling Equipment
Control Rod Drives
Pressurizer \& Recombiner
Heat Exchangers (Steam Generators)
Recirculation Pump
Containment Vessel
Instrumentation \& Controls
Interconnecting Piping
D20 Treatment \& Recovery System

1,435

300

300

770

264

32

340

192

640

475

622

Sub-Total

40

5,410

100

250

1800

$\frac{400}{500}$

7,500

3,500

2,596

550

1,000

820

360

48

1,440

576

1,037

1,120

1,074

164

5,000

1,200

1,900

900

500

52

3,560

1,483

1,139

1,837

2,320

395

20,286

(314) Turbn-generator Equipment

Turbo-generator, incl auxiliaries

1,253

Condenser, incl. circulation pumps

207

Condensate pumps

23

Feedwater Heaters

34

Feedwater Pump

Instrumentation \& Controls

Interconnecting Piping

$\mathrm{H}_{2} \mathrm{O}$ Make-up System

Sub-Total

(315) Accessory Electrica1 Equipment

(316) Miscellaneous Plant Equipment

Sub-Total (A)

Engineering (d 20\%

overhead a $10 \%$

$$
\text { Sub-Tota1 (B) }
$$

Contingency @ 20\%

10,785

10,440

2,080

931

42

158

73

390

182

1,763

780

746

2,230

35

1,989

7,506

75

17,233

500

1,500

2,800

175

470

919

8,914

23,961

49,238

1,783

891

4,792

9,376

2,396

4,688

11, 588

31,149

60,942

2.318

6,230

12,188

13,906

37,379

75.490

Total Construction Cost 
TABLE B $B-I V$

APPROKIMATION OF A 500 EMN BOILING D 20 PLANT

$\$ 1000$

Land (Same as for $250 \mathrm{EMW}$ )

Structures \& Improvements (Same as for 250 EMW)

Reactor Rlant

Reactor Proper \& Accessories (Same as for 250 EMW)

Remainder of Reactor (Cost at 250 EMW x 20.6)

Turbo-generator Plant

Turbo-generator \& auxiliaries

21,000

Condenser

4,000

Remainder of Turbo-generator P1ant (Cost at 250 EMW $\times 2^{0.6}$ )

8,000

$$
\text { Sub-Tota1 (C) }
$$

33,000

Accessory Electrical Equipment

4,120

Misce11aneous P1ant Equipment

1,340

$$
\text { Sub-Tota1 (D) }
$$

61,245

Engineering @ 20\% \& Overhead @ 10\%

Contingency @ 20\%

16,000 
experience was gained, that is, that 500 EMW could be obtained from the same reactor now providing $250 \mathrm{EMW}$. Hence the reactor and directly related costs were left the same.

Approximate turbine and condenser prices for the 500 EMW size were obtained from manufacturers.

The cost for land and improvements were left the same as for the 250 EMW plant.

The cost of the remaining equipment was raised by a factor of $2^{0.6}$ in accordance with customary practice in process plant estimating.

Using these figures and applying the same factors for engineering overhead and contingency, a figure of $\$ 95$ million was estimated for such a plant, or $\$ 190 / \mathrm{kw}$.

The heavy water inventory was obtained by assuming the same quantity in the reactor as was done for the 250 EMW case and increasing the amount outside the reactor by the same factor, namely, $2^{0.6}$. The result was a heavy water cost of $\$ 30 / \mathrm{kw}$.

Heavy water losses were approximated in the manner indicated above, giving a loss of $150 \mathrm{lb}$ per day or a unit power cost of about $0.5 \mathrm{mi} 11 \mathrm{~s}$.

From Figure 18 a unit construction cost of $4 \mathrm{mills} / \mathrm{kwh}$ was obtained for construction costs and $0.5 \mathrm{mills} / \mathrm{kwh}$ for heavy water inventory. Adding $1 \mathrm{mil} 1 / \mathrm{kwh}$ for maintenance and operation, a unit cost of $6 \mathrm{mills} / \mathrm{kwh}$ resulis. Assuming further that a 1.5 mill fuel cost will be attainable at this time, a total unit power cost of $7.5 \mathrm{mills} / \mathrm{kwh}$ is obtained.

It is conceded that the above figures are very approximate, but they are of some value in indicating that nuclear power, using a heavy water boiling reactor, should come close to being competitive with conventional power, if such large reactors can be developed and operated feasibly in utility networks.

\section{Equipment Manufacturers Consulted}

$\begin{array}{ll}\text { Pressure Vessels - } & \text { Consolidated Western Steel Division, } \\ & \text { U. S. Steel Corporation } \\ \text { Pumps } & \text { Worthington Corporation } \\ & \text { Byron Jackson Company } \\ & \text { Ingersoll-Rand Company }\end{array}$




$$
-14
$$

Heat Exchangers - The Babcock and Wilcox Company

Foster Wheeler Corporation

Turbo-generators - Al1is-Chalmers Manufacturing Company

General Electric Company

Westinghouse Electric Corporation 


\section{APPENDIX C}

\section{COSTS OF FUEL CYCLE STEPS}

The unit costs of converting uranium from one chemical form to another and of recovering uranium or plutonium from irradiated fuel are quite dependent upon:

1) the uranium enrichment

2) the batch size to be treated

3) the pexformance of the operation in a Government-operated plant as opposed to a privately-operated plant

4) the time period being considered (as the atomic power industry grows, most unit costs are expected to fall markedly)

Information on the effect of these variables is not complete. The available data are discussed below.

For normal or slightly enriched uranium (perhaps up to 3\% U-235), unit costs are appreciably lower than for more concentrated material, since in general the criticality problem is not encountered. Power reactors utilizing slightly enriched uranium contain in the range of 10,000 to 70,000 kilograms of this material. It will be assumed that batch sizes processed in the fuel cycle are sufficiently large so that the costs described are appropriate to batches of several tons or more.

\section{Purchase or Lease of Uranium Fuel}

Under the present regulaions, the AJC will sell or lease natural uranium to a reactor operator at a price of $\$ 40.00$ per kilogram in the matal ingot form only. A question of some interest in connection with heavy water reactors is whether the AEC might in the future aiso se1]. normal UO 2 directy. Large quantities of this material ane now matuactured in AEC plants, since the conversion of natural $\mathrm{UO}_{3}$ to UF 4 or UF 6 involves a preliminary reduction to the $\mathrm{UO}_{2}$ stage. There seems no great technical problem which would prevent the withdrawal of $\mathrm{UO}_{2}$ from the production process, although the particle size is somewhit smaller than for the $\mathrm{UO}_{2}$ commonly used in oxide pellet production. Selling of normal $\mathrm{UO}_{2}$ by the $\mathrm{AEC}$ would permit reactor operators to obtain this material at perhaps $\$ 38.00$ per kilogram of U-content, 
76

While normal $\mathrm{UO}_{2}$ prepared in large batches by reduction of Uf 6 would probably cost at least $\$ 42.50$ per klogram $U_{y}$ or a cost differential of $\$ 4.50$.

The AEC has recently published 1 a price scale for enriched uranium in the form of UF6 (see Table $C-I$ ) and has offered normal uranium as metal ingots at $\$ 40.00 / \mathrm{kgm}$. This price scale was used to determine the cost of fresh fuel, and it was assumed that this fuel was rented from the AEC at the established charge of $4 \%$ per dollar-year based on the published price scale. It was further assumed that the period required for all out-of plle fuel cycle steps was one year. Although a similar price scale has not been publiohed for depleted uranium, prices for such material can be calculated based upon the price scale equation which best fits the AEC prices for slightly enriched uranium.

Benedict 2 has published such an equation:

$$
c=37.48 \quad\left[(2 x-1) \ln \frac{449 x}{10 x}+449(x-0.00222)\right]
$$

where

$$
\begin{aligned}
& \mathrm{C}=\$ / \mathrm{kgm} \text { of contained uranium } \\
& \mathrm{x}=\text { welght fraction } \mathrm{U}-235 \text { in the uranium }
\end{aligned}
$$

\section{Preparation of Erriched Oxide or Metal}

Since enriched uranium is avaliable only in the form of UF6, the reactor operator must reduce the enriched UF6 to metal or to $\mathrm{UO}_{2}$ in order to prepare fuel elements.

$$
\underline{\mathrm{UF}} 6 \mathrm{O} \rightarrow \mathrm{UO}_{2}
$$

This step involves:

1) hydrolysis of UT6 to uranyl fluoride

2) precipitation of ammonium diuranate with ammonia

3) therma1 decomposition to $\mathrm{U}_{3} \mathrm{O}_{8}$

4) reduction of $\mathrm{U}_{3} \mathrm{O}_{8}$ to $\mathrm{UO}_{2}$ with hydrogen

For slightly enriched uranium in batch sizes of $3,000 \mathrm{~kg}$ and above, the unit cost picture as received from commercial firms for this fuel-ycle step is summarized below:

1 See Nucleonics, 14 , No. $12, \mathrm{p}, \mathrm{R} 2$ (December, 1956).

2 M. Benedict and T. H. Pigford, Chem。Eng. Prog.53, $145 \times$ March, 1957). 


\section{$=y$ \\ TABLE $C-I$ \\ ENRICHED URANIUM PRICES 1}

\begin{tabular}{l}
$\begin{array}{l}\text { Weight fraction } \\
U-235\end{array}$ \\
\hline
\end{tabular}

.0072

.0074

.0076

.0078

.0080

.0082

.0084

, 0086

.0088

.0090

.0092

.0094

.0096

.0098

.010

.011

.012

.013

.014

.015

.020

.025

.030

.035

.040

.045

.050

.060

.070

.080

.090

10

.15

.20

.25

.30

.35

.40

.45

.50

.55

.60

.65

.70

.75

.80

.85

.90
Base Charge as UF $6, f \cdot 0 . b$. Oak Ridge

$(\$ / \mathrm{kg}$ contained U) (\$/gm U-235 content)

40.50

42.75

45.25

47.50

50.00

52.50

55.00

57.50

60.00

62.75

65.25

67.75

70.50

73.00

75.75

89.00

103.00

117.00

131.25

145.50

220.00

297.00

375.00

455.00

535.50

616.50

698.25

862.50

$1,028.00$

$1,195.00$

$1,362.00$

$1,529.00$

$2,374.00$

$3,223.00$

$4,078.00$

$4,931.00$

$5,793.00$

$6,654.00$

$7,515.00$

$8,379.00$

$9,245.00$

$10,111.00$

$10,979.00$

$11,850.00$

$12,721,00$

$13,596.00$

$14,475.00$

$15,361.00$
5.62

5.78

5.95

6.09

6.25

6.40

6.55

6.69

6.82

6.97

7.09

7.21

7.34

7.45

7.58

8.09

8.58

9.00

9. 38

9.70

11.00

11.88

12.52

13. 00

13. 39

13. 70

13. 96

14.38

14.68

14.94

15.13

15.29

15.83

16.12

16. 31

16.44

16.55

16.64

16.70

1676

16.81

16.85

16.89

16.93

16.96

17.00

17.03

17.07 
Batch

Size:

Present

$3,000 \mathrm{~kg} \quad 10,000 \mathrm{~kg} \quad 20,000 \mathrm{~kg}$

Long Range

Above $3,000 \mathrm{~kg}$

Losses

U -235

Conen: $\quad 1.5 \% 2.0 \% 3.0 \% 1.5 \% 2.0 \% 3.0 \% 1.5 \% 2.0 \% 3.0 \%$ Normal to $3.0 \%$

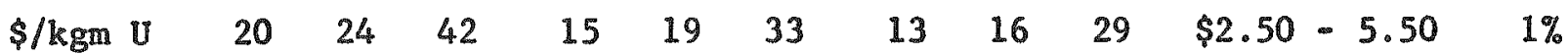

$$
\mathrm{UF}_{6} \rightarrow \text { Metal Ingot }
$$

Little information is avallable regarding the effect of batch size and technological improvement on this unit conversion cost. A 1ong-range estimate for slightly enrlched material processed in large batches is about $\$ 1.50$ to $\$ 2.50$ per kilogram. Present costs for small batches of enriched material are probably at least two or three times this figure.

$$
\mathrm{UO}_{2} \rightarrow \text { Pellets }
$$

At present uranium oxide is utilized in the form of small pellets which are inserted into the cladding material. The available estimates on converting $\mathrm{UO}_{2}$ to pellets are:

$$
\$ / \text { kgm U content } \frac{\text { Present }}{15} \frac{\text { Long Range }}{3.50}
$$

\section{Shipment of Irradiated Fuel}

The shipment of irradiated fuel has been discussed by Dryden ${ }^{3}$. The cost for this operation will depend to a considerable extent upon the security measures necessary for the shipment. It is believed that about $\$ 5 / \mathrm{kgm}$ is a representative cost.

\section{Chemical Processing}

A full reprocessing policy was recently issued by the AEC. This policy states that the AEC will reprocess fuel at a charge of $\$ 15,300$ per short ton of fuel. In addition, there are charges for clean-up of the plant before and after the processing of any particular batch. These charges apply to both natural and slightly enriched uranium.

There is an economic balance involving the fuel rental charge, the frequency of shipment between the reactor and the fuel reprocessing plant, the

3 Dryden, Nucleonics, 14, No. 7 p. 77 (July 1956). 


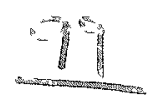

number of shipping cases and the reprocessing batch size. (In addition, the charge-discharge schedule of the reactor itself should probably be included in an economic optimization.) A separate memorandum is in preparation describing the results of such an economic balance. For puxposes of this report, it is sufficient to assume a flat charge of $\$ 20 / \mathrm{kgm}$ of fuel reprocessed.

$$
\text { Uranium Nitrate } \longrightarrow \text { UF6 }
$$

This unit conversion cost should probably in the long range be about $\$ 2.00$ to $\$ 2.50 / \mathrm{kgm}$. The AEC has stated that it will soon establish charges for converting uranium nitrate to uranium hexafluoride, and it is believed that the cost established may be of this order of magnitude.

\section{Plutonium Nitrate $\longrightarrow$ Buttons}

This cost has recently been declassified at a figure of $\$ 1.50$ per gram.

\section{Credit for Plutonium}

For plutonium purchased from non-U. $S$. sources, the AEC has stated a price of $\$ 12$ per gram, independent of the isotopic analysis of the plutonium. Recently the AEC has also announced that for domestic plutonium purchased between now and July 1, 1962, the price will range from \$45 to \$30 per gram, depending upon the Pu-240 content of the material. For the yeax July 1, 1962, to July 1, 1963, the buying price will be $\$ 30$ per gram, regardless of Pu-240 content. The AEC suggested that after 1963 the price might be expected to fall to the fuel value of plutonium.

For the purpose of this study, since heavy water reactors appear particularly attractive outside the United States, it was felt that $\$ 12$ a gram would be the more appropriate selection. However, the effect of the higher plutonium credit is discussed.

\section{Carrying Charges on Non-Depreciating Investment}

In addition to the funds tied up in construction of the plant, money must be committed for working capital of various kinds. A large amount of such working capital is tied up in the non-nuclear costs incurred in fabricating the fuel elements. As discussed previously 4 it is felt that a

4 American-Standard, Report AECU-3398, "Comparison of Calder Hall and PWR Reactor Types," March, 1957. 


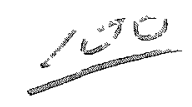

carrying charge of $12 \%$ per dollar-year is approprlate for such funds.

The calculation of the addition to the power-generating cost to cover this carrying charge is rather complicated because of the time-shape of the expenditure schedule for such items and of the receipt of power revenue to cover these costs.

For example, money must be committed for the fabrication of new fuel elements from six to eight months before these elements will produce heat for power generation. On the other hand, power revenue is received from a particular unit of fuel three or four months before the chemical processing charges must be paid for that unit. The rigorous approach to this problem is to find the charge per unit of power generated, which, at $12 \%$ per dollar-year, has a present value equal to the present value of the interest charges on the funds tied up in non-nuclear core parts. As a short cut, the assumption can be made that the non-nuclear investment per kilogram of fuel is outstanding for six months plus half the average exposure time for a fuel element. Hence, the non-nuclear inventory charge per kilogram of fuel would be:

$$
\begin{gathered}
0.12 \times \text { non-nuclear costs }(0.5+0.5 \times \text { exp.time in years) } \\
\text { or } \\
0.06 \times \text { non-nuclear costs }(1+\text { exp time in years })
\end{gathered}
$$

This non-nuclear carrying charge in heavy water reactors is frequently of a larger magnitude than the net fuel cost after plutonium credit. It somewhat counterbalances the advantages with regard to reactivity lifetime which are obtained by utilizing large cores at low specific power, since such cores have higher carrying charges.

\section{Charges For Heavy Water}

The $A E C$ has announced that in addition to the sale of heavy water at $\$ 28$ per pound, it will rent heavy water to reactor operators at a rate of $4 \%$ per dollar-year, based on the $\$ 28$ price. This rental policy will make considerable difference in the cost of power from small heavy water reactors, since the inventory charge for this material is quite expensive. Therefore, power costs have been calculated on the basis of both rental and sale of heavy water to the reactor operators. 


\section{Fuel Element Costs}

The cost of several types of zirconium-clad fuel elements which could be used in a natural uranfum heavy water reactor were estimated. The estimates are based on (1) published data when avallable, (2) verbal comunlcation with commercial metal suppliers and fuel element fabricators, (3) verbal comunications with reactor designers. Classified data and information of a confidential nature are not included, although the estimates are based on an evaluation of al the data.

The cost figures are estimated on the basis of present commerclal costs or on costs projected into the immediate future. It is reasonable to expect these costs to drop about $50 \%$ in the next ten years.

In the present analysis, several different fuel elements are compared on the basis of direct cost per pound of contained uranium. This figure includes the cost of raw materials, scrap, alloying, pelletlzing, fabricating, assembly, inspection, rejects, etc., but does not include the cost of uranium as furnished to the fuel element fabricator in the form of metal or $\mathrm{VO}_{2}$ powder.

The elements are first discussed in separate sections where each element is briefly described and the cost per element is broken down into material and fabrication costs. Table C-II compares the elements on the bas 1 of cost per pound of contained uranium. Only Elements $A$ and $B$ were used in the reactor designs given in this report, but a discussion of the effect of using other elements is included in section III.

The zirconium prices were estimated by dividing the price of raw material. (sponge, ingot, sheet or tube) by the estimated fraction recovered, $x_{\text {a }}$, by the fraction of zirconlum purchased which appeared in the finished fuel elements. This quotient ( () is the true zirconium cost per pound of airconiun In the finished element. If the total cost of zirconlum for a core loading was given and the cotal weight of zixconium in the core was given, $\alpha$ was determined by taking their ratio. Figure $C-1$ is a graph from which the cost of zirconium per pound of uranium can be determined for various values of and for various percentages (by weight) of zirconium in the element. This graph 11 ustrates the rapid increase $1 \mathrm{n}$ zirconium cost (per pound of contained uranium) with increasing per cent zirconium in the element. 


\begin{tabular}{|c|c|c|c|c|c|c|}
\hline & TABLE $\quad \mathbf{C}-1$ & & & & & \\
\hline FUEL ELEM & $\operatorname{ENT} \operatorname{cosT}$ & STIMATES & & & & \\
\hline & $\begin{array}{r}\text { Uraniu } \\
\text { Ts }\end{array}$ & $\begin{array}{l}\text { Alloy } 1 \\
\text { se Elemer }\end{array}$ & ate- & $\begin{array}{l}\text { Uranium } \\
\text { Type E1 }\end{array}$ & $\begin{array}{l}\text { Oxid } \\
\text { lement }\end{array}$ & \\
\hline & & Modified & & & & \\
\hline & $\begin{array}{c}\text { ANL } \\
\text { Concept }\end{array}$ & $\begin{array}{c}\text { ANL } \\
\text { Concept }\end{array}$ & EBWR & $\begin{array}{l}\text { G. E. } \\
\text { Dresden }\end{array}$ & PWR: & Hanford \\
\hline$d=\frac{\text { zirconium base price }}{\text { Fraction recovered }}(\$ / 1 b)$ & 80 & 80 & 80 & 80 & 120 & 80 \\
\hline$\%$ Zirconium (by weight) in element & 15 & 12 & 14 & 26 & 50 & 8.4 \\
\hline $\begin{array}{l}\text { Zirconium cost per pound of } \\
\text { uranium in element }(\$ / 1 b \quad 0)\end{array}$ & 14 & 10 & 13 & 29 & 120 & 8 \\
\hline $\begin{array}{l}\text { Niobium cost per pound of uranium } \\
\text { in element }(\$ / 1 \mathrm{~b} \quad \mathrm{U})\end{array}$ & 1.5 & 1.5 & 1.5 & 0 & 0 & 0 \\
\hline $\begin{array}{l}\text { Fabrication cost per pound of } \\
\text { uranium in element }(\$ / 1 b \text { U) }\end{array}$ & 19 & 14 & 18.5 & 41 & 50 & 19 \\
\hline $\begin{array}{c}\text { Total direct cost per pound of } \\
\text { uranium in element }(\$ / 1 \mathrm{~b} \mathrm{U})\end{array}$ & 34 & 26 & 33 & 70 & 170 & 27 \\
\hline
\end{tabular}

*Blanket 1 ement 


$$
103
$$

Figure $C-1$

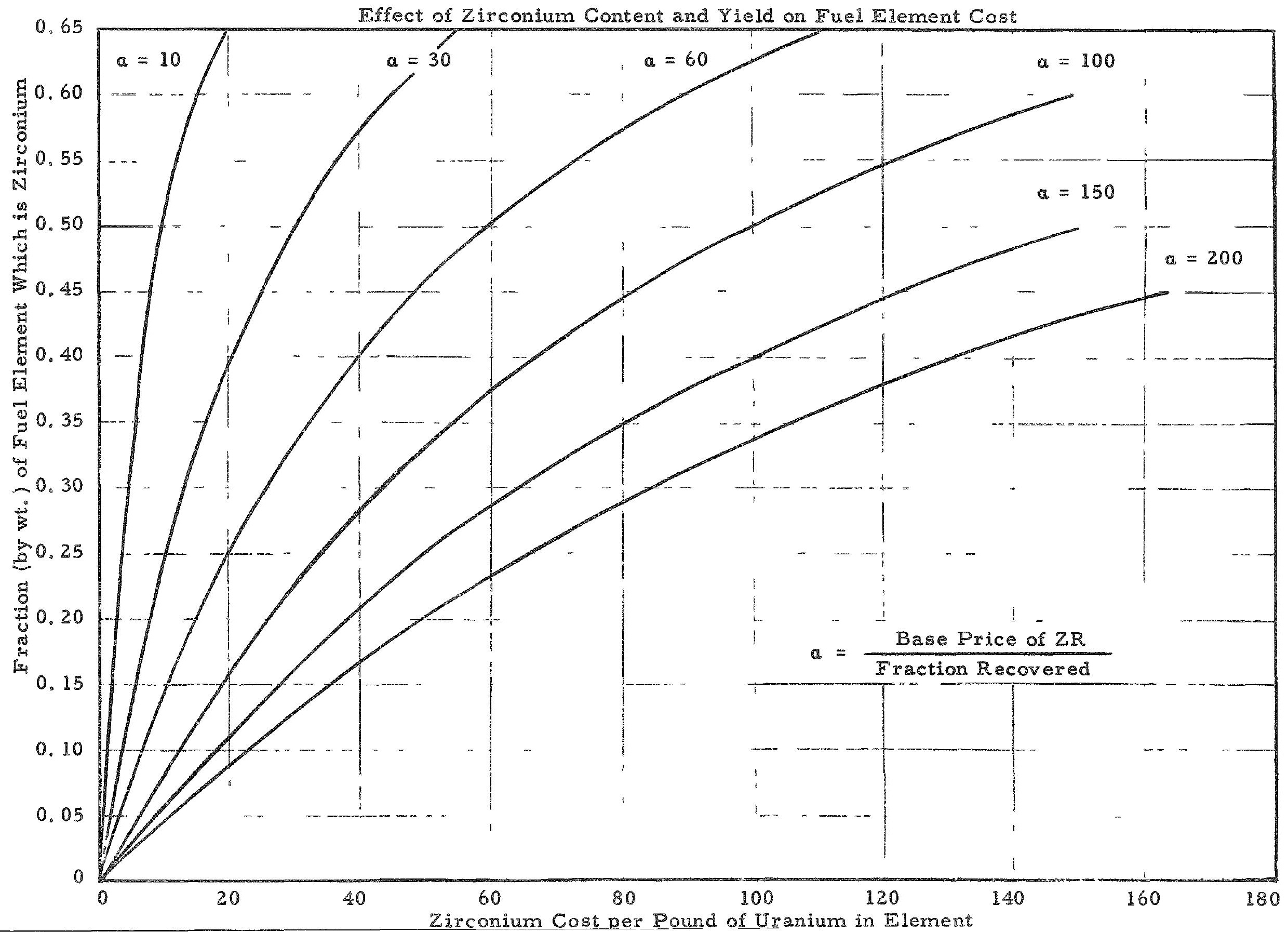




\section{Cos}

\section{Plate-Type Elements}

\section{a. Modified ANL Element}

Element $A$ is a modification of the Argonne element discussed below. The number of plates was reduced from nine to six, with an integrated meat width of 21 in. Instead of 29.78 in. The plate thickness was increased so that the total weight of uranium per element remained the same.

The direct cost* of the element has been estimated as follows:

$\begin{array}{lr}\text { Zirconium }(381 \mathrm{~b},+=\$ 80 / 1 \mathrm{~b}) & \$ 3,000 \\ \text { Niobium }(51 \mathrm{~b} \text { at } \$ 100 / 1 \mathrm{~b}) & 500 \\ \text { Fabricatior Cost } & 4,100 \\ \text { Total Direct Cost } & \$ 7,600\end{array}$

Weight of uxanium. $294 \mathrm{lb}$

Total direct cost per pound of ux anium $\$ 26$

b. ANL Element (Figure 3 ;

This element was proposed for heavy water reactor design by the Argonne National Laboratory, 5 It is made up of nine uranium-zirconium-niobium alloy plates clad with zurcaloy and held by spacers in a 6 -in, diameter by 12-ft zircaloy tube. The plates are produced by the "picture-frame" (rol1cladding) technique.

The direct cost of the element has been estimated as follows:

$\begin{array}{lr}\text { Zirconium }(551 \mathrm{~b},+=\$ 80 / 1 \mathrm{~b}) & \$ 4,400 \\ \text { Niobium }(51 \mathrm{~b} \text { at } \$ 100.1 \mathrm{~b}) & 500 \\ \text { Fabrication Cost } & 5,100 \\ \text { Total Direct Cost } & \$ 10,000\end{array}$

Weight of uranium $2941 \mathrm{~b}$

Total direct cost per pound of uranium $\$ 34$

Very rough estimates by commercial suppliers placed the direct cost of this element betweer $\$ 6,000$ and $\$ 18,000$. The value of $\$ 10,000$ is reasonable, sirce it falls within this range $3^{2}$.d is in good agreement with the commercial

* Direct cost includes everything but the cost of uranium as metal or v0 2 powder. 5 II. P. Iskenderian, et a1, Geneva Conference Paper P/Los Vol 3 (1955) 


\section{5}

cost (per pound of uranium) quoted for similar type elements (EBWR)。

c. EBWR Element

This element is made up of six uranium alloy, zircaloy-clad plates held between two side plates to form a box approximately $3-1 / 2$ in. square with 54 in. of active length

The direct cost of the element is estimated as follows:

$\begin{array}{lr}\text { Zirconium }(201 \mathrm{~b} . \%=\$ 80 / 1 \mathrm{~b}) & \$ 1,600 \\ \text { Niobium }(21 \mathrm{~b} \text { at } \$ 100 / 1 \mathrm{~b}) & 200 \\ \text { Fabrication cost } & 2,200 \\ \text { Total Direct cost } & \$ 4,000\end{array}$

Weight of uranium: $120 \mathrm{lb}$

Total direct cost per pound of uranium $\$ 33$

Two commercial suppliers quoted a direct cost of $\$ 4,000$ for this

element. ANL estimates a total direct cost (per pound of uranium) of $\$ 22.5$;

but it is believed that the somewhat higher figure is more realistic for commercial production.

\section{Oxide-In-Tube-Type Elements}

a. G.E. Dresden Element

This element is made up of $251 / 2 \mathrm{in}$ diameter zircaloy tubes, nine ft long, grouped in a square bundle and contained in a $3-3 / 4$ in. square zircaloy channel. Each tube is filled with $\mathrm{UO}_{2}$ pellets (1/2 in. diameter and $1 / 2$ in. long).

The direct cost of the element is estimated as follows:
Zirconium $(65 \mathrm{lb}, \gamma=\$ 80 / 1 \mathrm{~b})$
$\$ 5,200$
Fabrication cost
7,200
Total direct cost $\$ 12,400$
Weight of uranium: $177 \mathrm{Ib}$
Total direct cost per pound of
contained uranium
$\$ 70$

b. Hanford Element

A zircaloy jacketed uranium oxide element currently under development at Hanford contains only $8 \%$ zirconium. Details of this element have not 
been published, but it has been estimated that the total cost (excluding the cost of $\mathrm{vO}_{2}$ powder) will be about $\$ 27 / 1 \mathrm{~b}$ of contained uranium. The low cost is due to the low zirconium content (resulting from the unique design and the absence of a shroud or channe1) and the minimum amount of assembly work required

\section{c. FWR Blanket Element}

This element is made up of 120 tubes fastened into bundles about 6 in. square by $10 \mathrm{in.}$ long. Seven bundles are mechanically assembled end-to-end to form a 6-ft active 1ength. The tubes are filled with $\mathrm{UO}_{2}$ pellets

This element is considerably more expensive than the plate-type elements and the tube-type element discussed above. Fabrication has been estimated at $\$ 50 / \mathrm{lb}$ of contained uranium. The cost of zirconium is estimated to be $\$ 120 / 1 \mathrm{~b}$ of contained uranium The element is approximately $50 \%$ (by weight) zirconium compared with $24 \%$ for the $G . E$. element, $15 \%$ for the platetype elements, and $8 \%$ for the Hanford element. Practically all of the add 1 tional cost is due to the increased zirconium content which raises the total cost to $\$ 170 / 1 \mathrm{~b}$ of contained uranium, compared with considerably lower costs for the lower-zirconium designs

\section{Summaxy}

Table C-II summarizes the fuel element cost estimates given in the preceding sections.

$\mathrm{UO}_{2}$ powder and uranium metal costs are not included in the estimates The cost of producing $\mathrm{VO}_{2}$ ceramic parts from $\mathrm{vO}_{2}$ powder (about $\$ 5$ to $\$ 8 / 1 \mathrm{~b}$ of contained uranium as noted above) is included in the fabrication costs.

The zirconium cost per pound of zirconium in the finished elements (d) is about $\$ 120$ for the PWR design and about $\$ 80$ for the other elements. The higher PWR cost is due primarily to the low recovery of purchased zirconium. This relatively low recovery is probably a result of the complex design and the resulting difficulties in fabrication. A decrease in $\alpha$ might be justio fied in view of the recent decrease in sponge costs. The $\$ 120$ value, however, was calculated from official estimates (for the second PWR core) which pre sumably included a reduction in sponge price.

The fabrication cost and the total cost estimates correlate reasonably we11 with the per cent of zirconium in the elements. If the total direct 
cost (per pound of contained uranium) of each element is divided by the per cent zirconium, a fairly constant ratio, $2 \pm 0.5$ is obtained. The ratio of fabrication cost (per pound of contained uranium) to per cent zirconium is $1.6 \pm 0.6$ for all elements. These ratios point out the fact that fabrication costs and total costs are strongly dependent on the amount of zirconium handled

\section{Cost of Stainless Steel Elements}

If the uranium oxide elements were fabricated from stainless steel instead of zirconium, it would be reasonable to assume that:

1) $\mathrm{UO}_{2}$ fabrication costs ( $\$ 5 \approx \$ 8 / 1 \mathrm{~b}$ of uranium) would remain the same.

2) Stainless steel costs would be proportional to zirconium costs for each element.

3) Stainless steel fabrication ccsts would be proportional to zirconium fabrication costs for each element.

These assumptions and the following costs were used:

1) $\$ 7 / 1 b$ U for pellet fabrication cost.

2) An estimated proportionality factor of 10:1 for true metal costs per pound of metal in the element. (d for $s / \mathrm{s}=$ $10 \%$ of + for $\mathrm{Zr}$ )

3) An estimated proportionality factor of 10:1 for metal fabrio cation cost. This was based or direct comparative cost estimates for carrying out specific fabrication operations with zirconium as compared with stainless steel.

The total direct cost of stainless steel elements was thereby estimated as follows:

1) G.E. Dresden element $\$ 14 / 1 \mathrm{~b} U$

2) PWR element $\$ 24 / 1$ b U

3) Hanford element $\$ 10 / 1 b$ U

These costs for stainless steel elements are farther below the costs shown in Table C-II for zirconium elements than is commonly found. The main reason for this difference is that the zirconium costs of Table C-II are nearaterm estimates and are thus higher than predicted in the longer range. 
Information Sources on Fuel Elements

$$
13
$$

The following organizations were of invaluable assistance in compiling the above information on fuel-element costs:

$$
\text { Company }
$$

Metals and Controls Corporation

Sylvanla Electric Company

Argonne National Laboratory

G.E. Atomic Power Equipment Dept.

G.E. - Manford

Mallinckrodt Chemical Co.

Allegheny-Ludlum Steel Corp.

Wolverine Tube Company
Iype Data Obtained

Plate-type fuel elements

Plate type fuel elements

EBWR fuel elements

Dresden fuel elements

hanford oxide-type fuel

element concepts

Costs and technology of nuclear materials

Zirconium fabrication economics and technology

Zirconium fabrication economics and technology

Surmary of Over-all Fue1 Cycle Costs

Table C-III summarizes the fuel cycle costs used in this report. Especially for the cost of fuel and the inventory charge, no cost distinction was made between normal and slightly enriched fuel. In a power-reactor economy, it is believed that slightly enriched uranium will be almost as common an item in fuel-preparation plants as well normal uranium. The slight enrich ments present no criticality concern, and other operating problems are apparently no more difficult than for the normal type. Hence there seems no basis for a long range cost distinction in processing steps between normal and slightly enriched uranium. 


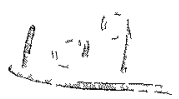

TABLE C-III

SUMMARY OF FUEL CONVERSION AND FABRICATION COSTS

Ship UF 6

$\mathrm{UF}_{6} \longrightarrow$ Meta1

Manufacture Fue1 Elements:

Element A

Element B

Ship Elements

Ship Irradiated Elements

Chemical Processing

Ship Uranium Nitrate **

UN $\longrightarrow$ UF $6 \%$

Ship UF $6 \%$

Sub-tota1 $\% * \%$

Element A

Element B
$\$ / \mathrm{kgm} \mathrm{U}$

\begin{tabular}{ll} 
Normal & Enriched \\
$\mathrm{U}$ & $\mathrm{U}$ \\
\hline
\end{tabular}

$\$$

$\$ 0.03$
$0.90 * \$ 1.50$

$\left\{\begin{array}{cc}57.00 & 57.00 \\ 75.00 & 75.00 \\ 0.03 & 0.03\end{array}\right\}$

$5.00 \quad 5.00$

$20.00 \quad 20.00$

$0.04 \quad 0.04$

$1.90 \quad 1.90$

$0.14 \quad 0.14$

$\$ 85.01 \quad 85.64$

$103.01 \quad 103.64$

* This figure is a correction factor necessary because the IBM 650 code used to compute the burn up cost treated normal uranium as UF 6 costing $\$ 39.10 / \mathrm{kgm}$, while actually normal uranium would be purchased from the $\mathrm{AEC}$ as the metal billet at $\$ 40.00 / \mathrm{kgm}$.

t\% At very long burnups, it is cheaper not to reclaim the Un 235 value left in spent fuel. In such cases these costs were omitted and the burn-up cost taken as the initial fuel cost.

To obtain the total per-kilogram fuel cycle cost, the following costs were added to this sub total: (a) the cost of converting plutonium nitrate to the metal, (b) the burn up cost after plutonium credit, and (c) the inventory carrying charge for uranium and non-nuclear core parts. 


\section{0}

APPENDIX D

\section{METHODS OF REACTOR PHISICS CALCULATIONS}

The diffusion theory methods used to calculate the core parameters in Tables D=I and D×II are those previously publisied by $J$. Cobb, et. al., of American-Standard. This method is dexcribed later. An exception to this method is the value of the fast multiplication factor, which was taken as 1.03 for 11 cases. The age, $\tau$, was calculated simply by applying a demsity correction to the age for room temperature $D_{2} 0,197$ in 2

For a11 cases considered the temperature of the water between the shrouds was assumed to be an average of $250^{\circ} \mathrm{F}$ 。

The isotopic change with exposure calculated from the following equations, using $\mathbb{N}_{25} / \mathbb{N}_{025}$ (the concentration of $\mathrm{U}-235$ atoms at some exposure divided by the initial concentration).

$$
\begin{aligned}
& \frac{d\left(N_{49} / N_{025}\right)}{d\left(N_{25} / N_{025}\right)}=-\frac{\left(N_{28} / N_{025}\right.}{\left(N_{25} / N_{025}\right.} \frac{c 28}{0+25} \cdot\left[C(1-p) \frac{25^{0} 49}{\sigma_{25}} e^{T B^{2}}\right.
\end{aligned}
$$

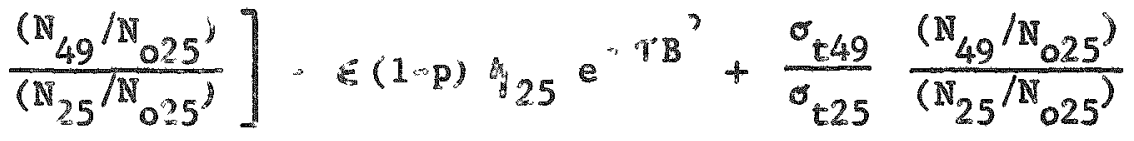

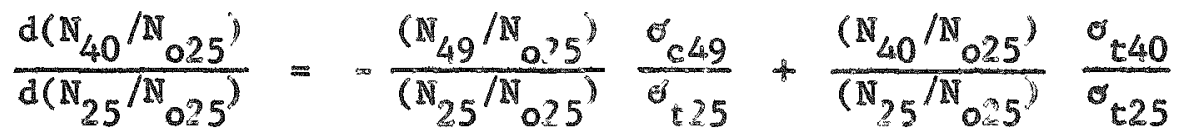

$$
\begin{aligned}
& \frac{d\left(N_{41} / N_{025}\right)}{d\left(N_{25} / N_{025}\right)}=\frac{\left(N_{40} / N_{025}\right)}{\left(N_{25} / N_{025}\right)} \frac{0_{440}}{0_{t 25}}+\frac{\left(N_{41} / N_{025}\right)}{\left(N_{25} / N_{025}\right)} \frac{041}{0_{225}}
\end{aligned}
$$

with the accumulated heat of fission produced given by

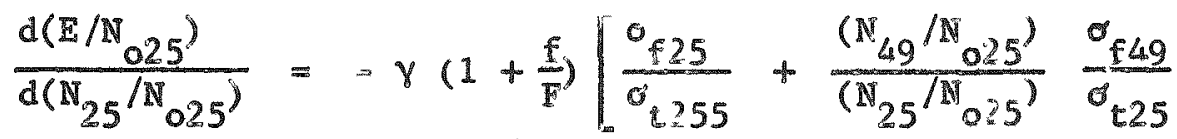

$$
\begin{aligned}
& \left.+\frac{\left(N_{41} / N_{025}\right)}{\left(N_{25} / N_{025}\right)} \frac{0_{141}}{25}\right]
\end{aligned}
$$

$\mathbb{N}_{25} \quad$ concentration of $U-235$

$\mathbb{N}_{28}$ concentration of $\mathrm{U} \sim 238$ (raken to be constant throughout exposure for isotope calculations)

(actual change was calculated approwimately) 


\section{$1 /$ \\ TABLE D-I}

FUEL ELEMENT A

\section{REACTOR PARAMETER SURVEY}

(Fresh Metal Values)

Fuel Element Type A: Six $2 r$ clad plates, each 0.17 in. thick. Total fuel plate width 21 in. Coolant channel width 0.35 in.

Fuel Element Type B: Nine $2 r$ clad plates, each 0.12 in. thick. Total fuel plate width 30 in. Coolant channel width $0.35 \mathrm{in}$.

\section{Case $\begin{gathered}\text { Density } \\ \text { Coolant } \\ \text { (gm/cc) }\end{gathered}$
Fuel Element A
richm
6" lettice,
$.35^{\prime \prime}$ channel width}

\begin{tabular}{|c|c|c|c|c|c|c|c|c|c|c|}
\hline 167 & .4 & 1.5 & 1.694708 & .9487382 & .5921009 & 0.9520002 & 25.65 & \multirow[t]{3}{*}{333.5} & \multicolumn{2}{|l|}{359.15} \\
\hline 168 & & 1.7 & 1.738048 & .9496795 & .5924663 & 0.9779181 & 23.37 & & \multicolumn{2}{|l|}{356.87} \\
\hline 169 & & 1.9 & 1.773862 & .9505867 & .5928328 & 0.9996404 & 21.46 & & \multicolumn{2}{|l|}{354.96} \\
\hline 177 & 66 & 1.5 & 1.694708 & 9485890 & .6730666 & 1.082009 & 22.78 & \multirow[t]{2}{*}{224.98} & 247.76 & 331 \\
\hline 178 & & 1.7 & 1.738048 & 9495355 & .6734432 & 1.111409 & 20.80 & & 245.78 & 453 \\
\hline 179 & & 19 & 1.773862 & .9504473 & 6738206 & 1.136036 & 19.15 & \multirow{4}{*}{157.65} & 244,13 & 557 \\
\hline 187 & .95 & 1.5 & 1.694708 & .9476514 & .7294091 & 1.171425 & 20.37 & & 178.02 & 963 \\
\hline 188 & & 1,7 & 1.738048 & 9485215 & .7297707 & 1.203082 & 18.65 & & 176.30 & 1152 \\
\hline 189 & & 1.9 & 1.773862 & .9493637 & .7301329 & 1229573 & 17.21 & & 174.86 & 1313 \\
\hline \multicolumn{11}{|c|}{$50^{\prime \prime}$ channe1 width } \\
\hline 227 & .4 & 1.5 & 1694708 & .9486844 & .5854995 & 0.9413327 & 25.87 & \multirow[t]{3}{*}{333.5} & 359.37 & \\
\hline 228 & & 1.7 & 1.738948 & 949 & 24 & 0.96 & 23.59 & & .09 & \\
\hline 229 & & 1.9 & 1.773862 & .9505326 & .5862261 & 0.9884438 & 21.68 & & 355.18 & \\
\hline 237 & .66 & 1.5 & 1.694708 & .9484988 & .6636337 & 1066744 & 23.08 & \multirow[t]{3}{*}{224.98} & 248.06 & 269 \\
\hline 238 & & 1.7 & 1.738048 & .9494452 & .66401105 & 1.095739 & 21.10 & & 246,08 & 389 \\
\hline 239 & & 1.9 & 1.773862 & .9503568 & .6643891 & 1.120028 & 19.46 & & 244.44 & 491 \\
\hline 247 & .95 & 1.5 & 1.694708 & .9475201 & .7181665 & 1.153210 & 20,73 & \multirow[t]{3}{*}{157.65} & 178.38 & 859 \\
\hline 248 & & 1.7 & 1.738048 & .9483901 & .7185326 & 1.184391 & 19.10 & & 176.66 & 1044 \\
\hline 249 & & 1.9 & 1.773862 & .9492320 & .7188994 & 1.210488 & 17.58 & & 175.23 & 1201 \\
\hline
\end{tabular}


(Continued)

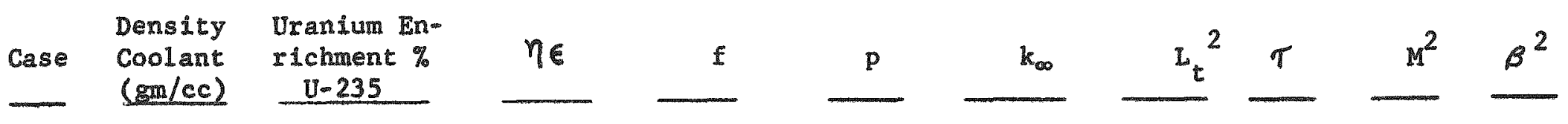

Fuel Element A

$7 "$ lattice,

$.35^{\prime \prime}$ channel width

\begin{tabular}{|c|c|c|}
\hline 161 & .4 & .71 \\
\hline 162 & & .8 \\
\hline 163 & & .9 \\
\hline 171 & .66 & .71 \\
\hline 172 & & .8 \\
\hline 173 & & .9 \\
\hline 181 & .95 & .71 \\
\hline 182 & & .8 \\
\hline $183.50^{\prime \prime}$ & channel & .9 \\
\hline $221^{\circ}$ & $=4$ & .71 \\
\hline 222 & & .8 \\
\hline 223 & & .9 \\
\hline 231 & .66 & .71 \\
\hline 232 & & .8 \\
\hline 233 & & .9 \\
\hline 241 & .95 & .71 \\
\hline 242 & & .8 \\
\hline a & & .9 \\
\hline
\end{tabular}

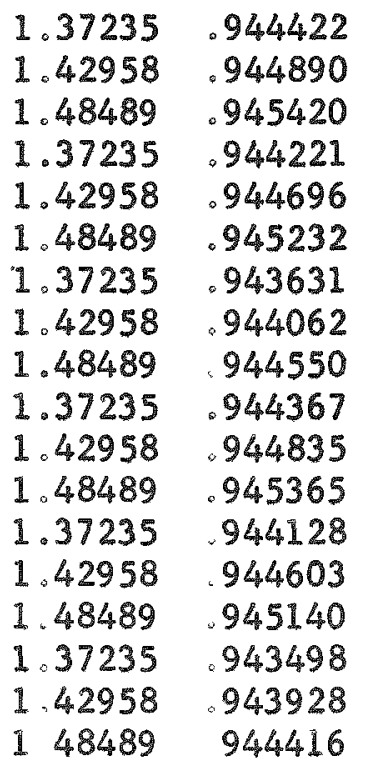

.736324

.736439

.787990

.788096

.788217

.824379

.824482

.824598

.732020

.732121

732236

781931

782037

782158

.817088

817192

.817309

$.35^{\prime \prime}$ channel width

$\begin{array}{lll}131 & .4 & .71 \\ 132 & & .8 \\ 133 & & .9 \\ 141 & .66 & .71 \\ 142 & & .8 \\ 143 & & .9 \\ 151 & .95 & .71\end{array}$

$\begin{array}{ll}1.37235 & .943971 \\ 1.42958 & 944465 \\ 1.48489 & .945020 \\ 1.37235 & .943753 \\ 1.42958 & .944254 \\ 1.48489 & .944816 \\ 1.37235 & .943145\end{array}$

.816468

.816540

816620

852732

.852808

852892

.878416
0.95420

0.99462

1.03385

1.02108

1.06434

1.10631

1.06756

1.11273

1.15654

0.948699

0.988888

1.02789

1.01313

1.05605

1.09770

1.05797

1. 10274

1. 14616

1.05770

1. 10248

1. 14592

1. 10442

1.15119

1.19656

1.13696
53.50

49.90

46.40

49.67

46.40

43.23

46.20

43.24

40.37

53.75

50.15

46.66

50.04

46.78

43.61

46.68

43.71

40.85

67.83

63.40

59.11

65.01

60.88

56,88

62.35
$241.39 \quad 294.88$

291.28

$287.79 \quad 117$

$\begin{array}{lll}189.98 & 239.65 & 087\end{array}$

$236.38 \quad 272$

$233.21 \quad 455$

$149.88 \quad 196.08 \quad 344$

193.12583

$190.25 \quad 822$

$241.39 \quad 295.14$

291.54 $288.05 \quad 096$

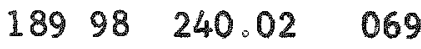
$236.75 \quad 236$ $23359 \quad 419$

$\begin{array}{lll}14988 & 196.56 \quad 386\end{array}$ $193.60 \quad 530$ $190.73 \quad 766$

$204.34 \quad 2722 \quad 211$ $267.75 \quad 382$ $263.45 \quad 553$

$173.25 \quad 238.26 \quad 438$ $234.13 \quad 645$ $230.13 \quad 854$

$146.27 \quad 20862 \quad 656$ 
(Continued)

\begin{tabular}{|c|c|c|c|c|c|c|c|c|c|c|}
\hline Case & $\begin{array}{l}\text { Density } \\
\text { Coolant } \\
(\mathrm{gm} / \mathrm{cc})\end{array}$ & $\begin{array}{l}\text { Uranium En- } \\
\text { richment \% } \\
\text { U-235 }\end{array}$ & $\eta \in$ & $\mathbf{f}$ & $\mathbf{p}$ & $k_{\infty}$ & $\mathrm{L}_{t}{ }^{2}$ & $T$ & $\mathbf{M}^{2}$ & $\beta^{2}$ \\
\hline \multicolumn{11}{|c|}{ Fuel Element $A$} \\
\hline \multicolumn{11}{|c|}{$\begin{array}{l}8^{\prime \prime} \text { lattice, } \\
.35^{\prime \prime} \text { channel width }\end{array}$} \\
\hline $\begin{array}{l}152 \\
153\end{array}$ & & $\begin{array}{l}.8 \\
.9\end{array}$ & $\begin{array}{l}1.42958 \\
1.48489\end{array}$ & $\begin{array}{l}.943602 \\
.944115\end{array}$ & $\begin{array}{l}.878489 \\
.878572\end{array}$ & $\begin{array}{l}1.18504 \\
1.23168\end{array}$ & $\begin{array}{l}58.51 \\
54.78\end{array}$ & & $\begin{array}{l}204.78 \\
201.05\end{array}$ & $\begin{array}{r}903 \\
1152\end{array}$ \\
\hline \multicolumn{11}{|c|}{$.5^{\prime \prime}$ channe1 width } \\
\hline 191 & .4 & .71 & 1.37235 & .943914 & .813539 & 1.05384 & 68.14 & 204.34 & 272.48 & 197 \\
\hline 192 & & .8 & 1.42958 & .944408 & .813609 & 1.09846 & 63.71 & & 268.05 & 367 \\
\hline 193 & & .9 & 1.48489 & .944964 & .813689 & 1.14174 & 59.42 & & 263.76 & 537 \\
\hline 201 & .66 & .71 & 1.37235 & .943658 & .848472 & 1.09880 & 65.47 & 173.25 & 238.73 & 413 \\
\hline 202 & & .8 & 1.42958 & .944159 & .848547 & 1.14533 & 61.35 & & 234.60 & 619 \\
\hline 203 & & .9 & 1.48489 & .944721 & .848631 & 1.19046 & 57.35 & & 230.60 & 825 \\
\hline 211 & .95 & .71 & 1.37235 & .943008 & .873256 & 1.13011 & 62.96 & 146.27 & 209.23 & 621 \\
\hline 212 & & .8 & 1.42958 & .943465 & .873331 & 1.17791 & 59.12 & & 205.40 & 866 \\
\hline 213 & & .9 & 1.48489 & .943977 & .873413 & 1.22426 & 55.40 & & 201.67 & 1112 \\
\hline \multicolumn{11}{|c|}{$\begin{array}{l}9^{\prime \prime} \text { lattice, } \\
.35^{\prime \prime} \text { chanme1 width }\end{array}$} \\
\hline 131 & .4 & .71 & 1.37235 & 943440 & .865962 & 1.12119 & 85.06 & 184,92 & 269.97 & 448 \\
\hline 132 & & .8 & 1.42958 & .943964 & .866015 & 1.16866 & 79.67 & & 264.59 & 637 \\
\hline 133 & & .9 & 1.48489 & .944548 & .866075 & 1.21471 & 74.45 & & 259.36 & 827 \\
\hline 141 & .66 & .71 & 1.37235 & .943202 & .892959 & 1.15585 & 83.16 & 163.67 & 264.83 & 631 \\
\hline 142 & & .8 & 1.42958 & 943733 & .893015 & 1.20480 & 78.05 & & 241.72 & 847 \\
\hline 143 & & .9 & 1.48489 & .944324 & .893077 & 1.25229 & 73.10 & & 236.77 & 1065 \\
\hline 151 & .95 & .71 & 1.37235 & 942574 & .912183 & 1.17995 & 81.34 & 144.03 & 225.37 & 798 \\
\hline 152 & & .8 & 1.42958 & .943061 & .912238 & 1.22986 & 76.50 & & 220.53 & 1042 \\
\hline 153 & & .9 & 1.48489 & .943602 & .912300 & 1.27826 & 71.81 & & 215.84 & 1289 \\
\hline \multicolumn{11}{|c|}{$5^{\prime \prime}$ channel width } \\
\hline 191 & .4 & .71 & 1.37235 & .943382 & .863788 & 1.11830 & 85.43 & 184.92 & 270.34 & 437 \\
\hline 192 & & .8 & 1.42958 & .943906 & .863840 & 1.16566 & 80.04 & & 264.95 & 625 \\
\hline 193 & & .9 & 1.48489 & .944489 & .863899 & 1.21559 & 74.82 & & 259.73 & 814 \\
\hline
\end{tabular}




$$
1 / 1
$$

- (Contimed)

\begin{tabular}{|c|c|c|c|c|c|c|c|c|c|c|}
\hline Case & $\begin{array}{l}\text { Density } \\
\text { Coolane } \\
\text { gmles }\end{array}$ & $\begin{array}{l}\text { Urandun 㗊 } \\
\text { I ichment \% } \\
\text { U-235 }\end{array}$ & $\begin{array}{l}m e \\
-\end{array}$ & $\begin{array}{r}1 \\
-\end{array}$ & $\underline{P}$ & $k_{\infty}$ & $\mathbb{L}_{\tau}^{2}$ & 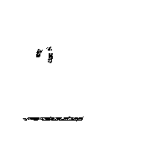 & $M^{2}$ & $\underbrace{2}$ \\
\hline \multicolumn{10}{|c|}{ Fuel Element $A$} & \\
\hline $\begin{array}{l}201 \\
202 \\
203 \\
211 \\
212 \\
213\end{array}$ & 95 & $\begin{array}{l}.71 \\
.8 \\
9 \\
71 \\
.8 \\
.9\end{array}$ & $\begin{array}{l}1.37235 \\
1.42958 \\
1.48489 \\
1.37235 \\
1.42958 \\
1.48489\end{array}$ & $\begin{array}{l}.943105 \\
.943635 \\
.944226 \\
.942432 \\
.942918 \\
.943460\end{array}$ & $\begin{array}{r}.889779 \\
.889834 \\
.889897 \\
.908314 \\
.908369 \\
.908431\end{array}$ & $\begin{array}{l}1.15161 \\
1.20039 \\
1.24770 \\
1.17476 \\
1.22446 \\
1.27265\end{array}$ & $\begin{array}{l}83.73 \\
78.62 \\
73.67 \\
82.11 \\
77.28 \\
72.59\end{array}$ & 163.67 & $\begin{array}{l}247.40 \\
24.2 .30 \\
237.34 \\
226.14 \\
221.31 \\
216.62\end{array}$ & $\begin{array}{r}612 \\
827 \\
1043 \\
772 \\
1014 \\
1258\end{array}$ \\
\hline
\end{tabular}




\section{TABLE D $-I I$}

FUEL ELEMENT B

\section{REACTOR PARAMETER SURVEY}

(Fresh Metal Values)

Fuel Element Type A: Six Zr clad plates, each 0.17 in. thick. Total fuel plate width 21 in. Coolant channel width 0.35 in.

Fuel Element Type B: Nine $2 r$ clad plates, each 0.12 in. thick. Total fuel plate width 30 in. Coolant channel width 0.35 in.

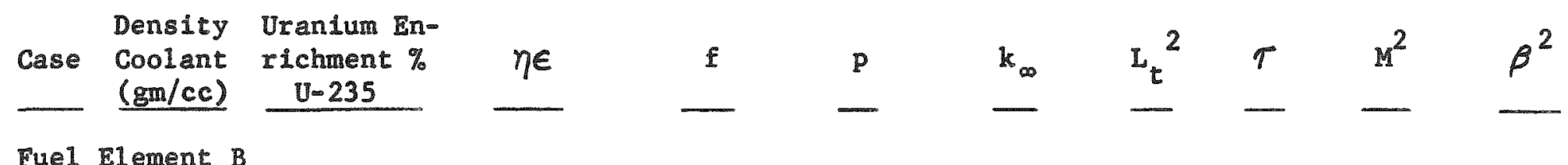

Fuel Element B

7" lattice,

$.35^{\prime \prime}$ channel width

$\begin{array}{lllllllllll}071 & .4 & .71 & 1.37235 & .9405549 & .701146 & 0.905019 & 64.79 & 384.3 & 449.1 \\ 072 & & .8 & 1.42958 & .9410831 & .701264 & 0.94345 & 60.40 & & 444.7 \\ 073 & & .9 & 1.48489 & .9416512 & .701369 & 0.98069 & 56.14 & & 440.4 \\ 081 & .66 & .71 & 1.37235 & .9403031 & .75786 & 0.97796 & 54.53 & 241.3 & 295.8 & \\ 082 & & .8 & 1.42958 & .9408425 & .757979 & 1.01949 & 50.90 & & 292.2 \\ 083 & & .9 & 1.48489 & .9414213 & .758118 & 1.05978 & 47.38 & & 288.7 & 207.1 \\ 091 & .95 & .71 & 1.37235 & .939372 & .796955 & 1.02739 & 46.59 & 154.53 & 201.1 & 136.2 \\ 092 & & .8 & 1.42958 & .939824 & .797074 & 1.07091 & 43.55 & & 198.0 & 358.1 \\ 093 & & .9 & 1.48489 & .940303 & .797207 & 1.11310 & 40.60 & & 195.1 & 579.7 \\ 074 & .4 & 1.0 & 1.532316 & .9421932 & .7015326 & 1.012829 & 52.48 & 384.3 & 436.78 & 29 \\ 075 & & 1.1 & 1.573436 & .9427130 & .7016672 & 1.040782 & 49.30 & & 433.60 & 94 \\ 076 & & 1.3 & 1.641192 & .9436961 & .7019368 & 1.087150 & 44.03 & & 428.33 & 203 \\ 084 & .66 & 1.0 & 1.532316 & .9419726 & .7582564 & 1.094467 & 44.36 & 241.3 & 285.66 & 330 \\ 085 & & 1.1 & 1.573436 & .9425005 & .7583949 & 1.124672 & 41.73 & & 283.03 & 440 \\ 086 & & 1.3 & 1.641192 & .9434972 & .7586722 & 1.174774 & 37.38 & & 278.68 & 627 \\ 094 & .95 & 1.01 & 1.532316 & .9407546 & .7973412 & 1.149394 & 38.06 & 154.53 & 192.59 & 776 \\ 095 & & 1.1 & 1.573436 & .9411833 & .7974753 & 1.180975 & 35.86 & & 190.39 & 951 \\ 096 & & 1.3 & 1.641192 & .9419855 & .7977436 & 1.233295 & 32.20 & & 186.73 & 1249\end{array}$


(Continued)

Case $\begin{gathered}\begin{array}{c}\text { Density } \\ \text { Coolant } \\ \text { (gm/cc) }\end{array} \\ \text { richment } \% \\ \mathrm{U} 235\end{gathered}$

Fuel Element B

$8^{\prime \prime}$ lattice,

$.35^{\prime \prime}$ channel width

\begin{tabular}{|c|c|c|c|c|c|c|c|c|c|c|}
\hline 011 & .4 & .71 & 1.37235 & .9401107 & .793048 & 1.02316 & 75.66 & 277.2 & 352.9 & 65.6 \\
\hline 012 & & .8 & 1.42958 & .9406655 & .793130 & 1.066567 & 70.67 & & 347.9 & 191.3 \\
\hline 013 & & .9 & 1.48489 & .9412593 & .793222 & 1.108659 & 65.82 & & 343.0 & 316.8 \\
\hline 021 & .66 & .71 & 1.37235 & .9398406 & .832395 & 1.07362 & 68.08 & 204.57 & 272.7 & 269.9 \\
\hline 022 & & .8 & 1.42958 & .9404066 & .832479 & 1.11918 & 63.70 & & 268.3 & 444.2 \\
\hline 023 & & .9 & 1.48489 & 9410112 & .832576 & 1.16336 & 59.44 & & 264.0 & 618.8 \\
\hline 031 & .95 & .71 & 1.37235 & .938889 & .859726 & 1.10774 & 61.57 & 152.77 & 214.3 & 502.8 \\
\hline 032 & & .8 & 1.42958 & .939368 & .859810 & 1.15464 & 57.71 & & 210.5 & 734.6 \\
\hline 033 & & .9 & 1.48489 & .939873 & .859903 & 1.200081 & 53.96 & & 206.7 & 967.9 \\
\hline 014 & .4 & 1.0 & 1.532316 & .9418234 & .7933157 & 1.144890 & 61.65 & 277.2 & 338.9 & 427 \\
\hline 015 & & 1.1 & 1.573436 & .9423624 & .7934087 & 1.176424 & 58.03 & & 335.23 & 526 \\
\hline 016 & & 1.3 & I. 641192 & .9433775 & .7935950 & 1.228694 & 52.03 & & 329.23 & 694 \\
\hline 024 & .66 & 1.0 & 1.532316 & .9415847 & .8326730 & 1.201385 & 55.79 & 204.57 & 260.36 & 774 \\
\hline 025 & & 1.1 & 1.573436 & .9421319 & .8327696 & 1.234485 & 52.60 & & 257.17 & 912 \\
\hline 026 & & 1.3 & 1.641192 & .9431604 & .8329628 & 1.289349 & 47.33 & & 251.90 & 1149 \\
\hline 034 & .95 & 1.0 & 1.532316 & .9403467 & .8599974 & 1.239177 & 50.73 & 152.77 & 203.50 & 1175 \\
\hline 035 & & 1.1 & 1.573436 & .9407949 & .8600914 & 1.273177 & 47.93 & & 200.70 & 1361 \\
\hline 036 & & 1.3 & 1.641192 & .9416294 & .8602797 & 1.329472 & 43.27 & & 196.04 & 1681 \\
\hline
\end{tabular}


TABLE D-III

GEOMETRICAL BUCKLINGS FOR VARIOUS CORE SIZES: RIGHT CYLINDERS

\begin{tabular}{c} 
Diameter \\
Active \\
Core \\
\hline
\end{tabular}

$90^{\prime}$

$95^{\prime}$

$100^{\prime}$

$10.5^{\prime}$

$110^{8}$

$11.5^{\prime}$

$12.0^{\prime}$

$12.5^{\prime}$

$130^{\prime \prime}$
$+2.2 \mathrm{ft}$

Reflector

Saving

$11.2^{\prime}$

$11.7^{\prime}$

$12.2^{\prime}$

$12.7^{\circ}$

$13.2^{\prime}$

$13.7^{\circ}$

$14.2^{\prime}$

14.71

$15.2^{\circ}$ $\left(10^{6}\right) \mathrm{cm}^{-2}$ Geometrica1

Buckling

283

259.5

238.7

220.3

203.9

189.3

176.2

164.4

153.8 


$\begin{array}{ll}N_{49} & \text { concentration of } \mathrm{Pu}-239 \\ \mathrm{~N}_{40} & \text { concentration of } \mathrm{Pu}-240 \\ \mathrm{~N}_{41} & \text { concentration of } \mathrm{Pu}-241\end{array}$

In equations that follow $\mathrm{N}$ will be the isotopic concentration with type indicated by subscript

$\sigma_{t} \quad$ is the total cross section (fission plus capture)

$\sigma_{c} \quad$ is the capture cross section

$\sigma_{\mathrm{f}} \quad$ is the fission cross sections

$V_{\mathrm{XX}} \quad$ is the neutrons produced per fission

$\eta_{25}$ is the neutrons produced per neutron absorbed in U-235

E is MWD/T with $\gamma$ chosen appropriately

$\mathrm{f} / \mathrm{F}$ ratio of fast to thermal fissions

$e^{-T B^{2}}$ is the fast leakage escape probability, with $T$ taken as the age to thermal energy

$\eta f$ was calculated from

$$
\begin{aligned}
& \eta \mathrm{f}=\left(\frac{\mathbb{N}_{25}}{N_{025}} \mathbb{N}_{25} \frac{\sigma_{E 25}}{\sigma_{t 25}}+\frac{N_{49}}{N_{025}} V_{49} \frac{\sigma_{f 49}}{\sigma_{t 25}}+\frac{N_{41}}{N_{025}}\right. \\
& \left.V_{41} \frac{\sigma_{f 41}}{\sigma_{t 25}}\right)
\end{aligned}
$$

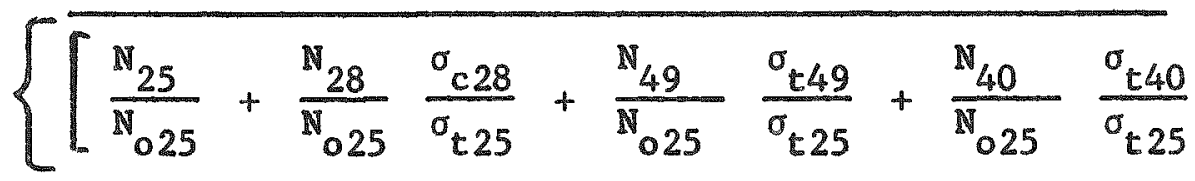

$$
\begin{aligned}
& +\frac{\mathbb{N}_{41}}{\mathbb{N}_{025}} \frac{\sigma_{t 41}}{\sigma_{t 25}}+\frac{\mathbb{N}_{f \cdot P}}{\mathbb{N}_{025}} \frac{\sigma_{t f \cdot P}}{\sigma_{t 25}}+\frac{\mathbb{N}_{\text {sm }}}{\mathbb{N}_{025}} \frac{\sigma_{t s m}}{\sigma_{t 25}}+\frac{\mathbb{N}_{x e}}{\mathbb{N}_{025}} \frac{\sigma_{t x e}}{\sigma_{t 25}} \\
& \left.+\frac{\mathbb{N}_{\text {a11oy }}}{\mathbb{N}_{025}} \frac{\sigma_{\text {a11oy }}}{\sigma_{t 25}}\right]+\frac{\mathbb{N}_{c 1 a d}}{\mathbb{N}_{025}} \frac{\sigma_{t c 1 a d}}{\sigma_{t 25}} \frac{\bar{\phi}_{c 1 a d}}{\bar{\phi}_{\text {meta1 }}}+\frac{\mathbb{N}_{\text {moderator }}}{\mathbb{N}_{025}} \\
& \left.\frac{\sigma_{t \text { moderator }}}{\sigma_{t 25}} \frac{\bar{\phi}_{\text {moderator }}}{\bar{\phi}_{\text {metal }}}\right\}
\end{aligned}
$$

$\mathbb{N}_{\text {alloy }} \mathbb{N}_{\text {clad }}, \mathbb{N}_{\text {moderator }}$ are the alloy, cladding, and moderator atom associated with the metal. The average fluxes, $\bar{\phi} / \bar{\phi}$ metal, were taken from the calculations performed for Tables $D-I$ and $D-I I$. 
The xenon and samarium concentrations, $\mathrm{N}_{\mathrm{Xe}}$ and $\mathrm{N}_{\mathrm{Sm}}$, are equilibrium values calculated in the ordinary manner. These equilibrium values were taken throughout the entire exposure period to be those resulting from Un-235 at its initial concentration.

The power densities employed to calculate the equilibrium Xe poisoning were?

\begin{tabular}{lccc} 
& $\begin{array}{c}\text { Coolant } \\
\text { Density }\end{array}$ & \multicolumn{2}{c}{ Specific Power (MW/Metric Ton) } \\
Element A & .4 & 16.5 & Pressurized \\
& .66 & 16.5 & 18.9 \\
Element B & .95 & & \\
& .4 & 25.4 & 37.9 \\
& .66 & 25.4 &
\end{tabular}

These power densities have subsequently been changed to:

$\begin{array}{ll}\text { Element A } & 11.12 \mathrm{MW} / \text { Metric Ton } \\ \text { Element B } & 15.98 \mathrm{MW} / \text { Metric Ton }\end{array}$

The effect of this change in equilibrium xenon concentration on buckling and hence upon allowable exposure is negligible. This is not true of the xenon transient, of which about $80 \%$ of the magnitude is directly proportional to the power density.

These calculations consider the flus to be uniform over the entire reactor.

$N_{f . p}$. is the number of fission products produced taken to be twice the number of atoms fissioned.

of.p. is half the average cross section of a fission product paix. Due to the neutron capture by fission products, this effective cross section changes with exposure. Again, as in the case of Xe and $\mathrm{Sm}$, this effective cross section is taken to be that of $U=235$ fission. 1

I J, W Webster, "The Low Cross-Section Fission Product Poison," ID0-16100. 


$$
1
$$

The thermal diffusion length was considered to be constant during exposure, as were the reactor parameters $p_{8} \epsilon$, and $T$.

The $\mathrm{Pu}$ credit was calculated on the basis of $\$ 12 / \mathrm{gram}$ of $\mathbb{P u}$ present at the end of exposure regardless of isotopic content.

The value as UF $_{6}$ of the uranium was calculated from the expression for the infinite cascade:

$$
c_{p}(x)=\left[\frac{\left(x-x_{0}\right)\left(1-2 x_{0}\right)}{x_{0}\left(1-x_{0}\right)}+(1-2 x) \ln \frac{x_{0}(1-x)}{x\left(1-x_{0}\right)}\right] c_{\Delta}
$$

where $\mathrm{x}$ is the wt \% $\mathrm{y}-235$ of the metal whose value is to be calculated, $x_{0}$ is the tails concentration taken as .0022 weight fraction U-235, and $\mathrm{C}_{\Delta}$ is the cost of separative work taken as $\$ 3725 / \mathrm{kg}$.

\section{Summary of Cross Sections and other Physical constants}

Thermal Values (Maxwellian average)

$$
\begin{aligned}
& \sigma_{\mathrm{c} 28}=2225 \text { barns } \\
& \sigma_{\mathrm{t} 25}=546.6 \text { barns } \\
& \sigma_{\mathrm{F} 25}=4624 \text { barns } \\
& V_{25}=2.46 \\
& \sigma_{\text {teU }}=8.3 \text { barns } \\
& \sigma_{t 49}=1292 \text { barns (150 barns added for resonance) } \\
& \sigma_{\text {f49 }}=822 \text { barns (150 barns added for resonance) } \\
& V_{49}=288 \\
& \sigma_{t 40}=523 \text { barns (100 barns added for resonance) } \\
& \sigma_{f 41}=1000 \text { barns } \\
& { }^{\circ} 41-400 \text { barms } \\
& 41=3.3 \\
& \sigma_{\mathrm{Xe}} 284\left(10^{6}\right) \text { barns } \\
& { }^{\sigma_{S n}}=53\left(10^{4}\right) \text { barns } \\
& \sigma_{c Z r}=.146 \text { barns } \\
& \sigma_{\mathrm{sZx}}=6.2 \mathrm{barns} \\
& \sigma_{\text {trze }}=6.2 \text { barms } \\
& \sigma_{\mathrm{cNb}}=890 \text { barns } \\
& \sigma_{\mathrm{sNb}}=6 \text { barns } \\
& \mathrm{g}_{2} \mathrm{O}=906\left(10^{-3}\right) \text { barns } \\
& 0_{\text {maxd }} 0=11.28 \text { baxms }
\end{aligned}
$$


Resonance Values

$$
\begin{aligned}
& \sigma_{\mathrm{SD}_{2} 0}=10.5 \text { barns } \\
& \sigma_{\mathrm{trD}_{2} \mathrm{O}}=8.109 \text { barms } \\
& \xi_{D_{2}}=.506 \text { (average change in the logartthm of the energy upon } \\
& \sigma_{\mathrm{sZr}}=6.2 \text { barns } \\
& \sigma_{\text {tr. }}=6.2 \text { barns } \\
& \xi_{2 x}=0.0218 \\
& \sigma_{\text {trU }}=8.0 \text { barns } \\
& \sigma_{\text {eff }}=7.5\left(1+3.4 \frac{s_{\text {eff }}}{M}\right)
\end{aligned}
$$

other Values

$$
\begin{aligned}
& \mathrm{N}_{U} \quad=0.0478\left(10^{24}\right) \text { uranium nucle1 } / \mathrm{cm}^{3} \\
& \mathrm{~N}_{\mathrm{Zr}}=0.04225\left(10^{24}\right) \text { zirconium nuclei } / \mathrm{cm}^{3} \\
& \mathrm{~N}_{\mathrm{Nb}}=0.05445\left(10^{24}\right) \text { niobium nuclei } / \mathrm{cm}^{3} \\
& \mathrm{~N}_{2} 0=0.03346\left(10^{24}\right) \text { deuterium oxide nuclei } / \mathrm{cm}^{3} \text { (at density } 1.1 \mathrm{grams} / \mathrm{cm}^{3} \text { ) } \\
& \gamma^{2}=0.943 \mathrm{MWD} / \operatorname{gran} \mathrm{U}^{235} \text { fissioned } \\
& f / F=.10 \text { fast fissions/thermal fission } \\
& \lambda_{x e}=2.1\left(10^{-5}\right) \mathrm{sec}^{-1} \text { Xenon decay constant }
\end{aligned}
$$

\section{Description of $4 F$ Code}

47 is a code for the Datatron which, by means of diffusion theory calcu lations with a few simple modifications of the recipe type, computes the four factors, $\epsilon, \eta$, f and $p$, the infinite multiplication factor and most of the twogroup constants for a homogeneous core equivalent to a heterogeneous lattice. Options are provided for five geometries, in three of which provision is made for moderation in two distinct regions. The possible geometries are shom in the figure following. 


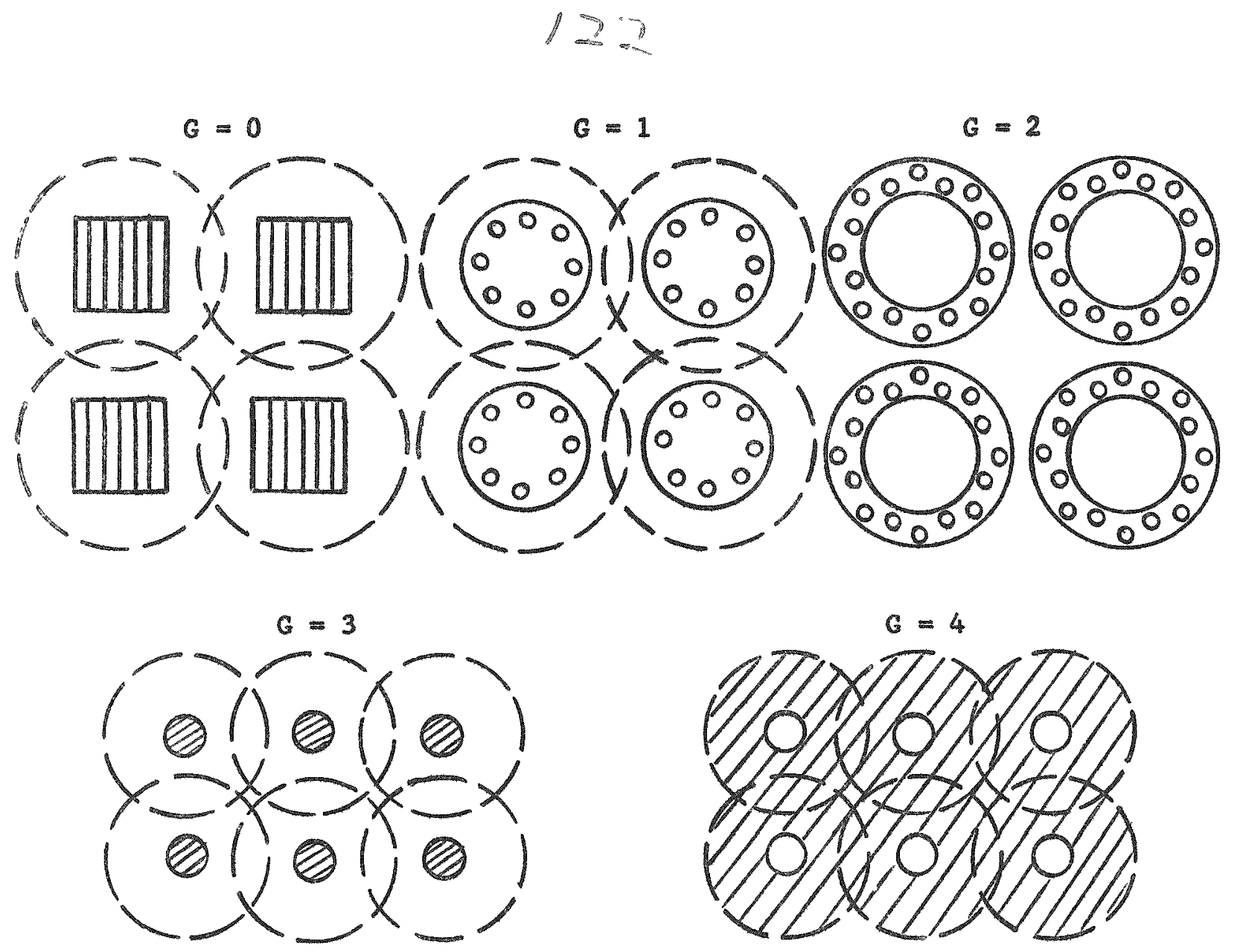

With a little imagination, a few more useful geometries to which the 4 F code can be applied by minor modification or in its present form can probably be found,

The purpose of the $4 F$ code is to provide an approximate relative computation of lattice parameters for use in the preliminary comparative study of reactor designs. The calculation takes on the order of a minute of machine time per case.

\section{Calculations}

The equations below are computed by the code in the order given and the results stored in the memory locations.

$$
\begin{aligned}
& t_{t}^{\sigma_{1}^{U}}=\eta^{25} t_{a}^{25} N^{25} \\
& t_{a}^{28}=\sigma_{a}^{28} \sqrt{\frac{\pi}{2} \frac{T 0}{T}}\left(1-N^{25}\right) \\
& \eta=\frac{t^{V} t^{\mathscr{\sigma}}{ }^{U}}{\left(N^{25} t_{a}^{\sigma^{25}}\right)+t_{a}^{\mathscr{C}^{28}}}
\end{aligned}
$$


123

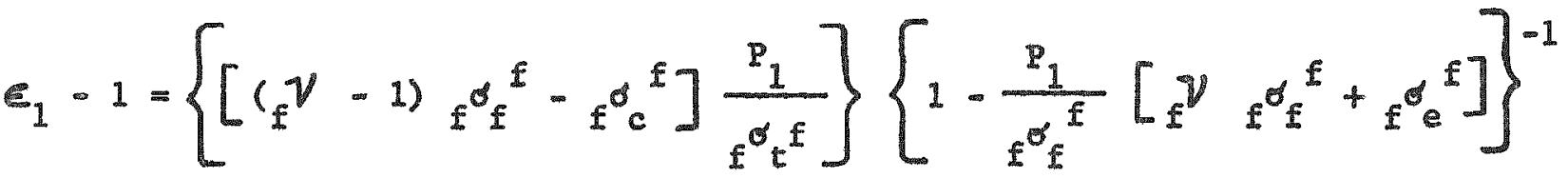

$$
\begin{aligned}
& \mathrm{P}_{2}=\Omega \mathrm{e}^{-2 \Sigma \mathrm{x}} \\
& \epsilon=1+\left(\epsilon_{1}-1\right)\left(1+P_{2}\right) \\
& t_{a}^{b^{a 1}}={ }_{0}^{b_{a}^{a 1}} \sqrt{\frac{\pi T_{0}}{2 T}} \\
& t_{a}^{c 1}=\sigma_{a}^{\sigma} c 1 \sqrt{\frac{\pi T}{2 T}} \\
& t_{a}^{s_{0}}=\sigma_{0}^{s_{0}} \sqrt{\frac{\pi T_{0}}{2 T}} \\
& t_{a}^{\sigma^{m_{1}}}=\sigma_{a}^{\sigma_{1}} \sqrt{\frac{\pi T_{0}}{2 T}} \\
& t_{a}^{\sigma^{m_{0}}}=\sigma^{\sigma}{ }_{a}^{m_{0}} \sqrt{\frac{\pi T}{2 T}} \\
& \alpha=\frac{\mathrm{N}^{25}}{1-0.01276 \mathrm{~N}^{25}} \\
& t_{f}^{\sigma 25}=\frac{q^{25} t^{6 a^{25}}}{t^{\nu}} \\
& \frac{N^{X e}}{N^{25}}=\frac{P \times 3.82 \times 10^{-2}}{\alpha+\frac{t_{a}^{\sigma_{a}^{X e}}}{t_{f}^{\sigma_{f}^{25}}} P \times 6.474 \times 10^{-2}} \\
& \frac{N^{S m}}{N^{25}}=\frac{.014 \times t_{t}^{\sigma_{f}^{25}}}{t^{\sigma}{ }^{S m}}
\end{aligned}
$$

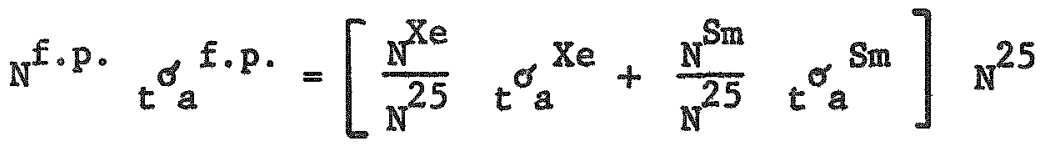

$$
\begin{aligned}
& t_{a}^{f}=t_{a}^{\sigma^{28}}+t^{\sigma} a^{25} N^{25}+t_{a}^{\sigma^{a l}} N^{a 1}+N^{f \cdot p} \cdot t_{a}^{f} f \cdot p \cdot \\
& P^{f}=\left\{\begin{array}{l}
p^{f} \text { (input) if } P^{f} \text { (input) is not equal to } 0 . \\
{\left[\frac{238-3 N^{25}}{P^{\mathbb{J}}}+\frac{\mathbb{N}^{a l} A^{a l}}{p^{a I}}\right]^{-1} \quad \mathbb{A}^{f} \text { if } P^{f} \text { (input) is equal to } 0 .}
\end{array}\right\}
\end{aligned}
$$

-D 7 - 
124

$$
\begin{aligned}
& A^{2}=238-3 N^{25}+N^{21} A^{21} \\
& t^{E}=t_{a}^{f} \frac{e^{f} x^{f .6023}}{A^{f}} \\
& t_{a}^{c 1}=t_{a}^{c l} \frac{p^{c 1} x .6023}{A^{c 1}} \\
& t_{a}^{\Sigma_{a}^{\text {So }}}=t_{a}^{\text {So }} \frac{e^{\text {So }} x^{.6023}}{A^{\text {So }}} \\
& t^{\Sigma}{ }^{m_{1}}=t_{a}^{m_{1}} \frac{e^{m_{1}} .6023}{A^{m_{1}}} \\
& t^{\Sigma^{m_{0}}}=e_{a}^{m_{0}} \frac{e^{m_{0}} 8.6023}{A^{m_{0}}} \\
& t^{\Sigma_{t r}^{m_{0}}}=t^{d} t r \frac{m^{m_{0}} \frac{m_{0} .6023}{m_{0}}}{A^{m_{0}}}
\end{aligned}
$$

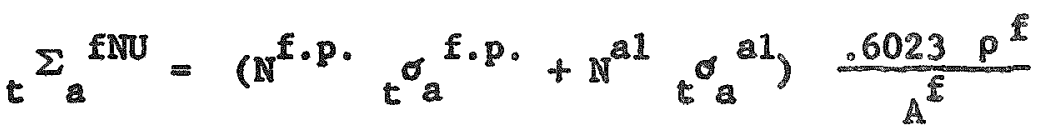

$$
\begin{aligned}
& t^{K^{m_{0}}}=\sqrt{3 t^{\Sigma m_{0}} t^{\Sigma m_{0}^{m_{0}}}}
\end{aligned}
$$

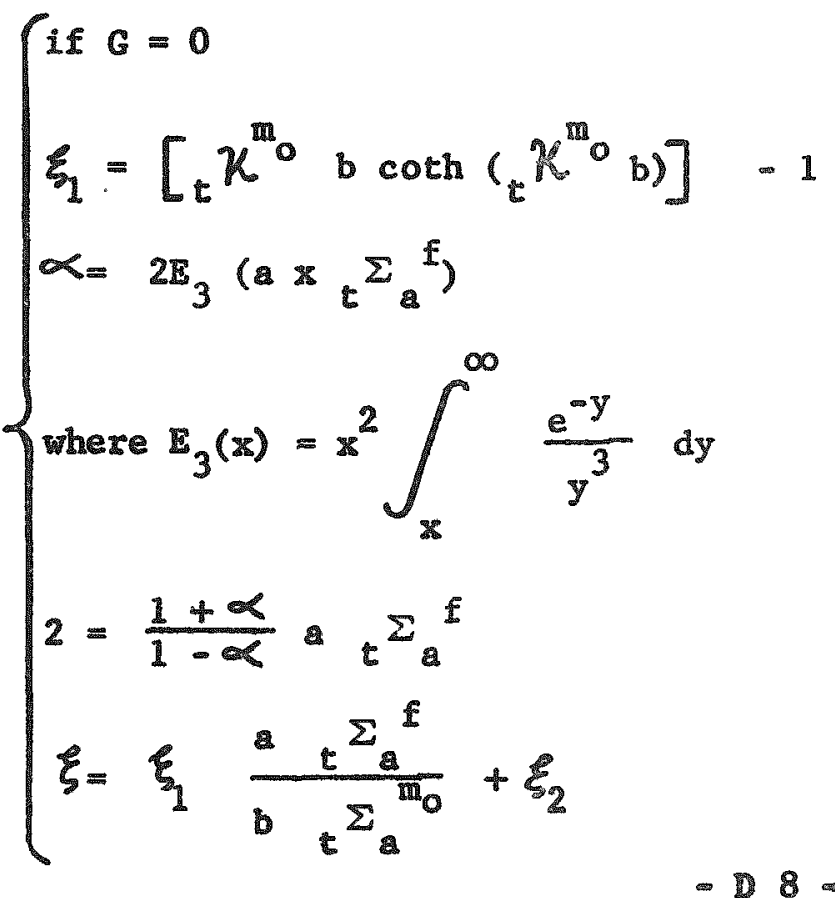




$$
\begin{aligned}
& \left\{\begin{array}{l}
\text { If } G=1,2,3 \text {, or } 4 \\
\text { Use cylindrical utilization subroutine with following assigaments. }
\end{array}\right. \\
& \frac{c}{K_{0}} \quad \frac{1,2 \text {, and } 3}{t^{K_{0}^{m_{0}}}} \frac{4}{\sqrt{t^{\Sigma_{a}^{f} / D^{f}}}} \\
& \text { Ro b a } \\
& \text { Ri } \quad \sqrt{\Sigma_{t}^{E} / t^{D^{f}}} \quad k^{k^{m_{0}}} \\
& \text { Ri a } \\
& \text { Di } \\
& t^{D^{f}}=\left(3_{t} \Sigma_{t r}^{f}\right)^{-1} \quad t^{D^{m}} \\
& \Sigma_{a}^{\Sigma_{a}} \quad \varepsilon_{2}^{m_{0}^{m_{0}}} \\
& t^{m_{0}} \\
& t^{D^{f}}=\left(3_{t} \Sigma_{t t^{\prime}}\right)^{-1} \\
& \Sigma_{a_{0}} \quad t^{\Sigma_{a}^{m_{0}}} \quad t^{\Sigma t} \\
& \text { si } 001 \\
& \text { So } \quad 1 \quad 0 \\
& \xi^{\prime}=\frac{\mathrm{Ri}^{2}}{\mathrm{R}_{0}^{2}} \frac{\Sigma_{\mathrm{ai}}}{\Sigma_{\mathrm{a}_{0}}}\left(\frac{1}{\mathrm{f}_{\mathrm{i}}}-1\right) \\
& \text { for } G=1,2 \text {, or } 3 \quad \xi \longrightarrow \xi \\
& \operatorname{for} G=4 \frac{1}{\xi^{\prime}} \longrightarrow \xi \\
& \mathrm{N}=\frac{\mathrm{v}^{\mathrm{U}}}{\mathrm{s}}+\mathrm{v}^{\mathrm{m}} \mathrm{o}+\frac{1}{2}\left(1+\frac{1}{\mathrm{~s}}\right) \mathrm{v}^{\mathrm{cl}}+\mathrm{v}^{\mathrm{so}}
\end{aligned}
$$

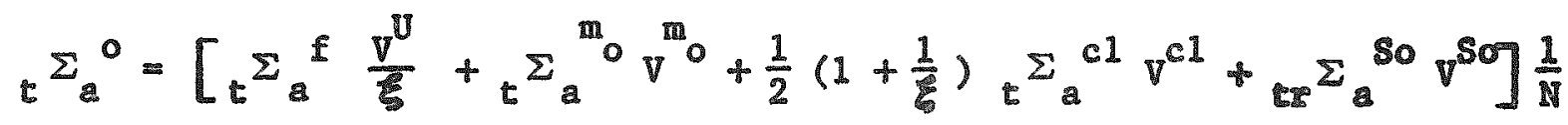

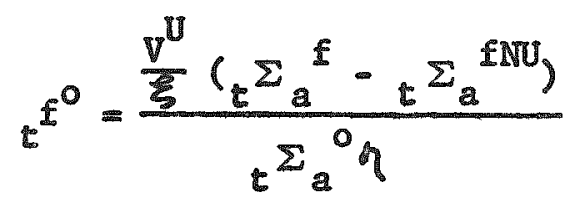

$$
\begin{aligned}
& t_{t r}^{\Sigma^{a l}}=t_{t r}^{a l} \frac{.6023}{\mathbb{A}^{f}} \rho f \\
& \text { - D } 9 \text { - }
\end{aligned}
$$




$$
\begin{aligned}
& t^{\Sigma}{ }_{t r}^{c 1}=t_{t r}^{c 1} \frac{.6023}{A^{c 1}} p^{c 1} \\
& t_{t r}^{\Sigma}=t_{t r}^{\sigma} \frac{.6023}{A^{S O}} \rho^{\text {So }} \\
& t^{\Sigma_{t r} m_{1}}=t^{\sigma}{ }_{t r}^{m_{1}} \frac{.6023}{m_{1}} \rho^{m_{1}}
\end{aligned}
$$

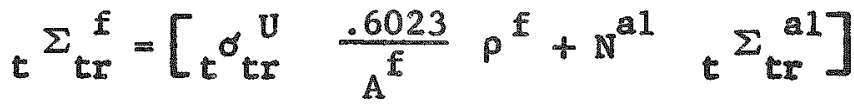

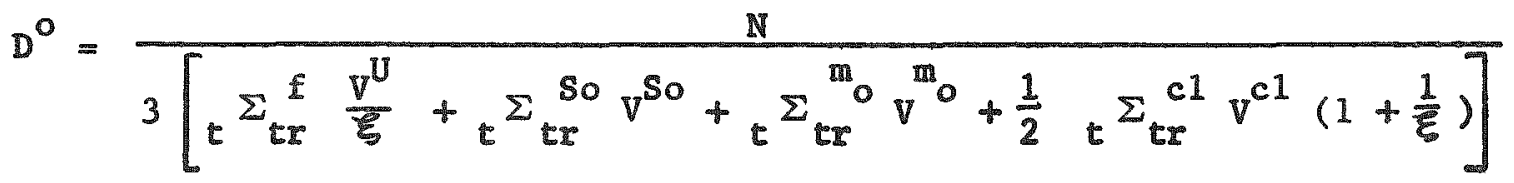

$$
\begin{aligned}
& K^{0}=\sqrt{\Sigma_{a}^{\Sigma^{0} / D^{0}}} \\
& t_{t r}^{\Sigma_{t r}^{1}}=t^{\Sigma_{t r}} \mathrm{~m}_{1}\left(1-v^{s_{1}}\right)+t_{t r}^{\sigma_{1}} s_{1} \frac{.6023 \rho^{s_{1}}}{\mathrm{~A}^{s_{1}}} v^{s_{1}} \\
& t^{\Sigma_{a}^{1}}=t^{\Sigma_{a}^{1}}\left(1-v^{\mathrm{m}^{1}}\right)+t_{t_{\mathrm{a}}}^{\mathrm{S}_{1}} \frac{.6023 \rho^{\mathrm{s}_{1}}}{\mathrm{~A}^{\mathrm{s}_{1}}} \mathrm{v}^{\mathrm{s}_{1}}
\end{aligned}
$$

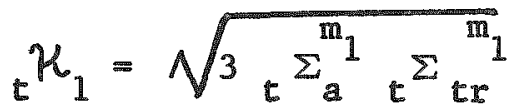$$
\text { ASSIGMMENT OF CONSTANTS FOR CALCULATION OF } t^{1}
$$

$\begin{array}{llll}\frac{G}{K} & \frac{0 \text { and } 1}{K_{0}^{1}} & \frac{2}{3 \text { and } 4} \\ R_{0} & K^{0} & \text { Bypass } \\ K_{i} & R^{1} & R^{0} & K^{1} \\ R_{i} & K^{0} & R^{1} & D^{1} \\ D_{i} & R^{0} & \Sigma_{a}^{1} \\ \Sigma a_{i} & t^{0} & D^{0} \\ D_{0} & t^{\Sigma_{a}^{0}} & t^{1} & \Sigma_{a}^{0} \\ \Sigma a_{0} & t^{\Sigma_{a}^{1}} & \end{array}$




\section{7}

ASSIGMMENT OR CONSTANTS FOR CALCULATION OF $t^{1}$ (cont.)

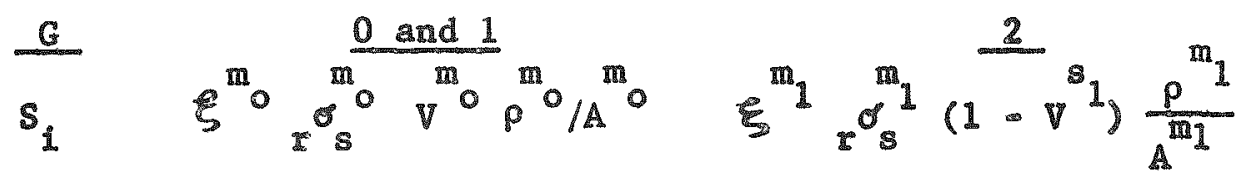

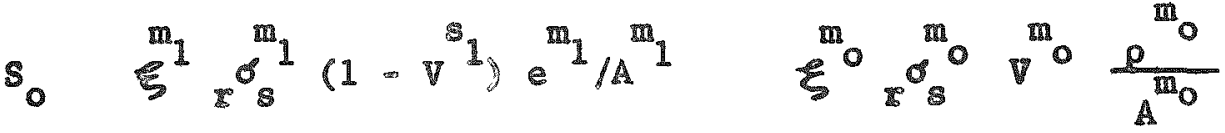

3 and 4

Bypass

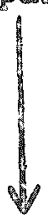

$\left.a_{i}=\left\{\frac{s_{0}}{\Sigma_{a_{0}}}-\frac{s_{i}}{\Sigma_{a_{i}}}\right] \frac{1}{\frac{I_{0}(i 1)}{I_{1}(i 1)}-\frac{D_{1} K_{1}}{D_{0} K_{0}} \frac{K_{1}(00) I_{0}(10)+I_{1}(00) K_{0}(i 0)}{K_{1}(00) I_{1}(10)-I_{1}(00) K_{1}(10)}}\right\}$

$f_{i}=\frac{\frac{\sum a_{i} R_{i a}}{K_{i}}+s_{i} \frac{R_{i}^{2}}{\Sigma a_{i}}}{s_{0}\left(R_{0}^{2}-R_{i}^{2}\right)+s_{i} R_{i}^{2}}$

if $G=0$ or 1

$$
f^{1}=f_{i}
$$

if $G=2$

$$
\mathbf{f}^{1}=1-\mathbf{f}_{\mathbf{i}}
$$

if $G=3$ or 4

$$
f^{1}=1
$$

$t=t^{1} \times t^{0}$

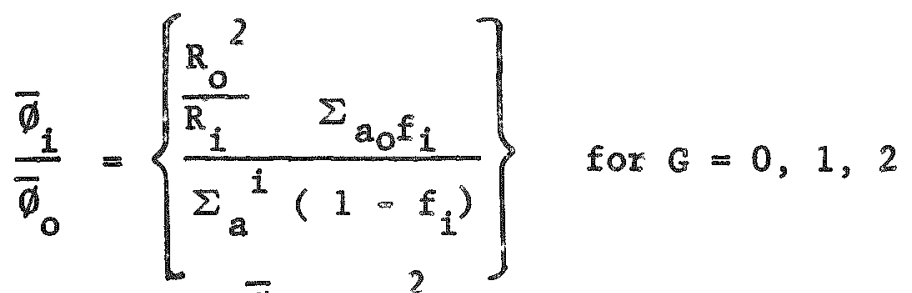

$t^{\mathrm{R}}=\frac{1+\frac{\bar{\phi}_{i}}{\bar{\phi}_{0}} \frac{\mathrm{R}_{i}^{2}}{\mathrm{R}_{0}^{2}}}{\frac{1}{\mathrm{D}_{i}} \frac{\bar{\phi}_{i}}{\bar{\phi}_{0}} \frac{\mathrm{R}_{i}^{2}}{\mathrm{R}_{0}^{2}}+\frac{1}{\mathrm{D}_{0}}}$ 


$$
\begin{aligned}
& 128
\end{aligned}
$$

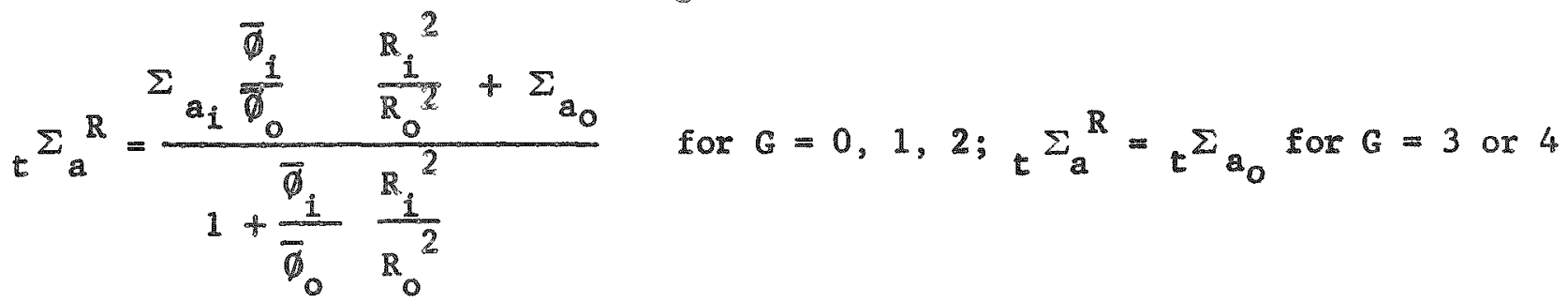

$$
\begin{aligned}
& K^{R}=\sqrt{t_{a}^{\Sigma} / D^{R}} \\
& \left(L^{R}\right)^{2}=\frac{\mathbb{D}^{R}}{\sum^{R}} \\
& \Sigma_{s}^{a 1}=\frac{.6023 p^{f}}{A^{f}} r_{S}^{\sigma^{a 1}} \\
& \Sigma_{S}^{c 1}=\frac{.6023 \rho^{c 1}}{A^{c 1}} r_{s}^{c 1} \\
& \Sigma_{S}^{S O}=\frac{.6023 p^{\text {So }}}{A^{S_{O}}} \mathbb{s}_{S}^{S_{O}} \\
& x_{s}^{m_{1}}=\frac{.6023 p^{m_{1}}}{A} x_{s}^{m_{1}^{m_{1}}} \\
& x_{s}^{m_{0}}=\frac{.6023 p^{m_{0}}}{A^{m_{0}}} r_{s}^{m_{0}} \\
& \Sigma_{a}^{a 1}=\frac{.6023 p^{f}}{A^{f}} \times x_{a}^{a 1} \\
& r_{a}^{m_{1}}=\frac{.6023 \rho^{m_{1}}}{m_{1}^{m_{1}}} \sigma_{a}^{m_{1}}
\end{aligned}
$$

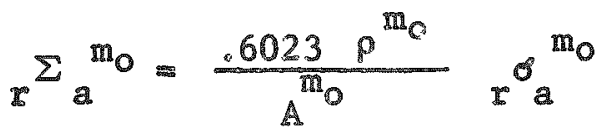

$$
\begin{aligned}
& \Sigma_{s}^{s_{1}}=\frac{.6023 \rho^{s_{1}}}{A^{s_{1}}} o_{s}^{s_{1}}
\end{aligned}
$$


129

$$
\begin{aligned}
& \Sigma_{a}^{s_{1}}=\frac{.6023 \rho^{s_{1}}}{A^{s_{1}}} \tau_{a}^{s_{1}}
\end{aligned}
$$

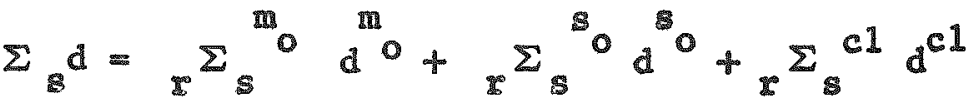

$$
\begin{aligned}
& s_{\text {eff }}= \begin{cases}s_{\text {sh }}\left[1-2 E_{3}\left(\Sigma \Sigma_{S} d\right)\right]+s_{\text {us }} & \text { if } C_{D}=0 \\
s_{\text {sh }}\left(1-c_{D}\right)+s_{\text {us }} & \text { if } C_{D}=0\end{cases} \\
& x_{a}^{U}= \begin{cases}{\left[c_{1}+c_{2} \frac{s_{\text {eff }}}{M}\right]\left(1-\mathbb{N}^{25}\right)} & \text { if } c_{3}=0 \\
\frac{c_{1}\left(1-N^{25}\right)}{C_{2}+\frac{M}{s_{\text {eff }}}} & \text { if } c_{3}=0\end{cases} \\
& \Sigma_{a}^{U}=I^{U} \frac{.6023 p^{f}}{\mathbb{A}^{\mathrm{f}}}
\end{aligned}
$$

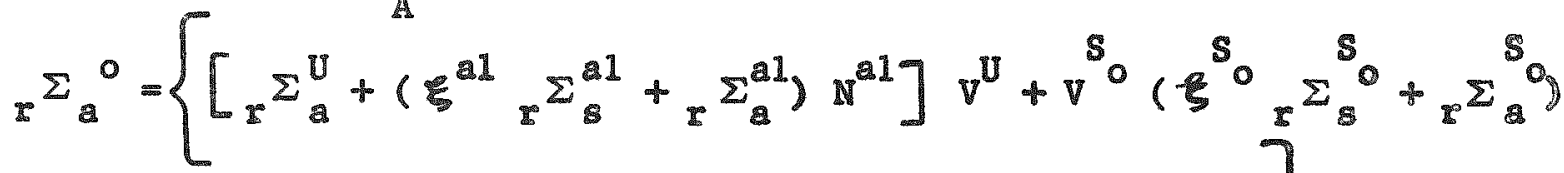

$$
\begin{aligned}
& +v^{c 1}\left(\xi^{c 1} \Sigma_{s}^{c 1}+\Sigma_{a}^{d}+\left(\xi^{m_{0}} \Sigma_{s}^{m_{0}}+\Sigma_{a}^{m_{0}}\right) v^{m_{0}}\right] \frac{1}{x_{u}^{m}} \\
& x^{0}=\frac{x_{a}^{\Sigma_{a}^{U}} v^{U}}{x_{a}^{\Sigma_{a}^{0}} \Delta^{U}} \\
& \Sigma_{t x}^{a 1}=\frac{.6023 p^{f}}{A^{f}} x_{t r}^{a 1} \\
& r_{\operatorname{tr}}^{c 1}=\frac{.6023 p^{c 1}}{A^{c 1}} r_{t r}^{c 1} \\
& x_{t x}^{S_{0}}=\frac{.6023 p^{S_{0}}}{A^{S_{0}}} x_{0}^{S_{0}}
\end{aligned}
$$

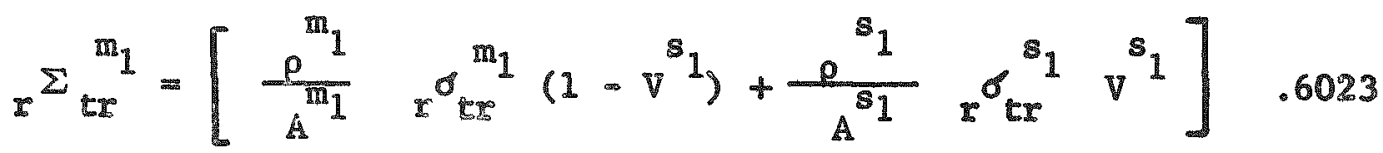

- D $13=$ 


$$
\begin{aligned}
& r^{\Sigma} \mathrm{mr}_{0}^{\mathrm{m}_{0}}=\frac{.6023 \rho^{\mathrm{m}_{0}}}{\mathrm{~m}_{0}} r^{\mathrm{m}_{0}} \\
& r^{\Sigma s_{1}}=\frac{.6023 \rho^{s_{1}}}{s_{1}} r^{s_{1}}{ }^{s_{1}}
\end{aligned}
$$

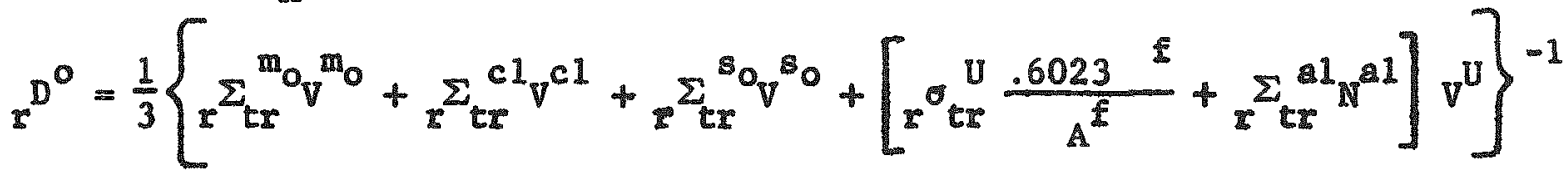

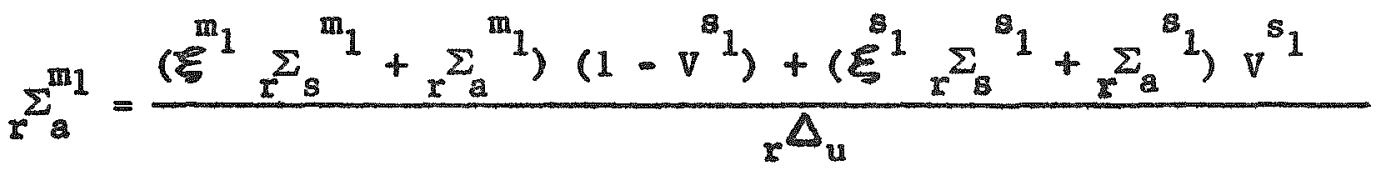

$$
\begin{aligned}
& r^{K_{0}}=\frac{r^{\Sigma_{a}^{0}}}{x^{D^{0}}} \\
& { }_{r} K_{1}=3_{r} \Sigma_{2}^{m_{1}} \Sigma_{t r}^{m_{1}}
\end{aligned}
$$

Use cylindrical utilization subroutine with following assignments.

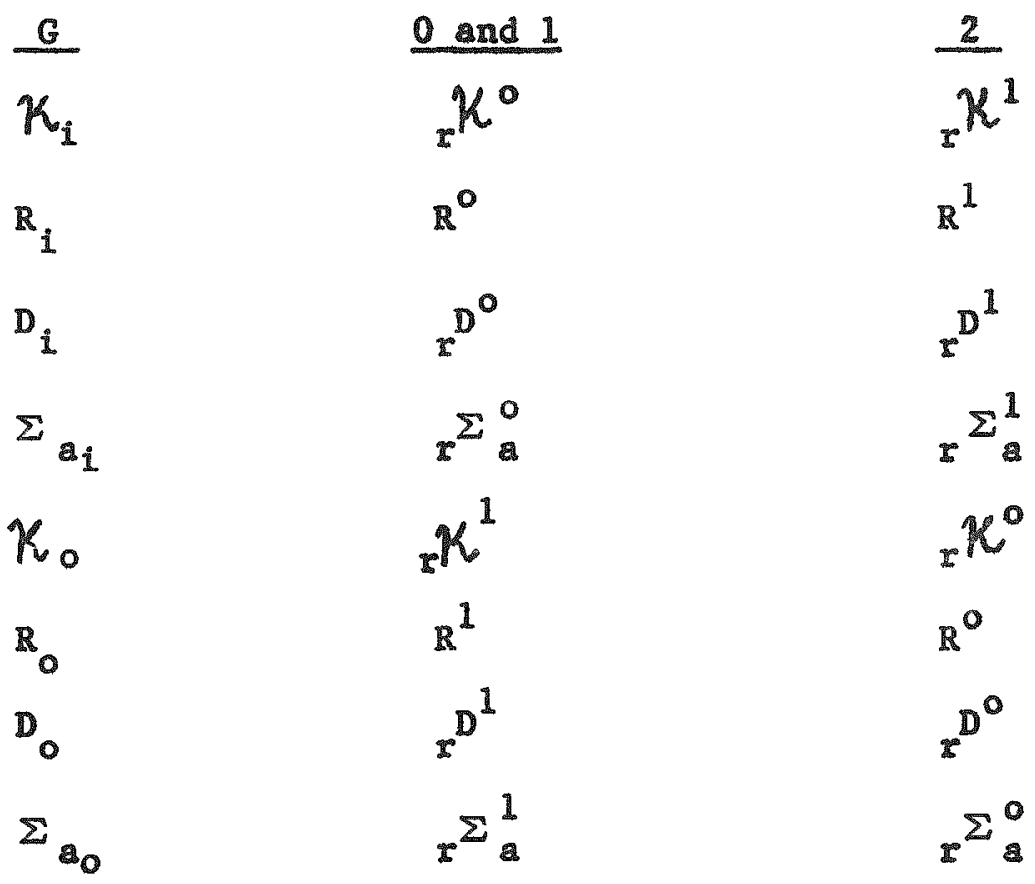

$s_{1} \quad \xi^{m_{0}} \Sigma^{\Sigma}{ }^{m_{0}} \frac{p^{m_{0}}}{m_{0}^{m_{0}}} v^{m_{0}} \quad \xi^{m_{1}} \Sigma^{\Sigma^{m_{1}}} \frac{p^{m_{1}}}{A_{1}^{m_{1}}}\left(1-v^{s_{1}}\right)$

$s_{0} \quad \xi^{m_{1}} \Sigma^{\Sigma^{m_{1}}} \frac{e^{m_{1}}}{A^{m_{1}}}\left(1-v^{s_{1}}\right) \quad \xi^{m_{0}} \Sigma^{m_{0}} \frac{p^{m_{0}}}{m_{0}} v^{m_{0}}$

3 and 4

Bypass

$$
x^{1}=f_{i} \quad x^{1}=1-f_{i} \quad x^{1}=1
$$




$$
\begin{aligned}
& x^{L}=x^{E_{0}} x^{x_{1}} \\
& p=\exp \left[-\frac{x^{2}}{1-x^{2}}\right] \\
& k_{\infty}=M \epsilon^{f}
\end{aligned}
$$




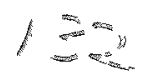

APPENDIX E

\section{REVIEW OF HEAVY WATER DESIGNS}

The purpose of this appendix is to summarize briefly the published documents dealing with work by Argonne National Laboratory on boiling heavy water reactors and by the Chalk River Project on pressurized heavy water reactors. These two organizations have given intensive study to the two respective types of heavy water reactors. In addition, the Du Pont Company, under contract with the U. S. AEC, is designing a heavy water pressurized reactor. Little has been published to date regarding the Du Pont project. In preparing this present report, the Du Pont group kindly supplied us with information on equipment, fuel element design, and heavy water losses. It was our impression that the Du Pont reactor design would draw heavily on Savannah River technology with respect to equipment and fuel elements, although consideration was being given to both pressurized-tube and pressurized-shell designs.

\section{Boiling Heavy Water Reactors (Argonne National Laboratory)}

A number of heavy water reactors operating on the direct boiling cycle have been designed by the Argonne group. Several designs were presented at the Geneva Conference, and recent1y detailed plans have been formulated to operate the EBWR with heavy water.

\section{Geneva Conference Design 1}

The paper presented by an Argonne group at the Geneva Conference provides an excellent description of the physics, engineering design, and economics of heavy water reactors. A reactor size of 1,000 thermal megawatts (248 net electrical megawatts) was described in detail, the principal features of which are:

1 H. P. Iskenderian, et a1, Geneva Conference Paper, P/495, Vo1. 3 (1955) 


\section{Core}

Diameter (ft) 12

Height ( $f t$ ) 12

Reflector thickness ( $f t$ ) 1.25

Pressure Vesse1 ID (ft) 15.2

Eue1

\section{Type}

Total weight (short tons)

Initial conversion ratio

Number of plates

Plate thickness $\left(\mathrm{in}_{\text {. }}\right)$

cladding

Cladding thickness (in.)

Lattice spacing (in.)

Shroud diameter (in.)

Number of fuel tubes

Average exposure level (MWD/short ton)

Heat Transfer

Core recirculation rate

$$
\text { (forced) gpm }
$$

Average coolant density ( $g / c c$ )

Reactor steam pressure (psia).

Reactor steam temperature (OF)

Average moderator temperature (OF)

Exit steam voids (vol. \%)

Power density (MW/ft of fuel assembly)

Maximum heat flux.

(Btu/hr-sq ft)

Average heat flux

(Btu/hr-sq $f t)$

\author{
Natural uranium \\ 43.4 \\ 0.901 \\ 9 \\ 0.15 \\ Zirconium \\ 0.02 \\ 8 \\ 6 \\ 295 \\ 10,000
}

Heavy Water

Inventory in reactor (short tons)

Inventory in power plant and reserve (short tons)

Losses (\% of inventory per year)

100

75,000

0.66

600

486

200

80

0.28

400,000

160,000

20

5

Designs were also summarized in the paper for a reactor size of $250 \mathrm{MW}$ of heat and for a comparative light water design.

Certain of the principal problems of heavy water reactors were discussed. It was pointed out that a pressurized type of heavy water reactor would require a large pressure vessel at 2,000 psi and that this was very difficult to fabricate. Also, fuel was to be charged and discharged through ports in the top of the vessel and a welded head employed on the pressure vessel, since it was felt that bolted, leak-tight heads of such large diameter would be difficult to procure. 
The safety aspects of heavy water reactors were emphasized: "The small quantity of uranium and low absorption cross section of the moderator account for a prompt neutron lifetime more than 10 times as long in a $D_{2} O$ reactor as in the $\mathrm{H}_{2} \mathrm{O}$ type. This is a very important factor from the safety standpoint inasmuch as short period excursions need not be considered in $\mathrm{D}_{2} \mathrm{O}$ reactors Since a significant part of the capital expenditure for a nuclear power plant is usually associated with safety provisions, the relative safety of a $D_{2} O$ reactor is expected to have an important bearing on the cost of electricity." Operation of Heavy Water EBWR 2

Recently studies have been undertaken on the operation of the EBWR with heavy water In this core size, some enrichment of the fuel is necessary A plate-type fuel element is proposed, and three different core designs are presented It was assumed that an average heat flux of $100,000 \mathrm{Btu} / \mathrm{hr}=\mathrm{sq}$ ft was appropriate on a11 designs with natural circulation. This report contains a rather thorough analysis of excursions caused by either a rapid rise in reactivity or a large but slow increase in reactivity. It was concluded that the present control rods of EBWR w11 be more than adequate for the $\mathrm{D}_{2}$ O 1 oading Pressurized Heavy Water Reactors (Chalk River Project)

Atomic Energy of Canada, Limited, has for several years conducted a vigorous and imaginative program in the design of heavy water power reactors. The position of nuclear reactors in the Canadian power complex bas been carefully examined, and the extent of cost reduction in nuclear power necessary for it to compete with conventional power has been analyzed.

Canadian power reactor designs are based on the use of natural uranium and heavy water, both of which are produced in Canada Recently emphasis has been placed on large power reactors designed to minimize neutron losses and to obtain long exposure levels. Canadian efforts along this line are to be carried forward by construction of an NPD (Nuclear Power Demonstration) reactor Rather complete detalis of this reactor design have been published, but recently the decision has been made to revise the published design

2 $\mathrm{H}, \mathrm{P}$. Iskenderian, "20-MW $\mathrm{D}_{2} \mathrm{O}$ Moderated Experimenta1 Boiling Water Reactor Design Studies," ANL 5685, February, 1957. 
Ear1y NPD Design $3,4,5$

$$
136
$$

The NPI was designed to be a pressurized-shell non-boiling power reactor of 20 electrical megawatts output, intended as a power demonstration reactor. Its unique feature was the absence of control rods, control belng carried out by varying the level of the $\mathrm{D}_{2} \mathrm{O}$ moderator. Other features were.

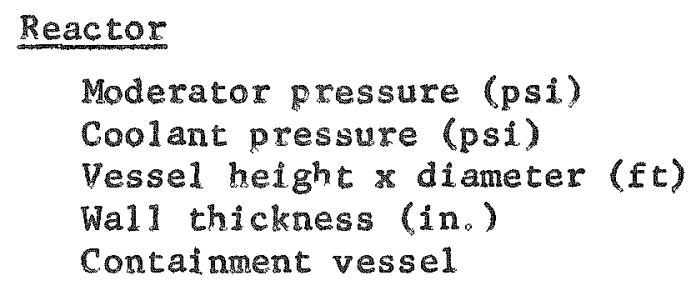

Fue1

Type

Cladding

Fuel tube diameter (in)

Fuel tubes/channel

Coolant channel OD (in.)

length of coolant channel ( $f t$ )

Number of coolant channels

Total $\mathrm{UO}_{2}$ in core (metric tons)

Total $\mathrm{UO}_{2}$ added/year (metric tons)

\section{Heat Transfer}

Coolant flow (gpm)

Reactor exit temperature ( ${ }^{\circ} \mathrm{F}$ )

Steam pressure (saturated), psia

Steam flow ( $1 \mathrm{~b} / \mathrm{hr}$ )

Maximum heat flux (Btu/hr-sq ft)

D20 Purification Plant

F1ow (gpm)

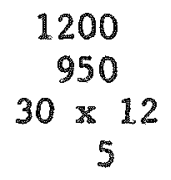

Natural uranium oxide Zi realoy 0.65

19

3.25

8.25

120

8

12

$$
\begin{array}{r}
12,000 \\
530 \\
425 \\
300,000 \\
300,000
\end{array}
$$

5,000

Proposed Modifications to NPD

As a result of their studies, the Chalk River group has determined that by frequent partial charge-discharges of horizontal fuel tubes, adjacent tubes being loaded from opposite ends, sufficient reactivity can be maintained with

3 "Canadian Atomic Energy Activities," Report to the United Nations, 1957

4. H. A Smith, "The Preliminary Design for NPD," AECL 240 (October, 1955)

I Bureau of National Affairs - Description of NPD - No 84, p 449.895, 1957 


\section{6}

natural uranium oxide to permit exposure levels of $10,000 \mathrm{MWD} / \mathrm{metric}$ ton $\frac{6}{9}, \underline{7}$ At this exposure level the fuel cycle cost is very low, and Dr. W. B. Lewis has presented data on the power-generating cost of a $200 \mathrm{EMW}$ reactor operating on this principle $\frac{7}{:}$

$\begin{array}{lcccc}\text { Item } & \begin{array}{c}\text { Rating } \\ \text { or }\end{array} & \begin{array}{c}\text { Capital } \\ \text { Investment }\end{array} & \begin{array}{c}\text { Annual } \\ \text { Interest }\end{array} & \begin{array}{c}\text { Operating } \\ \text { Cost }\end{array} \\ \text { Quantity } & \underline{\left(\$ \times 10^{6}\right)} & \underline{\text { Charge (\%) }} & \underline{\underline{(m i 11 \mathrm{~s} / \mathrm{kwh})}}\end{array}$

Turbogenerator plant 200 EMW 16

8.5

0.97

Reactor, auxiliaries, and building

$800 \mathrm{TMW}$

30

8.5

Inventory charges:

Heavy water

$3.2 \times 10^{5} 1 \mathrm{~b}$

9

6

0.39

Uranium

at $\$ 28 / 1 b$

110 metric tons 4 at $\$ 40 / \mathrm{kg}$

Non-nuclear parts

$\$ 30 / \mathrm{kg}$ 3

4

0.11 $25.8 \mathrm{ton} / \mathrm{hr}$ at
$10,000 \mathrm{MWD} / \mathrm{metric}$ ton $25.8 \mathrm{ton} / \mathrm{hr}$ at
$10,000 \mathrm{MWD} / \mathrm{metric}$ ton

0.09

Fuel Burn-up

Operating costs, including $\mathrm{D}_{2} \mathrm{O}$ loss at $1 \mathrm{lb} / \mathrm{hr}$

Presumably on the basis of such data, it has been decided to attempt to modify the NPD to a pressurized horizontal tube design with provisions for charging and discharging while operating $\frac{8}{\circ}$ The elimination of control rods is apparently still thought to be possible in the new design?

The figure of $5.27 \mathrm{mills} / \mathrm{kwh}$ is lower than would be predicted for a 200 EMW plant on the basis of assumptions employed in this present Size-Up report for the following reasons:

1) The plant cost of $\$ 230 / \mathrm{kw}$ estimated by Lewis should be compared with $\$ 302 / \mathrm{kw}$ used here for the 250 EMW pressurized design.

2) The annual "interest charges" given by Lewis are roughly half those appropriate on a U. S. private utility basis. This is a major difference.

6 W. B. Lewis, "Low Cost Fuelling Without Recycling," AECL 382, December 10, 1956.

I W. B. Lewis, Talk at National Industrial Conference Board, Fifth Atomic Energy Conference, Philadelphia, March 15, 1957, AECL 417. See also Nucleonics 15, No. 6, p. 71, June, 1957.

8 W. B. Lewis, Private Communication, June, 1957. 


\section{7}

3) The heavy water loss of $1 \mathrm{lb} / \mathrm{hr}$ is roughly one-quarter that assumed in Section III.

4) The Canadians assume fuel-cycle costs for fabrication and conversion of only $\$ 30 / \mathrm{kgm}$ using zirconium elements. Although they have studied this problem in some detail $\frac{2}{2}$ such costs are less than half those believed attalnable in the near future.

As shown in Section III, the 250 EMW plant of this report is estimated to have a power cost of $10.9 \mathrm{mills} / \mathrm{kwh}$ rather than the $5.27 \mathrm{mills} / \mathrm{kwh}$ given by Lewis. It should be stated that the Canadian estimates are predicated on a longer-range forecast than the Size-up designs, however.

2 H. K. Rae, "Fuel Processing and Recycling for Natural Uranium Power Reactors," Paper No, 57-NESC-102, 2nd Nuclear Engineering \& Science Conference, Philadelphia, March, 1957. 
CONSOLIDATED WESTERN STEEL

DIVISION UNITED STATES STEEL CORPORATION

APPENDIX I

\title{
PRESSURE VESSEL STUDY
}

\author{
PREPARE FOA \\ ATOMIC ENERGY DIVISION \\ AMERICAN RADIATOR \\ AND \\ STANDARD SANITARY CORPORATION \\ CONTRACT MO. AT-104)-3.109
}

MARCH, 1957

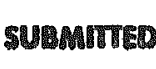

PDiftandanal

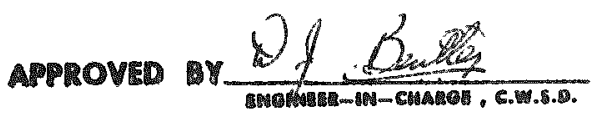

APPROVED BY

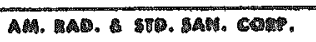


Title Page

1

Table of Contents

List of Dlustrations

Sumunary

Introduction

Discussion

1.0 General

Index

1.1 Materialo

1.2 Type of Construction

1.3 Maximum Vesse: Fabrication Dimens Lons

1.4 Field Fabrication Problems

2.0 Vessel Design

Index

2.1 Design pabulation

2.2 Design Analysts

3.0 Specifications-General Eroviston

Index

3.1 General

3.2 Scope of Worls

3.3 General specifications

3.4 Inspection

3.5 Testing

3.6 Instruction Books-Equipment Catalogs

3.7 Transportation

39

3.8 Erection

39

40

4.0 Specifications welding

Index

4.1. Solid Staniess Well Vesaels

42

4.2 stainleas clad steel Wall Vessels

43

4.3 Steel Wall containment Vessels

45

50 
CONSOLIDATED WESTERN STEEL

DIVISION UNITEO STATES STEEL CORPORATION

TABLE OF CONTEMTS

$\begin{array}{lr}\text { 5.0 Head Closures } & \\ \text { Index } & 54 \\ 5.1 \text { General } & 55 \\ 5.2 \text { Closure Iimitations } & 55 \\ 5.3 \text { Closure Design } & 61 \\ 5.4 \text { Economic Analysis of Closures } & 63 \\ 6.0 \text { Cost Date } & 66 \\ \text { Index } & 67 \\ 6.1 \text { Reactor Vessels } & 67 \\ 6.2 \text { Containment Vescels } & 68 \\ 6.3 \text { Clading } & 69 \\ 6.4 \text { Tabulation of Cost Data } & 70 \\ 6.5 \text { Head Closures } & 70 \\ 6.6 \text { Fabication } & \end{array}$

Appendix A - Intergretation of Code Deta 72

LISI OI ILUSTRATIONS AND FIGURES

Detall 2.13 - Boiling Water Vessel Outline 20

Pable 2.13 - Bolling Water Vessel Data 21

Deta11 2.14 - Pressurized Water Vessel Outline 22

Table 2.14 - Pressurized Water Vessel Outline 23

Figure $A-15^{\circ}-3^{\prime \prime}$ dia., 1000 psi, Bolling Water Vessel 24

Figure B $-11^{\prime}$ - $6^{\prime \prime}$ dia., 600 psi, Boiling Water Vessel 26

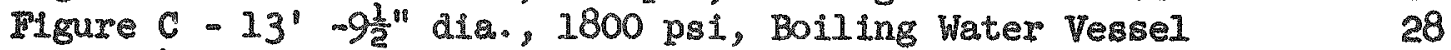

Detail 4.2390 - Typlcal Wela Bead Detail 48

Deta11 4.33 - "ypical Weld Bead Detail 52

Figure D - Loose Ring Flange Head Closure 56

Flgure - Mlanged Head Type Closure Wth Seal Weld 57

Figure - Welded Head Closure 58

Hyure - Head Hold-dom and Bridge man Type Closure 59

Higure H - Mypical Seal 62

Table 6.4 - Tabulation of Cost Data 69 
CONSOLIDATED WESTERN STEEL

DIVISION UNITED STATES STEEL CORPORATION 
This report covers, briefly, data concerned with the design, fabrication, transportation, and erection of containment, boiling water, and pressurized water vessels. A survey of pertinent factors concerning plate thickness, limiting fabrication dimensions, fabrication methods, and field fabrication problems, is presented and discussed.

An analysis of vessel design, together with vessel dimensions, weights, costs, and specifications, is included. A discussion of representative designs for removable heads is presented, taking into account such varfables as shape, thickness, seals and materials, together with fabrication sources, and code and inspection problems.

Following this report as Appendix A, are interpretations of the ASME Boiler and Pressure Vesse1. Code, as approved by the ASME Council, September 6, 1956, which eatablished the basic limiting factors for nuclear vessels of this nature. It has been determined that these vessels come under the provisions in the code for vessels containing lethal substances. The provisions of the Code do not limit vessel wall thickness, providing other sections of the code are met.

The thermal problems arising from internal heat generation due to neutron bombardment have not been investigated at the oral direction of the client. 


\section{INTROTUCITON}

By letters to Consolidated Western Steel Division, United States Steel, dated December 27, 1956, and January 5, 1957, the Atomic Energy Division of American Raliator and Standard Sanitary Corporation requested Consolidated to conduct a study covering the design of pressure vessels for pressurized water, and boiling water reactors. This study American expects to utilize as partial fulfiliment of a contract held by them with the Atomic Energy Commission for the study of heavy-water, natural-uranium power xeactors.

Subsequent to the above letters, consolidated has been informed by American that a contract ultimately to be executed with Consolidated would be given the Air Force designation AT-(04)-3-1.09.

A preliminary survey report on this subject was prepared, and delivered to American in the latter part of January, 1957. The accompanying report, more defintive and comprehensive, is expected to complete the requirements of this contract.

The ensuing report $1 \mathrm{~s}$ based upon vessels designed under ASME Code requirements as requested by American Standard and Sanitary Corp.

It is, however, the comsidered opinion of CWSD Enginesring Department that non-Code vessels may be designed and constructed with thinnex wall sections, still maintaining adequate safety factor:

This latter approach may prove to be the more eccnomical method of fabrication for the large heavy vessels required for heavy water moderated. reactors. 


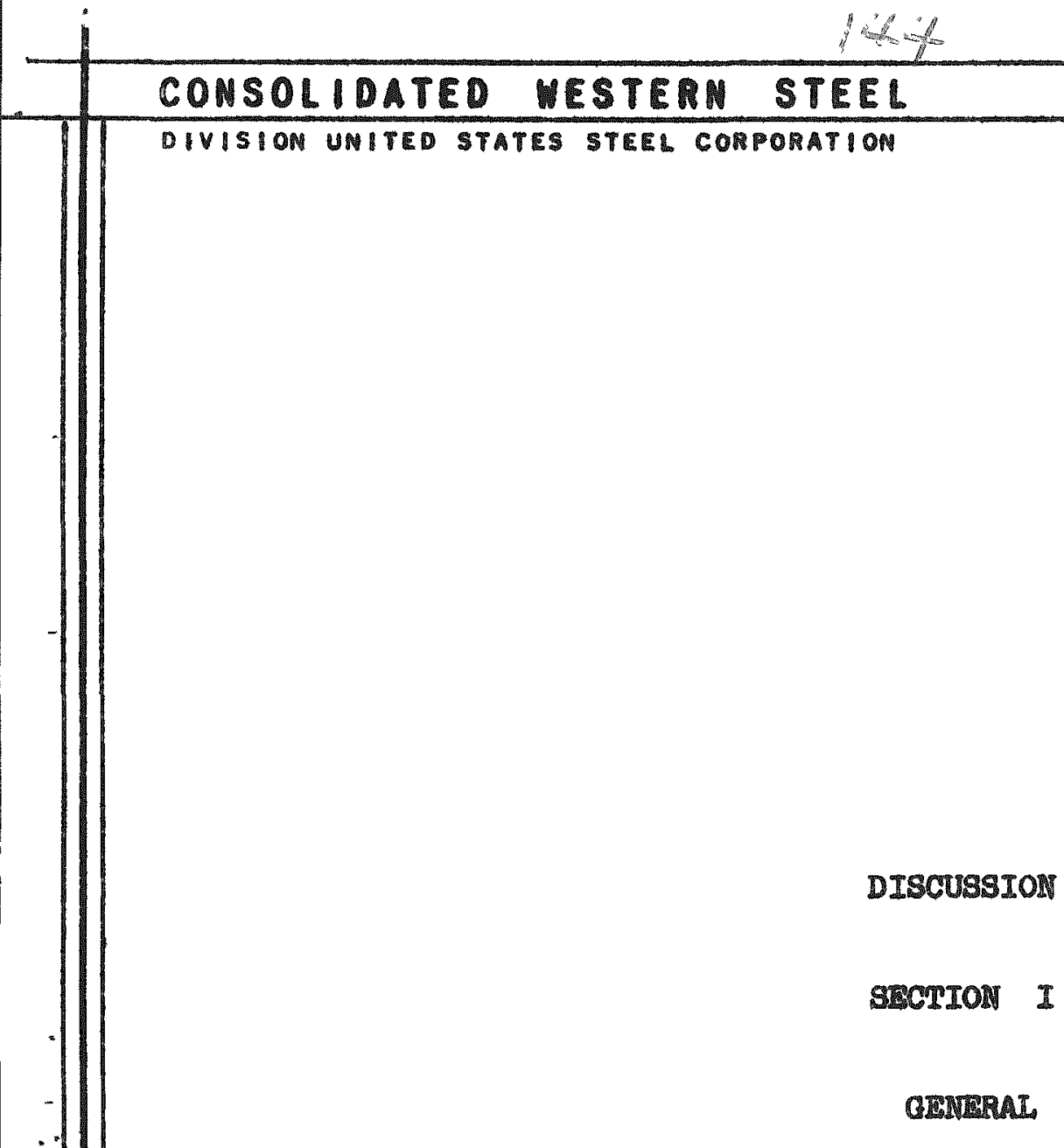

$3-12-57$

Page

7

63388 
1.1 Materials

1.11 Reactor Vessel.

1.111 General

1.112 Wall Thickness

1.113 Alternate Cladains Methods

1.114 Welaing Problems

11

1.115 Conclusions

1.12 Containment Vessels

1.121. General

12

1.122 Code Conformance

1.2 Type of Construction

1.21 Forged Ring Construction

1.211 General

1.212 Carbon or Iow Alloy Steel

1.213 Stalnless Steel

13

1.214 Tlustrative Example-Forged Ring Construction

13

1.215 Conclusions

1.3 Maximum Vessel Fabricating Dimens Lons

1.31 Shop Fabrication

1.311 Size Limitations - Prensportation

1. 312 Welght IImitation -Mranaportation

1.32 Fleld Fabrication

15

1.321 S1ze Limitations-Code

1.4 Field Fabrication Problems

1.41 General

1.42 Streso Relleving

1.421 ceneral

1.422 Fleld Furnace

1.423 Local Stress Relleving

1.43 Fleld Welding

1.431 Ceneral

1.432 Costs

1.44 Conclusions 


\section{CONSOLIDATED WESTERN STEEL}

DIVISION UNITED STATES STEEL CORPORATION

\subsection{GENRRAL}

\subsection{MATTERIALS}

\subsection{Reactor Vessels}

\subsection{General}

\subsection{Solid Stainiess Steel}

Evaluation of solid stalniess steel reactor vessels in this report has been based on the use of Type SA 167, Grade 11 steel, because the present Code restrictions provide the highest allowable atainless steel stress for this material. It has not been possible to ascertain definitely that this type of steel will be used ir constructing these vessel.s. Further study w111 be necessary to establish the most sultable type of material to satisfy optinum requirements of welding and forging. Such a study may indicate that materials not presently acceptable or listed under the ASME Boiler and Pressure Vessel Code would be more sultable than those now listed.

\subsection{Wa11 Section}

The Investigation preceding this report indicates that vessels made of either solld stainless steel or of clad material are practical, providing that those stanless steels acceptable for pressure vessel construction by the Code are also acceptable to the client when the effects of radiation are considered.

\subsection{Radiation}

Ixisting information indicates that the effect of radiation on most materials acceptable under the AGMa Code 18 not definitively known.

\subsection{Wall Mhickness}

\subsection{Masimun-1ukens Method}

Fither solid stainless steel or clad construction ia feasible up to the maximum wall thickness for which comercial clad plate is normaliy avallable. Using the Lukens Method, this pregent maximum is approximately $8.5 / 8$ ". 


\subsection{Maximum-Alternate Claddings}

Greater thicknesses than available by the Lukens method are feasible construction-wise if one or more of the following alternate methods of cladding are acceptable considering the environment of the vessel.

\subsection{Alternate Cladding Methods}

1.1131 Alternate methods of cladding, in addition to the Lukens Method, are the Double Shell Method, the Plating Method, and the Stitch Method, briefly described as follows:

\subsection{Double Shell Method}

This method comprises a complete interior leak-proof shell of stainless steel set into an outer carbon steel shell with intermediate areas vented. The outer carbon steel shell will develop the entire strength required to contain the involved pressures. The inner shell will be leak-proof and will provide the required corrosion resistance. The Double Shell Method, however, since the effects of internal heat generation is unknown, is not considered desirable.

\subsection{Plating Method}

This method comprises a chrome or nickel plate, approximately .007 to .010" thick, applied after the vessel is fabricated, stress relleved and ready for service. This plating is not recommended because of its fragility and its inability to withstand blows or abrasions.

\subsection{Stitching Method}

This method comprises fabricating stainless steel sectionally to match the interior contours of the vessel. Stitching each section in place separately by automatic welding techniques produces welds on approximately $2^{\prime \prime}$ centers. Following the stitching of the separate sections, stainless steel seal welding will be produced between each adjacent section to make the final shell.

\subsection{Continuous Stainless Steel Overlay Method}

This method comprises laying of a continuous weld metal bead of appropriate specification over the carbon or low alloy steel from which the vessel is fabricated. 


\section{CONSOLIDATED WESTERN STEEL}

DIVISION UNITED STATES STEEL CORPORATION

\subsection{Welding Problems}

1.1141 Use of the above mentioned cladding methods introduces severe welding problems because of the bi-metallic nature of the ressel.

\subsection{Lulsens Method}

Iukens Processing Cladding requires that the weld be made from the clad side starting considerably below the cladding thickness with stainless steel so that dilution of the stainless steel below the carbon surface is zero. Spectal welding technique: and procedures will be required to successfully fabricate a vessel in thlis manner and malntaln the clad integrity.

\subsection{Double She11 Method}

This method utilizes a separate stainless vessel constructed inside the carbon steel vessel to achieve the necessary corrosion resistance, etc. The cost of a finished vessel of this nature will be quite high since the labor will be essentially doubled, and a. very accurate flt must be achieved to guaxantee that the inner vessel, which is not designed as a pressure vessel, will not be over-stressed.

\subsection{Stitching Method}

In vessels where the Lukens Method of cladding is not possible or practical, it is felt that the stitching Method described above is most practical.

\subsection{Conclusions}

1.1151 A relative economic study indicates that the most economical construction, where feasible, is a clad vessel using the Lukens Process.

1.1152 The second most economical construction would be the solid stainless steel vessel.

1.1153 The third most economical vessel would be one constructed by the Stitching Method. That method appears to be the most economical process in vessels having a greater wall thickness thon can be produced using the Lukens Process. 
CONSOLIDATED WESTERN STEEL

DIVISION UNITED STATES STEEL CORPORATION

1.1152 The second most economical construction would be the solid stainless steel vessel.

1.1253 The third most econonical vessel would be one constructed by the Stitching Method. This method appears to be the most economical process in vessels having greater wall thickness than can be produced using the Lukens Process.

\subsection{Containment Vessels}

\subsection{General}

Evaluation of containment vessels in this report has been based on the use of material qualifled under Speciflcation SA 300 by the ASME Boiler and Pressure Vessel Code.

\subsection{Code Conformance-Thickness}

The ASME Code for Unfired Pressure Vessels establishes the following permissible wall thicknesses for low alloy steel which qualifies under SA-300, using a stress of $13,750 \mathrm{psi}$, and with internal pressure of 30 psig:

Stress Relief not required Preheat to $200^{\circ}$ F required

- 1.240 1nches max.

$-1.240-1.490$ inches

Since stregs relief of these large contalnment vessels is Impractical, the above are the practical design limits.

\subsection{Code Conformance-Dlameter}

The fleld fabrication of vessels is Iimited by the ASM Code for Unfired Pressure Vessels, which establishes the following permissible diameters for vessels of low alloy steel, quallfying under sA-300, using stress of $13,750 \mathrm{psi}$, and with internal pressure of $30 \mathrm{ps} 1 \mathrm{~g}$ :

Stress Relief not required Preheat to $200^{\circ}$ regulred

$$
\begin{aligned}
& \text { Cylinder } \\
& 90.3^{1} \\
& 90.3^{\prime}-108.2^{\prime}
\end{aligned}
$$

Sphere $151.67^{\prime}$ $151.67^{\prime}-181.67^{\prime}$

\subsection{Stress Relief}

Since stress relief of these large containment vessels is impractical, the above are the practical design limita. 


\subsection{TYPE OF CONSTRUCTION}

\subsection{Forged Ring Construction}

1.21.1 General

In addition to the more usual methods of construction of vessels described elsewhere in this report, consideram tion should be given the "Forged-RIng" type of construction.

\subsection{Carbon or Low-Alloy Steel}

1.2121 Maximum S1zes. Fisisting facllities permit the fabrication of vessels from low-carbon or low-alloy steel by ring forging techniques to $182^{\prime \prime}$ (15.17') finished 0.0 . maximum and with practical limits of wall thickness, $15^{\prime \prime}-17^{\prime \prime}$. Can lengths will vary from $2^{\prime}$ to $5^{\prime}$, dependIng on diameter and wall thickness.

It Is felt that vessels up to $192^{\prime \prime}$ (16') I.D. by $17^{\prime \prime}$ wall can be Iabricated by use of a forging process; however, it is believed that there are not now any available facilities for such fabrication above 182" O.D.

1.2122 Cost. Approximate costs for the carbon or lowmalloy steel forgings discussed above appear to be from $\$ 1.10$ to $\$ 1.50$ per pound.

Specifically, for a ring $13.8^{\circ}$ I.D. by $8^{\prime \prime}$ wall by $55^{\prime \prime}$ long, the price would be $\$ 1.23$ per pound.

1.2123 Conclusions. It appears that the price per pound decreases 5 Iightly with increased wall thickness for the same O.D.

\subsection{Stalnless Steel}

1.2131 Maximum Bize. Forgeability considerations limit the size of stainless steel forged rings to a maximum of $144^{\prime \prime}\left(12.0^{\prime}\right)$ finished $0 . D$. by appraximately $15^{\prime \prime}$ wa.1 thickness, in $27^{\prime \prime}$ can lengths.

\subsection{Illustrative Brample - Forged Ring Construction}

1.2141 Design Criteria. The assumption is made of a vessel fabricated with the forged ring technique, $182^{\prime \prime}$ finished $0 . D . \times 9.75^{\prime \prime}$ wal1 $\times 34.3^{\prime}$ in height, and operated under code provisions at 2000 psig. 
1.2142 cladaing. This vessel could be fabricated from SA302 steel, and clad by either of two methods:

a. By using the 1/4" SA304 stainless steel plate stitched on $2^{\prime \prime}$ centers, or

b. By laying on a continuous weld beam approximately 1/4" thick.

1.2143 Weight. The gross weight of such a vessel would be approximately 1,300,000 pounds, and net weight would be approximately 850,000 pounds.

1.2144 Cost. It would cost approximately $\$ 4,000,000$ to fabricate and install in the fleld, of which approximately $\$ 2,200,000$ would be required for shop work and $\$ 1,800,000$ for fleld work. See data on Vessel $D_{R}$ in Table 5.4 .

\subsection{Conclusions}

1.2151 Fabrication of plate vessels appears to be more economical than fabrication of forged ring vessels of the same wall thickness and diameter.

1.2152 The experience of Consolidated indicates that forged ring construction for the bare vessel costs approximately $40 \%$ more than clad construction of identical vessels.

\subsection{MAXIMUM VESSEL FABRICATING DIMENSIONS}

\subsection{Shop Fabrication}

1.311 Size Limitations-Transportation

1.3111 A practical limitation to vessel sizes in shop fabrication is the possibility of shipment. The American Association of Railroads advises that at the present time, ressels up to $11^{\prime}-2^{\prime \prime}$ in diameter by $50^{\prime}$ in length can be shipped without special routing.

1.3112 By special selection of route, vessels up to $13^{\prime}-6^{\prime \prime}$ in diameter by $100^{\prime}$ in length may be shipped.

\subsection{Weight Limitations-Transportation}

1.3121 Another limitation that must be taken into accourt has to do with weight; 70 tons of cargo may be shipped per car without special permit, but with a special permit, routing and cars, as much as 250 tons may be shipped per car. 
CONSOLIDATED WESTERN STEEL

VISIIN UNITED STATES STEEL CORPORATION

1.3122 However, end destinations of individual vessels must be investigated before fabrication to assure that special routings will be applicable.

\subsection{Field Fabrication}

\subsection{Size Limitations-Code}

1.3211 The field fabrication of vessels is limited by the ASME Code for Unfired Pressure Vessels, which establishes the following permissible diameters for vessels of low alloy steel, qualifying under SA-300, using a stress of 13,750 psi, and with internal pressure of $30 \mathrm{psig:}$

Stress Relief not required Preheat to 2000 F required

$$
\begin{array}{cc}
\frac{\text { Cylinder }}{90.3^{\prime}} & \frac{\text { Sphere }}{151.67^{\prime}} \\
90.3^{\prime}-108.2^{\prime} & 151.67^{\prime}-181.67^{\prime}
\end{array}
$$

\subsection{FIELD FABRICATION AND ERECTION PROBLEMS}

\subsection{General}

1.411 Field fabrication and erection of large pressure vessels, either of plate or forged ring construction, involves many special problexs not necessarily a part of shop fabrication. Included among these field problems are the additional costs and labors of field stress relleving, erection and joining.

1.412 Primarily, these additional problems relate to handling the sizes and weights of pleces required rather than problems of technique. Techniques for such fabrication or erection are well established.

\subsection{Stress Relieving}

\subsection{General}

1.4211 When any vessel becomes too large for shop fabrication, or to ship in one plece, field stress relieving is necessary to meet Code requirements, if wall is over $1-1 / 2^{n}$ thick.

1.4211 Field stress relieving presents new, but not insurmountable problems, not present when shop fabrication is feasible. Techniques, procedures and facilities for solution of these problems are presently well established and a matter of inconvenlence rather than complexity. 


\section{CONSOLIDATED WESTERN STEEL}

\section{0}

DIVISION UNITED STATES STEEL CORPORATION

\subsection{Field Furnace}

1.4221 Preferably, field stress relieving is accomplished by construction of a portable field stress relieving furnace, which method seems desirable up to a dlameter of at least 20:

\subsection{Local Stress Relieving}

1.4231 The code will accept, on Iarge vessels, local stress relieving of round seam welds in closed areas of not less than 4 times the thickness of metal, either side of weld. Because of technical difriculties, this method should be avoided, if possible.

1.4232 It has also been proven practical to stress relieve large field fabricated vessels by the use of a heated internal atnosphere. Obviously, this method necessitates the erection and operation os large heating units, which aubstantially increases the cost of the finished product.

\subsection{Field Welding}

\subsection{General}

1.4311. Welding problens appesring during field fabrication of such vesiels are due to the quantity of weld metal that mast be depositea in the fiela.

1.4312 Here argin, techniques and procedures for this work have been well established through long usage.

\subsection{Costs}

1.43el Field welding 1 , of course, more costly, more timeconsuning, and more difficult than shop welding since Pacilities are not as readily at hand, and working conditions are more difficult than working conditions in the shop.

\subsection{Conclusions}

1.441 Field fobrication involves more difficult handing and storage problems than shop tabrication, and requires un augmented field staff which is unable to perforr its duties as efficientiy as will shop fabrication.

1.442 Fleld joining of plates involves welaing undex adverse circunstances, and does not permit as great speed or efriciency as does shop velding. 
DISCUSSION

SECTION II

VESSEL DESICN 
155

CONSOLIDATED WESTERN STEEL

DIVISION UNITED STATES STEEL CORPORATION

\section{INDEX \\ SRETION II \\ VASSEL DESICN}

2.1 Design Tabulation

2.11 General.

2.12 Containment Vessels

2.13 Bolling Water Vessel Tabulation

21

2.14 Pressurized Water Vessel Tabulation 23

2.2 Design Analysis

2.21 Code Conformance

2.22 Material

2.221 Reactor Vessels

2.222 Containnent Vessels 25

2.23 Pressures

2.24 Temperatures

2.25 Tabrication

2.25I Wela Design

2.252 Joint Inspection

2.253 Jolnt Eficiency

2.26 Internal Water Pressure

2.27 Design Formulae

27

2.271 Reactor Vessels

2.272 Containment Vessels

27

27 


\subsection{VESSEL DESTGN}

\subsection{DESIGN TABULATION}

\subsection{General}

2.111 on pages 21 and \%" following, approximate dimensional and weight figures and estimated costs are tabulated for various boiling water and pressurized water reactor vessels.

2.112 Weights listed are net wejghts, and extrapolation of these figures to other vessels should be on the basis of these weights.

2.113 Theso tabulations are based upon data furnished Consolidated by American.

\subsection{Containment Vesse1s}

2.121 Studies made by Consolidated indicate that spherical containment vessels, of the sizes tabulated in this report, appear to be more economical than equivalent volume cylindrical vessels.

2.122 For this reason, data has been computed and is tabulated for both cylindrical and spherical vessels.

\subsection{Boiling Water Vessels Tabulation}

\subsection{This tabulation follows as page 21}

\subsection{Pressurized Water Vessels Tabulation}

2.141 Th:s tabulation follows as page 23.

\subsection{DESIGN ANALYSIS}

\subsection{Code Conformance}

2.211 Design of these vessels shall be in conformance with section I, ASM Boiler and Pressure Vessel Code, and subsequent interpretam tions of this Code as approved by the ASM Council, September 6, 1956, included herein as Appendix A.

2.212 Design is also in compliance with section VIII of the same Code,

$$
\begin{array}{cccc}
\text { paragrephs } U 1-C-2 & U G-23 & U G-36 \text { to } 53 & \text { UCS }-6 \\
U G-5 & U G-27 & U W-12 & U C S-15 \\
U G-16 & U G-32 & U-W-16 & U C S-16 \\
& & & U C S-23
\end{array}
$$

and such other paragraphs as may be deemed appropriate by Consolidated. 


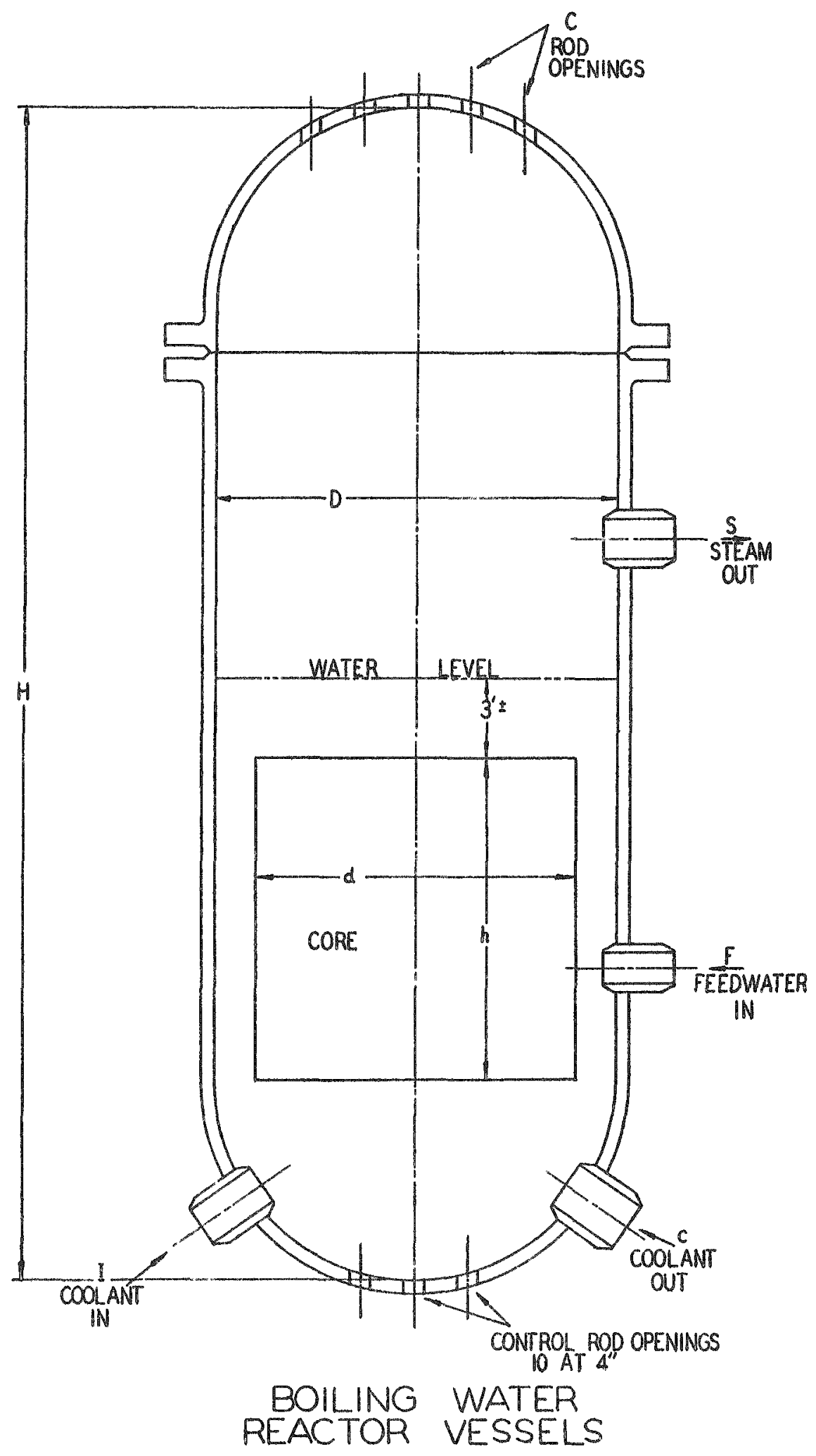


TABLE 2.13

\begin{tabular}{|c|c|c|c|c|c|c|c|c|c|c|c|c|c|c|c|c|c|c|}
\hline \multirow{3}{*}{$\begin{array}{c}\text { OPER. } \\
\text { PRESS. }\end{array}$} & \multirow{3}{*}{$\begin{array}{l}\text { OPER. } \\
\text { TEMP. }\end{array}$} & \multirow{3}{*}{ DIAM. } & \multirow{3}{*}{$H T}$. & \multirow{3}{*}{$\begin{array}{l}\text { ACTME } \\
\text { DIAM. } \\
d\end{array}$} & \multirow{3}{*}{$\begin{array}{c}\text { CORE } \\
\text { HT. } \\
h\end{array}$} & \multicolumn{8}{|c|}{ NOZZLE APERTURES } & \multirow{2}{*}{\multicolumn{2}{|c|}{$\begin{array}{c}\text { ROD } \\
\text { OPE } \\
\text { C }\end{array}$}} & \multicolumn{2}{|c|}{$\begin{array}{c}\text { Uisi!s } \\
3 n-502\end{array}$} & \multirow{3}{*}{$\begin{array}{c}\text { COST } \\
\text { EST. } \\
\text { (CLAD) }\end{array}$} \\
\hline & & & & & & \multicolumn{2}{|c|}{$S$} & \multicolumn{2}{|c|}{0} & \multicolumn{2}{|c|}{1} & \multicolumn{2}{|c|}{$F$} & & & \multirow{2}{*}{ Triact } & \multirow{2}{*}{$\begin{array}{c}W T \\
W\end{array}$} & \\
\hline & & & & & & No. & SIZE & NO. & SIZE & NO. & SIZE & NO. & SIZE & No. & SIZE & & & \\
\hline PSI & ${ }^{\circ} \mathrm{F}$. & FT. & FT. & $\mathrm{FT}$. & FT. & & IN. & & IN. & & IN. & & IN. & & IN. & IN. & TONS & DOLLARS \\
\hline & & & & & & & & & & & & & & & & & & \\
\hline 600 & 486 & I) & & & & & & & & & & & & & & 300 & 142 & \\
\hline 800 & $51 \overline{8}$ & $y$ & & & & & & & & & & & & & & 400 & 190 & \\
\hline 1000 & 545 & 15.30 & 45.00 & 12.0 & 12.0 & 1 & 18 & 3 & 22 & 3 & 18 & 1 & 4 & 20 & 8 & 5.00 & 239 & $1,505,700$ \\
\hline 1200 & 567 & lit & & & & & & & & & & & & & & 600 & 288 & \\
\hline 1400 & 587 & 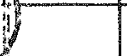 & & & & & & & & & & & & & & 7.00 & 340 & \\
\hline & & & & & & & & & & & & & & & & & & \\
\hline 600 & 486 & 1 & & & & & & & & & & & & & & 2.75 & 108 & \\
\hline 800 & 518 & $y$ & & & & & & & & & & & & & & 400 & 148 & \\
\hline 1000 & $54 \overline{5}$ & 14.40 & 4200 & 110 & 110 & 1 & 16 & 3 & 20 & 3 & 16 & 1 & 12 & 18 & 8 & 5.00 & 186 & \\
\hline 1200 & 567 & 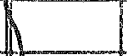 & & & & & & & & & & & & & & 6.00 & 222 & \\
\hline 1400 & 587 & L & & & & & & & & & & & & & & 6.50 & 260 & \\
\hline & & & & & & & & & & & & & & & & & & \\
\hline 600 & 486 & 1 & & & & & & & & & & & & & & 2.50 & 88 & 8 \\
\hline 800 & 518 & 7 & & & & & & & & & & & & & & 3.50 & 116 & \\
\hline 1000 & 545 & 13.25 & 36.25 & 100 & 10.0 & 1 & 13 & 3 & 18.5 & 3 & 14 & 1 & 10 & 16 & 8 & 4.50 & 149 & $\overrightarrow{0}$ \\
\hline 1200 & 567 & & & & & & & & & & & & & & & 550 & 182 & 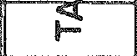 \\
\hline 1400 & 587 & 1 & & & & & & & & & & & & & & 6.50 & 215 & \\
\hline & & & & & & & . & 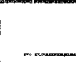 & & & & & & & & & & $\frac{\pi}{\omega}$ \\
\hline 600 & 486 & 4 & & & & & & & & & & & & & & 250 & 71 & \\
\hline 800 & 518 & D & & & & & & & & & & & & & & 350 & 99 & \\
\hline 1000 & 545 & 1225 & 33.25 & 90 & 9.0 & 1 & $10^{-}$ & 3 & 17.0 & 3 & 12 & 1 & 8 & 14 & 8 & 4.00 & 115 & \\
\hline 1200 & 567 & 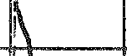 & & & & & & & & & & & & & & 500 & 142 & \\
\hline 1400 & 587 & $D$ & & & & & & & & & & & & & & 6.00 & 170 & \\
\hline & & & & & & & & & & & & & & & & & & \\
\hline 600 & 486 & 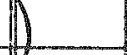 & & & & & & & & & & & & & & 225 & 73 & 650,520 \\
\hline 800 & 518 & 7 & & & & & & & & & & & & & & 300 & 88 & \\
\hline 1000 & 545 & 11.50 & 3300 & 80 & 80 & 1 & 6 & 3 & 1.6 & 3 & 10 & 1 & 5 & 12 & 8 & 4.00 & 117 & \\
\hline 1200 & 567 & & & & & & & & & & & & & & & 4.50 & 131 & \\
\hline 1400 & 587 & & & & & & & & & & & & & & & 550 & 160 & \\
\hline & & & & & & & & & & & & & & & & & & \\
\hline & $3-12-$ & & & & & & & $\begin{array}{l}=g e \\
=1 \\
=1\end{array}$ & & & & & & & & & & \\
\hline
\end{tabular}




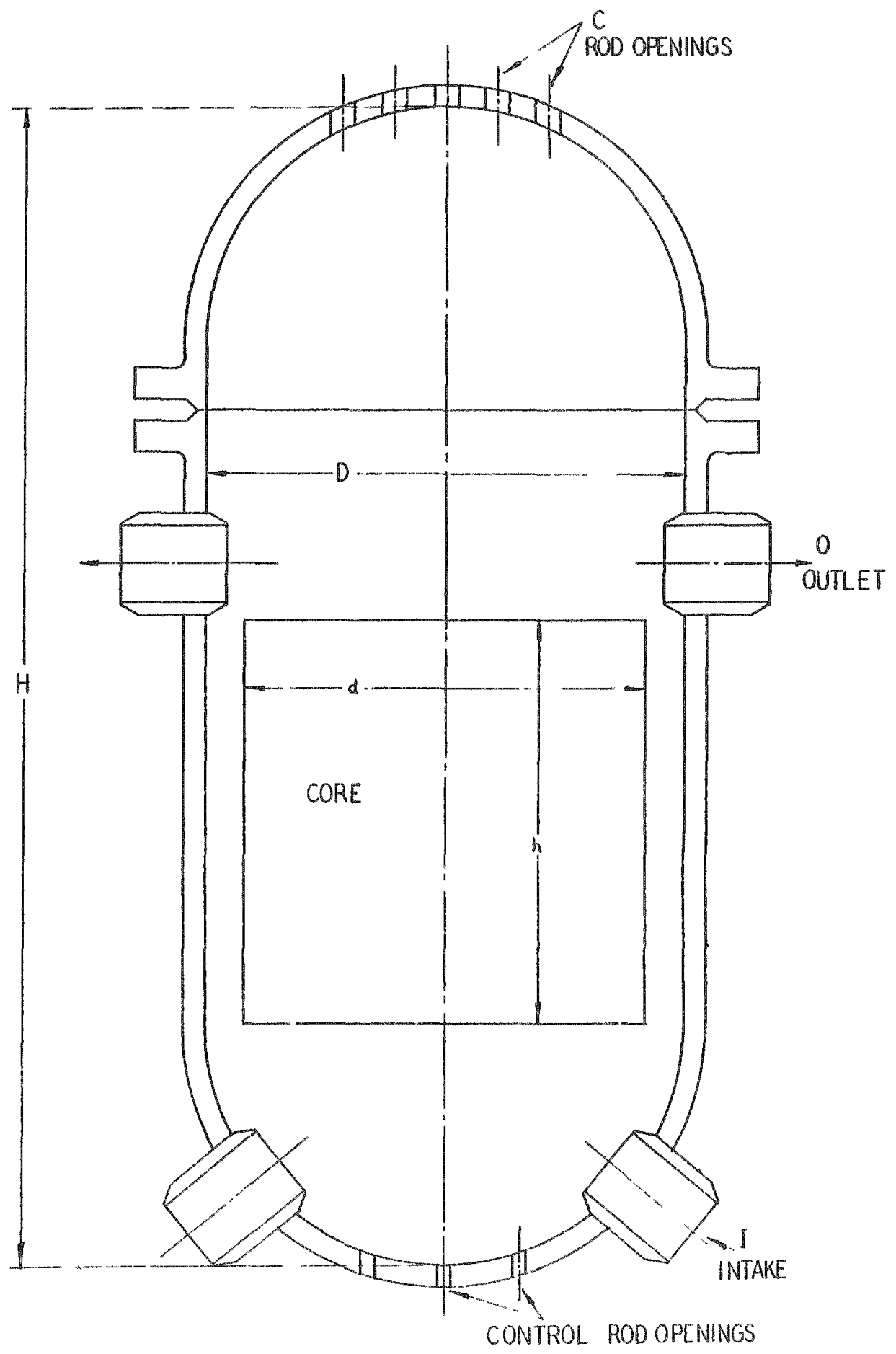

PRESSURIZED WATER

REACTOR VESSELS 
CONSOLIDATED WESTERN STEEL

DIVISION UNIT : STATES STEEL CORPORATION

TABLE 2.14

\section{PRESSURIZED WATER VESSELS}

REACTOR VESSEL

\begin{tabular}{|c|c|c|c|c|c|c|c|c|c|c|c|c|c|c|c|c|c|c|}
\hline \multirow{3}{*}{$\begin{array}{l}\text { OPER. } \\
\text { PRESS. }\end{array}$} & \multirow{3}{*}{$\begin{array}{l}\text { OPER. } \\
\text { TEMP. }\end{array}$} & \multirow{3}{*}{ DIAM. } & \multirow{3}{*}{ HT. } & \multirow{3}{*}{$\begin{array}{l}\text { ACTME } \\
\text { OLAM. } \\
d\end{array}$} & \multirow{3}{*}{$\begin{array}{c}\text { CORE } \\
\text { HT. } \\
h\end{array}$} & \multicolumn{8}{|c|}{ NOZZLE APERTURES } & \multirow{2}{*}{\multicolumn{2}{|c|}{$\begin{array}{l}\text { ROD } \\
\text { OPENINGS } \\
\text { C }\end{array}$}} & \multicolumn{2}{|c|}{$\begin{array}{r}\text { USNGG } \\
\text { SA-SO? }\end{array}$} & \multirow{3}{*}{$\begin{array}{l}\text { COST } \\
\text { EST. } \\
\text { (CLAD) }\end{array}$} \\
\hline & & & & & & \multicolumn{2}{|c|}{5} & \multicolumn{2}{|c|}{ Q } & \multicolumn{2}{|c|}{1} & \multicolumn{2}{|c|}{ F } & & & \multirow{2}{*}{$\begin{array}{c}\text { Thich } \\
1\end{array}$} & \multirow{2}{*}{$\begin{array}{c}W T \\
w\end{array}$} & \\
\hline & & & & & & NO. & SIZE & NO. & SIZE & No. & SILE & No. & SI2E & No. & SIZE & & & \\
\hline PSI & $F$ & $\mathrm{FT}$. & $F T$. & $\mathrm{FT}$. & FT. & & IN. & & IN. I & & IN. & & IN. & & IN. & IN.: & TONS & DOLLARS \\
\hline & & & & & & & & & & & & & & & & & & \\
\hline & & & & & & & & & & & & & & & & & & \\
\hline 1400 & 587 & & & & & & & & & & & & & & & 6.00 & 189 & \\
\hline 1600 & 605 & $\longdiv { 1 2 . 6 }$ & 30.2 & 106 & 106 & & & 4 & 24 & 4 & 24 & & & 20 & 8 & 6.50 & 203 & \\
\hline 1800 & 621 & & & & & & & & & & & & & & & 7.50 & 237 & \\
\hline 2000 & 636 & 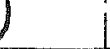 & & & & & & & & & & & & & & 8.50 & 268 & \\
\hline 1800 & 621 & 13.8 & 34.4 & & & & & 4 & 24 & 4 & 24 & & & 42 & 8 & 8.40 & 330 & $2,475,660$ \\
\hline & & & & & & & & & & & & & & & & & & \\
\hline 1400 & 587 & & & & & & & & & & & & & & & 7.00 & 264! & \\
\hline 1600 & 605 & 13.4 & 33.4 & 10.0 & 10.0 & & & 4 & 20 & 4 & 20 & & & 36 & 8 & 7.80 & 292 & \\
\hline 1800 & 621 & & & & & & & & & & & & & & & 8.40 & 325 & \\
\hline 2000 & 636 & & & & & & & & & & & & & & & 9.50 & 385 & \\
\hline & & & & & & & & & & & & & & & & & & 8 \\
\hline & & & & & & & & & & & & & & & & & & 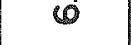 \\
\hline 1400 & 587 & & & & & & & & & & & & & & & 5.00 & 103 & $\omega$ \\
\hline 1600 & 605 & $\$ 10.0$ & 23.0 & 6.5 & 6.5 & & & 4 & 181 & 4 & 18 & & 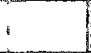 & 30 & 85 & 5.50 & 114 & $\overline{0}$ \\
\hline 1800 & 621 & & & & & & & & & & . & & 3 & & & $600^{\prime}$ & 124 & $F$ \\
\hline 2000 & 636 & 2 & & & & & & & & & & & 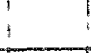 & & & 7.00 & 145 & $\omega$ \\
\hline & & & & & & & & & & & & & & & & & & $\bar{c}$ \\
\hline 1400 & 587 & & & & & & & & is & & & & & & & 4.00 & 58 & 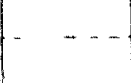 \\
\hline 1600 & 605 & 884 & 218 & 6.4 & 6.4 & 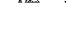 & & 4 & 16 & 4 & 16 & & & 25 & 8 & 4.50 & 66 & - \\
\hline 1800 & 621 & & & & & & & & & & & & & & & 5.00 & 73 & 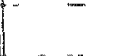 \\
\hline 2000 & 636 & & & & & & & & & & & & & & & 6.00 & 88 & \\
\hline & & & & & & & & & & & & & & & & & & \\
\hline & & & & & & & & & & & & & & & & & & . \\
\hline & & & & & & & & & & & & & & & & & & 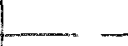 \\
\hline & & & & & & & & & & & & & & & & . & ... & $\ldots$ \\
\hline & & & & & & & & & & & & & & & & & & \\
\hline & & & & & & & & & & & & & & & & & & 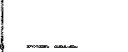 \\
\hline & & & & & & & & & & & & & & & & & & \\
\hline
\end{tabular}




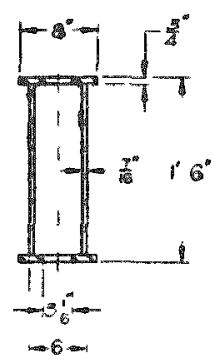

SECTION C-C. RETAINER HEAD

3" DIA HOLD-DOWN BOLTS OMITTED FOR CLARITY
M2O OIA NOZZLE-

SUPPORT ERACKETS
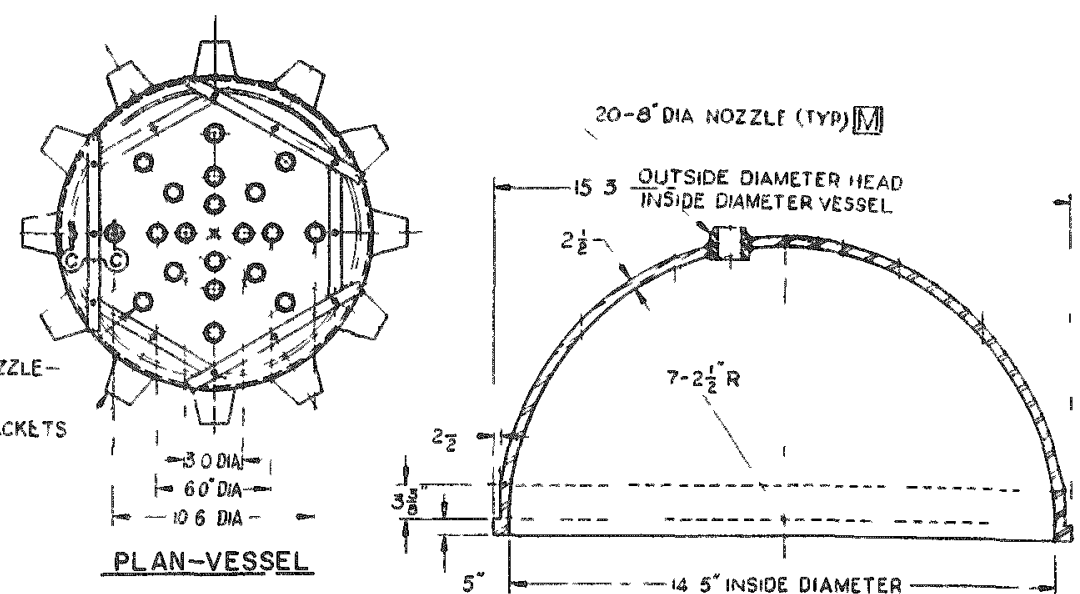

1

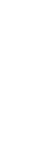
1 . 1 - 7 - GLAND DRAIN $\frac{1}{3 a^{n}}$ 5 FT 7 -VESSEL SHELL

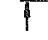

(1)

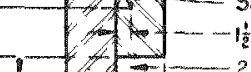

$5 \frac{1}{4}+2 \frac{1}{2}+-15$

2 CLEARANGE TO ALLOW ASSEMESIY

DETAIL D MEAD CLOSURE

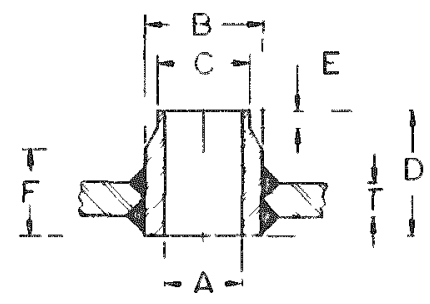

DETAIL E

TYPICAL NOZZLE REINFORCEMENT THROUGH VESSEL SHELL.

NOZZLE DIMENSIONS

\begin{tabular}{|c|c|c|c|c|c|c|}
\hline 0 & UUAN & $A$ & $\mathrm{~F}$ & C 11 & $E$ & $r$ \\
\hline FEW & 20 & 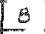 & $12^{2}$ & & & \\
\hline STEAM & 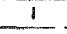 & 18 & 28 & & & \\
\hline$F$ & 1 & {$[4$} & 8 & & & \\
\hline & 10 & 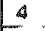 & 6 & 14 & & $10^{n}$ \\
\hline 4 & \$ & 18 & $28^{\circ}$ & & & 1102212 \\
\hline$\pi$ & 3 & 2 & & & & \\
\hline
\end{tabular}

$3-12-57$

[18 DIA SIEA, O] 4 DIA FEED
WATER OPEAMU

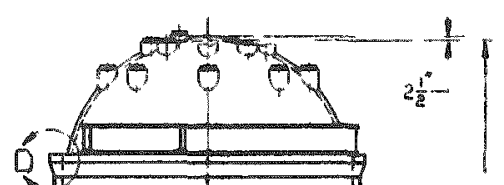

CUTREAR
SURRACES
TOMATCH
VESSEL $\quad[-20=1$

SECTION A-A

CROSS SECTION OF HEAD OMITTING HOLD-DOWN BRACKETS

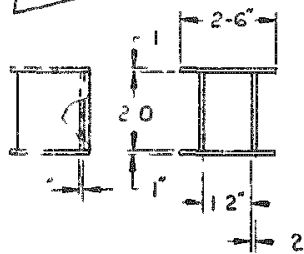

DETAIL $F$ SUPPORT BRACKET

\section{NUTE}

1 MM"ERHAL S 302 HADE YESOEL G"AI HLESS S FEEL L LA'S

2 ". W WHAL TH HCKMESS $5 \%$ " LOWF R HEAD THKRTESSO

ELEVATION-VESSEL

$2_{6}$

3 AI L NOZ"LE SUMFA ES UN INTERIOR F - ESSEL, IMINLESG YTEEL GLAD

4 PE. K HEAD NOZZLE ENDS TO FIT $5 T 01500^{\circ}$ WELD NECK F ANGE

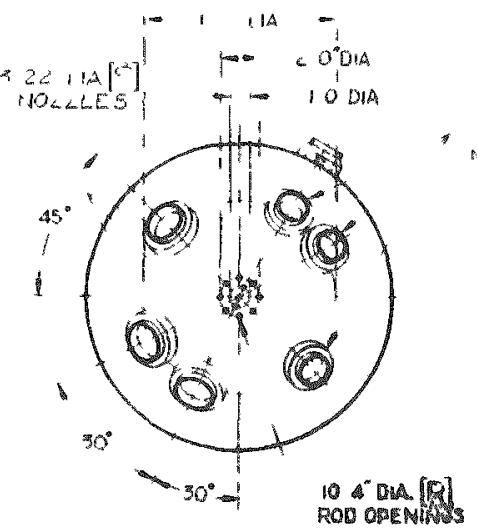

BOTTOM VIEW-VESSEL.
FIGURE A

$15^{\prime}-3^{\prime \prime}$ DIAMETER, 1000 PSI BOILING WATEA REACTOR VESSEL 


\subsection{Material}

\subsection{Resctor Vessels}

2.2211 This study is based on reactor vessels being built of low-alloy steel $8 A-302$, Grade $B$, with $5 \%$ cladding, using - a stress of 20,000 psi.

\subsection{Containment Vessels}

2.2221 This study is based on containment vessels being built of steel qualified to SA-300, using a stress of 13,750 psi.

\subsection{Pressures}

2.231 Pressures used are in accordance with design sheets furnished Consolidated by Amexican.

\subsection{Temperatures}

2.241 Temperatures are calculated on the basis of using saturated stean at the given pressures.

\subsection{Fabrication}

\subsection{Weld Design}

2.2511 Design is based on the use of welded, rolled, and/or forged construction with double welded butt joints, stress relieved (unless wall thickness 1 s less than $1-1 / 2^{\prime \prime}$ ).

\subsection{Joint Inspection}

2.2521. As specifled in sections 3 and 4, this report, joints will be elther radiographed or inspected by the iluid penetrant method, or other allowable inspection methods a aproved by the code.

\subsection{Joint Efficiency}

2.2531 A joint efficiency of $95 \%$ has been assumed.

\subsection{Internal Water Preasure}

2.261 A possible stat1c head of water Inside the vessel has been ignored as a minor fector in wall thickneas calculations. 

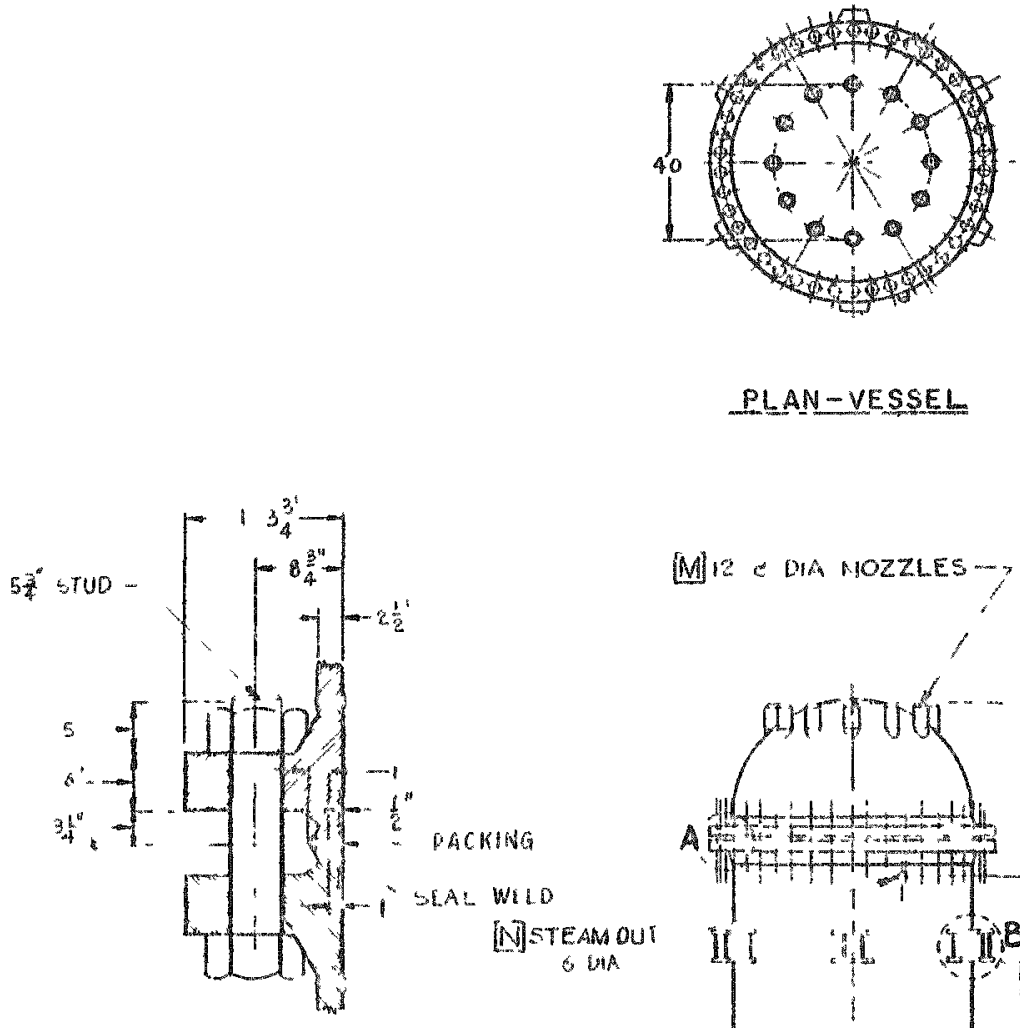

DETAIL A MEAD CLOSURE

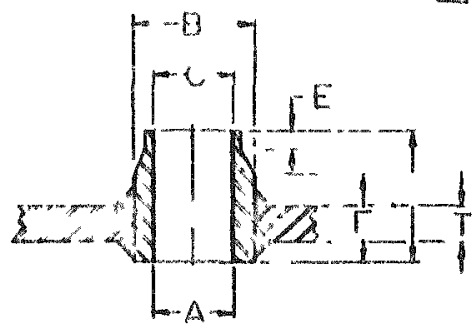

DETAL C

TYPICAL NOZZLE REINFORCEMENT THROUGH VESSEL SHELL
NOZZLE DIMENSIONS

\begin{tabular}{|c|c|c|c|c|c|c|c|c|}
\hline LOCATION & QUAN & $A$ & $B$ & c & 0 & $E$ & 10 & $T$ \\
\hline MPFWWDE & 13 & $8^{\circ}$ & $\sqrt{115^{2}}$ & & 73 & & 48 & 13 \\
\hline N $[: J E A M$ & 1 & $6^{\prime \prime}$ & $10^{\circ}$ & & $9^{2}$ & 1 & {$[65$} & 25 \\
\hline (O) 64 & 1 & 5 & $9^{4}$ & & 85 & 1 & 6 & $2 \% 1$ \\
\hline the & 3 & 16 & 22 & & $9.3^{\mathrm{n}}$ & & 50 & 13 \\
\hline R the & 3 & 10 & $\sqrt{18}$ & & 83 & $i^{2 \pi}$ & 58 & $|i| 3 \mid$ \\
\hline tom & 10 & 4 & $7^{\circ}$ & & 100 & 34 & 148 & 13 \\
\hline
\end{tabular}

$3-12-57$

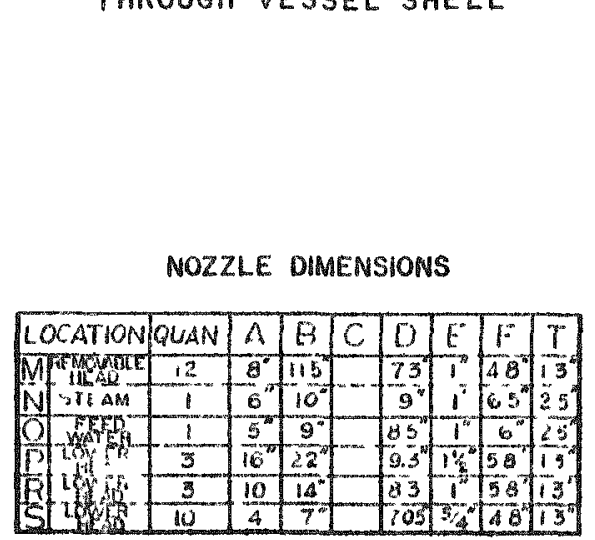

PLAN-VESSEL

MH $C$ DIA MOZZLES
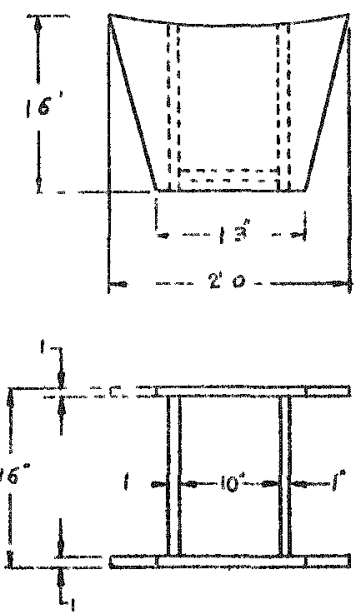

DETAL B SUPPORT BRACKET

\section{NOTES}

1. MATERIAL-SA-302 INSIDE VESSEL STAMULESS STEEL DLAD

2 CYL WALL THAKKNESS, 2.5"

BOTH MEADS THICKNESS, 1.S"

3 ALL NOZZLE SURFACES ON INTERIOR OF VESSEL, STAAINLESS STEEL

4.NECK HEAD NOZZLE ENOS TO FIT

STO $1500^{*}$ WELD NECK TLANGES

ELEVATION VESSEL STAINLESS STEEL

6 ALL WELDS FULL PENETRATION

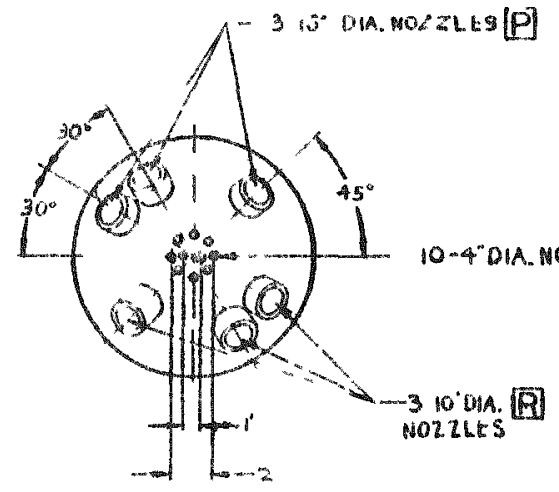

DOT $10 M-V E S S E L$

$546 x^{\circ}$

$v^{2} \rightarrow 6$

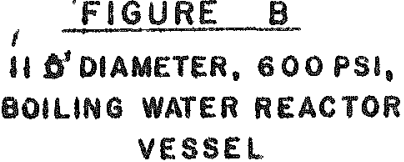

03388 


\section{4}

CONSOL IDATED WESTERN STEEL

DIVISION UNITEO STATES STEFL COKPORATION

\subsection{Destgn Formulae \\ 2.271 Reactor Vessels \\ 2.2711 Reactor vessels have been designed in accordance with formulae in paragraph UG-27 of the Code:}

Cylindrical Shell

$t=\frac{P R}{S E-0.6 P}$
Spherical She11

$t=\frac{P L}{2 S E-0.2 P}$

where

$$
\begin{aligned}
& t=\text { Wall Thickness in inches } \\
& P=\text { Design Pressure, pounds per square Inch } \\
& R=\text { Inside Radius of shell, in inches, without } \\
& \text { allowance for corrosion. } \\
& I=\text { Inside Radius of sphere, In Inches, without } \\
& \text { allowance for corrosion. } \\
& \mathrm{S}=\text { Mximum allowable stress, pounds per square } \\
& \text { inch. } \\
& \mathrm{E}=\text { Joint Efficiency }=95 \% \text {, assumed, stress-relieved. } \\
& I=\text { Joint Lfficiency }=80 \% \text { assumed, non-stress relleved. }
\end{aligned}
$$

2.272 Contalnment Vessels

\subsection{Design}

Containment vessel design is the same as reactor veasel design except for material (see paragraph 2.22 above).

\subsection{Pressure}

Pressure has been assumed at 30 psig.

\subsection{Stress Relier}

Containment vessels will not be stress relieved, since it has been practical to hold wall thickness to the I1mits aiscussed in paragraph 1.122 above.

\subsection{Inspection}

Radiographic inspection will be used. 


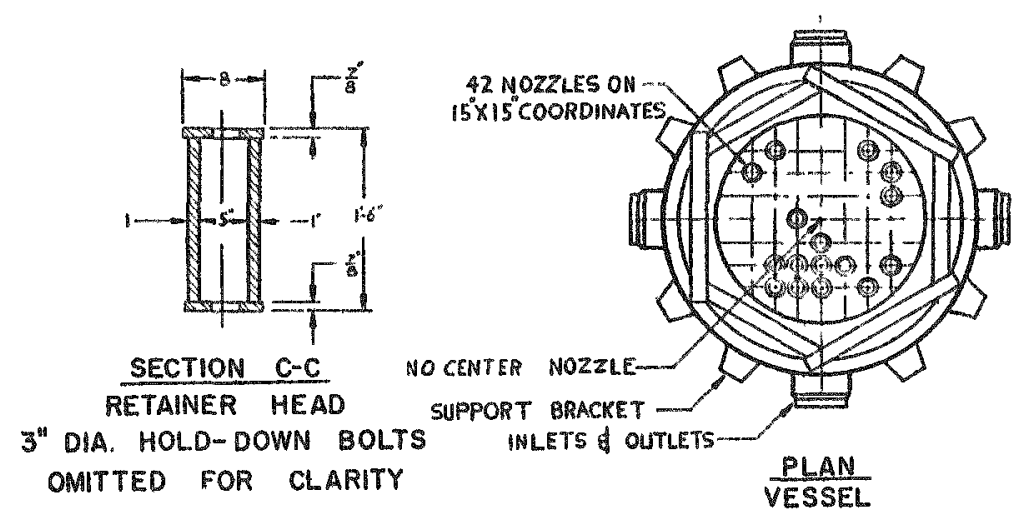

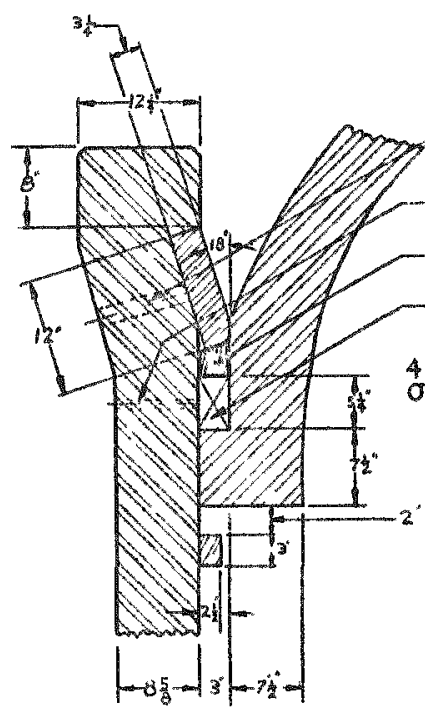

DETAIL D HEAD CLOSURE

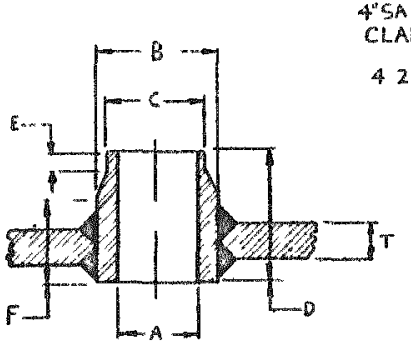

DETAL E

TYPICAL NOZZLE REINFOACEMENT

THROUGH VESSEL SHELL

\section{NOZZLE DIMENSIONS}

\begin{tabular}{|c|c|c|c|c|c|c|c|c|}
\hline LOCATION & GLAATII & $\mathbf{A}$ & $B$ & c & 0 & $E$ & $\mathrm{~F}$ & $\mathrm{r}$ \\
\hline N DORE & 4 & 24 & 34 & 28 & (1) & & & $8^{5}$ \\
\hline $\begin{array}{l}\text { PINLE } \\
\text { R.SOE }\end{array}$ & $\frac{4}{10}$ & $\frac{24^{4}}{4^{4}}$ & $\frac{30}{8}$ & & $\sqrt{\frac{24}{15}}$ & $\frac{2^{\prime \prime}}{2^{\prime \prime}}$ & & $\frac{48}{48}$ \\
\hline
\end{tabular}

$3-12-57$
- SEGMENT RNOCK-OUT HOLE

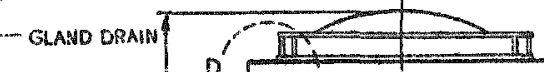

SEAI ING RING

SEAL (GEE FIGS)

i

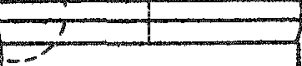

24DIA

N

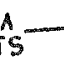

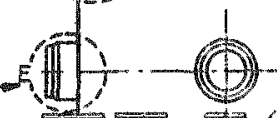
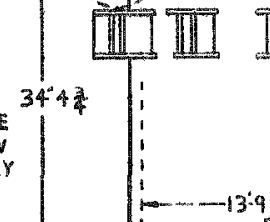

\& OIA.INLEYS

$\mathrm{F}$
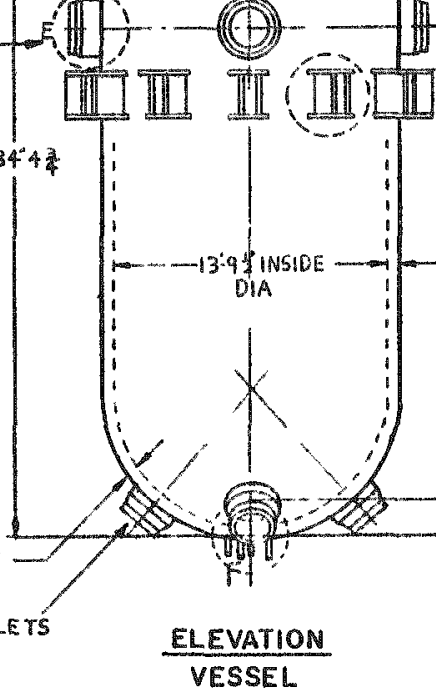

VESSEL

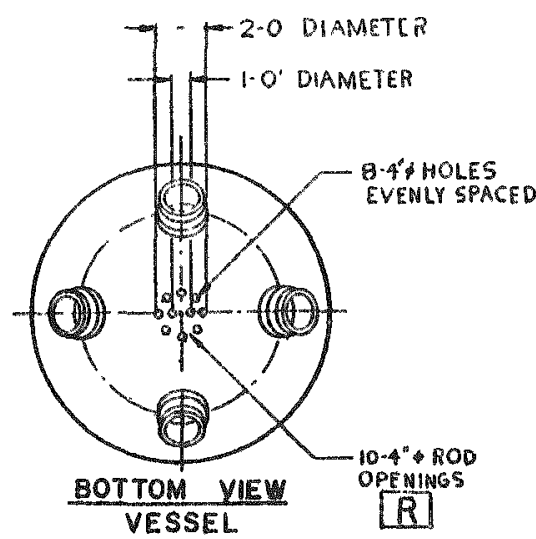

Page

28

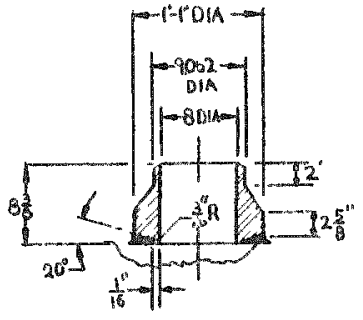

TYPICAL MEAD NOZZLE JOINT REINFORCEMENT

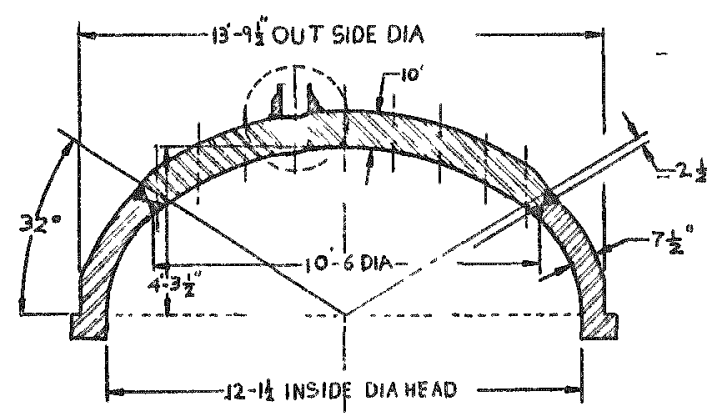

SECTION A-A

CROSS SECTION OF HEAD

OMITTING HOLD-DOWN BRACKETS

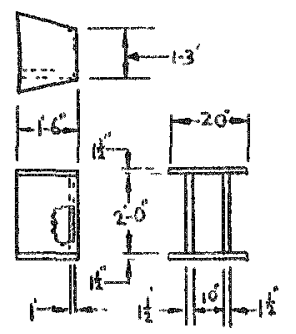

DETAIL $F$

SUPPORT BRACKET

\section{NOTES}

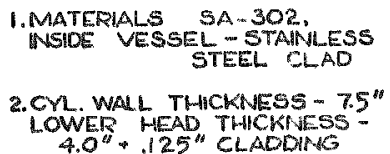

3. ALL NOZZLE SURFACES ON MTTERIOR OF VESSEL STANLESS STEEL CLAD

A. NECK HEAD MOZZLE ENDS TO FIT STO. $150^{\circ}$ WELD NECK FLANGES

5.ALL WELUS ON WTERIOR OF VESSEL STANNLESS STEEL

G.ALL WELDS FULL PENETRATION

FIGURE $C$

$13.8^{\circ}$ DIAMETER, 1800 PSI

BOILING WATER

REACTOR YESSEL 63388 
CONSOLIDATED WESTERN STEEL.

DIVISION UNITED STATES STEEL CORPORATION

2.2725 Heads

The bottom heads of containment vessels will be semielliptical; and the top heads w111 be bemispherical.

\subsection{Drawings}

Wo dravings illustrating this design are included in this report. 


\section{CONSOLIDATEO WESTERN STEEL}

\section{DIVISION UNITED STATES STEEL CORPORATION}

DISCUSSION

SECIION III

SPECIFICATION - GENERA PROVISION 
INDEXX

SRCTION III

SPECIFICATIONTS-GRMVERAT PROVIS IONS

3.1 General 33

3.2 scope of Work 33

3.3 General Specifications

3. 31 Codes

3.32 Certificates

3.33 Materials

3.331 Reactor Vessels

3.332 Containment Vessels

3.34 Cleaning

3.341 Materials

3.342 Preliminary cleaning

3.343 rinal Cleaning

3.344 Acid Cleaning

3.345 Neutralizing

3.346 Wire Brushing

3.35 Bolting

3.36 Cladding

3.4 Inspection

3.41 Procedure

3.42 Inspection-Visual

3.43 Inspection-Penetrant Method

3.5 Testing

3.51 Hydrostatic Testing

3.511 Reactor Vessels

3.512 Closures and Seels

38

3.52 Pneumatic Testing

3.53 Material and Test Records

3.6 Instruction Books - Equipment Catalogs 39

3.7 Transportation 39

3.8 Erection 40 


\subsection{SPECIFICATION-GENERAI PROVISTONS}

\subsection{GENERAT}

This speciflcation presents generol and speciflc materials, processes, and procedures for fabricating nuclear reactor pressurized water, boiling water and contalnment vessels.

The subject vessels may be described as equipment containing lethal substances, and termed crit1cal apparatus.

Generally, the specification, deslgn and fabrication of pressurized and bolling water reactors and containment vessels, togethex wh required appurtenances, W111 conform to the mandetes of the 1956 revision (Addenda and Case Rulings) Section I of the ASME Pressure Vessel Code.

It is contemplated to fabricate the subject vessels by any one of the methods listed below, or by any combination of auch general methods:

a. Welded forged sections (thick wall only)

b. Formed and welded solld plate (to 10" wall)

c. Any combination of forged ox welded plate construction.

\subsection{SCOPE OF WORK}

The scope of work will consist of procuring or furnishing perannel, material, manufacturing facilities, labor and equipment to engineex, design, detail, fabricate, test and erect Bolling Water, Preasurized Water Reactor Vessels, in addition to such Containment Vessels as specified hereinafter and as proposed in subsequent design studies and recommendations.

\subsection{GENERAI SPECI FTCATIONS}

\section{31 Codes}

All vessels described in this specification will be constructed in accordance with applicable provistons of section I or section VIII of the ASME Boller and Pressure Vessel Code, Including Case Interpretations of AsMe Boller and Pressure Vescel Code, approved by ASME Counc11 September 6, 1956 and des1gnated Case Nos. 1223. 1224, 1225 and 1226, as presented in Appendix A to this report. 
Specific exceptions from Code requirements shall include the following:

a. Sarety valves shall not be attached to the vessel proper.

b. Provisions for inspection handholes and manholes shall be omitted.

c. Provision for regular, periodic inspection of internal and external surfaces and welds shall be omitted.

\subsection{Certificates}

The ressel manufacturer shall furnish the buyex with:

1. ASME Code Certificate

2. Hartford Insurance Company Certiflcate of Inspection 11gting:

(a) Maximum Operating Pressure

(b) Maximum Operating Temperature

(c) Design Pressure

(d) Design Temperature

(e) Minimum Test Pressure

(f) Maximum Collapsing Pressure

(g) Mininum Allowable Heating and Cooling Rate

\subsection{Materials}

3.331 Pressurized and Bolling Water Reactor Vessels

a. Clad Vessels

Low Alloy steel SA-302 Grade B with 5\% SA-304 extro low carbon stainless clad will be used.

b. Unclad Vessels

SA 167 Grade 11 steel will be used.

\subsection{Containment Vessels}

Steel qualifled under $\$ \mathrm{~A}-300$ at 13,750 pai allowable atresk vill be used.

\subsection{Cleaning}




\section{CONSOL IDATED WESTERN STEEL}

\subsection{Materials}

Matexials and chemlcals used in process cleaning for ressels under considexation shall be new, clean and of commerclal quality. Materials will generally consist of the following:

(a) Muriatic Acid

(b) Inhjultor (Formaldehyde, ACP Rodine $\# 60$, or equivalent)

(c) Stoddard Solvent

(d) Trichlorethylene

(e) Sand (40 Mesh)

(e) Alundum Grit (60 Mesh)

(g) Abrasive paper or cloth

(h) Steel Wre Brushes (Stainless Steel)

\subsection{Preliminary Cleaning}

Prior to welding; grease, 011, dirt, etc. shall be removed by the most suitable chemical process.

Abrasive cleaning (if required) shall be used to remove the remaining surface imperfections by application of sand, or alundum grit, under pressure, until the surface is visibly and chemically clean. Grease, oil, etc. must be removed prior to abrasive cleaning. Caution should be used in the application of grit, not to exceed the length of time necessary to clean the surface. Care must be exercised to guard against uneven and unnecessary erosion. Surfices shail not be handled after abrasive cleaning unt11 welding is completed.

\subsection{Final Cleaning}

Final cleaning of the surface (if varranted) may be accorplished by one of the following methods:

(a) Alkaline solution of 5-8 ounces per galion (Concen tration in hot 185 to $210^{\circ}$ F).

(b) Soltened water may be used to remove trace impurities after preliminary cleaning.

(c) Cleaning may be accomplished by immersion, scrubbing, or steam jet spray. 


\section{CONSOLIDATED WESTERN STEEL}

\subsection{Acid Cleaning}

Acid cleaning may be used if required, following abrasive cleaning or to remove rust traces unremoved by previous cleaning. Prepare a solution of $40-60 \% \mathrm{HCI}$ by volume with remalnder tap water at temperature of $120-140^{\circ} \mathrm{F}$. Time of application shall be 15-60 seconds or unt11 removal of contaminants is effected.

\section{$3 \cdot 345$ Neutral1zing}

Parts shall ve thoroughly rinsed by tap water with residual particles being removed by wire brush scrubbing, during flushing operation. Application of hot water to rinsing process will speed drying.

\subsection{Wire Brushing}

Haud brushing or mechanical power-ariven brushing will produce acceptable results. Apply brushing until surface appears free of scale, rust, etc. Chemical cleaning must precede wire bmushing to remove oil, grease, etc.

\subsection{Bolting}

Bolting will conform to ASME Code.

\subsection{Cladding}

Cladding material where used on vessel surfaces and appurtences shall be stainless steel Type 304, extra low carbon. The bond integrity of all clad material will be demonstrated by admitting Nitrogen Gas at 2,000 psi between the two intemal surfaces of a sample not less than $8^{\prime \prime}$ square. Gas leakage sha.1 be indicated by a liquid soap solution applied to the entire clad. surface. Bond integrity shall be established prior to rabxication and prior to stop testing. Cladding tests shall also precede rolling or pressing operations in ordex to discover defective materials at an early date. 


\subsection{INSPECCIION}

\subsection{Procedure}

The contractor will submit a detailed inspection procedure conforming to ASME Codes before beginning work.

3.42 Inspection-Visual

Visual inspection shall be made to determine that no cleaning solutions are entrapped in seams or between adjacent surfaces. No visible films shall be left on any surface subsequent to cleaning.

\subsection{Inspection-Penetrant Method}

3.431 Inspection of the surfaces of welded joints for detection of cracks, inclusions, and defects may be effected by means of the Penetrant Method. This method is applicable to the inspection of non-porous, non-absorbent materials which will be unaffected by reaction to the chemicals used in the process.

3.432 Two types of inspection methods are available:

3.4321 Fluorescent Penetrant

After application and processing, the penetrant fluoresces, or glows, strongly after exposure to "Black Iight" (3,600 plus or minus 300 Angstrom Units Wave Length). Inspection by Fluorescent Penetrant will be restricted to two types:

\subsection{1(1) Posto-Emulsification Procedure}

Application of the emulsifier is made separately after application of penetrant.

\subsection{1(2) Combined Penetrant-Emulsifiter Procedure}

In this procedure, the emulsifier and penetrant are combined for application in a single operation.

\subsection{Non-FIuarescent Penetrant}

3.4231 Color of the penetrant contrasts strongly with back ground after examination under white Ilght. 


\subsection{Testing}

\subsection{Hydrostatic Testing}

3.517 Reactor Vessels - Hydrostatic testing will be used on vessels where the weight of water used in the test is not sufflcient to cause deformity. Testing will follow code requirements with all vessels tested to $150 \%$ of maximum allowable working pressure.

3.512 Closures and Seals - No external leakage will be permitted from any seal or closure device. A total leakage of one (I) gallon $p \in r$ hour will be allowed from all internal seals on any one vessel. All contaminated leakage shall be returned to the system or disposed of to the contaminated waste lines.

\subsection{Pneumatic Testing - Reactor and Containment VesseIs}

3.521 Pneunatic testing will be used where vessel structures are sufficiently large to preclude the use of hydraulic tests. Tests will be conducted to not less than design pressure, with a mixture of $10 \%$ helium and $90 \%$ air. Leakage shall not exeed. 0.001 total pressure per hour as determined by a mass spectrometer. Leakage source shall be determined by a ceneral Electric, or equivulent, leak detector, by isolating suspect weld areas by the plastic bag method and "sniffing" for leakage source. AII defects shall be satiefactorlly rewelded.

Strain gaging will be required on contalnment vessels to closely observe structural yield pattexns. Automatic data reduction will assure close control of testing procedure and give adequate warning of criticul yield patterns in time to prevent structural deformation or failure.

3.522 Testing conditions will be individually tailored to correlate with the design of the ressel.

3.523 A detalled procedure for testing all vessel structures, either hydrostatlcally or pneumatically, will be submitted after vessel desigr is completed.

\subsection{Material and Test Records}

3.531. All lests on materials required by Section I, Power and Boilers of the 1956 Edition (including addenda and interpretations) of the ASME Boiler and Pressure Vessel Code, will be applied to each plate or portions thereof, forging or casting, utilized in the construction of Reactox or Containment Vessels. Results of tests will be approved before incorporation of the material into vessel ascemblies. 
3.532 The following information will also be supplied for recora or approval.

3.5321 Plate number records, heat numbers, Mill Test Reports.

3.5322 Forgings and all heavy plate will be radiographed or non-destructively tested by other approved methods bofore incorporation into the structures. Defects in materials shall be reviewed by the contractor and. American standard to determine acceptance or rejection.

3.5323 Permanent records giving location of plates, forgings, etc., shall be reported and preserved on final drawings or other adequate records.

\subsection{IMSTRUCTTON BOOKS - EQUIPMENT CATALOCS}

3.61 The contractor shall prepare a comprehensive Instruction and Calculation Manual containing the following items:

a. Detailed, explanatory representation of finished and assembled structures.

b. Design and operating criteria.

c. Complete design and stress calculations.

d. A reproducible copy of the Ceneral and Detail Specifications, together with twenty ifive (25) copies of same.

e. Details and results of material, weld, procedure tests and hydrostatic tests.

I. Reproduction of Mill Teste.

g. Reproductions of ASME and Insurance Certificates required by the ASME Boiler and Fressure Vessel Code.

h. A Iist of recommended spare parts.

1. Five (5) copies of equipment vendor's specifications and dirnensions of major purchased items.

\subsection{TRANSPORTATION}

3.71 A Transportation and shipping schedule will be prepared by the Contractor indicating the overall plan of shipment, proposed dates of shipment, routes, and methods of prote; ing equipment. during transit. 


\subsection{ERECTION}

3.81 The Contractor shall be responsible for transferring pressure vessels, components, and equipment or appurtences from the rail site to the erection site and shall provide field supervision and erection crew to completely erect, rield fabricate, and test, vessels and equipment.

3.82 The Contractor ahall also be responsible to connect all external piping to the vessel, together with installation of reactor vessel internal components. Whe Contractor shall conduct and supervise all Hydrostatic and Pneumatic Proof Tests. 
TMDEX

SECTION IV

SPECIFTCATIONS - WETDING

4.1 Solid Stainless Wall Vessels

4.11 General

4.12 Welding-Head and girth Seams

4.13 Welding-Nozzles

4.14 Welding-Attachments

4.15 Stress Relleving

4.2 Stainless Clad Steel Wall Vussels

4.21. General

4.22 Qualification

4.23 Welding-Iongitudinal Seams

4.24 Preparation

4.25 Welding-Head and Girth Seams

47

4.26 Welding-Nozzles

47

4.27 Depositing Stainless Overlays

47

4.28 Welding-Attachments

49

4.29 Stress Relieving

4.3 steel Wall Containment Vessels

4.31 General.

4.32 Cleaning and Inspection

50

4.33 Typical Weld Bead Detail

50

52 


\subsection{SPECIFICATION - WELDIIG}

\subsection{SOLID STATNLESS WALI VESSEL}

4.11 General

4.111 All welding shall be done in accordance with section VIII and IX of the ASME Boiler and Pressure Vessel Code as latest revised.

4.112 Manual welding on Type 304 stainless steel shall be done using Type 308 stainiess steel coated electrodes.

4.113 Automatic welding on Type 304 stainless steel shall be done using Type 308 stainless steel wire and Arcos Arcosite B4 flux.

4.114 No preheat shald be used. Interpass temperatures shall be limited to $225^{\circ}$ I. $\max$.

4.215 The stainless steel surface shall be protected by spattex proof compound and a heavy paper or cardboard covering to avold marring the inside surface. No fitup attachments shall be made to the inside surface of the plate.

4.116 Wherever possible, welding shall be done in a dowhand flat position.

4.117 No peening shall be permitted on stainless steel welds.

4.118 Welding operators and procedures shall be qualified in accordance with Section IX of the ASME Boiler and Pressure Vessel Code. All completed welds shall be 100 percent $X-r a y$ radiographed in accordance with paragraph UW-5I of Section VIII of the ASME Boiler and Pressure Vessel Code. In addition, progressive X-ray inspection shall be used to check the weld quality during the welaing operation.

\subsection{Welding - Head and Girth Seams}

4.121 Tack weld ring sections together with Iype 308 electrodes using a $15^{\circ}, 3 / 8^{\prime \prime}$ radius, $3 / 16^{\prime \prime}$ land, double V-groove joint.

4.122 Deposit veld passes starting on the inside.

4.123 Deposit 5 weld beads on the inslde cleaning each pass 
thoroughly by wire brushing with stainless steel brushes. Inspect each pass visually and by Dye-Chek. Chip or grind out all defects and repair before proceeding with subsequent passes.

4.124 Check alignment of plates accurately at this point.

4.125 Backchip weld from outside to sound metal. Deposit 10 weld beads Inspecting each bead visually and with Dye-Chek.

4.126 Dye-Chek inspection of each weld bead pass shall not be required on subsequent passes, however, periodic Dye-Chek Inspection should be made where defects are suapected. Each weld bead layer shall be thoroughly cleaned and visually inspected for defects.

4.127 Turn plate over, depostt 10 weld beads on the Inside and then X-Iay inspect. Continue depositing 10 weld beads first on one side and then on the other, $x$-raying each time until the weld groove is filled to the required depth.

4.128 Inspect completed weld by Dye-Chek and X-xay.

\subsection{Welding-Nozzles}

4.131 Nozzles shall be welded using a combination fillet and double bevel joint as show on the drawing. (Figure)

4.132 Inspect welds by means of Dye-Chek and $\mathrm{x}$-ray radiograph.

\subsection{Welding - Attachnents}

4.141 AI1 attachments to the stalniess steel surfaces shall be made using Iype 308 stainless steel weld metal.

\subsection{Stress Relieving}

4.151 All stress relieving of shop welds shall be done in accordance with paragraphs UW-lyo and UCS-50 of Section VIIT of the ASME Boiler and Pressure Vesal Code. Provisions applicable to the Type 304 stainless steel materiol shall apply.

4.152 Where practicable field welded joints shall be locally stress relleved by heating a band equal to twice the plate thickness or more on each side of the veld as specified in paragraph UW-40 of Section VIII of the ASME Bollex and Pxessure Vessel Code. 


\subsection{STADVLSS CLAD STEIT WATL VDSSELS}

4.21 General

4.211 All welding shall be done in accordance with section VIII and IX of the ASMIS Boller and Pressure Vessel Code as latest revised.

4.212 Al1 menual welding on ASTM A-302 Grade B material shall be done using AWS Class $\$ 9015$ electrodes.

4.213 A11 automatic velding on ASM A-302 Grade B metertal shal1 be done by the submerged-arc process uging Iinde 40 wire and Iinde Unionmelt 80 Iux.

4.214 Manual welding on Type 304 stainiess steel shall be done using Type 308 stainiess steel coated electrodes. However, before applying Iype 308 weld metal to ASTM A-302 Grade B steel, the surface shall first be "buttexed" with Iype 310 (25 Cr 20 II) stainless steel coated electrodes. Ihis latter procedure shall be used both when applying the stainless clad to the groove welds and when applying stainless steel overlays.

4.21.5 Automatic welding on Type 304 stainless steel shall be done using Iype 308 stainless steel wire and Arcos Arcosite B4 flux. All ASTM A-302 Grade B steel surfaces sholl tixst be buttered using Iype 310 stainless steel wire and Arcos Axcosite B4 Mux before applying the Type 308 weld deposits.

4.216 A minimum preheat temberature of $300^{\circ}$ F. shall be used during a11. Welding operations on ASTM A-302 Grade B steel.

4.217 The stainless clad steel suxiace shall be protected by spatter proof compound and a heavy paper or cardboard covering to aroid marring the suriace.

4.218 A11 wedges for fitup must be driven on the carbon steel side only. Use wood under all clamps applied to the stainless clad steel surface. No fitup attachments shail be velded to the stainless clad steel surface.

\subsection{Qualification}

4.221 Wherever possible, all welding shall be done in a downand flat position. 
4.222 Peening may be used only with extreme caution when absolutely necessary to control distortion when depositing the carbon steel welds. No peening shall be permitted on stainless steel welds.

4.223 Welding operators and procedures shall be quallifed in accordance with Section IX of the ASME Boller \& Pressure Vessel Code.

4.224 A11 completed welds shall be 100 percent $X$-ray radiographed in accordance with paragraph UW-5I of section VIII of the ASME Boller and Pressure Vessel Code. In addition, progressive $\mathrm{X}-\mathrm{xay}$ inspection shall be used to check the weld quality during the welding operation.

\subsection{Welding - Iongitudinal Seans}

4.231 Tack weld longitudinal seams together from the carbon steel side using AWS CIoss $\mathbb{E}-9015$ electrodes.

4.232 Preheat by heating plate to $300^{\circ}$ F. with mitiple flame torches covering a band equal to the plate thickness each side of the seam. Check bottom of groove wit. Rempilstiks to make cextain that the proper temperature has been reached.

4.233 Deposit weld passes starting on the stainzess clad steel side using the upproximate sequence shown on the attached sketch.

4.234 Deposit 5 wild bexds on the inside cleaning each pass thoroughy by wixe brushing. Inspect each pass visually sud by Magnaflux. Chip, are gouge or grind out all defects and repisix botore pxoceding with subsequent passes.

4.235 check aidgnment of plates. Peen if necessary to correct Por distortion.

4.236 Buclkchip weld from carbon steel side to sound metal. Deposit 10 reld beads inspecting each bead visually and with Magratilux.

4.237 Afiex deponiting 5 weld weads on one side and 10 weld beads on the other, $x-r a y$ weld 100 percent. Chlp, are gouge, or grind out wil detects and repalr. 
4.238 Magnaflux inspection of each weld bead pass shall not be required on subsequent passes, hovever, periodic Magnaflux inspection should be made where defects are suspected. Each weld bead layer shall be thoroughy cleaned and visually inspected for defects.

4.239 Turn plate over, deposit 10 weld beads on the clad side then $X$-ray inspect. Continue depositing 10 weld beads first on one side and then on the other $X$-raying each time until the weld groove is filled to the required depth as indicated on the attached sketch. Weld ASTM A302 Grade B steel only to within $1 / 4$ inch of the clad steel surface.

4.24 Preparation

4.241 Chip or grind carbon steel surface smooth and deposit I/8" approximately layer of Type 310 weld metal.

4.242 Thoroughly clean weld surface by blasting with stainless steel shot and apply finish layers of stainless steel using iype 308 weld metal deposits.

4.243 Inspect completed weld by Dyemcheck and X-xay per Code requirements

4.25 Welding - Head and Girth Seams

4.251 Weld head and girth seams by placing xing sections on rollers, tacking them together from the carbon steel side, and weld while rotating the vessel.

4.252 Weld head and girth seams using the same procedure as specified for the longitudinal seams.

\subsection{Welaing-Nozzles}

4.261 Stainless steel nozzles shall be welded using a combination fillet and double bevel joint as show on the drawing.

4.262 Welding on the stainless clad side shall be done first with Type 310 stainless steel electrodes to butter the carbon steel surfoce then with Type 308 stainless steel weld metal.

4.263 Welding on the carbon steel side shall be done using Type 310 stainless steel weld metal only.

4.264 Inspect welds by means of Dye-check and $X$-ray rad.ograph. 


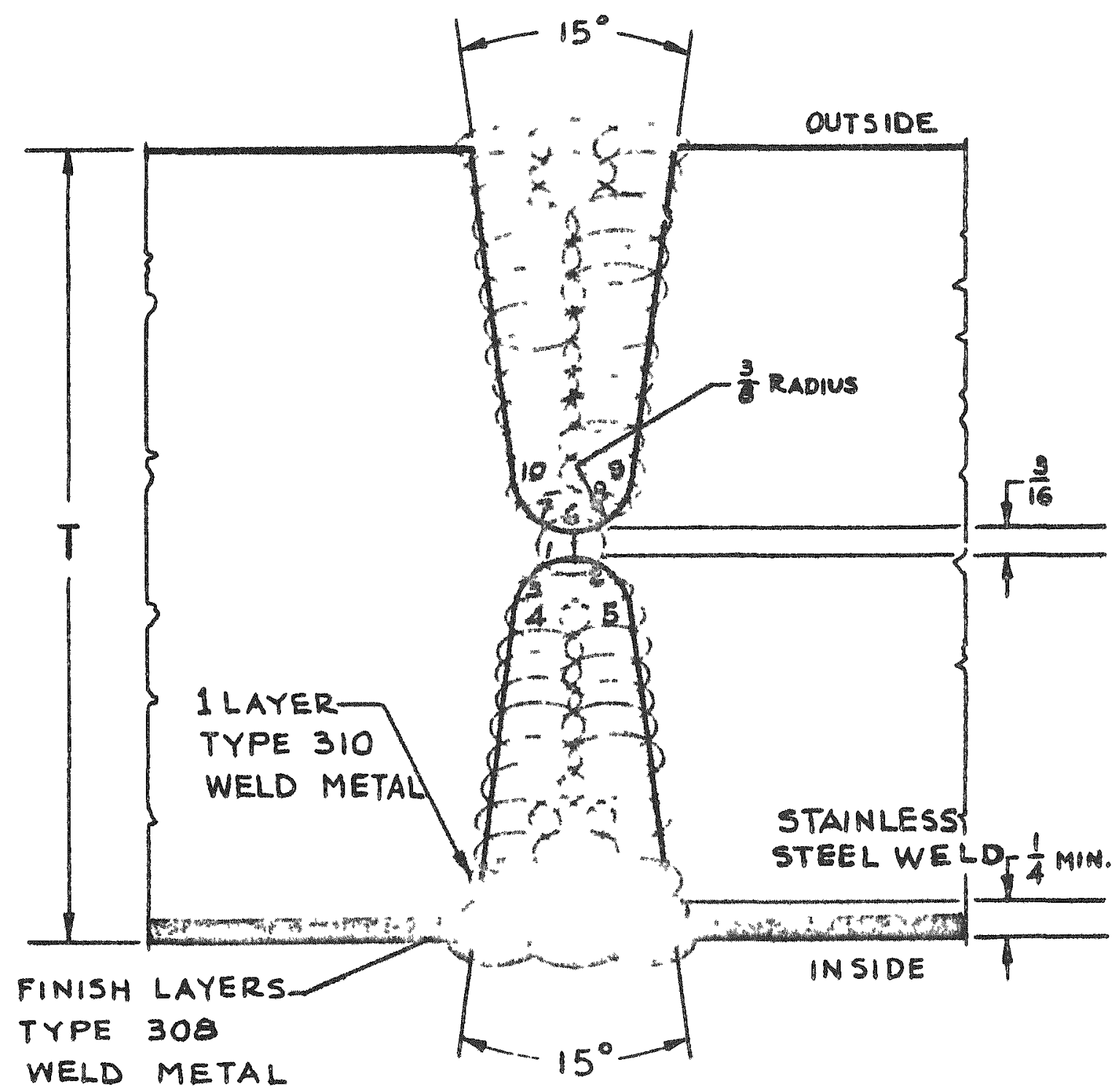

Fig. $4.239 a$

Typical weld bead sequence.

The sequence may be varied to surt the manual or automatic welding condifion being used.

Details

Heavy Wall Stainless Clad Steel

Vessels 


\subsection{Depositing Stainless overlays}

4.271 In depositing stainless steel overlays on carbon steel flanges, the surface shall first be buttered with a $1 / 8$ inch layer of Iype 310 weld metal before depositing the finish veld layers with Type 308 weld metal.

4.272 Build up stainless steel overlays to a depth of $3 / 8$ inch then machine finish to $1 / 4$ inch thickness.

\subsection{Welding - Attachments}

$4.281 \mathrm{AII}$ attachments to the stainless steel clad surface shall be made using Iype 308 stainless steel weld metal.

4.282 All carbon steel attachments to the outside surface of the vessel shall be welded using Alls class f9015 electrodes.

\subsection{Stress Relieving}

4.291 All stress relieving of shop welds shall be done in accordance with paragraphs UW 40 and UCS-56 of Section VIII of the ASME Boiler and pressure vessel code. Rrovisions applicable to the ASTM A302 Grade B backing material shall apply.

4.292 Where practicable field welded joints shall be $10 \mathrm{cally}$ stress relieved by heating a band equal to twice the plate thickness or more on each side of the veld as specified in paragraph UW-40 of Section VIII of the ASM Boiler and pressure vessel code.

4.293 Preheating and peening of each weld bead in field welds may be used for stress relieving in lieu of thermal stress relieving where the latter procedure ls not practicable. 


\subsection{STEEL WALL CONTAINMENT VESSELS}

4.31 General:

4.311 All welding shall be done in accordance with Section VIII and IX of the ASME Boiler and Pressure Vessel Code for Unfired Pressure Vessels.

\subsection{Manual Welding}

All manual weIding on ASM 285 Grade C material shall be done using AWS Class B60XX electrodes.

\subsection{Automatic Welding}

Automatic welding on ASTM A-285 Grade C material shall be done using any one of the following wire and flux combinations:

Iincoln I60 wire with Iincoln 760,780 , or 840 flux. Linde oxweld 36 wire with unionmelt 20 , 80 or 90 flux. Linde oxweld 29 or 43 wire with tajonmelt 50 or 90 flux.

\subsection{Preheat}

No preheat shall be required for plate 1-1/4" thick or less except that when the base metal temperature is within the range of 0 to $32^{\circ} \mathrm{F}$, inclusive, the base metal within 3 inches of the place where welding is to be started shall be heated to a temperature warm to the hand.

4.315 Weld Qualification

Welding operators and procedures shall be qualified in accordance with Section IX of the ASMT Boiler and Pressure Vessel Code.

\subsection{Sequence}

All vertical seams shall be completed in any one course and the adjacent course before welding round seams.

\subsection{Joint Design}

Vertical seams shall be welded using a $60^{\circ}$ double vee groove, 1/8" land joint. Round seams shall be welded using a $60^{\circ}$ offset double vee groove $1 / 8 "$ lend joint as shown on the attached sketch.

\subsection{Cleaning and Inspection}

4.321 Cleaning

All seams shall be thoroughly cleante ot all rust, scale, dirt and grease prior to welding. Fach weld bead pass shall be thoroughly cleaned of slag before depositing subsequent passes. 
4.322 Backgouging

AII seams shall be chipped, arc-gouged, or ground to sound metal before welding the second side. All gouged grooves shall be power brush cleaned betore welding.

4.323 Inspection

AII welds shall be $100 \% \mathrm{X}$-ray radiographed in accordance with paragraph UW-51. of section VIII of the ASME Boiler and Pressure vessel Code. In addition, spot radiographing shall be used to check the weld quality during the welding operaticn.

4.324 Repairs

All deflective welds shell be backchipped, arc-gouged, or ground to sound metal and repalred by welding.

4. 325 Cracks

The propagation of weld cracks when they occur shall be stopped by drilling a 1/4" diancters hole at each end of the crack.

4. 326 Tdentificacion

AII weld: shall be identified by stamp marks of the operator along side of the welds or repairs.

4.33 Typlical Weld Bead Deta11

4.331 See rigure 4.33 un page 52. 


\section{4}

CONSOLIDATED WESTERN STEEL

DIVISION UNITED STATES STEEL CORPORATION

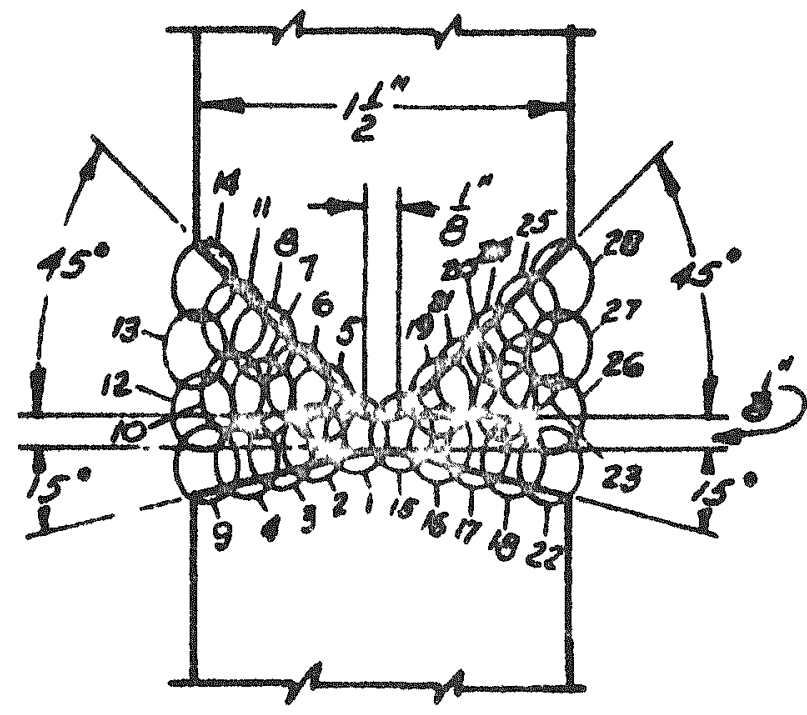

HORIZONTAL SEAMS

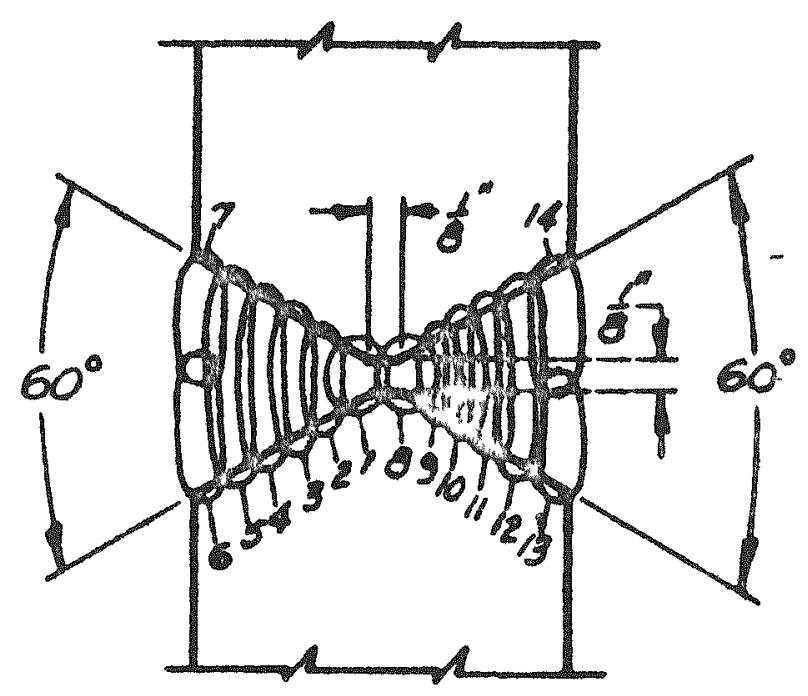

VERTICAL SEAMS

Fig. 4.33

Typical weld bead sequence for manual welding on containment vessels. The sequence may be varied to suif the manual or automatic welding being used.

\section{Details}

\section{Containment Vessel Welding}


DISCUSSTON

SECTION $V$

HEAD CLOSURES 


\section{INDEXX \\ SECIION $\mathrm{V}$ \\ HEAD CLOSURES}

\subsection{General}

5.11 Conventional Dype Closures

5.1. Suitable Closures for Reactor Vessels

55

5.121 Large Vessels

5.122 Small Vessel.s

55

55

5.2 Closure Limitations

5.21 Bolted Joint Iimitations

5.22 Pressure Limitations

5.23 Code Iimitations

5.3 Closure Design

5.31 General

5.32 Comparison of Closure Designs

61

5.321 Closures $D$ and $E$

61

5.322 Closures II and $G$

61

5.323 Conclusion

61

61

5.33 Details of Closures

5.331 Details-Closure F

5.332 Detalls-Closure G

61

61

61

5.4 Economic Analysis of Closures

5.41 Ceneral

5.42 Ratio of Costs

5.421 Using Low Alloy Steels

63

5.422 Using Solid Stainless Steels 


\section{CONSOLIDATED WESTERN STEEL}

DIVISION UNITED STATES STEEL CORPORATION

\subsection{Head Closures}

\subsection{Genera.}

\subsection{Conventional Type Closures}

5.111 Conventional type closures for large diameter heads, such as metallic seals, flat gashets used with raised face flanges, and various other unique sealing axrangements have becu developed over a period of years for use in conventional pressure vessels and piping.

5.112 None of the conventional sealing arrangements seens to lend itself directly to the application of removable heads for rewotor service.

\subsection{Sultable closures for Reactor Vessels}

\subsection{Large Vessols}

5.1211 For large vessels, it appears desirable to produce a double seal which will permit the space between the seals to be monitored to determine the effectiveness of the inner seal, and insure zero external leakage.

5.1212 It 1 s the opinion of Consolidated that the most efretive seal for this purpose is a modified Bridgeman type double scal, which will allow monitoring of the inner seal. Most of the closures illustrated on the vossels in this report are based on this type of seal.

\subsection{Suall Vessels}

5.1221 Tor small dianeter vessels, it may be feasible to use i normal closure, with some type of flat gasket for the inner seal, with a seal weld on the outer seal.

5.1222 This type of closure is also illustrated on the drawings.

\subsection{Closure Limitontions}

\subsection{Bolted Joint Limitations}

5.211 The maximum diameter that can be efrectively sealed with a bolted connection is a function of the code Ilimitations on the allowable stress of the bolting material. 


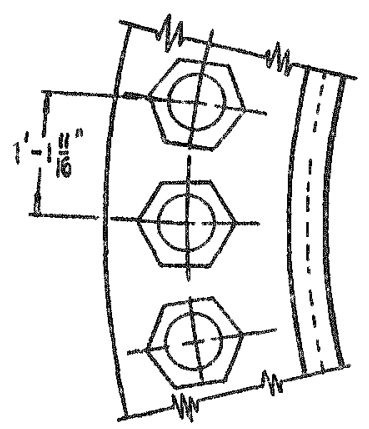

RING DETAIL

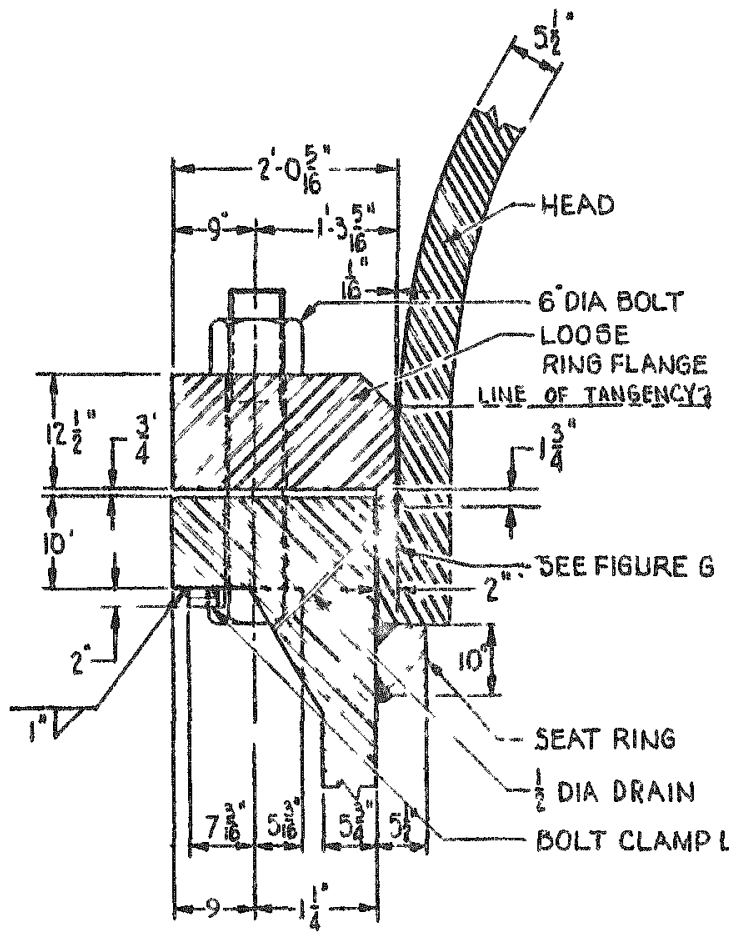

CLOSURE DETAIL
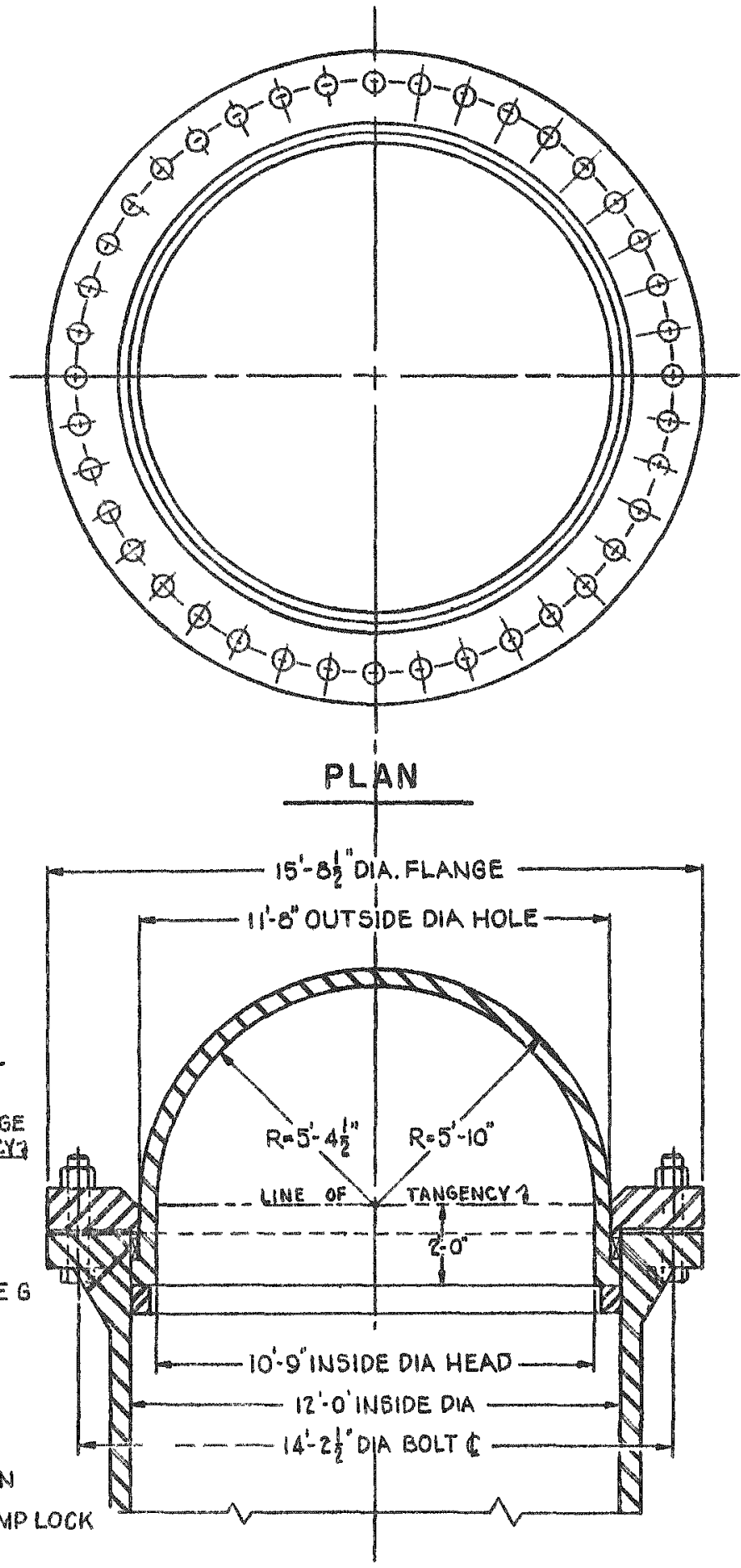

CROSS SECTIONAL ELEVATION

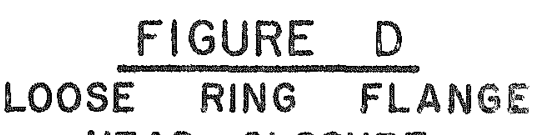

HEAD CLOSURE 


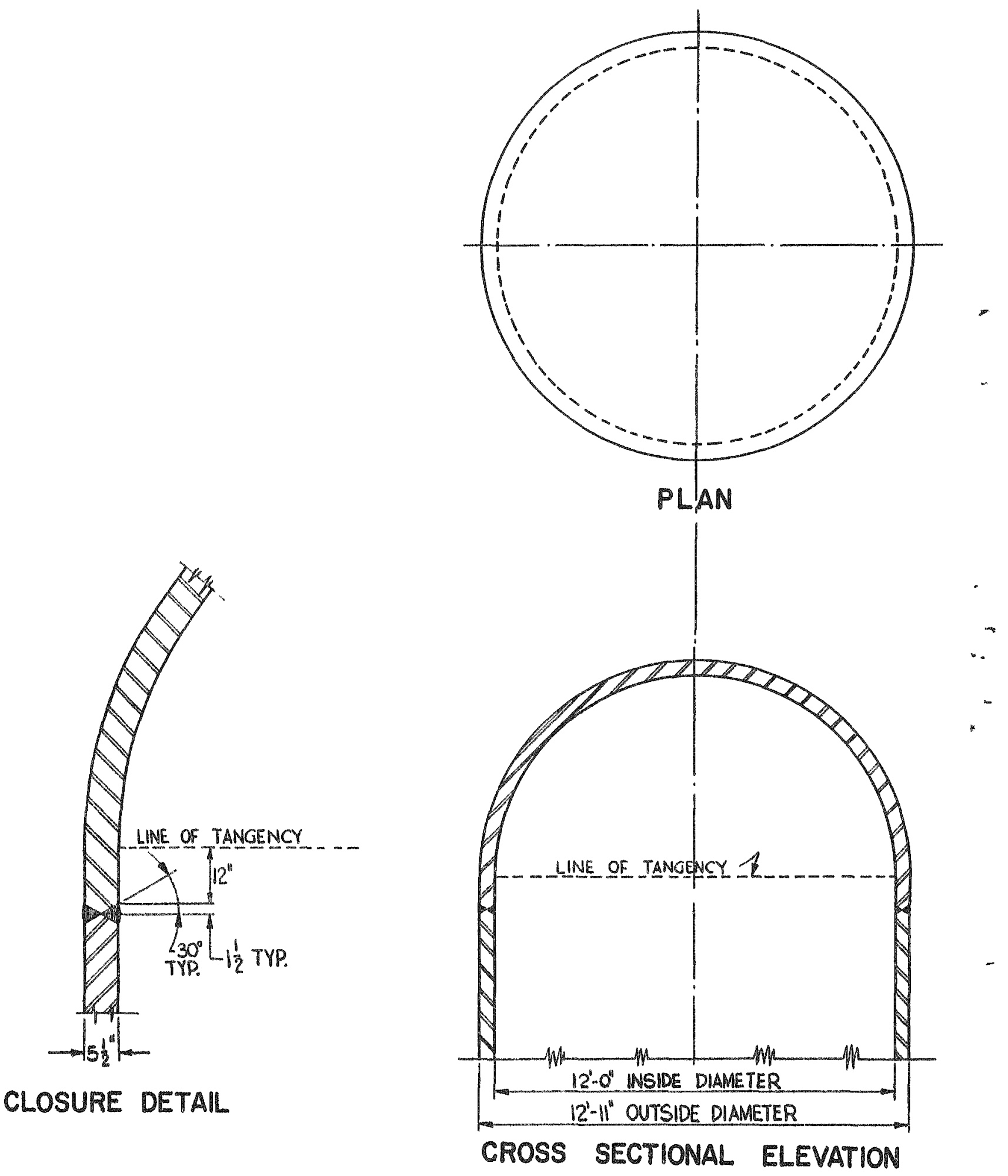

\section{FIGURE $F$ \\ WELDED \\ HEAD CLOSURE}




\section{CONSOLIDATED WESTERN STEEL}

DIVISION UNITED STATES STEEL CORPORATION
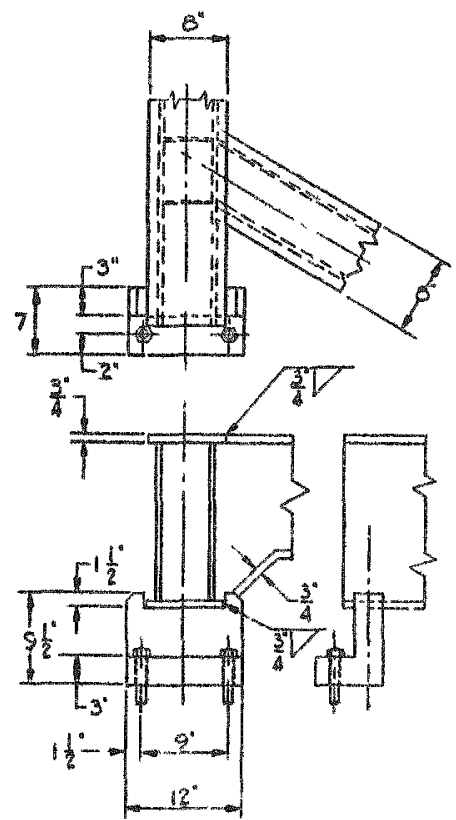

DETALL A
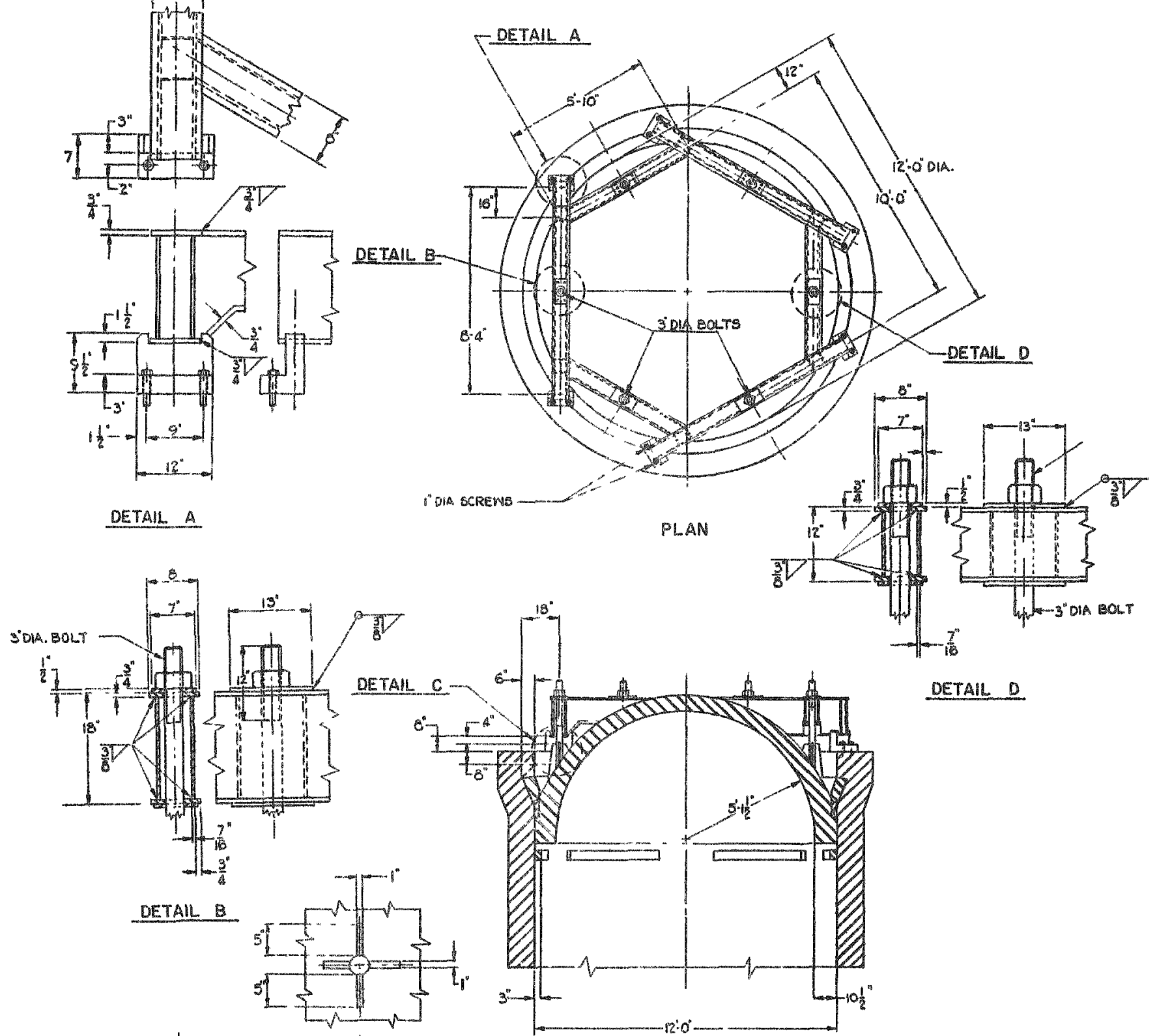
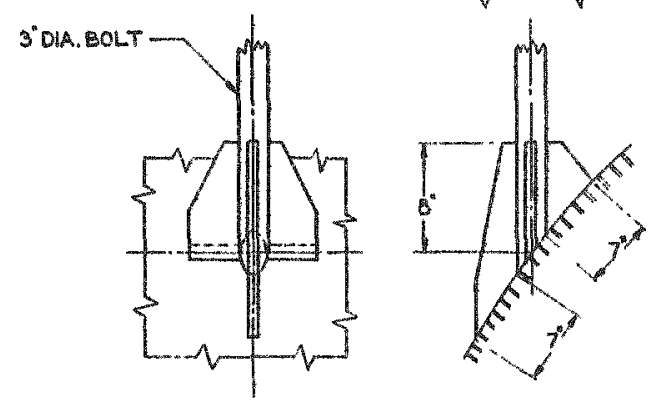

DETAL $C$

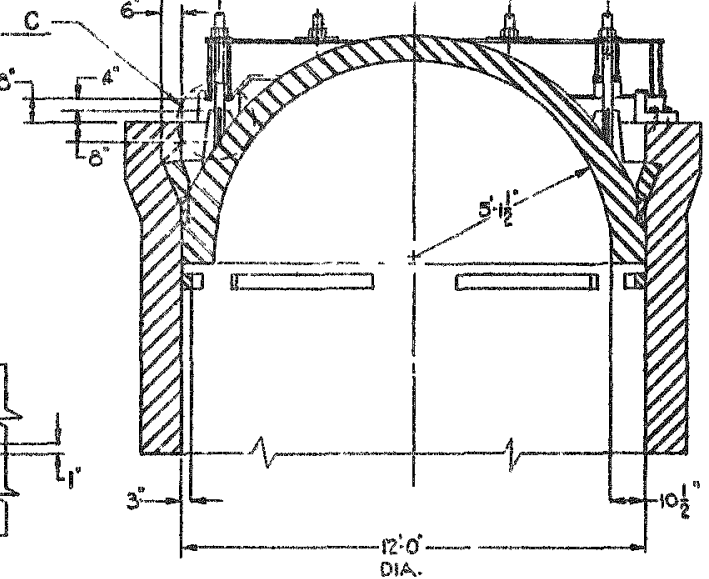

CROSS SECTIONAL ELEVATION

FIGURE 6

T" $A L$ HEAD HOLD DOWN 
5.212 Under certain conditions of size and pressure, the Code may require more bolts than can be accommodated in the avallable bolt circle.

5.213 When this limitation is reached, the most practicable removable head closure appears to be the shear key axrangement 1llustrated by the enclosed vessel drawings. This connection is designed to be within Code requirements.

\subsection{Pressure Limitations}

5.221. For a bolted closure where the bolts are in tension, the maximum pressure that can be effectively sealed is a function of the maximum preloed that can be applied to the bolts. The bolts must be preloaded so that the stress in the bolt under pressure does not exceed the preload stress to insure that the sealing surfaces do not part because of deflection.

5.222 The modified Bridgeman type seal presented herein avoids this difficulty since additional pressure merely serves to apply additional forces to the seal, thereby causing a tighter seal as the pressure is increased.

5.23 Code Iimitations

5.231 The Code merely sets minimum standards, and does not in any sense relieve the designer or manufacturer from design responsibility. Therefore, there is aot, to Consolidated's knowledge, any 1 imitation affecting the shear key type closure presented.

\subsection{Closure Designs}

$5 \cdot 31$ General

5.311 Four possible closure designs for large diameter heads are show in the accompanying drawings.

$$
\begin{aligned}
& \text { Figure D } \text { Loose Ring Head Closure } \\
& \text { E } \text { Fanged Head Type Closure } \\
& \text { F } \text { Welded Head Closure } \\
& \text { G Typical Head Hold-Down }
\end{aligned}
$$

5.312 Figure H shows details of the seal suggested for use with the tabulated vessels, Figures $A, B$, and $C$. 


\subsection{Compartson of Closure Designs}

5.321 Closures $D$ and

5.3211 Closures shown on Figures $D$ and $\mathrm{E}$ are restricted in thelr usage to the maximum diameter and pressure able to be accommodated by the flange bolts in the space allowed. wthin the applicable sections of the Boiler Code.

5.322 Closures $\mathrm{F}$ and $\mathrm{G}$

5.3221 Closures shown on Figures $\mathrm{F}$ and $\mathrm{G}$ are not restricted in their usage by any provisions of the code other than those Iimitations imposed by the code on other portions of the vessels studied.

\subsection{Conclustion}

5.3231 In view of paragraphs 5.21 and 5.22 , closures on Figures F and $G$ will apply to a.11 of the vessels reported herein.

\subsection{Details of Closures}

5.331 Details - Closure I

5.3311 The closure shom on Figure F consists of hemispherical head attached by means of a simple double "V" butt weld.

5.3312 This constmuction makes head removal difficult, if not impossible, without possibility of destroying the vessel.

\subsection{Details - Closure G}

5.3321 The closure show on Figure $G$ is the modified Bridgeman type seal previously generally discussed (and also ldentified as shear key type closure).

5.3322 Application of this seal provides two general sealing areas with an annular space between. This annular space can be monitored to determine the effectiveness of the inner seal, and to prevent leakage through the outer seal.

5.3323 Forces on the head due to internal pressure are carried. through the Bridgeman type seal to a series of segments loaded in sheax to transmit the load to the vessel shell.

5.3324 An extexnal frame is provided with sufficient bolts to lift the head against the seal, and insure the init lal setting of the seal. These bolts and this frame are of sufficient strength and rigldity to maintain the seal under internal vacuum conditions.

5.3325 This closure permits releswely rapld head removal when required. 
CONSOLIDATED WESTERN STEEL

DIVISION UNITED STATES STEEL CORPORATION

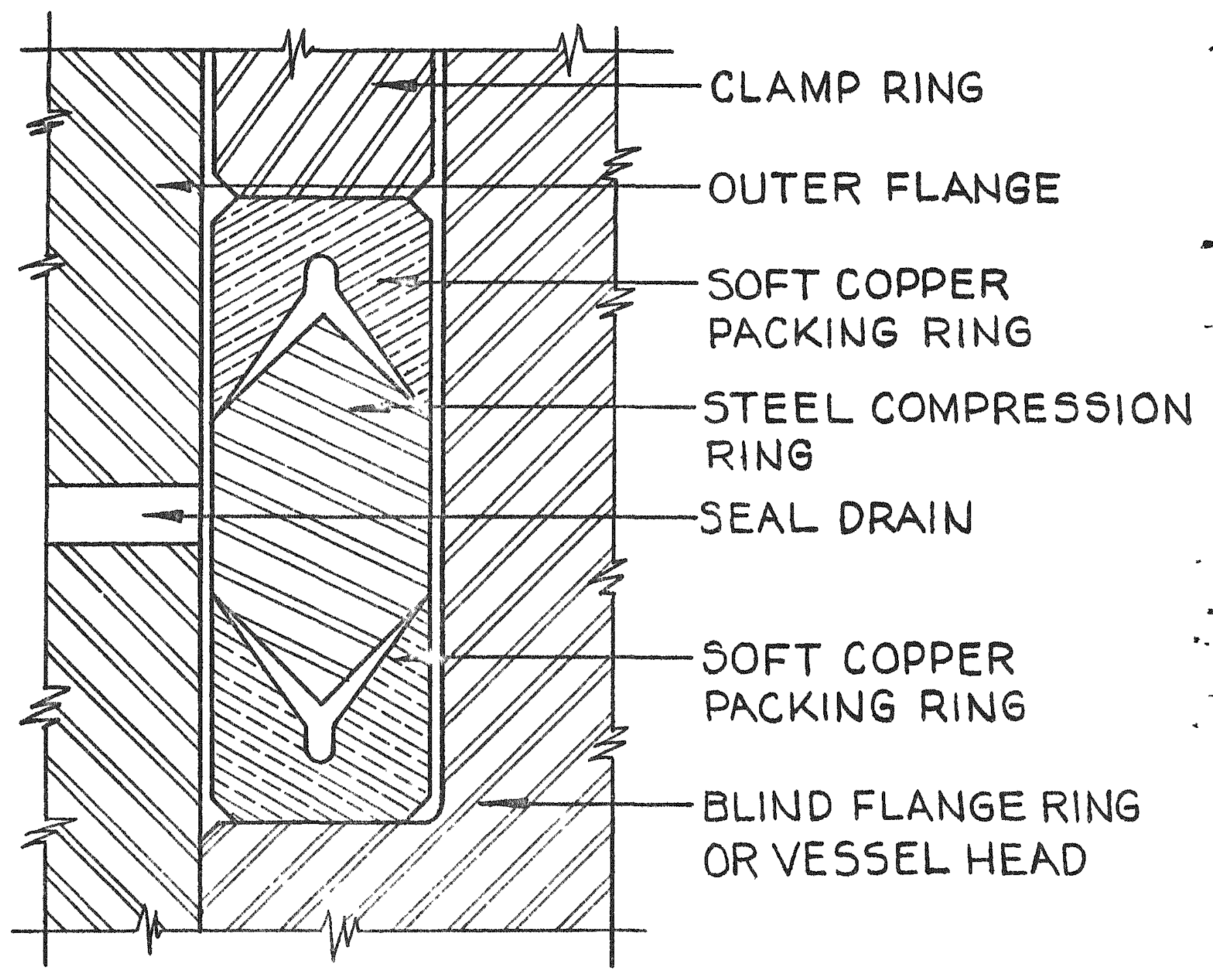

FIGURE $H$

TYPICAL SEAL 
CONSOLIDATED WESTERN STEEL

DIVISION UNITED STATES STEEL CORPORATION

\subsection{Economic Analysis of Closures}

\subsection{General}

5.411 The relative costs of the various closures discussed appears to be a function of costs of the sealing material itseli, and of the number of bolts and bolt holes which must be produced, since the general conidguration of the several joints are very similar.

5.412 In general, the shear key, or Modified Bridgeman type of closure is more economical to produce than any other practical closure. The difference of costs between this type of a closure and $a$ bolted closure increases with size and the internal pressures to be contained.

\subsection{Ratio of Costs}

5.421 The relative costs of the closures shown on Figures $D, E, F$ and $\mathrm{G}$ are as follows:

\subsection{Using Low Alloy Steels}

Assuming Closure $F$ as unity, the cost ratios would be about as follows, if fabricated from low-alloy lowcarbon steel with cladding applied separately:

Closure $F$, hemispherical welded head - 1

G, Bridgeman type seal - 3

D, loose ring head closure -6 to 7

E, Ilanged head type closure -6 to 7

\subsection{Using Solid Stainless Steels}

Again assuming Closure $F$ in low-alloy steel as unity, the cost ratios would be about as follows, if fabricated from stainless steels:
Closure $F$, hemispherical welded head
G. Bridgeman type seal
$-1-1 / 4$
D, loose ring head closure
$\mathrm{X}$, flanged head type closure
$-3-3 / 4$
$-1-1 / 2$ to $8-3 / 4$
$-7-1 / 2$ to $8-3 / 4$ 
CONSOLIDATED WESTERN STEEL

DIVISION UNITED STATES STEEL CORPORATION 


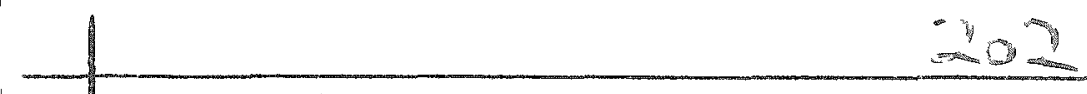

CONSOLIDATED WESTERN STEEL

OIVISION UNITED STATES STEEL CORPORATION

DISCUSSION

SECTION VI

COST DATA 


\subsection{Reactor Vessels}

6.11 General

6.12 Extrapolation of Data

6.13 Conclusion

6.2 Containment Vossels

6.21 General.

67

6.22 Shape Comparison

68

6.23 Details anitted

68

6.24 She11 Thickness

68

6.25 Extrupolation of Deta

68

6.3 cladding

6.31 Type 304 Sininless Cladding

68

6.4 Iabulation of Cost Data

69

6.5 Head Closurer

70

6.6 Fabrication

70

6.61 General

70

6.62 Field Frection

70 


\subsection{COST DATA}

\subsection{REACTOR VESSTELS}

\subsection{Genera1}

6.111 At the request of American, pocilic cost date has been studied and is tabulated in Table 6.4 below, for fabrication and erection of three 111ustrative reactor vessels, with IIke data for appropriate contuinuent vessels.

6.112 Relationships have 2130 been established between clad plate construction, solid stainless construction, and forged ring construction.

\subsection{Extrapolation of Data}

6.121 These verseld have been selected so that the reaults of these cost studles may be extrapolated approximately for 11. of the vesse1s 11sted by relating these pound prices to the welghts of the other versels included in the survey.

6.122 Since the tabulation of reactor vessel data in Tables 2.13 and 2.14 1Ist net weights, then the cost per pound based on net weight must be used to extrapolate the cost of the other vessels.

\subsection{Conc1usion}

6.131 This study indicatea that through the ranges of sizes investigated, the pound price of the vessels decrease as the diameter of the veasels increases.

\subsection{CONTAINMENIT VESSELSS}

\subsection{General}

6.211 As indicated above, cost data has been studied for containex vessels of various internel volumes, comparable with the reactor vessels also so studied.

6.212 These containment vessels are designed for code compliance, and may be code fabricated and erected without stress reliev Ing. 


\subsection{Shape Comparison}

6.221 The tabulation, Table 6.4, includes cost data covering fabrication and erection of both cylindrical and spherical vessels to establish the most economical approach to the containment problem.

\subsection{Details Omitted}

6.231 Since detailed data on openings, structural supports, or foundations would be dependent upon more definitive design than is now practicable, the cost of these items is not included in the tabulated figures.

\subsection{Shel1 Thickness}

6.241 Tabulated costs are based on aniform shell thickness throughout each vessel.

6.242 It is recognized that specific designs would dictate varying shell thicknesses, but the tabulated costs are definitive enough to establish an adequate basis for comparison purposes.

\subsection{Extrapolation of Data}

6.251 The three reactor vessels estimated and tabulated in Table 6.4 , in general, cover the range of costs believed to be encountered in fabricating vessels of this type.

6.252 In view of the above, it is believed that the approximate cost of any size containment vessel probable to be required for application in this reactor study can be determined with reasonable accuracy by extrapolating the tabulated values.

6.253 See paragraph 6.122 for use of tabulated weights.

\section{3 cladding}

\subsection{Type 304 Stainless Cladding}

6.311 An analysis indicated that 1/4" type 304 ELC stainless steel sheet can be applied as cladding by stitch welding on $2^{\prime \prime}$ centers for approximately $\$ 50$. per square foot.

6.312 In addition, a vessel of this type may be clad by laying a continuous bead of appropriate stainless steel as an overlay, 
CONSOLADATED WESTLMH STEEL

DIVISIOA LNITEI DATI , HIL IIOMAIIOA

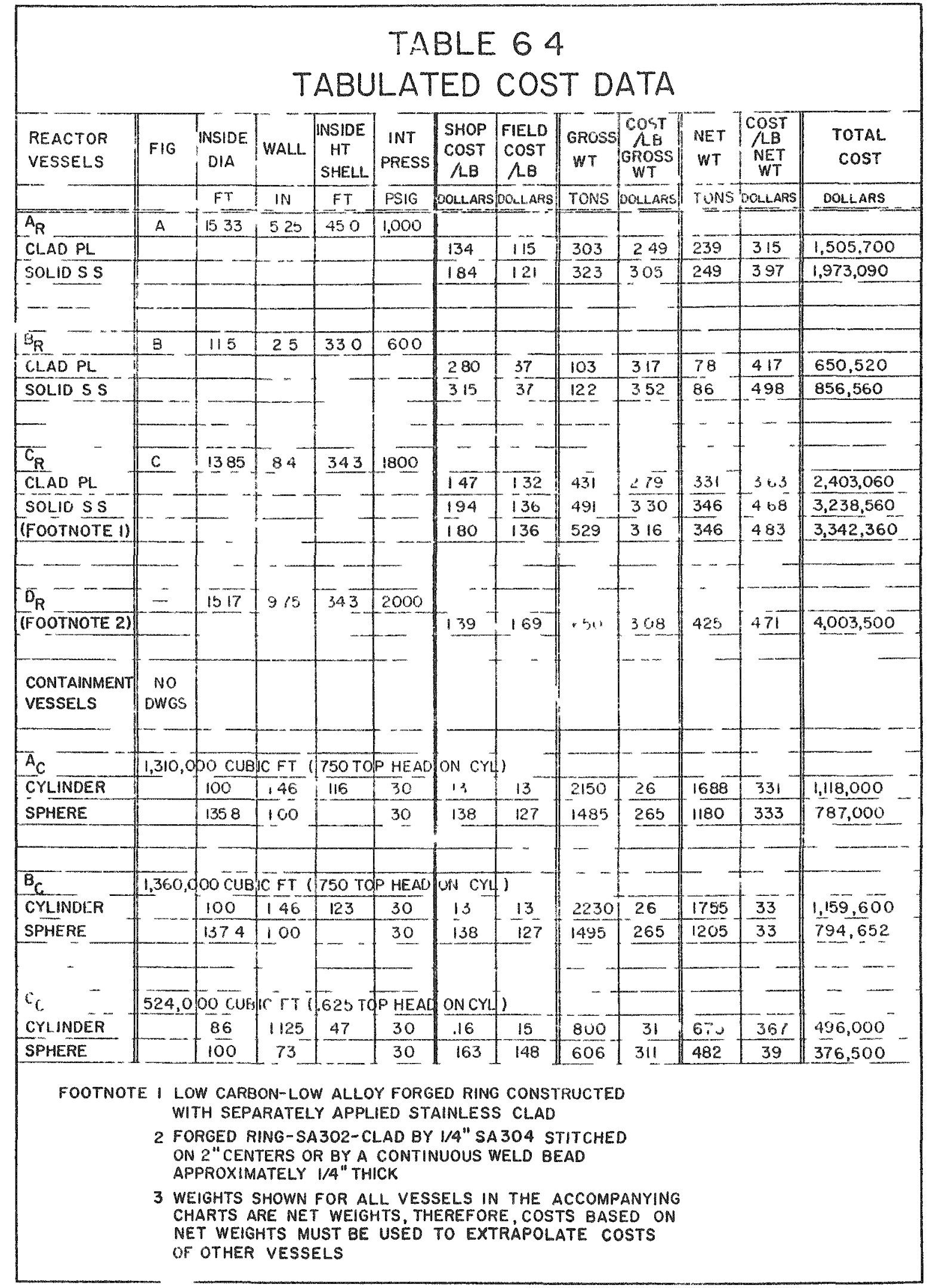

$3-12-5 i$

pase

53388

69 
machining to approximately 1/4" thickness for approximately $\$ 306$ per square foot.

\subsection{Tabulation of Cost Data}

6.41 This data is Iisted in Table 6.4, attached.

\subsection{Head Closure}

6.51 For economic analysis of head closures see paragraph 5.4 , this report.

\subsection{Fabrication}

\subsection{General}

6.611 Ms a generalized statement, vessels that can be transported. in one piece are more economical if they are completely Iabricated in the shop.

\subsection{Meld Erection}

6.621 Vessels requiring field erection after shop fabrication will have increased costs of approximately $20 \%$ over tull. fabrication in the shop.

6.622 If stress relieving is required, approximately $\$ 100,000$ for each site must be added to the figures derived by the method in 6.621 above to allow for increased field equipment and freilities.

6.623 Additional amounts may be required for other erection Pacilities. 
CONSOLIDATED WESTERN STEEL

DIVISION UNITED STATES STEEL CORPORATION

APPENDIX A

CODE IIITERPRETATION

$3-12-57$ 


\title{
Interpretatiom of ASME Boiles and Premare Vesmel Code
}

\author{
Approved by ASME Cowacil. September 6.1956.
}

Cose No. 1223

(Interpretation of Par. P.108)

Indusiry: May austenitic stainless steel materials conforming to one of the grades of specifications acceptable in Secrion : be used in welded construction without 2 atress-relief heat-treatment after welding at required by Par. P-108? Are any opecial inspection requirements necesmary?

Roply: (a) It is the opinion of the Commitses that thermal hear treatment. including stress-relief, of austenitic stainless-steel weldments is neicher required nor prohibited; therefore, the joints of all parts of austenitic stainless stect, regardless of thickness, welded under the provisions of Section I are exempi from the stress-relieving requiremenss of Par. P.108.

(b) All weldments over $3 / 4$ in. ehick shall be examined for the detection of cracks by the muid penetrant method. This examination shall be made follow. ing heat trearment if hear-treatment is performed.

(c) Weldments tequired to bo radio. graphed by the requirements of Par. P. 102(h) shall be radiographed following heat-treatment if heat-trcatment is performed.

Cautionan Niote: In recognition of cona sroversial upreasen relative to the effecl of thermal treasment of aussenutic stainless seets, mandarory requrements for such have been ometed Service exprerience is too limused so permus comparison between the relatuve safery of as-welded and shermally created, uncluding stress-fchered, ausenitic steel weldments, puresularly an thick sectums. It is suggeseed that reberence be made to the Non-Mandacory Apperdix of Part UHA at the 1950 Secruan Vill.
Cose No. 1224

(Special Ruling)

Ingquary: Neirher Section I nor Section VIII of the ASME Boiler and Pressure Vessel Code as now written precisely covers pressure vessels that are an integra! part of a nuclear installation. Under what rules shall elrey be construcred?

Reply. The Committee recognizes that to the desigg of nuclear installations. requirements will differ from those of conventional boilers and pressure vessels.

$1-$ It is the opinion of the Commitre shat vesscels that are an unegral part of nuclear installacions buile in accordance with the requiremenes of the ASME Boiler and Pecssure Vessel Code as modified or detined in this and subsequene casss, mect the intens of the Code, and each vesscl shall be marked as required by the section to which is is built including the appropriate Cade Symbol. In addieion the words, "Case No. - " shall apprear on she Data Reprors.

2-All vessels that are an integral part of nuclear installations shall be constructed an accordance either wish the requirements of Section or wieh the requirements of Sectuon VIII for vessels har are to contain lethal substances.

3-Ir is antended that jurisdicrion over paping exgernal to vesscls shall ierminare at:

(1) The first circumerential joint for welding end connections; or,

(2) The face of the first mange in bolted Aange comnections; or.

(3) The first chreaded ins in that sype of connection. 
Coss No. 1225

(Special Ruling)

Ingurey: Various safery requiremenes of Seccion I and Section VIlll would actually be hazardous if applied lirerally to the design of nuclear reactors. May these requirements be modified for reac. rors of the pressurized warer and boiling waser types?

Reply: It is the opinion of the Commirtec that nuclear reactors of the pressurized-water and boiling-water-typewsll meet the intent of the Cude and shall be marked in accordance wieh Case No 1224 if the following provisions are sner:

(1) Torally enclosed pop-ype safery or relief valves shall he provided. bur need nut be directly areached to the ressel provided there is no valve berween the vessel and the safery or reliel valve, also they shall be anscallod as close as as prac. rical to the vessel. They shall gor dascharge to the atmosphere, and shall discharge to a sutable svercm designed to condense any vapors At least ewo salkety or relict valves are restured and tho cotal capacaty shall be sufficient to insurc: that the design pressure is not exceded by more than 10 per cent

(2) Diresr reiding pressure gages are not reguired it bedst twu independent desses for derermanng pressure are ruqured and these shall not be dependent on the same cxternal suurce of energy.

3) Inspiction openugs, gage glasses, is ater columns, and gage cocks are not required.

\section{Cus No. 1226}

(Special Ruling)

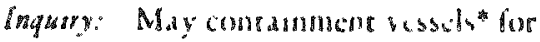
mulicap reactor mostallarions be buif under Section BII, Code for Untured Pressure Vissels wathout stress relicving as specified in Par. UW'-2Ca

Reply: It as the appinion ot the cionthnurtec that thess contanment vesscls fall under the carcgory of those contaming lethal substarces but still may be bulte

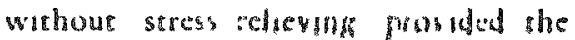
followng regunch : sto sts ith:

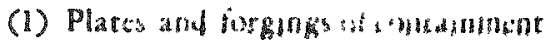
vessels cxposd to the elemeng fion ju-

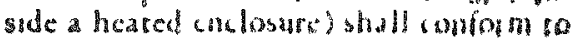
specifacanoms \$A.300 far plates and $\$ A$. 350 for forment These and ather ma. cersals and the constructura shall ment the impace ecso requarcments of Par. L'G -84 as a remperature nor less than $30 \mathrm{~F}$ holowe the lowest recorded ambient tomperature of the drea wh wheh the containment vessel is to be erwited. except that the bowest sist comperature may be assumed to be so for any pare in the l'necel stares

(2) Niding procedurs atnd operators shall be giallibed on accordanie with secrion 1.8

(3) All doors, muzles, and opemeng frames shall be persembled mea shell plate and stress relucrid as complete asscmblics for weldug ancu the shell. Also. special consuderation should bo given to mahe the Jesign of the reinforcs. ment for large optungs as strong as the shell (ere Par. ('A-7)

(4) The thutiness of shell and hoal plates shall not exueed that for whuth stress rclief is requared an dccordance with Par. IC.S.56.

(5) All longicudinal and curcuntercursal founts shall be of the double weided but bypeand shall be fully radiographed un sccurdancs wath Bar. UH'-51. All welds on doors, nozzles, and openings frames, and all welds that cannot be radogeaphod shall bo sirmunod tor

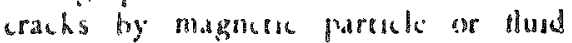
penetrane enechod of anspersom

6. The case number shall appose on the Aanufururos Data Kcport form

- Conbarmina Vessels are chose outer vessels which enclose the prumary reaceor vessel and/or purtions of the primary coolant corcuit. The cuntainment vessels are not

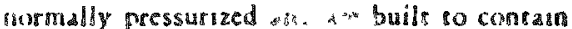

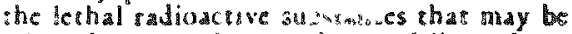
relessed an case al an acculegt ar failure of any fot of the primary reactor vessel ur comant

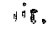

